Johannes Trenkle

\title{
Digital Transformation in Small and Medium-Sized Enterprises
}

Strategy, Management Control, and Network Involvement

\section{Nomos}


Wirtschaft und Recht für Mittelstand und Handwerk

Studien und Dissertationen aus dem Ludwig-FröhlerInstitut für Handwerkswissenschaften

herausgegeben von

Prof. Dr. oec. publ. Gunther Friedl,

Technische Universität München

Prof. Dr. iur. Martin Burgi,

Ludwig-Maximilians-Universität München

Band 3 
Johannes Trenkle

\section{Digital Transformation in Small and Medium-Sized Enterprises}

Strategy, Management Control, and Network Involvement

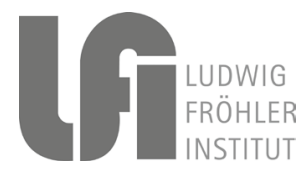

Nomos 
The Deutsche Nationalbibliothek lists this publication in the Deutsche Nationalbibliografie; detailed bibliographic data are available on the Internet at http://dnb.d-nb.de

a.t.: TU München, Diss., 2020

ISBN 978-3-8487-7809-6 (Print)

978-3-7489-2213-1 (ePDF)

British Library Cataloguing-in-Publication Data

A catalogue record for this book is available from the British Library.

ISBN 978-3-8487-7809-6 (Print)

978-3-7489-2213-1 (ePDF)

Library of Congress Cataloging-in-Publication Data

Trenkle, Johannes

Digital Transformation in Small and Medium-Sized Enterprises

Strategy, Management Control, and Network Involvement

Johannes Trenkle

$201 \mathrm{pp}$.

Includes bibliographic references.

ISBN 978-3-8487-7809-6 (Print)

978-3-7489-2213-1 (ePDF)

1st Edition 2020

(c) Johannes Trenkle

Published by

Nomos Verlagsgesellschaft mbH \& Co. KG

Waldseestraße 3-5|76530 Baden-Baden

www.nomos.de

Production of the printed version:

Nomos Verlagsgesellschaft mbH \& Co. KG

Waldseestraße 3-5 | 76530 Baden-Baden

ISBN (Print): 978-3-8487-7809-6

ISBN (ePDF): 978-3-7489-2213-1

DOI: https://doi.org/10.5771/9783748922131

- Non Commercial - No Derivations 4.0 International License. 


\section{Acknowledgments}

First and foremost, I would like to thank Prof. Dr. Gunther Friedl for taking over the supervision of this dissertation. Your curiosity to various contemporary topics initiated this work. Your assessments and advice have shaped, guided, and clarified my project, and continue to be an inspiration to me in dealing with complex challenges. I greatly appreciated the wonderful doctoral seminars that fostered the progress and content of this thesis. From your Chair of Management Accounting and the Ludwig-FröhlerInstitut, friends and colleagues have enriched the past years and contributed to this dissertation. From a variety of great people in the institutions' teams, each and every one of whom I include, I express my special thanks to Dr. Markus Glasl for the trust he placed in me, for the great scientific freedom and his continuous support, Dr. Markus Buchner for his unrestricted, friendship-based assistance and conversations from day one, Dr. David Matthäus for inspiration and encouragement from valley to mountain and back down again, Dr. Andrea Greilinger for her mentoring at the beginning, Tobias Beibl for an always open door, as well as Daniel Beck, Anna Hepp, Dr. Cornelia Hojer, Matthias Regier, Prof. Dr. Peter Schäfer, Dr. Christian Stoll, Andrea Stübner, and Dr. Friedrich Walcher for their helpful endeavors. I also thank Uschi Steffl, Astrid Jellen, and Christine Suchy for their cordial help in all administrative matters. As a partner of the chair and great character, Dr. Christian Göttsch had a significant positive influence on the interpretation of my findings.

I sincerely thank Prof. Dr. Janine Maniora for acting as second supervisor of this dissertation and Prof. Dr. David Wuttke for heading my examination committee.

Support of outstanding students from TUM, especially my co-author Carl-Philipp Beichert, has influ-enced this work. In addition to him, I extend my gratitude to Alexander Berchtold, Simon Bodensteiner, Martin Engert, Karl Margraf, Angela Rothenhäusler, and Paul Warmuth for their commitment.

Contact with digitally successful firms was essential for my case collection. I thank Georg Räß from the Chamber of Crafts for Munich \& Upper Bavaria for his outstanding support in accessing the field. 
On behalf of all partners of the consulting company zeb, I am deeply grateful to Michael Herkert and Horst Kleinlein, who accepted my wish to study for a doctorate and made it possible at short notice.

My family has deliberately and accidentally influenced this work. I am especially indebted to my dad for his advice and experience and my mom for her trust. My parents-in-law Dr. Lothar and Gabi Neubauer and above all my parents Dr. Thomas and Barbara Trenkle have shown me that a dissertation can be a valuable part of life and have therefore always supported me. I thank my grandmother, Eva Trenkle, for her devotion and for conveying the value of perseverance. I owe a lot to my sister Dr. Katharina Trenkle with her husband Erwin Lara Gallegos and my niece Leonie, on whom I can always rely, be it for educational exchange of ideas, the best steak, or anything else. Finally, unrestricted thanks and love go to my wife Dr. Julia Trenkle for your unremitting encouragement and your ability to make us talk; and to my son Lorenz, who has shown me for several months that every day can hold a miracle. 


\section{Abstract}

In light of a dynamic spread of hard- and software across all elements of society, established companies of all sizes have to absorb digital technologies to stay competitive and realize economic benefits. They have to enter in digital transformations. This dissertation takes the view of and provides structural support to small and medium-sized enterprises (SMEs).

Essay I describes a digital transformation strategy framework along the four categories "use of technologies", "changes in value creation", "organizational aspects", and "financial aspects". I apply a case based, qualitative research approach to identify common categories and inherent configuration options of a firm-individual digital transformation strategy based on the experiences of SMEs that have successfully incorporated digital technologies in their business and operating model. I find SMEs thereby to accept limitations regarding their degree of strategic freedom and to consider organizational aspects including a strong focus on existing employees more intensely compared to large companies.

Essay II draws on empirical evidence regarding the benefits of management control systems usage in SMEs and develops components to create a digital transformation control system. By applying cultural, planning, administrative, and performance indicator-based controls, SMEs may realize e.g. performance and quality benefits and can faster adapt to the increasingly digital business environment. I develop knowledge from a casebased, qualitative research design, analyzing thoughts as well as intentional and unintentional actions of SME proprietors who successfully mastered digital transformation in their companies. The resulting model is integrated into existing, well-known management control system concepts and opens them for application in the context of digital transformation.

At last, essay III introduces 11 precisely characterized, empirically grounded innovation networks. The involvement in networks is a promising support for SMEs to complement their limited resources regarding innovation and research and development capacity. By developing a holistic, generic typology based on existing scientific knowledge and a data set of 300 purposefully sampled networks, common and distinguishing features between existing network types are clarified. The study mobilizes a sequential mixed methods approach, combining a qualitative content analysis 
with consecutive hierarchical agglomerative clustering. The essay summarizes various existing characterizations of networks and uses them as an input to develop the first, comprehensive, empirically based network typology. 


\section{Table of Contents}

$\begin{array}{ll}\text { List of Figures } & 13\end{array}$

$\begin{array}{ll}\text { List of Tables } & 15\end{array}$

$\begin{array}{ll}\text { List of Appendices } & 17\end{array}$

1 Introduction 19

1.1 Introduction to digital transformation 19

1.2 Relevance of small and medium-sized enterprises 23

1.3 Background and literature 27

1.3.1 Strategy drives digital transformation 27

1.3.2 Management control as a success lever throughout digital transformation 31

1.3.3 Networks to promote digital transformation 35

1.4 Methodologies 39

1.4.1 Essays I and II 39

1.4.2 Essay III 42

1.5 Results and contributions 44

1.6 Dissertation structure 46

2 Essay I: Survival in the digital age - a framework for formulating a Digital Transformation Strategy in SME 48

Abstract essay I 48

2.1 Introduction 49

2.2 Background 51

2.2.1 Digital transformation as a key management challenge 51

2.2.2 Importance of and core elements constituting a digital transformation strategy $\quad 52$

2.3 Research design, sample, and methods $\quad 54$

2.3.1 Research design $\quad 54$

2.3.2 Sample 54 
2.3.3 Data sources $\quad 56$

$\begin{array}{lll}\text { 2.3.4 Data analysis } & 56\end{array}$

2.4 Case descriptions $\quad 57$

$\begin{array}{ll}\text { 2.4.1 Carpenter }(\mathrm{A}) & 57\end{array}$

$\begin{array}{ll}\text { 2.4.2 Denturist }(\mathrm{B}) & 58\end{array}$

2.4.3 Electronics technician (C) 58

2.4.4 Electronics technician (D) 59

$\begin{array}{ll}2.4 .5 & \\ \text { Joiner }(\mathrm{E}) & 60\end{array}$

$\begin{array}{ll}\text { 2.4.6 Metalworker }(\mathrm{F}) & 61\end{array}$

$\begin{array}{lll}2.4 .7 & \text { Tailor }(\mathrm{G}) & 61\end{array}$

2.5 Guidelines for formulating an SME's digital transformation strategy $\quad 62$

2.5.1 Use of technologies dimension $\quad 62$

2.5.2 Changes in value creation dimension 64

2.5.3 Organizational changes dimension 66

$\begin{array}{lll}2.5 .4 & \text { Financial aspects dimension } & 68\end{array}$

2.6 Discussion 69

2.7 Conclusion, Contribution, and Limitations 72

$\begin{array}{ll}2.8 \text { Appendix essay I } & 74\end{array}$

3 Essay II: Options for designing a digital transformation control $\begin{array}{ll}\text { system } & 79\end{array}$

$\begin{array}{ll}\text { Abstract essay II } & 79\end{array}$

$\begin{array}{ll}3.1 \text { Introduction } & 79\end{array}$

3.2 Theoretical background $\quad 82$

3.2.1 Approaching management control from the SME perspective $\quad 82$

3.2.2 Management control systems as a lever of success in digital transformation? $\quad 84$

3.3 Research design, research methods, and sample characteristics $\quad 86$

$\begin{array}{lll}3.3 .1 & \text { Research design } & 86\end{array}$

$\begin{array}{ll}\text { 3.3.2 Sampling approach } & 87\end{array}$

$\begin{array}{ll}\text { 3.3.3 Data sources } & 93\end{array}$

3.3.4 Methods of data analysis $\quad 94$

3.4 Case descriptions 96

3.4.1 Electronics technician $(\mathrm{H}) \quad 96$ 
3.4.2 $\operatorname{Modeler~(I)} \quad 98$

$\begin{array}{ll}3.4 .3 \text { Heating engineer }(\mathrm{J}) & 100\end{array}$

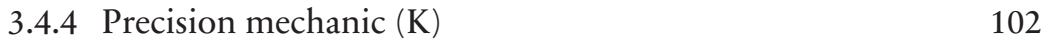

3.5 Results: Components of a digital transformation control system 103

$\begin{array}{ll}3.5 .1 \text { Cultural controls } & 104\end{array}$

$\begin{array}{ll}3.5 .2 \text { Planning } & 106\end{array}$

$\begin{array}{ll}\text { 3.5.3 Administrative controls } & 107\end{array}$

3.5.4 Performance indicator-based control objects 111

$\begin{array}{ll}3.6 \text { Discussion } & 114\end{array}$

3.7 Contribution, Limitations, and Conclusion 119

$\begin{array}{ll}3.8 \text { Appendix essay II } & 122\end{array}$

4 Essay III: Guidance in the network jungle-a typology of intercompany innovation networks 132

$\begin{array}{ll}\text { Abstract essay III } & 132\end{array}$

$\begin{array}{ll}4.1 \text { Introduction } & 133\end{array}$

$\begin{array}{ll}4.2 \text { Theoretical background } & 134\end{array}$

4.2.1 SMEs' benefits from collaboration and network integration $\quad 135$

4.2.2 Formal inter-organizational innovation networks 136

4.2.3 Typologies of networks 139

4.3 Sample characteristics and methods 142

4.3.1 Sample 142

4.3.2 Qualitative content analysis 144

$\begin{array}{ll}\text { 4.3.3 Quantitative cluster analysis } & 147\end{array}$

$\begin{array}{lr}4.4 \text { Results: Types of networks } & 150\end{array}$

4.4.1 Avid Persuaders 151

4.4.2 Value Chain Drivers 152

4.4.3 Collective Facilitators 153

4.4.4 Niche Specialists 154

4.4.5 Lateral Thinkers 155

4.4.6 Transnational Opportunity Seekers 156

4.4.7 Financially Resilient Connectors 157

4.4.8 Local Trend Sponsors 159

4.4.9 Regional Activists 160

4.4.10 Associated Industry Supporters 161

4.4.11 Dynamic Research Groups 162 
4.5 Discussion 163

4.6 Conclusion, implications, and limitations 171

4.7 Appendix essay III 175

5 Conclusion 179

5.1 Summary of research findings and limitations 179

5.2 Avenues for further research 182

$\begin{array}{ll}\text { References } & 185\end{array}$ 


\section{List of Figures}

Figure 3-1: MCS package similar to Malmi \& Brown, 2008, adapted for digital transformation.

Figure 4-1: Morphological box of collaboration characteristics, based on Killich (2011, p. 18).

Figure 4-2: Distribution of analyzed networks by federal state.

Figure 4-3: Distribution of analyzed networks by size (number of actors).

Figure 4-4: Cluster size: distribution of networks by cluster size (number of member networks). 


\section{List of Tables}

Table 1-1: $\quad$ SME definition of the European Commission (European Commision, 2015).

Table 1-2: $\quad$ 2016: SME details (number of companies, annual turnover, staff headcount) (IfM, 2018).

Table 2-1: $\quad$ Overview of cases under analysis

Table 3-1: Initial cases to inspire code development for MCS in digital transformation (see also: Trenkle, 2019)

Table 3-2: $\quad$ Sample cases for second interview round—overview

Table 4-1: Definition of network characteristics for survey during the directed content analysis.

Table 4-2: $\quad$ Merged cluster variables

Table 4-3: $\quad$ Final set of cluster variables

Table 4-4: Typology of formal inter-organizational innovation networks

Table 4-5: Assignment of the identified networks to previous literature 


\section{List of Appendices}

Appendix 2-1: Digital transformation strategy - Use of Technologies $\quad 74$

Appendix 2-2: Digital transformation strategy - Changes in Value Creation $(1 / 2)$

Appendix 2-3: Digital transformation strategy - Changes in Value Creation $(2 / 2)$

Appendix 2-4: Digital transformation strategy - Organizational Changes

Appendix 2-5: Digital transformation strategy - Financial Aspects

Appendix 3-1: Cultural controls in digital transformation

Appendix 3-2: Planning in digital transformation

Appendix 3-3: Administrative controls (1/4) in digital transformation

Appendix 3-4: Performance indicator-based control objects (1/3) in digital transformation

Appendix 4-1: Initial network characteristics considered in the qualitative content analysis.

Appendix 4-2: Declaration of co-authorship for essay III 


\section{Introduction}

This dissertation consists of three essays, each of which is aimed at a selected field of interest in the course of digital transformation in small and medium-sized enterprises (SMEs). All essays share a common basis regarding the introductory background of digital transformation and relevance for SMEs. Therefore, this introduction starts with an explanation of basic definitions and concepts in the debate of digitalization, e.g., by linking the publicly discussed concept of digitalization with the management task of digital transformation. In addition, the relevance of the presented studies is highlighted by brief numerical background information on the SME landscape in Germany and Europe. In section 1.3, I give an overview of the practical and theoretical background of the three essays. Section 1.4 outlines some overarching as well as essay-specific methodological principles, before I summarize results and contributions in section 1.5 and conclude this introduction by outlining the structure of this dissertation.

\subsection{Introduction to digital transformation}

"Now a third revolution is under way. Manufacturing is going digital. [...] Like all revolutions, this one will be disruptive. Digital technology has already rocked the media and retailing industries, just as cotton mills crushed hand looms and the Model T put farriers out of work."

(see: theEconomist, 2012)

We experience "new types of automation, growing digital networks, artificial intelligence and its application in predicting and influencing human behavior, mass surveillance, robotics and man-machine interaction, and power shifts towards some state and non-state actors. [...] the increasing digitization is changing the foundations of our existence,..."

(see: ZEIT-Foundation 2018, p. 1)

Digitalization has been an omnipresent phenomenon for a decade. At all levels and among all members of society, definitions, impact, challenges, opportunities, and threads are discussed. What is digitalization, and how does it relate to digitization or digital transformation, further catchwords around the ongoing debate? What does digitalization mean for members 


\section{Introduction}

of a society, but especially for companies, and its management? How are businesses affected and what do they have to consider to secure a superior position in their relative competitive environments? The present dissertation identifies relevant observations and discussions from a theoretical as well as a practical perspective with regard to three major fields of interest in digital transformation: strategies, management control, and network involvement. These aspects in general have been empirically or conceptually targeted by scholars, but existing literature neglects the specifics of small and medium-sized enterprises (SMEs), and is restricted in terms of its empirical contexts, e.g. by targeting only selected industries, staying purely conceptual, or relying on private secondary data only. By addressing such shortfalls, which I will specifically mention in the topic introductions in sections 1.3 .1 to 1.3 .3 , I will expand existing knowledge, thereby delivering core empirical findings to contribute to scholarly and practitioner discussions to foster successful development of SMEs dealing with technology absorption.

Therefore, in this starting chapter, I will first lay out some necessary definitions to put the existing literature around digitalization into order. I will also give a brief introduction on the expected impact of the growing technology infusion in daily business to explain the imperative for executives of all companies to consider concepts and measures toward technology usage. By drawing on the existing literature, I will derive three relevant areas of interest to expand existing knowledge on digitalization in the context of SMEs.

Digital transformation is the managed adaptation of digitalization, emphasizing the change aspect when introducing technology into a company environment. Throughout this thesis, I treat it as a "probabilistic organizational change philosophy where digital technologies are used to fundamentally transform an organization's business model and value network" (see: Riasanow, Setzke, Hoberg, \& Krcmar, 2018, p. 11). This incorporates the maximum breadth of intra- and inter-organizational influences that technology absorption can have on a company, its business model, and its operating model. Included are changes in ways of working, roles, and business offering caused by the adoption of digital technologies in an organization, or in the operation environment of the organization in order to ensure sustainable value creation (Gimpel \& Röglinger, 2015; Wiesböck \& Hess, 2019). The related terms digitization and digitalization are often used synonymously, which leads to a lack of precision that may cause confusion. Digitization relates to the (pure) technical process of converting analog information into a digital format (Katz \& Koutroumpis, 2013; Ne- 
groponte, 1995). By bringing all types of information down to the lowest common factor, i.e., binary digits, digitization dematerializes information and decouples information from physical carriers and storage, transmission, and processing equipment (Tilson, Lyytinen, \& Sørensen, 2010). Thus, digitization is not the same as, but the prerequisite for, digitalization, which summarizes "manifold sociotechnical phenomena and processes of adopting and using these technologies in broader individual, organizational, and societal contexts" (see: Legner et al., 2017, p. 301-302). Three waves of digitalization have been identified: The first wave focused on technologies replacing paper as a physical carrier with computers, leading to greater automation in work routines. The second wave gave birth to the internet as a global communication infrastructure, resulting in changes to firms' value creation logics and new types of businesses, such as e-commerce or intermediaries. Today, we are experiencing the third wave, where the converging SMAC ${ }^{1}$ technologies and continuing miniaturization, combined with ever-increasing processing power, storage capacity, and communication bandwidth, have made the vision of ubiquitous computing come very close to reality (Legner et al. 2017, p. 301-302). ${ }^{2}$ These definitions point out the variety of influences that company executives have to consider with regard to technology adoption. Some adoptions are simple replacements of analog vs. digital data, comparable to writing and processing reports on a digital device. Other changes, considering their influence on products and sales channels, may raise the necessity for revolutionarylike actions compared with a company's status quo. Discussion of the management of digitalization-incorporated change is thus not new. Tushman \& Reilly, 1996, introduce the principle of "ambidexterity" for successfully dealing with technology-related change in corporate environments. They claim that companies need to combine elements of exploitation and exploration to master evolutionary and revolutionary change within a single company, while at the same time admitting that implementation is quite difficult in practice. The management of digitalization still remains as intangible from a theoretical as well as a practitioner point of view as executives struggle to narrow it down to a clear agenda. In the managerial discussion, some see technology at the center of the discussion, whereas others focus on customer behavior and engagement; for some decision makers, it represents a completely new way of doing business (Dörner \& Edel-

1 Social, mobile, analytics, cloud computing; see El Sawy et al. 2016; Kohnke 2017.

2 For an illustrative example to show the difference between digitization and digitalization based on the Finnish modus of tax gathering, see Parviainen et al. 2017. 


\section{Introduction}

man, 2015). "The challenge isn't just to recognize innovative technology but also to apply it to your existing business model. In some cases, this requires breaking the business model and coming up with an entirely new way of doing business.” (Earley 2014, p. 58).

The necessity to define a management approach toward digital transformation follows directly from the massive and radical impact that digital technologies can have on companies and the society to which they belong (Yoo, Boland, Lyytinen, \& Majchrzak, 2012). New sectors, new products, and new services will emerge, including the creation of new job descriptions (Degryse, 2016). New production technologies will foster the use of innovative materials, and automation across production processes will move jobs from the factory to offices and support the roles of designers, engineers, information technology specialists, logistics experts, and digital marketing staff. Technology can make repetitive tasks obsolete (theEconomist, 2012). Customer centricity becomes an imperative by rethinking business models based on customer expectations, physical products and services are enhanced with digital capabilities, new technologies make assets more durable and resilient as data-based analytics are transforming modes of maintenance, and all this together will require new forms of cooperation and organization (Schwab, 2015).

Economists have identified technological change as one key engine of economic growth (Galenson, 2010). The positive impact of exploitation and exploration of digital technologies alongside their incorporated business opportunities as well as inherent threats for companies and societies are broadly discussed. Thereby, most authors fundamentally agree on the positive effects of digital transformation on companies, e.g., increase in sales and productivity, increased flexibility, more accurate capacity allocation, growth resulting from larger markets, and deeper market knowledge. Positive effects on employment, increased market efficiency, a higher standard in the quality level of goods and services, and increased innovativeness can be added to the list of beneficial expectations (Atkinson \& Kay, 2018). Companies that do not address higher quality and innovativeness are potentially disrupted by new competitors or established competitors that adapt more quickly to the new environment (Downes \& Nunes, 2013). Several retailers have gone under or failed to deliver profits for years as online retailing has become self-evident for most buyers. Analog photography has turned from being the industry standard to a hobby for enthusiasts. Products are replaced, and service models are remodeled by digital access options based on customers' increasing convenience. Therefore, potentially negative effects pose severe threats such as the large-scale substi- 
tution of human work by machines and robots and the resulting social inequality caused by the disappearance of large numbers of medium-skilled jobs (Brynjolfsson \& McAfee, 2014; Earley, 2014), sophisticated criminal cyber activities (Greengard, 2016), and potential defamation or simply false information via social media channels. The necessity to establish management practices to govern these complex transformations leads to an acknowledgment that digital transformation is a high-priority management task and that digital transformation can cause competitive distortions at an as yet unknown level of dynamics, which makes steady observation of technologies even more important for company owners. None of the presented developments is limited to large companies only, instead all companies face the challenge to find appropriate measures to meet future challenges. This dissertation is focusing on SMEs as a distinctive field of research. Therefore, in the next chapter I will define SMEs as a specific research unit and emphasize their relevance.

\subsection{Relevance of small and medium-sized enterprises}

Across Europe, SMEs are considered to be one of the most important sources of success for the economic development (European Commision, 2015). SMEs are mostly owner managed and combine high innovativeness with a national or international perspective on markets and high levels of social responsibility. The future of this successful model thus depends on the ability to recognize the most important trends at a strategic level and, at the same time, to formulate answers to them at the operational level (Astor, Rammer, Klaus, Klose, \& Böllhoff, 2016).

The European Commission, as shown in Table 1-1, defines SMEs based on their "Staff headcount", their "Annual turnover", and their "Total assets". ${ }^{3}$

3 Details to calculate the numbers are given in (European Commision, 2015). A further requirement to be considered an SME is to be an autonomous enterprise (see: European Commision 2015, p. 15-16). The "or-" link between "Annual turnover" and. 
Table 1-1: SME definition of the European Commission (European Commision, 2015). 4

\begin{tabular}{|c|c|c|c|c|c|}
\hline Category & $\begin{array}{l}\text { Staff } \\
\text { headcount }\end{array}$ & \multirow{4}{*}{ and } & $\begin{array}{l}\text { Annual } \\
\text { turnover }[€]\end{array}$ & \multirow{4}{*}{ or } & Total assets $[€]^{5}$ \\
\hline Micro & $<10$ & & $\leq 2$ Mio. & & $\leq 2$ Mio. \\
\hline Small & $<50$ & & $\leq 10$ Mio. & & $\leq 10$ Mio. \\
\hline $\begin{array}{l}\text { Medium- } \\
\text { sized }\end{array}$ & $<250$ & & $\leq 50$ Mio. & & $\leq 43$ Mio. \\
\hline
\end{tabular}

For example, in Germany, there are in total 3,483,691 companies registered, of which 3,461,555, i.e., 99.4\%, are SMEs. Together, they account for $\sim 2,315$ EURbn in annual turnover, representing a $33.2 \%$ share of all companies' value added. They employ more than 16.0 million people, providing a job to $52.0 \%$ of the German nation's employed population (IfM, 2018). These numbers indicate the outstanding weight that SMEs carry in German economic prosperity on an almost equal level since years (IfM, 2016).

Among the different types of SME companies indicated in Table 1-2, i.e., micro, small, and medium-sized enterprises, based on their staff numbers, the vast majority $(88.1 \%)$ are micro companies with fewer than 10 employees. Nevertheless, because of their high number, they account for $25.2 \%$ of yearly SME turnover and $24.8 \%$ of total SME headcount. Small companies $(9.6 \%)$ represent $32.2 \%$ of annual SME turnover and $35.4 \%$ of SME headcount. Medium-sized enterprises (2.3\%) stand for $42.6 \%$ of annual SME turnover and $39.6 \%$ of SME staff headcount.

4 Details to calculate the numbers are given in (European Commision, 2015). A further requirement to be considered an SME is to be an autonomous enterprise (see: European Commision 2015, p. 15-16).

5 "Total assets" indicates that at least one of the values must be below the given boundary value by a company in order to be categorized accordingly. 
Table 1-2: 2016: SME details (number of companies, annual turnover, staff beadcount) (IfM, 2018).

\begin{tabular}{|l|l|l|l|l|l|l|}
\hline Category & \multicolumn{2}{|l|}{$\begin{array}{l}\text { Number } \\
\text { of com- } \\
\text { panies }\end{array}$} & $\begin{array}{l}\text { \% of SME } \\
\text { total }\end{array}$ & $\begin{array}{l}\text { Annual } \\
\text { turnover } \\
\text { [€bn] }\end{array}$ & $\begin{array}{l}\text { \% of SME } \\
\text { total }\end{array}$ & $\begin{array}{l}\text { Staff } \\
\text { head- } \\
\text { count }\end{array}$ \\
\hline Micro & $3,050,074$ & $88.1 \%$ & 584,02 & $25.2 \%$ & $3,989,676$ & $24.8 \%$ \\
\hline Small & 332,821 & $9.6 \%$ & 746,11 & $32.2 \%$ & $5,718,568$ & $35.6 \%$ \\
\hline Medium-sized & 78,660 & $2.3 \%$ & 985,46 & $42.6 \%$ & $6,353,046$ & $39.6 \%$ \\
\hline SME total & $\mathbf{3 , 4 6 1 , 5 5 5}$ & & $\mathbf{2 , 3 1 5 . 5 9}$ & & $\mathbf{1 6 , 0 6 1 , 2 9 0}$ & \\
\hline Large & 22,136 & & $4,652.69$ & & $14,797,798$ & \\
\hline Total & $3,483,691$ & & $6,968.28$ & & $30,859,088$ & \\
\hline
\end{tabular}

Across the European Union, $99.8 \%$ of all enterprises are considered to be SMEs, employing $66 . \%$ of the total workforce and accounting for $56.4 \%$ of value added (European Commission, 2019; Eurostat, 2020). These numbers clarify the paramount importance of ensuring a beneficial environment for SMEs for the successful economic development of Europe.

SMEs have a number of special features that make them a differentiated research area compared with large companies. Pfohl, 2006, elaborates a range of special SME characteristics based on a broad literature review. Their (1) leadership is dominated by the company owner, leading to relatively scarce professional knowledge about management techniques, scarce decision making in groups, limited headroom for counteraction in case of mistaken decisions, and poor strategic planning. SMEs' (2) organization is tailor-made hierarchical, focused on the owner-manager, who accumulates several roles and interacts tightly across interconnected staff, shows a low degree of formalization, and can therefore be regarded as highly flexible. (3) Production processes are marked by a low degree of work-sharing. Machinery is deployed universally and depends strongly on a small number of basic innovations, which finally leads to low economies of scale. SMEs' (4) sales are used to meet demand in small dimensions, incorporating a high degree of customization, in a limited regional and/or highly specialized segment. (5) Research \& development ( $R \& D$ ) activities are usually not institutionalized in a department structure and are executed at short range, incorporating a high degree of intuition. Often, new products and services are developed to meet demand and are less based on a fundamental research ambition, due to limited time budgets from invention to monetization. Regarding (6) funding, most SMEs are owned by families and do not have access to capital markets, which leads to overall limited financial re- 


\section{Introduction}

sources and poor risk mitigation measures. A small number of employees, especially when it comes to academic background, are a specialty regarding SMEs' (7) buman resources. Further differences arise in the areas of (8) logistics, (9) procurement, and (10) waste disposal, which I consider as having a lower impact regarding the forthcoming research projects.

Furthermore, as many SMEs are family-owned businesses, I expect many attributes considering the management of family firms worth mentioning. As one example, Carney, 2005, describes three dominant propensities that characterize governance in family firms: Parsimony refers to the fact that family firms make decisions keeping in mind the family's personal wealth. As people tend to be more prudent with their own money, they are likely to consider opportunities more carefully and to search for opportunities more efficiently. Personalism centers authority in an owner-manager, reducing internal bureaucratic constraints. They tend to avoid formalized management and transparency practices that inhibit the prerogatives of ownership, potentially resulting in the freedom "to engage in longer-term innovation practices and in building internal knowledge structures conducive to finding opportunities" (Patel \& Fiet 2011, p. 1180). Particularism refers to an owner-manager's ability to include non-rational, calculative criteria in her/his decision making. Motives and goals may be driven by noneconomic considerations such as altruism, nepotism, or the wish to improve social status. Further characteristics of family businesses with regard to decision making in situations of high uncertainty include a high degree of risk avoidance (Kontinen \& Ojala, 2010) as well as a paucity of slack resources (Fernández \& Nieto, 2005).

All these attributes describe the specialties that characterize SMEs as a distinct field of investigation. One can argue that the presented characteristics are still very broad and far from ring-fencing a homogeneous group of companies in which to conduct research. I explicitly target this broadly defined set of companies in order to maximize the theoretical as well as practical implications resulting from my studies. In the essays, I will elaborate the specifics of the companies that supported this research and thereby narrow the context, so that the reader can judge the contextual explanation power at an individual level. The variety of SMEs provides the fruitful context for all three essays to follow, targeting strategies in the context of digital transformation (section 1.3.1), management control throughout digital transformation endeavors (section 1.3.2), and finally potential network types to enhance limited individual innovation resources (section 1.3.3). 


\subsection{Background and literature}

\subsubsection{Strategy drives digital transformation}

"Strategy, not technology, drives digital transformation."

(see: Kane, Palmer, Philips, Kiron, \& Buckley, 2015)

The first essay ${ }^{6}$ focuses on digital transformation strategies as managements' and SME owners' starting point to succeed in digital transformation. Companies seek competitive advantages from digital transformation by incorporating technology in their established business and operating models (Main, Lamm, \& McCormack, 2018). Still, there is no standard recipe for digital transformation implementation. Researchers agree that this requires a holistic approach, across the entire organization of a company, across all operational processes, resources, internal and external users in order to thereby bring about a significant change in the habits and working methods of employees (Henriette, Feki, \& Boughzala, 2015; Loonam, Eaves, Kumar, \& Parry, 2018). Whereas leaders in digital transformation tend to rely on elaborate digital strategies, less digitally mature organizations focus on selected technologies only (Kane et al., 2015). Yet there is a scholarly discussion on how an integrated digital transformation strategy should be designed. Advancing digitalization and information technology will have a strong, inevitable impact on the business level strategy (Drnevich \& Croson, 2013). So previous literature has focused strongly on the relationship between business and IT strategy and the alignment of both.

Across company sizes, earlier researchers called for an IT strategy aligned with but subordinate to the business strategy (Henderson \& Venkatraman, 1993; Hirschheim \& Sabherwal, 2001; Hussin, King, \& Cragg, 2002). Along with the recent spread of social, mobile, analytics, and cloud technologies (SMAC), academic focus has shifted toward an integrated, strategic view of business and IT (Bharadwaj, El Sawy, Pavlou, \& Venkatraman, 2013; McDonald, 2012), targeting an optimum level of digital transformation at the level of each individual company (Grover \& Kohli, 2013).

Academia has made the first steps in order to generalize about necessary actions in digital transformation, laying the groundwork to develop frame-

6 Essay is published: Trenkle, Johannes (2019). Survival in the digital age - A framework for formulating a Digital Transformation Strategy in SME. Proceedings of the 19th International Conference on Electronic Business (pp. 428-442). ICEB, Newcastle upon Tyne, UK, December 8-12. 


\section{Introduction}

works for the configuration of a digital transformation strategy, but mostly failing to follow a holistic approach. As an example, a digital business strategy for online music content providers should incorporate insights from analyzing the mechanics of building, maintaining, and monetizing content as well as different groups of platform and community users, taking into account the digital management of their mutual interactions (Oestreicher-Singer \& Zalmanson, 2013). These results show the importance of an integrated view on business and technology at a company strategy level. Further case study-based articles target digital business strategies and organizational implications within the publishing and newspaper industry. These specific industries were chosen as examples in which competitive pressure from digitalization-induced change started relatively early (Horlacher \& Hess, 2016; Karimi \& Walter, 2015; Lanzolla \& Anderson, 2008; Øiestad \& Bugge, 2014; Oliver, 2018). The results incorporate the concept of exploitation and exploration in a digital transformation strategy, besides a focus on necessary innovation capacities and capabilities such as resources, processes, and values. A single case study from the retail industry adds inter- and intra-company organizational change aspects to the list of digital transformation strategy ingredients (Hansen \& Sia, 2015). El Sawy, Amsinck, Kræmmergaard, \& Vinther, 2016, derive the ingredients for digital leadership from a single case study of a world-leading toy manufacturer: a distinct business strategy and business model, an enterprise platform, digital mindset, high-performance corporate IT and workplace environment. Their results point the way to an appropriate level of practical orientation in information strategy research, which is in line with further claims from academia (see, e.g, Teubner, 2013).

Matt, Hess, \& Benlian, 2015, developed a digital transformation framework to guide companies holistically when developing and defining a digital transformation strategy. According to its universal structure, the digital transformation of every company can be built up along four key dimensions that are well coordinated with each other (Matt et al. 2015, p. 340341):

Use of technologies: a company's strategic position and future ambition toward new technologies, as well as its ability to exploit them. The firm can choose whether it strives to achieve market leadership in terms of technology usage, creating the opportunity to set its own technological standards, or whether it relies on proven standards and limits its technology use to streamline business operations. The definition of a technological level of ambition is incorporating a decision on business risk-triggering a tradeoff between the competitive advantages of becoming a technological mar- 
ket leader and standard setter and the risk of technological failure and the imperative of investments in technological competences.

Changes in value creation: the influence of digital transformation strategies on the way a firm aims to add and create value. It contains an estimation of the steps of change in its classical, analog core business toward new, digital activities. It depicts opportunities to expand and enrich the current products and services portfolio as well as requirements for different forms of monetization or adjustments to firms' business scope if there is a change in addressed markets or customer segments.

Structural changes: modifications in a company's operations, i.e., structures, processes, and skill set. Exploitation and exploration of new technologies and digital activities may require structural adaptations, e.g., in the management setup. An assessment is important in this context whether it is mainly products, processes, or skills that are affected by change. It might be reasonable to integrate limited adaptations into existing corporate structures, whereas changes that are more substantial might be fenced better in a separate subsidiary within the firm.

Financial aspects: deliver transparency about the urgency to act in the face of declining margins in a firm's core business and about a firm's financial scope to invest in a digital transformation endeavor. Financial power fuels and limits every strategic transformation. In times of potentially disruptive change, lower financial pressure on the core business may reduce the perceived urgency to act, whereas companies already under financial pressure might lack external ways to finance a transformation. An open assessment of the financial situation is therefore considered a prerequisite for transformational success.

Matt et al. (2015), discussing their digital transformation framework, call for further research on digital transformation strategies, considering different industries as well as different firm sizes. The four categories have therefore been detailed further, based on case study insights from mediumsized to large media companies (Hess, Benlian, Matt, \& Wiesböck, 2016), as well as insurance corporations (Wiesböck et al., 2017). As a result, the "use of technologies", "structural changes", and "financial aspects" dimensions show potential for generalization, at least in an environment of companies above 500 employees. Regarding the "changes in value creation" domain, single industry-focused studies are highly specific, with the results prohibiting any generalizing conclusions. Small companies with fewer than 500 employees or even smaller enterprises and their differentiating characteristics remain unaddressed within existing studies. Therefore, to my knowledge, there are no scientific studies yet focusing holistically on 


\section{Introduction}

the issue of digital transformation in SMEs. An analytical transfer of the existing results around digital transformation strategies to an SME setting is possible, but the specific conditions in SMEs are not sufficiently appreciated, and the results would not be equal to those of previous studies in terms of their empirical foundation and significance.

Hence, this essay seeks to enlarge the existing literature on digital transformation strategies in an SME context, as I raise the research question: How does the SME context influence core elements of a digital transformation strategy? Following a theoretical categorization by Helsen et al., 2017, I take a research view between "contingency theory" and a "situation-specific approach" to elaborate theory in the field of digital transformation strategies. Explicitly targeting SMEs, I expect that a digital transformation strategy must be tailored to each organizations' context, but at the same time is constructed from a range of categories that can be generalized across various firms. The target is to find a set of guiding questions that a SME-represented by its management-can follow in order to define its digital transformation strategy along an empirically derived path of question and answer options. This structure proved to be a promising way to present results based on the already mentioned examples from industryspecific, large corporation environments (Hess et al., 2016; Wiesböck et al., 2017). The hereby identified strategic questions are enriched by answer options, identified by analyzing the experience of SME managers who successfully handled digital transformation in their companies. This procedure intends to provide a twofold, value-added approach: extending existing scholarly research on digital transformation as well as bridging the gap to practical, everyday business challenges. Focus is therefore not on the timely process of digital transformation, but on the variety of strategic considerations of the management, as well as visible occurrences in the companies.

After defining a digital transformation strategy in a first step, it all comes down to execution to become a digitally successful enterprise. Scholars provide an array of empirical evidence, that management control measures might support decision makers in SMEs to manage digital transformation journeys in a performant way. Therefore, the second essay, which I will introduce in section 1.3.2, targets "digital transformation control". 


\subsubsection{Management control as a success lever throughout digital transformation}

"The ability to plan business decreases. Accordingly, it is indispensable to continuously check the validity of the premises underlying the planning and the business model and to develop a controlled trial-and-error culture" (see: Schäffer \& Weber, 2016)

The management of digital transformation remains a challenge for leaders in companies of all sizes. The bandwidth of potential influences includes adaptations of company' visions, methods of value creation, structures, and finances (Matt et al., 2015). I assume that any support managers can get throughout this complex change process is warmly welcomed, building the logical bridge toward management control systems (MCS), i.e., systems, rules, practices, values, and other activities that management puts in place in order to direct employee behavior (Malmi \& Brown, 2008).

Yet the definitional challenge remains around the variety and breadth of the term management control, especially in the SME context. Scholars, when analyzing MCS in the context of SMEs, include classic literature in the field of management accounting, enclosing organizational rules and routines (see: López \& Hiebl, 2015; e.g., Burns \& Scapens, 2000; Johnson \& Kaplan, 1987), the multidimensionality of a balanced scorecard approach (R.S. Kaplan \& Norton, 1992), management accounting techniques in a broad sense including budgeting, performance evaluation, costing, decision making, communication, and strategic analysis (e.g., Chand and Dahiya, 2010; Ahmad and Zabri, 2016). The breadth of investigated objects and phenomena points toward the particular German concept of "controlling", a coordination function within a company's leadership system to align planning, control, management information, organization, and human resources management (see e.g., Küpper et al., 2013).

This viewpoint is also supported in the existing literature. Some examples are mentioned here in order to show the variety of aspects under consideration when analyzing MCS in SMEs. De Lema \& Duréndez, 2007, analyze the adoption of management control tools in a sample of family vs. nonfamily firms, taking a particular financial focus, and look at management accounting systems, cash budgets, and financial analysis. Within their implementation, they see a database for gaining transparency on full costs and therefore delivering decision support for financial planning and control systems. Finding that family firms make less use of such analytical tools, they conclude that a more structured approach may provide benefits for family firms, yet lacking further detail. Gunawan, Ellis-Chadwick, \& 


\section{Introduction}

King, 2008, add performance indicators to the discussion that fit especially to online activities. This includes financial aspects as well as nonfinancial activities, including logistical processes such as delivery and returns as well as web excellence performance indicators such as website popularity and customers' online shopping experience. The resulting selections of around 30 performance indicators on web retailing and 30 dimensions of performance indicators remain highly specific to online retailing and neglect, e.g., the structural or cultural aspects of management control. Budgeting and incentive scheme design from a SME perspective have been identified, among others, as further differentiating aspects within the scope of management control (Jorissen, Laveren, Martens, \& Reheul, 2005). Various potential measures of cash management usage as part of performance management have been shown by Howorth \& Westhead, 2003.

Across the variety of potential measures, scholars have identified in general three motives of SME managers in introducing MCS measures: a wish to increase business performance, a higher level of professionalization, and a higher degree of rationality in taking decisions. The following paragraphs give background on these motivations.

SMEs implement MCS in general driven by the wish for performance optimization. Performance thereby captures managers' perceptions of their firms' competitive position (Duréndez Gómez-Guillamón, Ruíz-Palomo, García-Pérez-de-Lema, \& Diéguez-Soto, 2016), product profitability improvements, and cost reductions (Adler, Everett, \& Waldron, 2000), improved product development performance (Davila, 2000), or overall financial performance (e.g., J. Dekker et al., 2015; Sharma \& Bhagwat, 2007; Songini \& Gnan, 2015). In the case of a high degree of management autonomy, as is the position in owner-managed SMEs, MCS usage leverages financial performance, measured by sales growth, return on sales, gross profit, and net profit as well as return on equity and return on investment (Kallmuenzer, Strobl, \& Peters, 2018). In order to explain the provenance of positive performance impacts, there is evidence that the adoption of management control techniques improves SMEs' ability to control costs, measure performance, determine investments, and fix prices, thereby allowing SMEs' resources to be optimized (Laurinkevičiūte \& Stasiškienè, 2011; Villarmois \& Levant, 2011).

Amat, Carmona, \& Roberts, 1994, show that SMEs, like all other companies, develop over time on an institutional level, striving for professionalization. This ambition is credited to challenges from external factors such as competition and the social and political environment, as well as internal 
factors such as the need for profitability, adjustments in control and authority. Amat et al., 1994, show that this continuum of recurring tensions provides the origins for simple, partially formalized MCS, setting the basis for an ongoing increase in professionalization regarding management practices. Paternalistic management practices, based on direct supervision and nonfinancial controls, can be replaced by standardized processes and financial controls (see also: Giovannoni, Maraghini, \& Riccaboni, 2011). Craig \& Moores, 2005, highlight the ability of a balanced scorecard model, adapted to the special conditions in family firms, to support successful company development. They find that objectives in the fields of systems and structures, employee friendliness, knowledge-sharing, openness, and familiness encourage a professional management style, vital for firms' development. In order to formalize the discussion on the process of professionalization itself in SMEs, Dekker, Lybaert, Steijvers, Depaire, \& Mercken, 2013, introduce four types of family firms (Autocracy, Domestic Configuration, Clench Hybrid, and Administrative Hybrid), based on their degree of usage of multidimensions of management control instruments. From this typology and the dimensions used, Dekker, Lybaert, Steijvers, \& Depaire, 2015, show that especially the professionalization measures "nonfamily involvement", "implementing human resource control systems", and/or "decentralizing authority" result in a positive effect on a firm's performance. Nevertheless, professionalization does not appear on its own. It requires family members' adequate education in management accounting or business, a family's esteem for the associated information, and finally willingness to professionalize management control (Hiebl \& Mayrleitner, 2017). Given these prerequisites, management control measures can act as a sort of common language to drive SMEs' process of professionalization (Giovannoni et al., 2011).

An increase in leadership rationality is another beneficial finding related to the use of MCS in a SME context. Assuming the individual firm-optimized level of graduation, i.e., an adequate level of calibration with regard to calculative controls, family-centric controls, procedural controls, and especially pragmatic and minimal controls, the use of MCS "[...] can foster economic rationality and thereby reduce familial affectivity" (El Masri, Tekathen, Magnan, \& Boulianne, 2017, p. 179). El Masri et al., 2017, argue that it is about every SME on its own deciding whether it wants to strengthen a business or a family identity, relying pervasively on either rational control measures or minimal, pragmatic measures, and call for a company-specific calibration, an important aspect in facilitating the attain- 
ment of objectives by the adequate use of management control instruments.

A partially independent body of literature focuses on the benefits that SMEs can realize by the use of MCS. These include facilitated decision making (Chand \& Dahiya, 2010; Duréndez, Madrid-Guijarro, \& GarcíaPérez-de-Lema, 2011; Villarmois \& Levant, 2011), improved quality of strategic analysis (Chand \& Dahiya, 2010; Garengo \& Bernardi, 2007; Peel \& Bridge, 1998; Tapinos, Dyson, \& Meadows, 2005), better integration of the business plan and key performance indicators (Manville, 2007), resource optimization (Laurinkevičiūtė \& Stasiškienè, 2011; Villarmois \& Levant, 2011), overall quality improvement (Chand \& Dahiya, 2010), and faster adaptation to the surrounding environment (Amat et al., 1994; Laurinkevičiūtė \& Stasiškienè, 2011). I consider all these aspects to be highly appreciated in the context of digital transformation. Nevertheless, recent publications emphasize future research opportunities concerning MCS in SMEs, e.g., targeting regional setting, firm size including constraints and performance outcomes, various adaptation aspects of management control measures in SMEs in contrast to large enterprises, staff related topics, or the role of networks (e.g., López \& Hiebl, 2015; Quinn et al., 2018). The role that MCS can play in a digital transformation journey appears to be a new, yet open aspect. This fact is somewhat surprising as technology and technology usage appear to be one of the most commonly examined independent variables in management control research around SMEs (Chenhall, 2003; Otley, 2016). This study aims to show the variety of MCS able to support successful digital transformation in a SME setting. Given this explorative research setting, I expect that the manifold technological opportunities "would require controls to encourage flexible responses, high levels of open communication within the work force and systems to manage the interdependencies. Traditional, mechanistic MCS based on financial controls would not seem to suit these circumstances." (Chenhall, 2003, p. 139).

Lately, practitioners have seen a potential paradigm shift in management control, incorporating agile methods in the spectrum of management control measures. "We've always done it this way' is a deadlocked attitude that doesn't work. Rather, it is necessary to set up an agile digitization roadmap that allows quick decisions and a demand-oriented reaction to new market requirements - in the sense of a trial-and-error approach that allows for mistakes." (Haberich, 2018). Academia has also put the trial-and-error concept on the research agenda (see, e.g, Schäffer \& Weber, 2016). Therefore, I investigate the role that trial-and-error plays as part of management control procedures from an empirical perspective. 
In line with essay I, in essay two I also follow a research view of "contingency theory" and "situation-specific approach" (Helsen et al., 2017). I search for a system of controls that might support SMEs' digital transformation efforts. Within a set of universal control categories that can be generalized across companies, I expect that every SME manager must design an individual control system for a company. Therefore, I strive for maximum variance throughout my analysis, presenting a construction kit, from which both academic addressees can derive pointers for further analysis and practitioners can find support in designing an adequate MCS. I answer the question: How should a digital transformation control system be designed?

In addition to the application of control measures, integration into networks plays a significant role for the success of SMEs in digital transformation. With this I am anticipating a result from essay I at this point. Together with my co-author, I therefore dedicate essay III to standardizing the discussion about networks and network types, since existing literature examines different levels and characteristics of networks and does not enable a directed, comprehensive analysis and discussion of network types.

\subsubsection{Networks to promote digital transformation}

"Even very good technologies will flounder if they do not connect effectively to outside complementary technologies, while seemingly inferior ones may overtake them if they are better connected. The need for effective connections requires firms to collaborate with others in their ecosystem, as well as to compete with them."

(see: Chesbrough, 2003, p. 60)

SMEs are lagging behind large companies in terms of digital transformation (BMWi, 2018). This situation is dangerous regarding their future viability, as innovation in business and operating models, especially digital innovation, is key to staying competitive (Nambisan, Lyytinen, Majchrzak, \& Song, 2017), also for SMEs. SMEs need to overcome shortfalls in innovation power and handling environmental pressure (Agostini \& Nosella, 2019), as well as limited resources and special IT know-how (Mieke, 2008). Nevertheless, barriers to embarking on innovation activities have increased in recent years, e.g., estimated high economic risk, innovation costs, and a lack of financial resources (Rammer, Gottschalk, Peters, Bersch, \& Erdsiek, 2016). Sydow, 2001, found that these obstacles can be overcome by collaborative activities and networks, as they can reduce the need for capital as well as the strategic risk. Valkokari \& Helander, 2007, conclude that part- 


\section{Introduction}

nership in cooperative activities and networks is an appropriate measure to compete and innovate in changing business environments.

Casals (2011) structured previous literature supporting the high relevance of networks for SMEs as well as their need and motivation to collaborate by providing a SME cooperation framework. The reasons to collaborate are divided into external reasons, i.e., the industry environment, and internal reasons that refer to the firm. Internal reasons include learning and exchange of experience, access to external sources of innovation, and the search for complementary resources including $R \& D$ activities. External reasons can include the desire for internationalization as well as for creating new business opportunities. The achievement of these collaboration objectives is sought through a variety of different collaboration approaches, including innovation networks. Policy makers therefore put support for collaboration on their agenda and offer public funding as well as various support programs to promote engagement in networks (Rammer et al., 2016) in order to foster technology transfer at the interface of industry and research and integrate SMEs into initiative programs (BMWi, 2020). To strengthen competitiveness, networking, innovation power, and employment among SMEs is the objective of a set of promotions and (financial) support programs (Buhl, Sedlmayr, \& Meier, 2019).

$\mathrm{We}^{7}$ find existing literature on innovation networks to use heterogeneous methods and target heterogeneous purposes and aspects, which makes it impossible to compare existing network types and derive universal guidance for SMEs. To illustrate this aspect, we provide a brief review of existing literature. Friese, 1998, found a broad, cross-disciplinary use of terms related to networks, such as collaboration, network, and cluster, depending on the perspectives of each author. Aspects that influence the existing literature can be summarized by questions that potential members ask when they have to decide whether to participate in a network.

"Why should companies participate in a network?" Organizations, especially companies, exchange resources and gain a competitive advantage via network participation that they could not obtain alone (Child, Faulkner, \& Tallman, 2005; Sydow, 2001; Wissema \& Euser, 1991). Motivation for participation is derived from two directions (Casals, 2011). Collaboration via networks can be fostered by companies' objectives to minimize costs, referencing the Transaction Cost Approach (Williamson, 1981). On the other

7 Essay III is based on a joint research project by Carl-Philipp Beichert and myself. I refer to both of us when using 'we' in the context of essay III. Each author's contribution is declared in Appendix 4-2. 
hand, referencing the Resource Based View, collaboration is a way to bundle individually limited resources to develop a long-term competitive advantage, thereby opening internal resources toward external knowledge (Loasby, Pfeffer, \& Salancik, 1979; Williamson, 1981). We follow the second view and see collaboration as a measure to reduce uncertainty of resource availability in line with Sydow, 1992. SMEs thereby gain the opportunity to increase strategic flexibility and to reduce capital requirements by accepting the risk of a loss of strategic autonomy and an increase in coordination costs (Sydow, 2001).

"What is a network?" All networks we consider for our study consist of three or more organizations linked through multilateral ties. The connections are targeted to facilitate the achievement of a common major goal (Provan, Fish, \& Sydow, 2007) or a bundle of different objectives (Morschett, 2003), e.g., access to new or complementary knowledge, marketing, an increase in economies of scale, and risk sharing (Mariti \& Smiley, 1983). To coordinate efforts toward a network's objective, some degree of coordination is required. Across networks, scholars find a combination of market and hierarchy, i.e., competitive and collaborative elements (Sydow, 1992), or even claim that networks represent an independent form of coordination (Powell, 1990). In order to overcome this objection, researchers suggest classifying networks via typologies (Provan et al., 2007; Provan \& Kenis, 2008) that share market- and hierarchical-oriented characteristics (Friese, 1998; Sydow, 1992). In order to realize the desired, competitive advantages for the network members, this implies complex reciprocal, collaborative rather than competitive and relatively stable relationships, whereas the entities involved are legally independent, but economically dependent enterprises and organizations (Sydow, 1992). Further distinguishing factors, we consider, include, e.g., formality of formation (Cross, Nohria, \& Parker, 2002; Van Aken \& Weggeman, 2000) and organization structure (Sydow, 2001).

What is the focus of a network? We focus on networks that have specialized in R\&D activities in a broad sense as a decisive factor to foster the competitiveness of companies by leveraging product innovation and market success of new products (Hottenrott \& Lopes-Bento, 2016; Schilling, 2013). The involved partners combine their different skills and knowledge bases. A collaboration via networks offers the opportunity to unlock tacit knowledge and use it to support technological innovation toward products, processes, or services (Powell, 1990; Van Aken \& Weggeman, 2000).

"What types of networks exist?" In our study, we follow Provan et al., 2007, and Provan \& Kenis, 2008, to differentiate networks based on ty- 
pologies. So far, the literature lacks a consistent typology of networks grounded in empirical data, which makes it difficult to compare existing studies with each other and limits the significance of the results for decision makers in practice. Case study and interview-based typologies do not allow for generalization (see, e.g., Bau, Bentivegna, \& Forster, 2014; Provan et al., 2007). In our study, we reference academic predecessors by relying on their identified network characteristics including the direction of value creation (Hagenhoff, 2008; Killich, 2011; Morschett, 2003; Payer, 2008; Schmidt \& Kiefer, 2003), geographic concentration (Eckert, 2009; Hess, 2002; Killich, 2011; Morschett, 2003; Payer, 2008; Schmidt \& Kiefer, 2003), intensity of collaboration (Killich, 2011; Schmidt \& Kiefer, 2003), firmness of commitment (Hagenhoff, 2008; Killich, 2011; Schmidt \& Kiefer, 2003), duration (Eckert, 2009; Hagenhoff, 2008; Killich, 2011; Morschett, 2003; Schmidt \& Kiefer, 2003), goal identity (Eckert, 2009; Killich, 2011), and functional involvement (Eckert, 2009; Hagenhoff, 2008; Hess, 2002; Killich, 2011). Further aspects that we include cover network governance (Provan \& Kenis, 2008), network structure (Child et al., 2005; Glückler, Dehning, Janneck, \& Armbrüster, 2012; Schuh, Kampker, \& Rittstieg, 2011; Sydow, 2001), type of control (Sydow, 2001), positioning of the actors in the value chain (Achrol \& Kotler, 1999; Bau et al., 2014; Dussauge \& Garrette, 1999; Gereffi, Humphrey, \& Sturgeon, 2005; Hess, 2002; Sydow, 2001), local and regional focus (Cooke, Gomez Uranga, \& Etxebarria, 1997; Inkpen \& Tsang, 2005; Payer, 2008; Porter, 1998; Schuh et al., 2011; Sydow, 2001, 2010), and purpose and common objectives of the actors (Bau et al., 2014; Lyytinen, Yoo, \& Boland, 2016; Priestley \& Samaddar, 2007; Wissema \& Euser, 1991; Yoo, Lyytinen, \& Boland, 2008).

As a result of our literature review, we find various network characteristics that help to describe and differentiate network types, yet a compelling typology that agglomerates all these different aspects is missing. We target this research gap and ask: What are the predominant types of formal inter-organizational innovation networks and how can they be characterized? To answer this research question, we consider network attributes from existing studies and apply qualitative and quantitative methods. Thereby, we take up Provan et al. (2007), who call for a study that combines existing insights with an empirical analysis at network level. We combine the previously mentioned attributes and a large data set that we build from an analysis of a selection of formal inter-organizational innovation networks to derive a comprehensive typology with a solid empirical foundation. 


\subsection{Methodologies}

Across the three essays in this dissertation, I applied different research approaches supporting the elaborated research questions. Whereas essay I and essay II both rely on qualitative research designs, essay III mobilizes a mixed methods approach, combining a qualitative content analysis and a quantitative cluster analysis. An in-depth description of the methodologies applied throughout the three essays in this dissertation is given at the level of each study. Therefore, within 1.4, I will provide summaries of the applied methodologies and give reasoning and background.

\subsubsection{Essays I and II}

The general assumption leading the two studies is that techniques and measures that proved useful for leaders in terms of digital transformation may be reasonable blueprints to be adopted by comparable companies in comparable contexts, all facing the opportunities and challenges of technology adoption. Therefore, both studies aim to comprehensively show the variety of potential decisions and measures that have proved to foster a successful mastering of digital transformation in the cases under analysis (van de Ven, 2007). The absence of prior research in my specific fields of interest results in great difficulty in formulating a priori hypotheses (Ferreira \& Merchant, 1992); a deductive research design in the sense of a positivist approach (Morgan \& Smircich, 1980) is accordingly ruled out. Nevertheless, the given research backgrounds provide basic literature and guidance for further studies. Therefore, my studies use the concept of abduction for a strived theory elaboration, i.e., "a creative inferential process aimed at producing new hypotheses and theories based on surprising research evidence" (see: Timmermans and Tavory, 2012, p. 167). In both studies, I mobilize a case-based research design that "investigates the contemporary phenomenon [of digital transformation; author's note] in depth and within its real-life context [SMEs that successfully mastered steps of digital transformation; author's note]" (Yin 2014, p. 16). The fact that digital transformation is a multi-faceted phenomenon and therefore requires "description, interpretation and explanation" (Lee et al. 1999, p. 164) when analyzing data supports this chosen approach.

To clarify the necessity to rely on acts of interpretation (J. W. Creswell \& Creswell, 2018), I give an illustrating example from essay II. If I ask a SME owner-manager "Did you apply symbols to clarify the high priority of 


\section{Introduction}

digital technologies toward your staff?", from my experience, he will most likely say "No". But if I walk around the production side and see modern, especially design-oriented, workstations at all workplaces and I ask the owner why he chose exactly the given models, he might answer: "Well, we wanted to create a modern, innovative working environment, so employees feel inspired to support our digital progress." This example shows that he implicitly establishes symbols without keeping a control dimension in mind. I came across similar scenarios many times across data collection and analysis phases; therefore data structures (Gioia, Corley, \& Hamilton, 2013) in the appendices of the papers are designed to shed light on this aspect and help the reader to follow my analyses.

Similar methodologies were already applied in the field of research by preliminary studies, that direct my research interest. Regarding essay I, indepth, single case studies yield points of reference for large organizations, especially in B2B and retail environments (e.g., El Sawy et al. 2016; Hansen $\&$ Sia 2015). More comprehensive digital transformation frameworks focus on large companies in specific industries, e.g., media and insurance (Hess et al., 2016; Wiesböck et al., 2017). The possibility of generalizing the existing results and therefore the transferability to a SME setting are low, but the methods proved useful in generating interesting insights. Regarding essay II, qualitative methods were also mobilized in the form of various single and multiple case studies (López \& Hiebl, 2015).

In essay I, units of analysis are digital transformation mechanisms in SME; in essay II, I search for measures of management control that are mobilized throughout the digital transformation journeys of SMEs. As both are rarely empirically observable, my empirical units of analysis in both cases are examples of SMEs that successfully mastered digital transformation. In essay I, I draw on evidence from seven SMEs, taking an in-depth view of their strategic considerations throughout digital transformation journeys. Essay II relies on data concerning 11 SMEs, gathered within two consecutive rounds of interviews, tracing their digital transformation efforts and taking an in-depth view of their management control usage throughout their digital transformation endeavors. Multiple cases thus add confidence and robustness to my findings (Miles, Huberman, \& Saldaña, 2014; Yin, 2014). Narrative sections within both essays deliver dense description, which I regard as necessary to interpret the results in the given context (Pratt, 2009). Context, stories, and meaning are intended to promote an audience's understanding of the applicability of the obtained results (Langley, 1999, p. 696-697). 
For sampling, I applied preselection criteria (Eisenhardt, 1989; Miles et al., 2014), guiding a purposeful sampling approach. Essay I relies on critical case sampling, i.e., cases that are "rich in information because they are unusual, special or make a point quite dramatically" (see: Fletcher \& Plakoyiannaki, 2009, p. 179), whereas essay II combines critical case sampling and theoretical sampling, i.e., cases that are supposed to fit to "emerging concepts in order to explore the dimensional range or conditions along which the properties of concepts vary" (see: Fletcher \& Plakoyiannaki, 2009, p. 179). I selected all cases from the German skilled craft sector. Being considered a unique German phenomenon without clear boundaries regarding its sectorial limits, skilled craft companies provide services as well as manufacturing goods (Glasl, Maiwald, \& Wolf, 2008). In all, 98 professions belong to the skilled craft sector, being explicitly listed in the German "Trade and Crafts Code" (HwO, n.d.). Based on an evaluation of the employee numbers across the sector, I consider craft businesses to be typical representatives of SMEs. Membership of the chamber of skilled crafts is mandatory for all businesses that belong to this sector. I selected the cases in close cooperation with a group of technology experts from the chamber of skilled crafts of Munich and Upper Bavaria, as they are in close contact with technology leaders in the sector. They also helped me to approach the companies and therefore worked as door openers and a means of prioritization, which was important owing to the significant time constraints of the company owners. The cases "permit logical generalization and maximum application of information to other cases [...]" (Patton, 1990, p. 182). In the sample companies, IT was used (a) for fundamentally altering traditional ways of doing business by redefining business capabilities and/or (internal or external) business processes and relationships, and/or IT was used (b) to dramatically change how tasks are carried out, and is therefore recognized as being important in enabling the firm to operate in different markets, serve different customers, and helped to gain considerable competitive advantage by doing things differently (Dehning, Richardson, \& Zmund, 2003; Lucas, Agarwal, Clemons, El Sawy, \& Weber, 2013, p. 372). ${ }^{8}$ Additionally, the companies may have re-

8 In the original set of criteria by Dehning et al. (2003) as well as Lucas et al. (2013), a third criterion for IT to be considered transformational targeted potential strategic acquisition activity. This aspect was excluded for this study. 


\section{Introduction}

ceived public funds for their digital transformation efforts. ${ }^{9}$ The scope of digital transformation as the investigated phenomenon is thus not limited. Some cases have specialized in the production of highly individual woodworks, leveraging the opportunities provided by automated production. Others have completely digitized their operating model, being far ahead in terms of digital transformation from the current standards in their respective fields and realizing gains in efficiency and quality. Again, others make use of robotics in their production facilities, or they have invented highly technical clothing.

The main sources of data were interviews with the owner-managers of the SME under analysis. The decision to focus on the owner-manager as reference person to describe digital transformation is based on the central role s/he and her/his personal perception role played in a SME's leadership (Pfohl, 2006). As far as possible, I collected multiple types of data as a basis for triangulation. Triangulation is considered a central element in qualitative research in order to improve its quality (e.g., Flick 2014; EasterbySmith et al. 2008; Guba et al. 1981). Denzin, 1978, developed a systematic approach to triangulation and distinguishes four different types of triangulation: different data sources, different investigators, different theories, and different methods. I applied triangulation based on different data sources and different investigators. The interview data were triangulated by information from the SMEs' websites, social media channels, books written by the owners, company brochures, media articles, and gild information materials. Junior researchers, who accompanied my onsite visits to the companies, wrote down their impression and understanding of each company's development in case reports, which contributed to the dense case descriptions.

\subsubsection{Essay III}

We draw inspiration for our essay from previous research on innovation networks and clusters (Bau et al., 2014; Delgado, Porter, \& Stern, 2016) and combine it with a mixed method approach (Täuscher \& Laudien, 2018). Therefore, we conduct a qualitative content analysis followed by a

9 In 2017, the government of Bavaria introduced the so-called "Digitalbonus“, a public funding program where SMEs were able to apply for financial support via grants or credits in their efforts in digital transformation. For more information, see https://www.digitalbonus.bayern/. 
quantitative cluster analysis. We use a directed content analysis to compile a comprehensive data set (Hsieh \& Shannon, 2005) and subsequently apply a hierarchical clustering approach using Ward's linkage method to analyze the results of the first method (Ward, 1963). In order to identify networks in a structured manner, we used a large online listing of networks provided by "Clusterplattform Deutschland" (BMWi, 2020), a comprehensive online directory of formal inter-organizational innovation networks in Germany.

We translate qualitative information about networks and clusters into numerical data via qualitative content analysis for further quantitative analysis (Potter \& Levine-Donnerstein, 1999). First, codes, i.e., network characteristics, are derived from theory and previous research findings. Over the course of the study, characteristics that appear to be less appropriate, difficult to interpret, or can only be determined based on a highly subjective assessment are removed, which leads to a continuous adaptation of the coding during this process (Hsieh \& Shannon, 2005). We generate our data set based on publicly available information on the websites of the identified networks and corresponding information provided by "Clusterplattform Deutschland" (BMWi, 2020). Networks or characteristics are removed from the data set in case of insufficient information availability. In order to reduce elements of subjective interpretation during the coding process, the coding of qualitative information is partly counter-checked by the co-authors.

The quantitative analysis aims to identify groups of networks with similar features in the previously generated binary data set (Backhaus, Erichson, Plinke, \& Weiber, 2018). We secure analyzability of our sample by conducting a frequency analysis, eliminating doubled characteristics, and checking for critical correlations (Everitt, Landau, Leese, \& Stahl, 2011). Based on previous studies, we decide to use hierarchical agglomerative clustering (HAC) (Bau et al., 2014; Delgado et al., 2016; Täuscher \& Laudien, 2018) and follow the approach suggested by Backhaus et al. (2016). Therefore, we first select a distance measure and linkage method that determines how the algorithm combines the objects in our data set into clusters. We find that the Euclidean distance measure in combination with Ward.D2 as the linkage method deliver the most meaningful results (Ward, 1963), both aiming to maximize homogeneity within the clusters and generate clusters that are as different as possible (Backhaus et al., 2018). We apply various methods to indicate an optimal number of clusters (Everitt et al., 2011; Han, Kamber, \& Pei, 2012; Kassambara, 2017) and find an optimal number of 11 clusters for our analysis. 


\subsection{Results and contributions}

My empirical investigations about digital transformation in SMEs that constitute the core of my dissertation yield important results toward the academic as well as practitioner communities. Based on qualitative methods in use, my investigations may also serve as a foundation for future research (Peirce, 1934; Timmermans \& Tavory, 2012). In the next paragraphs, I summarize the main results and contributions.

Essay I deepens our understanding of SME development options in the context of digital transformation. A digital transformation strategy is the starting point for a successful digital transformation. Empirical work dealing with digital transformation strategies currently focuses on selected industries and large companies with at least 500 employees (e.g., Hess et al., 2016; Wiesböck et al., 2017). The specific characteristics of small and micro enterprises (Pfohl, 2013) are not considered, which poses a severe threat for the future viability of European economies (European Commision, 2015). In order to close this research gap, I have collected case studies of selected SMEs that have been particularly successful in mastering digital transformation. As a result, I develop and enrich an existing strategic decision framework, considering specific, cross-sectorial SME characteristics (Matt et al., 2015). This creates a multifaceted space of potential strategic development directions.

The results imply that SMEs' success in digital transformation does not result from chance and luck but can be structured along the generally applicable categories of "use of technologies", "changes in value creation", "organizational aspects", and "financial aspects". The categories are mobilized in the form of strategic questions and associated decision options to guide owners of SMEs successfully through the process of digitally transforming their companies. The questions intend to guide SME proprietors and managers through development options, based on which specific adjustments to the business and operating model can be individually determined. This expands the academic understanding of areas of strategic decision making options in the currently tense and dynamic field of digital transformation. The essay thus provides many starting points for further empirical research to investigate specific decision levers and their interplay. The strong foundation in the case study data makes the work equally useful for owners and decision makers in SMEs who are currently confronted with the challenges of progressive digitalization.

Essay II combines existing conceptualizations of MCS, the innovative aspect of agile methods, and the management of digitalization to elaborate 
configuration options of a digital transformation control system. So far, all these aspects have been treated separately by scholars. They cover MCS and measures in generic conceptualizations (e.g., Malmi \& Brown, 2008), demand the mobilization of trial-and-error as a selected, agility-enabling measure to deal with dynamic market environments caused by progressing digitalization (e.g., Schäffer \& Weber, 2016), and treat digital transformation strategy development as outlined in Essay I. Nevertheless, relying on literature that confirms potential benefits for SMEs from management control usage, e.g., performance increase (e.g., J. Dekker et al., 2015) and adaptability to uncertain environments (e.g., Amat et al., 1994), I deduce that the use of MCS can promote successful digital transformation. In order to investigate this nebulous, yet untreated, research gap, I first collected case studies that are successful in terms of digital transformation, conducted an analysis of their use of MCS, and then went back into the field to collect more case studies that are also successful on their journey to digital transformation, but are also known to take a structured approach in their efforts.

My study makes several contributions. First, I structure the existing literature regarding potential benefits of MCS usage in SMEs. Second, I empirically find overall four categories of management control measures applied in the cases under analysis. Throughout their digital transformation journeys, SMEs make use of cultural controls, planning, administrative controls, and performance indicator-based controls. I am therefore able to advance the MCS as a package framework by Malmi \& Brown, 2008, toward controls with a special focus on digital transformation. I do not find a unidirectional link between strategic considerations and the establishment of management control measures (Merchant \& van der Stede, 2007). SME managers tend to iterate strategic considerations based on observations from management control measures, also incorporating informal and subjective observations, which favors adaptability to the ideas of Malmi \& Brown, 2008. Trial-and-error turns out to be used as one control procedure among others, not giving it the power of a radical shift in management control paradigms (Schäffer \& Weber, 2016). For practitioners in charge of managing a SME, my collection of management controls can deliver a blueprint to refine existing MCS or may even be used as a starting point to establish a MCS in the case that individual digital transformation drives a SME's organizational complexity.

Essay III establishes an empirically grounded, generic typology of formal inter-company networks with a special focus on R\&D and innovation. Therefore, we first review existing research on the distinguishing character- 


\section{Introduction}

istics of networks. Based on the identified attributes, we conduct a directed, qualitative content analysis to compile a comprehensive data set as a basis for further quantitative analysis (Potter \& Levine-Donnerstein, 1999). To develop a typology from the compiled data set, we applied a cluster analysis using HAC to account for similarities and differences across the identified network attributes. Based on the results of the cluster analysis, we identified 11 different types of networks, which we tried to name distinctively according to outstandingly different attributes: Avid Persuaders, Value Chain Drivers, Collective Facilitators, Niche Specialists, Lateral Thinkers, Transnational Opportunity Seekers, Financially Resilient Connectors, Local Trend Sponsors, Regional Activists, Associated Industry Supporters, and Dynamic Research Groups

Our typology adds a holistic, empirically grounded conceptualization to the existing literature that is dominated by theoretical considerations (e.g., Sydow, 1992) or small-scale empirical analyses (e.g., Bau et al., 2014). It highlights that typologies are a suitable model to differentiate several forms of inter-company networks (Provan \& Kenis, 2008). From this, multiple avenues for further research can be derived, e.g., toward analysis of network performance at the individual member as well as the network level. The essay furthermore provides practical orientation. For policy makers, it leverages understanding of the network universe, which we consider crucial when supporting networks as a decisive source of innovation among SMEs. For SME managers, it provides orientation when searching for a suitable network engagement.

\subsection{Dissertation structure}

Three essays targeting digital transformation in SMEs together form this dissertation. The essays emerge from different, independent research projects, all led by different research topics, whereas especially essay II builds on the findings and partially encloses data of essay I, and the motivation for essay III stems from findings from the project directing essay I. All projects have in common that they are fully based on or encompass the use of qualitative research methods. As selected concepts, especially regarding the definition of digital transformation as well as the specifics of SMEs, are provided repeatedly, the sequence of the review of the essays is not specified. In Chapter 2, which consists of Essay I, I draw a framework for formulating a digital transformation strategy in SMEs. Chapter 3 comprises Essay II, where I give an overview of management control measures that 
serve as ingredients to develop a digital transformation control system, based on measures which have proved useful in SMEs that have successfully mastered digital transformation. Essay III in Chapter 4 targets formal, inter-company innovation networks and identifies common, empirically grounded network types. In Chapter 5, I conclude the dissertation by summarizing the contributions and main findings, elaborating limitations, and suggesting avenues for future research. 


\title{
2 Essay I: Survival in the digital age - a framework for formulating a Digital Transformation Strategy in SME
}

\author{
Johannes Trenkle \\ Technical University of Munich \\ TUM School of Management \\ j.trenkle@tum.de
}

\begin{abstract}
I
Many digitally successful companies have established a dedicated digital transformation strategy. A small and medium-sized enterprise (SME) perspective on this topic remains unclear. I fill this research gap with a qualitative research approach. Main findings include a set of 14 strategic questions along four summarizing categories - use of technologies, changes in value creation, organizational changes, and financial aspects. Three out of these four categories hold true in SME environments as they are valid in large corporation settings. I recommend establishing the term "organizational changes" instead of "structural changes" in order to increase fit to the mindset of SME owners. Answer options enrich these strategic questions, based on the experience of successful examples from the field. I identify differences between SME and large corporations in the areas of value creation, organizational changes and financial aspects. This paper elaborates theory on digital transformation strategy, contributing to understand management behavior and decision levels in an economic environment, where the adaptation of digital technologies has become an imperative.

Keywords: digital transformation, digital transformation strategy, SME, case research.

Status: Published ${ }^{10}$
\end{abstract}

10 Essay is published: Trenkle, Johannes (2019). Survival in the digital age - A framework for formulating a Digital Transformation Strategy in SME. Proceedings of the 19th International Conference on Electronic Business (pp. 428-442). ICEB, Newcastle upon Tyne, UK, December 8-12. 


\subsection{Introduction}

This study combines the view of SME with existing literature about frameworks to develop digital transformation strategies. I contrast new, crosssector findings from SME knowledge to previous, single industrial, large company contexts and answer the question: How does a cross-sector SME context influence core elements of a digital transformation strategy? Academic groundwork (e.g.: Matt, Hess and Benlian, 2015) has identified core areas affected by digital transformation on a strategic level. By analyzing the digital transformation of selected SME from various industries I show to what extent the same strategic categories are at the center of the digital transformation in SME as it is the case in large companies.

In private as well as in business environments, modes and habits of communication, information, research, as well as simple and sophisticated working processes almost naturally involve the use of hardware and software. There is no doubt that companies must react to the modifications the progress of technologies is causing in society and in their business environments. Technological advancements require existing companies to act in two directions: to adapt their business models, but also to rethink their entire industries (see e.g.: Lucas et al. 2013). Digital transformation focuses on change aspects in ways of working, roles, and business offering caused by the adoption of digital technologies in an organization, or in the operations environment of the organization, in order to assure sustainable value creation (Gimpel \& Röglinger, 2015).

The academic groundwork of this paper is given by the digital transformation framework of Matt et al. (2015), who developed a generic conceptual model along guiding categories to formulate a digital transformation strategy: Use of technologies, changes in value creation, structural changes, and financial aspects. The representative contextual power of these four dimensions was proven for diversified, large scale companies (Hess et al., 2016; Wiesböck et al., 2017). My project eliminates industry specificity by taking a view on digital transformation across sectors.

In order to ensure competitiveness by leveraging digital technologies, SME must gear up for digital transformation. SME show a range of differentiating organizational criteria that make them merit separate consideration (see e.g.: Carney, 2005). Some outstanding aspects include: (1) Leadership: outstanding influence of the company owner on management decisions. (2) Organization: owner-manager-centered hierarchical design, roleaccumulation, tight personal interconnections across staff. (3) Production process design: low degrees of work-sharing, universal machinery, strong de- 
pendence on small numbers of basic innovations and low economies of scale. (4) Sales: lot-size-one, high degree of customization, limited regional and/or highly specialized segment. (5) R\&D: no institutionalized R\&D department, short-range, highly intuitive $\mathrm{R} \& \mathrm{D}$ activities, limited financial resources, short time budgets from invention to monetization. Around 3.5 million companies in Germany are SME, representing 99.4\% of all companies in Germany (see e.g. European Commision, 2015). Together they account for $\sim 2,200$ EURbn in annual turnover, representing a share of $34.1 \%$ of all companies' value added. They employ more than 15.5 million people, providing a job to $52.7 \%$ of the German nation's employment. They all face the challenge to find a successful way of handling the progress of digital technology usage. Based on the large number of SME in Germany, I expect recurring challenges at firms with comparable size, and from comparable industries, giving knowledge about cross-sector digital transformation mechanisms a sizeable audience also from the practitioner community.

From the author's knowledge, digital transformation strategies in SME remain unaddressed in literature. This study fills this gap by relying on a multiple case research design, applied to seven family owned SME from different sectors. All of them are considered typical SME, who have successfully mastered steps towards digital transformation and therefore are rich in information. By conducting open, semi-structured interviews with the seven company owners and members of the management, I provide deep insights. I triangulated the interview data by additional data sources like company websites, social media channels, books written by the company owners, press articles, and financial data. Thereby, this paper elaborates the digital transformation framework of Matt et al. (2015) towards an applicability in situations, where SME owners, independent of their profession, define a digital transformation strategy for their firm.

I find a set of 14 guiding questions a SME owner -independent from sector or industry- can follow in order to define an individual digital transformation strategy along an empirically derived path. Answer options, based on experience of successful examples from the field, enrich these strategic questions. These findings provide a twofold value-added: elaborate the scholar research on digital transformation as well as bridging the gap to practical, all-day business challenges. 


\subsection{Background}

\subsubsection{Digital transformation as a key management challenge}

The ongoing advancement of digital technologies provides an unquantifiable number of challenges for businesses of all sizes. It is a sort of "mission impossible" to find a C-level representative from large, publicly listed multinationals, who has not publicly committed to the necessity of a "digital change". Digitization, digitalization and digital transformation have become omnipresent catchwords, often lacking clarity. Scholar literature has tried to ascribe these phrases a unique definition. Digitization defines the (pure) technical process of converting analog information into a digital format (see e.g.: Negroponte, 1995). By bringing all types of information down to the lowest common factor, i.e. binary digits, digitization dematerializes information and decouples information from physical carriers and storage, transmission, and processing equipment. This development, in connection with multiple users' wish to benefit from the negotiation and arrangement of the meaning of the bits, set the basis for a need in interoperable standards and common definitions of application and service interfaces (Tilson et al., 2010). Therefore, the term Digitalization comprises the manifold sociotechnical phenomena and processes of adopting and using these technologies in broader individual, organizational, and societal contexts. Matt et al. (2015) argue that the ubiquity of information technology pushes companies to explore new digital technologies and to exploit their benefits, which involves transformations of key business operations and affects products, processes, organizational structures and management concepts. In order to realize manifold potential benefits like increases in sales or productivity, innovations in value creation, and novel forms of interaction with customers, companies have to open themselves to change, within their own structures as well as beyond their borders (Matt et al., 2015).

Digital transformation therefore emphasizes the change aspect, i.e. the managed adaptation, focusing on changes in ways of working, roles, and business offering caused by the adoption of digital technologies in an organization or in the operation environment of the organization in order to assure sustainable value creation (Gimpel \& Röglinger, 2015). Riasanow et al. (2018), p. 13, define digital transformation "as probabilistic organizational change philosophy where digital technologies are used to fundamentally transform an organization's business model and value network". It is about managing internal efficiency, external opportunities, and addi- 
tionally disruptive change (Parviainen, Tihinen, Kääriäinen, \& Teppola, 2017). It touches a company holistically, including external partners along its supply chain (Bowersox, Closs, \& Drayer, 2005), comprising the "use of new digital technologies to enable major business improvements (such as enhancing customer experience, streamlining operations or creating new business models)" (Fitzgerald et al. 2013, p. 2).

Several experts consider the impact of digitalization similar to the impact of the industrial revolution. Downes \& Nunes (2013) describe how entire business models can be reshaped or replaced by what they call "bigbang disruption”. Traditional industries or business models like e.g. video gaming, stock exchanges, analogue photography, portable navigation tools, physical book sellers, or physical newspapers can suffer substantial losses of significance or become obsolete, as new incumbents use digital opportunities on supply (company) and demand (user) sides. E.g. Lucas et al. (2013) show that the impact of technological advancements requires existing companies not only to adapt, but to rethink entire industries.

\subsubsection{Importance of and core elements constituting a digital transformation strategy}

Via digital transformation, companies target to compete better by using digital innovations (Main et al., 2018). In order to stay competitive, companies must actively manage challenges arising from a deep penetration of technology in their entire business- and operating models. Though the imperative to act is well accepted in general, the execution of digital transformation yields many obstacles. Henriette, Feki and Boughzala (2015) argue that a digital transformation project involves the implementation of digital capabilities to support business model transformations. They call for collaboration and interaction throughout a company`s whole organization, across operational processes, resources, internal and external users, and by this causing major change in employees' habits and ways of working. An explicitly formulated strategy for implementing digital technologies is essential in order to realize the full benefits from digitalization. Less digitally mature organizations tend to focus on individual technologies to solve lone standing problems, whereas elaborate digital strategies guide successful business transformation in most digitally mature organizations (Kane et al., 2015).

Earlier research focuses on IT-strategy, that must be aligned, but subordinate to the business strategy (see e.g. Henderson \& Venkatraman, 1993; 
Hirschheim \& Sabherwal, 2001), even in an SME context (Hussin et al., 2002). However, researchers recently claimed for a new type of digital business strategy, nevertheless struggling how to get there. Bharadwaj et al. (2013) call for an evolution from IT-strategy into a digital business strategy, comprising IT-strategy and business strategy into an overarching phenomenon, which is defined as an organizational strategy formulated and executed by leveraging digital resources to create differential value (Bharadwaj et al. 2013, p. 472). Others demand for a standalone digitaledge strategy, taking into account the specific nature of SMAC technologies, incorporating digital and physical resources, and concentrating on specific business outcomes rather than grand strategies (McDonald, 2012). Both viewpoints agree urging for an integrated view on business and technology in the light of digital transformation, but they remain unclear about how to incorporate actions on the actual transformation steps. Furthermore, as it has been shown that not all digitalization that is possible is desirable, e.g. due to negative effects of transparency towards competitors (Grover \& Kohli, 2013), companies need to consider an individual optimum of digital infusion to their business strategy.

Scholars have identified necessary strategic actions in digital transformation, thereby laying the ground to develop industry specific frameworks for the configuration of a digital transformation strategy. A case of a digital business strategy for online music content providers fosters the call for an integrated view on business and technology on a company strategy level (Oestreicher-Singer \& Zalmanson, 2013). Further case study-based articles discuss guidelines for digital business strategies and organizational implications with a special focus on publishing and newspaper industry (see e.g.: Øiestad \& Bugge 2014). Results indicate the necessity to entrench elements of exploitation and exploration into a company's digital transformation strategy, next to necessary innovation capacity and capabilities like resources, processes, and values. An imperative to include inter- and intracompany organizational change aspects in a digital transformation strategy can be derived from a case study from the retail industry (Hansen \& Sia, 2015). An example from a toy producer lists distinctive characteristics of business strategy and business model, an enterprise platform, necessary mindset, corporate IT, and workplace environment necessary in order to create digital leadership (El Sawy et al., 2016).

The digital transformation framework by Matt et al. (2015) represents a clear step towards a holistic approach for the construction of a digital transformation strategy. It claims that every digital transformation endeavor should be structured along four, well aligned key dimensions (Matt et 
al. 2015, p. 340-341): 1) Use of technologies: a company's strategic position and future ambition towards new technologies, as well as its ability to exploit them. 2) Changes in value creation: the influence of digital transformation on the way, a firm aims to add and create value. 3) Structural changes: modifications in a company's operations, i.e. structures, processes, and skill set. 4) Financial aspects: deliver transparency about the urgency to act in the face of declining margins in a firm's core business, and about a firm's financial scope to invest in a digital transformation endeavor. These four dimensions have been explored by scholars, taking a case based view on diversified media companies (Hess et al., 2016) and medium to large scale insurance companies (Wiesböck et al., 2017). While in both studies, the strategic configuration especially of the "use of technologies", "structural changes", and "financial aspects" dimensions show potential for generalization, the designs of the "changes in value creation" dimension - not surprisingly - does not allow for any transfer of conclusions across sectors. Furthermore, small companies and their specific attributes are excluded from any investigation so far.

Due to their special attributes, a plain analytical transfer of existing knowledge around digital transformation strategies to SME is not permissible.

\subsection{Research design, sample, and methods}

\subsubsection{Research design}

I apply a case based research design that "investigates the contemporary phenomenon in depth and within its real-life context" (Yin 2014, p. 16). Units of analysis are digital transformation mechanisms in SME. Within a narrative section, I describe the cases in order to give the audience context, stories and meanings in order to promote understanding of each case's situation. Meanings and patterns are elaborated using an abductive approach.

\subsubsection{Sample}

I purposefully chose selected examples of SME, who successfully mastered digital transformation. The scope of digital transformation as the investigated phenomenon is not limited. All cases stem from the German skilled craft sector, a unique German phenomenon that is not clearly delimited as 
Table 2-1: Overview of cases under analysis

\begin{tabular}{|c|c|c|c|c|c|c|c|}
\hline $\begin{array}{c}\text { Company } \\
\text { (Crafts) }\end{array}$ & Carpenter & Denturist & $\begin{array}{l}\text { Electron- } \\
\text { ics techni- } \\
\text { cian }\end{array}$ & $\begin{array}{l}\text { Electron- } \\
\text { ics techni- } \\
\text { cian }\end{array}$ & Joiner & $\begin{array}{l}\text { Metal- } \\
\text { worker }\end{array}$ & Tailor \\
\hline $\begin{array}{c}\text { Abbrevia- } \\
\text { tion }\end{array}$ & A & B & $\mathrm{C}$ & $\mathrm{D}$ & $\mathrm{E}$ & $\mathrm{F}$ & G \\
\hline $\begin{array}{c}\text { Core busi- } \\
\text { ness }\end{array}$ & $\begin{array}{l}\text { Wood- } \\
\text { work }\end{array}$ & $\begin{array}{c}\text { Dental } \\
\text { technolo- } \\
\text { gy }\end{array}$ & $\begin{array}{l}\text { Industri- } \\
\text { al-fire pre- } \\
\text { vention } \\
\text { technolo- } \\
\text { gy }\end{array}$ & $\begin{array}{l}\text { Capaci- } \\
\text { tive and } \\
\text { optical } \\
\text { sensor } \\
\text { technolo- } \\
\text { gy }\end{array}$ & $\begin{array}{l}\text { Wood- } \\
\text { work }\end{array}$ & $\begin{array}{l}\text { Metal } \\
\text { construc- } \\
\text { tion, plas- } \\
\text { tics injec- } \\
\text { tion } \\
\text { molding }\end{array}$ & Textiles \\
\hline $\begin{array}{c}\text { Number of } \\
\text { staff }\end{array}$ & $\sim 20$ & $\sim 40$ & $\sim 20$ & $\sim 130$ & $\sim 35$ & $\sim 30$ & $\sim 5$ \\
\hline Founded & 1995 & 1981 & 1997 & 1983 & 1999 & 1985 & 1961 \\
\hline $\begin{array}{c}\text { Target } \\
\text { market }\end{array}$ & Germany & Germany & $\begin{array}{l}\text { World- } \\
\text { wide }\end{array}$ & $\begin{array}{l}\text { World- } \\
\text { wide }\end{array}$ & Europe & Germany & Germany \\
\hline $\begin{array}{l}\text { Principal } \\
\text { client } \\
\text { relation }\end{array}$ & B2C & $\mathrm{B} 2 \mathrm{C} / \mathrm{B} 2 \mathrm{~B}$ & B2B & B2B & B2C & $\mathrm{B} 2 \mathrm{C} / \mathrm{B} 2 \mathrm{~B}$ & $\mathrm{~B} 2 \mathrm{C} / \mathrm{B} 2 \mathrm{~B}$ \\
\hline $\begin{array}{l}\text { Organiza- } \\
\text { tional } \\
\text { scope of } \\
\text { digital } \\
\text { transforma- } \\
\text { tion }\end{array}$ & Processes & $\begin{array}{l}\text { Products } \\
\text { and pro- } \\
\text { cesses }\end{array}$ & $\begin{array}{l}\text { Products } \\
\text { and pro- } \\
\text { cesses }\end{array}$ & Processes & Processes & Processes & $\begin{array}{c}\text { Products } \\
\text { and pro- } \\
\text { cesses }\end{array}$ \\
\hline
\end{tabular}

a business sector, comprising services and manufacturing goods providers. 98 professions belong to the skilled craft sector, being listed in the German "Trade and Crafts Code". Based on an evaluation of the employee numbers across the sector I consider craft businesses typical representatives of SME. Together with technological consultants from the chamber of skilled crafts for Munich and Upper Bavaria I selected outstandingly successful examples of digitally transformed SME, who's actions “permit logical generalization and maximum application of information to other cases [...]" (Patton 1990 , p. 182). In order to identify those critical cases, I used different preselection criteria (see e.g.: Miles, Huberman and Saldaña, 2014). The sample SME must have fully or partially transformed their business- and/or operating model. As a basis for judging the relative degree of digital transformation in their respective fields, IT was used (a) for fundamentally altering traditional ways of doing business, or (b) to dramatically change how tasks are carried out and therefore is recognized as being important in enabling the firm to operate (see e.g.: Lucas et al., 2013, p. 372). Sampling continued until no new insights emerged from additional case analysis, 
meaning until theoretical saturation was reached. The final sample consisted of seven cases, all located within a radius of 80 kilometers around $\mathrm{Mu}-$ nich, Germany. In order to allow for an acceptable degree of generalizability across the SME sector, I chose an industry-spanning approach. Table 2-1 gives an overview of the seven case companies under analysis.

\subsubsection{Data sources}

Main source of data were semi-structured, open interviews with owner managers of the selected SME. When the owner manager suggested to include additional knowledge carriers (e.g. children working in the company or co-managers), I always agreed. The number of interviews I conducted in each firm ranged from one to three. Overall, I conducted 11 interviews, which is more than in previous studies (Hess et al., 2016; Wiesböck et al., 2017). The interview data was triangulated based on availability by further sources of information, e.g. the firms ' websites, brochures, social media activities, books, financial data, or guild information materials. I also asked accompanying junior researchers to write down their impression, providing a common understanding to formulate each company's case report.

\subsubsection{Data analysis}

The interviews were recorded, transcribed and coded. I applied first cycle coding methods labeling the data blocks (Miles, Huberman and Saldaña, 2014). Then, I adopted second cycle coding methods in order to group and summarize the initially found first cycle codes into "a smaller number of categories, themes, or constructs" (see e.g.: Miles et al. (2014), p. 86). Emerging pattern codes laid the basis for cross-case analysis. From the first case, an initial SME digital transformation framework was developed. Following, I examined successive cases to see whether new patterns found match the findings from previous cases or increase variance (Yin 2014; Miles et al. 2014, p. 103).

In order to ensure a satisfying degree of transferability, case reports provide thick description. Validity and reliability in coding are supported by a three stage process proposed by Campbell et al. (2013), where I as a senior coder at start identified blocks of meaning in the interview transcripts. I gave the so-called unitized data as well as the first version of the codebook to a junior coder in order to redo the coding. After this, we compared our 
codes, which resulted in an inter-coder reliability of 0.74 on concept-level, 0.75 on theme-level, and 0.82 on dimension level (Campbell et al., 2013; Miles et al., 2014). After discussing and negotiating the results as well as eliminating ambiguity, inter-coder reliability reached 1.00 on all pattern levels.

\subsection{Case descriptions}

\subsubsection{Carpenter (A)}

A is family-owned and was founded in 1995 , currently employing 20 people. The main business is custom-made woodwork. From start, innovative production technologies where a central element in the company founders' investment activities, targeting to simplify processes and reduce production costs. The firm's strategic focus lies on private upmarket customers with a demand for high quality individualization. The automatization of production processes based on cutting-edge numerical control (NC)-machinery, able to fulfil highest requirements in the elaboration of complex geometries, helped to meet increasing customer requirements. For visualizing complex, personalized products, CAD programs are in use throughout the sales process. Considering its location in the countryside, the firm in recent years strengthened its capabilities around online customer interaction by combining a website, built according to customer feedback, with a structured online marketing approach.

CAD usage and the frictionless integration of automated production via computerized NC machines led to successful positioning in high quality, high margin sector. Being among the firsts to use these techniques in classical woodwork gave the company a competitive advantage. Highly elaborate, digital sketches including inherent NC-production-programs represent a marketable product on their own, creating an additional field of revenue. Due to the high degree of automation, the company realized efficiency gains, based on reductions in waste, increased quality, and the ability to employ lower skilled people in production. To replace mailings and newspaper advertisements, a new website was launched in 2015, which is constantly updated based on customer feedback. In parallel, A started to make use of search engine optimization (SEO) and search engine marketing (SEM). Whereas sales and customer base are increasing, the marketing budget was reduced by $80 \%$. 


\subsubsection{Denturist (B)}

The owner manager founded company B in 1981. With a yearly turnover of $\sim 1.5$ EURmn, the company employs $\sim 25$ people by manufacturing dental prostheses. It combines traditional dental with digital technologies. The company started digital transformation in 2002, when the owner bought the first automated milling machines for dentures. Then, as now, competing companies still traditionally produce dentures with a lot of manual effort. In order to achieve highest accuracy, the company since a decade relies on natural tooth recording using intraoral 3D-scanners, a modus operandi still ahead of industry standard. Based on digital scanning and modeling, the move to automate production appeared logical. Recently, the company digitally addressed office support processes and invested in digital proposal generation, order management and e-invoicing. Digital transformation is driven by the owner manager's fascination with the opportunities that digital technology offers across the entire value chain. He constantly observes the market for innovations around his core business, but also strives to leverage his company's capabilities and capacities even beyond.

The firm sees digital technologies as enabler of business goals and to remain one of the leading dental technology laboratories. Throughout its existence, the company was able to enhance its client base constantly by offering high quality dentures at lower cost in a shorter range of time. B's owner has developed several innovative production techniques, incorporating 3D-printing, and milling. This enabled the firm to work with nonstandard materials and enabled additional products like drilling templates for dentists. B, based on own patents, sells self-developed techniques to other companies worldwide. The deep penetration of digital technologies in the value chain allowed to increase quality, reduce costs by almost eliminating defective goods, and speed up production processes.

\subsubsection{Electronics technician $(\mathrm{C})$}

C is specialized on automated firefighting solutions for industrial machinery. Founded in 1997, today it employs $\sim 20$ people in Germany and $\sim 10$ in China to serve worldwide clients. Products are customized to client needs and offered including installation and maintenance, being constructed for spatial limited areas in machines. Digital transformation was a reaction to fast corporate growth and incorporated organizational challenges. C's in- 
dustrial customers requested firefighting devices to be implemented in automated production lines already in planning and construction phases. Therefore, the company developed necessary digital interfaces. Resulting remote maintenance services are now offered additionally to the regular service portfolio. All customer communication is enabled digitally incl. electronic billing. $\mathrm{C}$ owns a data base covering all historical installations. Thereby, physical maintenance works at clients' sights, causing costly production outages, can be planned with a high degree of precision, including necessary parts and actions. This led to quality and efficiency improvements of products and services. At the time of this study, the firm is in the latest development stages of a completely new product family, based on the digitalization of industrial fire prevention.

The newly innovated, digitally enriched product will set a new industry standard regarding reaction times and integration in digital machinery environments. The company expects to benefit from tighter strategic alliances with its current as well as new customers. Also, $\mathrm{C}$ is increasing its efficiency due to comprehensive reduction in manual office work as well as digital tool usage in preparation of assembly and installation processes. Employees, based on the cloud database, digital part lists and office workflow management, can use travelling times more effectively. While in earlier years billing took several months, as technicians are on assembly for several weeks in a row, billing is now executed within days.

\subsubsection{Electronics technician (D)}

$\mathrm{D}$ is a world market leading producer of sensors for various fields of applications. Based in Munich, it owns branch offices in China and the USA. Core products are capacitive level sensors and optical sensors, which the company develops and produces tailor-made for its B2B client base. The firm, founded in 1983, is family-owned with 120 employees. Due to its core product focus on sensor technology and constant R\&D activities, working with digital technologies always was part of D's DNA. Customers request the firm to stay at the edge of digital developments with respect to products and processes. On the product side, the firm engages in the internet of things (IoT), developing sensors, which can communicate among each other as well as among a network of machines. On the process side, D has introduced a new enterprise resource planning (ERP) system with a customer interface, so that customers can place their orders directly within the company's order management system. Feedback from customers is giv- 
en via a one-click feedback system, thereby creating an early warning system for potential process threats. Being in a knowledge driven industry led $\mathrm{D}$ to implement a comprehensive, yet easy to use, social-media-like internal communication platform and included knowledge management system. An automated database using text blocks was introduced in order to avoid extensive editorial work when creating user and production manuals. As the company is active globally, social business networks play a major role to communicate with partners and customers.

High customer centricity involving digital technologies has led the firm to conquer a niche market and to develop its unique selling proposition. The ERP-integrated order management helped to reduce office work and to avoid recurring mistakes due to manual data handling. Automated billing will be the next step to realize an order execution without manual interference. In order to tighten customer relationships, D is participating in the creation of a platform based B2B web shop, incorporating partner companies and allowing business customers to order integrated solutions online.

\subsubsection{Joiner (E)}

E's owner started the joinery with three employees in 1999. Today the firm employs $\sim 30$ people. It remains family-owned and serves the European market, focusing on production and distribution of woodwork with linoleum surfaces. At the time the owner started E, market situation was difficult caused by high competition. In wish for flexibility in personal life and less market pressure, the owner decided to leverage technological options he had in his manufacturing site, specializing his product portfolio on tables with linoleum surfaces. Based on first market success of the product, customer demand, and opportunities of e-commerce, the company opened its first web shop in 2005. Since then, E strives to use innovative technology to distribute products in a convenient, customer-centered manner, e.g. via an online 3D-configurator and integrated live chat function for direct customer interaction. Relying on online sales as single distribution channel included investments in SEO and SEM. In order to streamline the order execution process, $\mathrm{E}$ introduced a product-data management tool, which interconnects order entry, production terminals and customer communication.

The interplay of a highly specialized product portfolio, automated cutting, milling and finishing machines in production, and online sales, led 
the company to conquer a niche market. The company's expertise regarding user experience and technological capabilities around its web shop provide competitive advantage. The high degree of automation throughout the production processes yields efficiency gains. By avoiding manually caused information gaps as well as defects, customer rejects and waste were minimized. The employment of lower skilled people in production led to decreasing labor costs.

\subsubsection{Metalworker $(\mathrm{F})$}

With $\sim 30$ employees, F, since 1985, is focused on the individual development and production of special purpose tools via metal and mold construction. Furthermore, it produces specialized parts for bicycles and bicycle trailers, and engages in plastic injection molding.

F's owner and management ascribe digital technologies a support function. In order to reduce the workload of office employees, e.g. taking calls by customers regarding orders and special requests, the company created its own web shop. As demand for plastic injection molding and customer requirements in this area have increased over the last years, the firm in this business field applies material handling via robots as well as digitally supported production planning.

The establishment of the web shop enabled higher sales as well as increased efficiency regarding office work. The automated production processes in plastic injection molding leveraged productivity, whereas product quality became better and output has increased.

\subsubsection{Tailor $(\mathrm{G})$}

G was founded in 1961. Being originally a toll manufacturer for leather goods, the present owner, the founder's son, created his own collection of traditional costumes and fashion. With currently $\sim 5$ employees, the company produces traditional dresses, high quality clothing for motor cyclists, and technologically enriched special clothing. Motivation for first steps of digital transformation came from customer requests 10-15 years ago. Out of a scientific project, the company was asked to combine textiles with sensors in order to document motions of the wearer. This newly gained knowledge today is used to enlarge G's product portfolio. The firm develops and distributes functional work fashion incl. sensors, e.g. to measure 
vital signs and environment data. As a basis for all products, the company relies on customer satisfaction and good quality. Defects are repaired inhouse in order to gain knowledge and to improve new products. Due to concerns around quality and theft of intellectual property, the company only makes little use of digital technologies in production. Only standard sewing patterns are digitally exchanged with outsourcing partners, all critical expertise is kept in-house.

Proficiency in digital technology handling enabled $G$ a position as preferred partner of various institutions and business partners, incl. universities, scientific institutes, and large corporations, when it comes to digitally enriched clothing and wearables. In order to gain financial and structural headroom for further R\&D and product innovations, the company currently separates its wearable solutions business from the core business, traditional and biker clothing. Vision thereby is to improve the life of customers along their daily routines by a useful combination of digital technology and elaborate artisanship. Nevertheless, by exploiting light templates in combination with laser cutting, $G$ was able to leverage quality and profitability of traditional products as well.,

\subsection{Guidelines for formulating an SME's digital transformation strategy}

The following section unfolds a decision framework in the form of strategic questions, each enriched by answer options company owners can choose from in order to structure individual digital transformation journeys. The basic structure was provided by the four dimensions of the Digital Transformation Framework (Hess et al., 2016). Summarizing tables of all dimensions can be found in the appendix to this paper, 2-1 to 2-5.

\subsubsection{Use of technologies dimension}

The adoption of information technology across the company depends on the importance the owner ascribes to their usage. A general level of ambition lays ground for the intensity of technological penetration throughout the firm.

Question 1: How significant is your firm's IT to achieve strategic goals? The importance firm owners ascribe to the strategic necessity of adopting digital technologies shows great variation across the various companies. Opportunities as well as strategic imperatives dictated by clients are seen from 
different perspectives. Some firm owners consider IT to be an enabler of strategic goals. By actively absorbing digital technologies, they see new business opportunities arising. Being an enabler urges a firm to constantly observe the digital future an screen the market for technological advancements, e.g. in collaboration with scientific institutions. In contrast, other firm owners ascribe IT a support function to reach their strategic goals. In this latter case, digital technologies drive market developments, urging companies to adopt to a changing environment in order to stay competitive. Firms with a supporter lens screen the technological landscape for sources of improving their operations or aligning their processes with clients' value chains.

Question 2: How ambitious is your firm's approach to new digital technologies? In SME, technological ambition of the company owner is crucial for organization's openness towards digital advancements. Thereby, individual ambition is independent from the strategic role of IT as labeled in question 1, as personal experiences of the company owner, existing capabilities among the company's employees or among firms' networks, the financial situation of the company, or the risk-taking appetite as well as some inventive genius are more decisive factors. While cautious company owners may in general trust on well-established technologies with a proven record of accomplishment and reliability, more curious and entrepreneurial minds might strive to dive deeply into new technological developments. Those firms who are at the forefront of innovating new technologies are labeled innovators. They search for cutting-edge technology, regarding their products and services as well as with a view on their operations. Companies, who are not engaged in this fundamental style of research but see opportunities from being the first ones to apply new sorts of technologies to their individual field of business, are named early adopters. They actively screen the market for recent developments, in their own field as well as in other sectors, and try to exploit them as early as possible in their own field. The most conservative firms, called followers, rely on wellestablished solutions, which have already been applied in similar environments and to similar challenges. Motives of the firms' own accord mainly arise from the wish of leveraging efficiency across processes; external triggers are mainly customer requirements. 


\subsubsection{Changes in value creation dimension}

Defining the model of value creation is the most severe task for the owner of a company. As digital technologies have proven to revolutionize competitive landscapes within a few years, a digital transformation strategy must target the mode of generating revenue, sources of efficiency, and the constitution of a firms' value network.

Question 3: How can your firm digitally leverage sales? The ubiquity of the internet accompanied by IoT technologies are changing purchase and sales processes in both $\mathrm{B} 2 \mathrm{~B}$ as well as B2C relationships. It is an important task to define the role of digital channels in market positioning. Firms need to define how digital their interface to customers and their interaction to potential buyers should be, a crucial point in an SME environment where often there is no sales team, but instead company owners and their office support staff do sales. The cases imply that online presentation of products and services on the company's website or via social media channels is an imperative, independent from the target customer base. B2C as well as B2B focused companies all try to be present online at least with a website, but also using private and business social media sites. The same holds true for product sale via web shops. The decision for direct online sales is more dependent on the type of products offered, market dynamics and current and future customer habits than on the target customer base. Sophisticated online responsiveness labeled as the ability to enter in a mutual dialogue with the customer, using the website or social platforms as a trigger, is mainly deployed by B2C focused firms. This is also the case for the engagement in SEO and SEM. Both are only practiced by selected case companies after thorough investigation of the impact of their marketing budget allocation.

Question 4: How can we adapt our product portfolio? Digitalizing the product portfolio and thereby exploiting opportunities for new sources of revenue creation is a crucial task within a digital transformation strategy. It yields the chance to stay competitive and to differentiate against competitors. Digital technologies can become components of products themselves, but they can also be utilized in the development and production of analogue products to create competitive advantages. Furthermore, the case companies leverage options for individualization and standardization. Digital production techniques and data analytics allow the realization of so far impossible geometries in production, as well as digital simulation and calculation of products and services, and thereby facilitate an offering of client-individual customization via design and functionality. On the other 
hand, digitally enriched and data driven production processes reveal the feasibility of using identical parts or materials in situations where customers do not value manually enabled individualization.

Question 5: How can your firm increase the efficiency of its processes? Five out of seven cases under investigation mentioned that usage of digital technologies is mainly seen from a standpoint to increase efficiency throughout process operations. Only companies B and G tended to see digitally enabled product adaptations as their key focus, despite also exploiting digital technologies throughout their operating models. Main source of efficiency improvements across the cases is the substitution of manual production steps by automated production, thereby realizing speed advantages. Nevertheless, superior quality of goods by reducing rejects, trash and processing time is always seen in combination of seeking speed advantages. To realize the full speed and quality potential of digital production facilities, all cases benefit from a major shift in craft process operations. Traditionally, the usual, time consuming mode of operations was to program necessary metrics into every single machine on its own, which is now done centrally and only once. Another source of efficiency is the reduction of average wages in production by employing lower skilled people who need less training and experience for the handling of digital machines in contrast to manual material treatments.

Question 6: How can your firm leverage efficiency across its value network? All company owners see digitally facilitated or enabled vertical and horizontal partnerships along their value chain as a key factor of success in digital transformation. The internet, simplified methods of data processing, and communication via mobile tools make inter-company cooperation more efficient or even possible, as new partners can be identified via internet and social media research. Some cases use outsourcing in production, enabling an efficient allocation of technological production capabilities across the value chain, e.g. a focus on the production of selected goods, preliminary production steps or focus on design and on-site assembly. As conceptualization and realization of website design and updating as well as a firm-tailored IT infrastructure are considered rather complex tasks, all cases outsource website programming and hosting, operational systems programming, and IT services. Companies $\mathrm{C}$ and $\mathrm{D}$ are connected to their customers via electronic data interchange ("EDI") interfaces, allowing them an automated exchange of product and process data with their customers and contributing to a favorable strategic position, based on tight digital and processual integration. Some innovator companies struggle that key partners do not understand the favorable impact of their products, 
processes and services. Therefore, both pursue the technological education of key business partners, aiming for tight interaction and realizing joint digital progress.

Question 7: Where is it an option not to engage in digital transformation? It revealed to be interesting where leaders in digital transformation see potential analogue hideaways in contrast to digital imperatives. Usage of digital communication channels is considered an absolute must. The same holds true for the implementation of digital production technology. However, the company owners admit that not everything that can be handled digitally must be handled digitally. In case of proven economic disadvantages like insufficient quality of automatically vs. manually crafted products, permanent resistance from the staff leading to processual distortion, or a high risk of knowledge theft, some company owners decided to omit digital potentials. Still, almost all company owners state that some persistent advantages they draw from technology usage would not have been possible without failure, so a general "refusal of digital" is not considered a viable decision option. At last, customer requirements may slow down digital transformation as they require paper-based exchange of information.

\subsubsection{Organizational changes dimension}

Going through a digital transformation requires a company to reconsider its organizational structure. Firms must define responsibilities, decide about the appropriate entity structure, plan on how to realize a necessary employee structure and how to ensure that a required skill set becomes integrated to the firm.

Question 8: Who is in charge of the digital transformation endeavor? A specialty of SME is the centralization of leadership where the company owner mostly plays the strategically decisive role. When it comes to digital transformation, most cases show a joint responsibility of the management team in decision making. In four of the cases, the management team consists only of family members; two cases have a person in charge of the position of technical director, comparable to the role of a chief technology officer. In all cases with a team approach, the mode of operation is that one dedicated member of the team is responsible for making suggestions towards technological improvements, but final decision and execution are taken care of as a team.

Question 9: Do you plan to integrate new operations into existing structures or to create separate entities? In the execution of digital transformation, some 
company owners reach a seminal moment, where they ask themselves about the strategic relationship between their traditional and their future business models. Across the case companies there where two decisive factors that bring along the strategic question of how to arrange the future company structure. At first it can occur that new business operations require technologically skilled employees like engineers or IT specialists, who tend to earn a lot more compared to previous employees. At second, necessary investments tend to raise considerations around financial resources and the incorporated risk profile of the company.

Question 10: What types of operational changes do you expect? Being able to react and adapt requires a clear understanding of expected changes that digital transformation will cause across own as well as contiguous industries. The most important area of change is seen in the improvement of business processes, where incremental developments in the future are expected at an even more intense level than today. Mainly affected are production and office related areas, where e.g. the use of workflow management systems, product data management systems as well the integration of NC programming and production still yield a lot of headroom for improvement regarding usability and customizability to individual requirements of businesses. Along come expectations around a new set of required skills based on digital technologies. In all areas of the firms, employees will need at least a basic understanding of digital tools. A third aspect of expected change concerns products and services. The firms agree that classical craft products will remain also in a digitalized world, but clients' expectations regarding quality, design, and delivery times will increase due to the exploding number of design and functional options, logistics, and digital production techniques. Besides, digitally enriched products are expected to see considerable market growth.

Question 11: How can your firm realize a target employee structure? As most of the case companies expect a changing skill set among their staff, the acquisition of necessary competencies is seen of major importance. All firms agree that two modes must go together. On the one hand, the companies must develop their existing staff by fostering general willingness to develop additional knowledge. On the other hand, all companies agree on the long-term necessity of attracting young employees, so called digital natives, to push digital transformation. Thereby the formal qualification, e.g. in a certain skilled craft, steps back against the digital affinity and knowledge of digital tools of applicants. Hereby, all cases see a positive side effect of being a digital leader. Whereas many companies generally complain about 
the scarcity in skilled workforce, the companies under investigation consider their reputation as a clear advantage in this war for talent.

Question 12: How can you personally acquire necessary competencies and inspiration? The ability to assess technological advancements requires the company owners to be familiar with major technological developments in their fields. All cases show that mastering digital transformation requires both, formal competencies as well as the inspiration to transfer them to their traditional craft business models. Since both go hand in hand, there is no difference between the options where to obtain them. Internally, company owners source their knowledge from regular feedback, given by their staff. External sources for expertise are evaluated by the case companies purposefully on an implicit cost-benefit-basis. All cases consider the chamber of skilled crafts a valuable source of knowledge but vary in the intensity of usage. Some rely on the consulting services of selected experts, whereas others regularly take part in information sessions. Other options to obtain external knowledge and impulse are voluntary, self-organized experience exchange groups, or trade fairs, where company owners search for products and machinery augmenting their sources of value creation, in addition to meeting clients and highlight their own developments. A last option to capture external knowledge are specific vertical networks, including e.g. practitioners from related industries, and scholars from academia.

\subsubsection{Financial aspects dimension}

Most of digital transformation efforts require significant investments, e.g. in assets, human capital, but also R\&D. The case companies ascribe 30$70 \%$ of their total yearly investments to digital technologies. They also agree on an implementation and learning time of at least one year until positive effects from digital transformation components are realized. Therefore, a solid financial structure is critical. At the same time, eroding margins in traditional core business areas may trigger company owners to consider steps towards increasing efficiency or exploiting new revenue sources. To finance all endeavors, different sources of capital are worth evaluating.

Question 13: How strong is the financial pressure on your current core business? If primarily analogue business models continue to deliver sufficient profits, many company owners neglect the necessity for digital transformation. When margins start to plunge, it may be too late. Therefore, company owners should carefully evaluate their whole product portfolio based 
on the inherent financial pressure, i.e. the ability to deliver stable or, at best, increasing margins. As soon as they see signs for margin deterioration, action becomes an imperative. For SME, this aspect becomes even more important due to limited economies of scale. Four of the seven case companies see a major threat for themselves as well as other craft businesses, when industrial players enter competition with small-capacity craft businesses, e.g. based on technological advancements that enable lot size one without profit limitations.

Question 14: How will you finance the digital transformation endeavor? Financing digital transformation activities remains a tough question for SME, especially as limited financial resources are one of the key characteristics. In general, due to limited size and recoverable assets, banks remain reluctant when it comes to lend money, especially for digitally ambitious endeavors without proven economics. Still, most cases under investigation see a mix of internal funds from cash flows and loans by their house bank as sufficient. Additional equity financing to fund digital venture ideas is only considered by one firm owner. The rationale is the lack of openness and understanding of his house bank for innovative business ideas, accompanied by own risk considerations to secure the persistence of traditional business. Therefore, the owner sees no alternative than using all financing options possible for gaining headroom for incremental growth, especially private equity in the form of venture capital and crowdfunding. Wherever possible, all companies have already applied for public funds, e.g. economic development programs, subsidized loan programs, or research funds.

\subsection{Discussion}

Confirmations and differences from existing findings arise on three levels: the style in which SME owners tend to think about the development of their business compared to employed managers, relevant categories to be covered, and around the options company owners can choose from in order to individualize their digital transformation strategies.

SME owners think in a selected style about the formulation of their individual digital transformation strategy. This holds true across all categories but becomes obvious when defining aspects of future value creation and organizational aspects. It appears that SME owners tend to define a strategy for their firm highly realization focused. This is indicated by the fact that they ask themselves e.g. "How can my firm digitally leverage sales?" and see the options "Present products on website or in social media", "Es- 
tablish web shop", "Engage in Search Engine Optimization/Marketing", and "Communicate with customers online". They also ask, "How can my firm adapt its product portfolio?", potentially with "Fully digital products", "Production techniques/ patent usage", "Individualization", and "Standardization". I find that SME leaders take a multichannel perspective as well as a limited number of potential optimizations in their product offering for granted and set this knowledge in the context of their business. Results from larger corporations tend to be contradictory. While findings from media industry are in line with my results (Hess et al., 2016), findings from insurance industry indicate that the decision options towards a digital sales channel transformation is not predetermined between analog/ physical (Wiesböck et al., 2017). Dissociated from any industry specificity, SME leaders seem to sacrifice some degree of freedom in their decision making towards the scope of their digital transformation in order to gain focus on the realization of benefits.

The general architecture of the digital transformation framework (Matt et al., 2015) is corroborated by this study. Use of technologies, changes in value creation, and financial aspects remain top-level strategic dimensions valid for SME. This fortification shows the theoretical suitability of the construct to analyze digital transformation on a common ground. Regarding applications in practice, this finding indicates that practitioners can define digital transformation strategies with at least an acceptable probability to succeed for various companies on the common ground of the proposed categories. Nevertheless, in order to increase fit with the driving thoughts of the owners of the companies under analysis in this study, I suggest to introduce an "organizational changes"-dimension instead of a structural changes dimension. In their initial framework, Matt et al. introduced "structural changes" referring to "variations in a firm's organizational setup, especially concerning the placement of the new digital activities within the corporate structures" (Matt et al. 2015, p. 341). While I agree on the importance to assign responsibilities, organizational positioning of new activities, focus on operational changes and the development of competencies, I see these aspects in an SME context affecting structural as well as operational aspects. As SME show differential structural characteristics compared to larger corporations, operational and human centric aspects like employee structure or business network of the owner manager gain higher importance compared to formal responsibilities and compared to the integration of new operations in the firms' structures. The term "organizational changes" incorporates more emphasis on human factors in the concep- 
tion of a digital transformation and therefore provides a better representation of the SME context.

Regarding strategic questions and options within the overall four categories of the digital transformation framework, I find three categories to be influenced by the SME environment. Only the use of technologies category, defining the importance a company is placing on IT in general, and its technological ambition, proves valid also for the seven SME companies in this study, as it has done for media companies (Hess et al., 2016) and insurance companies (Wiesböck et al., 2017). As this fact confirms the generalizability of the digital transformation framework as a theoretical construct, it points out an essential acknowledgment for the management practice in digital transformation: ascribed significance and ambition by either company owners or managers form the basis of success in digital transformation throughout every business environment.

The category changes in value creation is strongly influenced by the SME setting. I find five strategic questions SME owners ask themselves around the future scope of their value creation metrics. The structure of these questions represents a comprehensive toolbox where digital technologies support the management of SME to strengthen elementary parts of their business model. This comprehensiveness has not been identified within specific industrial, large corporation environments. Digital transformation strategies in the media industry are limited to transformations in sales, product offering, and resulting future main business scope, neglecting an efficiency perspective (Hess et al., 2016). Large insurance franchises cover aspects of operations and efficiency next to sales, product offering and new sources of revenue creation and ask for the future main business scope (Wiesböck et al., 2017). Covering and bundling those same aspects, the SME perspective I present is less differentiated based on its industry-neutrality. New questions from the SME perspective arise in two fields. Firstly, SME owners strive for inter-company efficiency by trying to leverage efficiency across their entire value networks in collaboration with suppliers, partners and clients. Secondly, they urge to become indispensable partners for their clients by getting connected to them via automated interfaces or engage in the technological education of their business partners. Another SME specialty is depicted by the option not to engage in digital transformation.

Having elaborated on the term organizational changes in the contrast to structural changes before, I find SME influence especially on the content level of this category. The owner manager himself together with his management team always takes the responsibility for transformational actions. 
There is no C-level structure of responsibilities as seen in large company environments (see e.g. Hess et al., 2016; Singh \& Hess, 2017; Wiesböck et al., 2017). SME always take steps of digital transformation based on an integration in existing corporate structures. Only in the case of highly ambitious initiatives, SME consider founding new legal entities. In this perspective as well as in the focus of expected operational changes, there is no difference in the findings on SME compared to larger corporations. Further differences arise from the operationalization of competency building. Large corporations from media and insurance industry take a portfolio management approach towards competency building, incl. takeovers and external sourcing (Hess et al. 2016; Wiesböck et al. 2017). SME focus only on two areas of actions: they develop their existing staff and are eager to attract young, digital affine talent. It is in the particular interest of SME owners to find ways to personally acquire the necessary knowledge about digital technologies. Taking their own responsibility for the firm for granted, they consider proficient knowledge around future developments driving their business as mandatory and evaluate multiple options for knowledge generation. Surprisingly, research on large corporations neglects this aspect.

Finally, this study extends the financial aspects category from the SME perspective. SME owners as well as corporate managers examine the margin development in their core business areas in order to prioritize the necessity of investments in digital technologies. When it comes to financing, SME differentiate more sources of capital in comparison to large corporations, incl. public funds. External equity financing and crowdfunding remain niches, but still observable.

\subsection{Conclusion, Contribution, and Limitations}

This study extends previous work on digital transformation strategies in specific industries, all conducted based on case studies of large corporations, to a cross-sector SME setting. I show that the general categories along which SME and large corporations structure their digital transformation endeavors do not differ widely. "Use of technologies", "Changes in value creation", and "Financial aspects" are useful categories to serve companies of all sizes. The SME perspective adds some options on the detailing level. While large companies additionally focus on structural aspects in their digital transformation, I ascribe the term organizational aspects better fit to the conceptual considerations within SME. The absence of hierar- 
chy between categories points out complexity and multidimensional nature often ascribed to digital transformation.

For the analysis, I have chosen a clearly defined segment of the German economy, covering about one million SME. Collaboration with technology experts of the chamber of skilled crafts guaranteed access to the firms under analysis, yielding reliable and unbiased data. With the number of seven cases, I more than double the sample size of comparable studies in large corporations. Picking up skepticism about external validity of casebased research in general, seven cases out of one million is far from being representative. This study claims transferability to the context of heterogeneous challenges SME face when dealing with explicit or implicit thoughts of strategy development towards digital transformation. There is a need for more research to ascertain whether the findings of this study can be more broadly generalized. Further investigation should focus on whether the questions found can be confirmed within SME different from the skilled crafts sector, including businesses from other countries.

Focusing on examples of successful digital transformation in SME, the emerging patterns must be interpreted within the limitations of a cross-sectional, exploratory research design, particularly its inability to determine directions of causality. Though I used triangulation to find publicly available evidence for the owner manager statements gathered in interviews, it is not clear e.g., whether process efficiency improvements were intended, or whether they can be ascribed to the inventive genius of an individual in combination with a trial-and-error process. Future research might analyze digital transformation from a longitudinal, process-oriented standpoint or incorporate management control systems research to find out whether success in digital transformation endeavors is controllable. The results of the present study can also serve as a promising point of departure to investigate the mid to long-term (non-)financial benefits from digital transformation. Based on observations during my visits at the companies' facilities I speculate that leaders in terms of technology absorption tend to be successful also in economic terms. Nevertheless, publicly available data was not sufficient to provide any assertion on that topic.

Digital transformation is a long and multilayered development with many outside and inside variables SME owners must consider. The given results aim to support SME owners and managers to motivate themselves and their staff to get inclination and inspiration for a productive way to deal with digital opportunities. By addressing this issue with a structured approach, results shall help to overcome obstacles, avoid mistakes and therefore perpetuate businesses. 
2 Essay I: Survival in the digital age

2.8 Appendix essay I

\begin{tabular}{|c|c|c|c|c|c|}
\hline 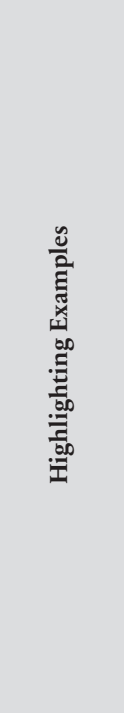 & 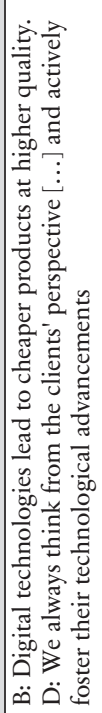 & 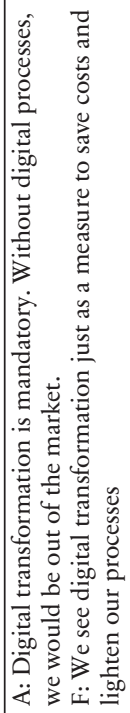 & 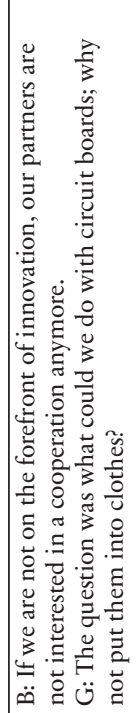 & 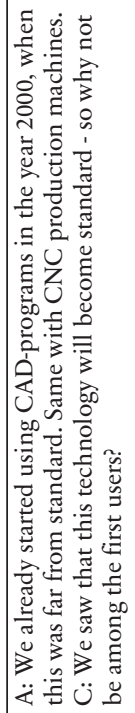 & 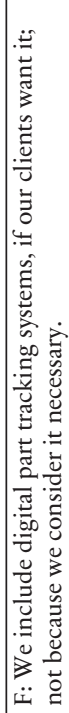 \\
\hline 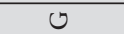 & $\star$ & & $\star x$ & & \\
\hline$\omega$ & & $x$ & & & $x$ \\
\hline 피 & & 4 & & $x$ & \\
\hline 0 & $\star$ & $\star x$ & & $\star$ & \\
\hline$u$ & $\star$ & & & $\star x$ & \\
\hline$\infty$ & $\star x$ & & $x$ & & \\
\hline$\ll$ & & $\star x$ & & $\star x$ & \\
\hline 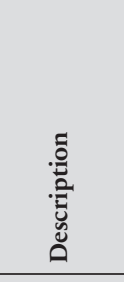 & 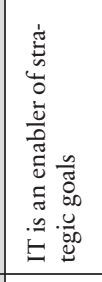 & 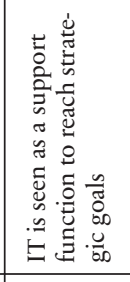 & 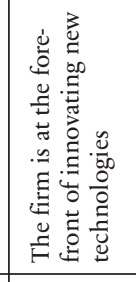 & 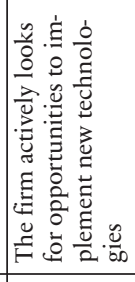 & 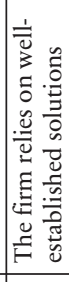 \\
\hline 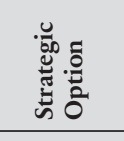 & 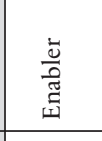 & 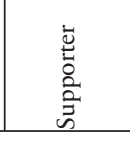 & 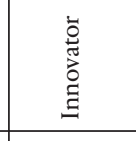 & 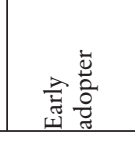 & $\begin{array}{l}\overrightarrow{0} \\
\vdots \\
\overline{0} \\
0 \\
\end{array}$ \\
\hline 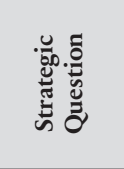 & \multicolumn{2}{|c|}{ 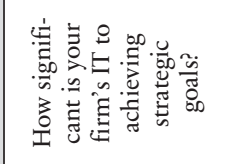 } & \multicolumn{3}{|c|}{ 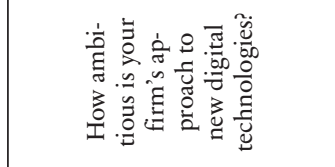 } \\
\hline 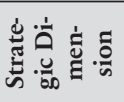 & \multicolumn{5}{|c|}{ 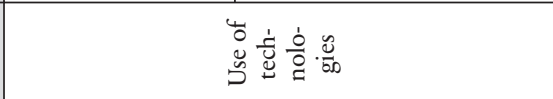 } \\
\hline
\end{tabular}




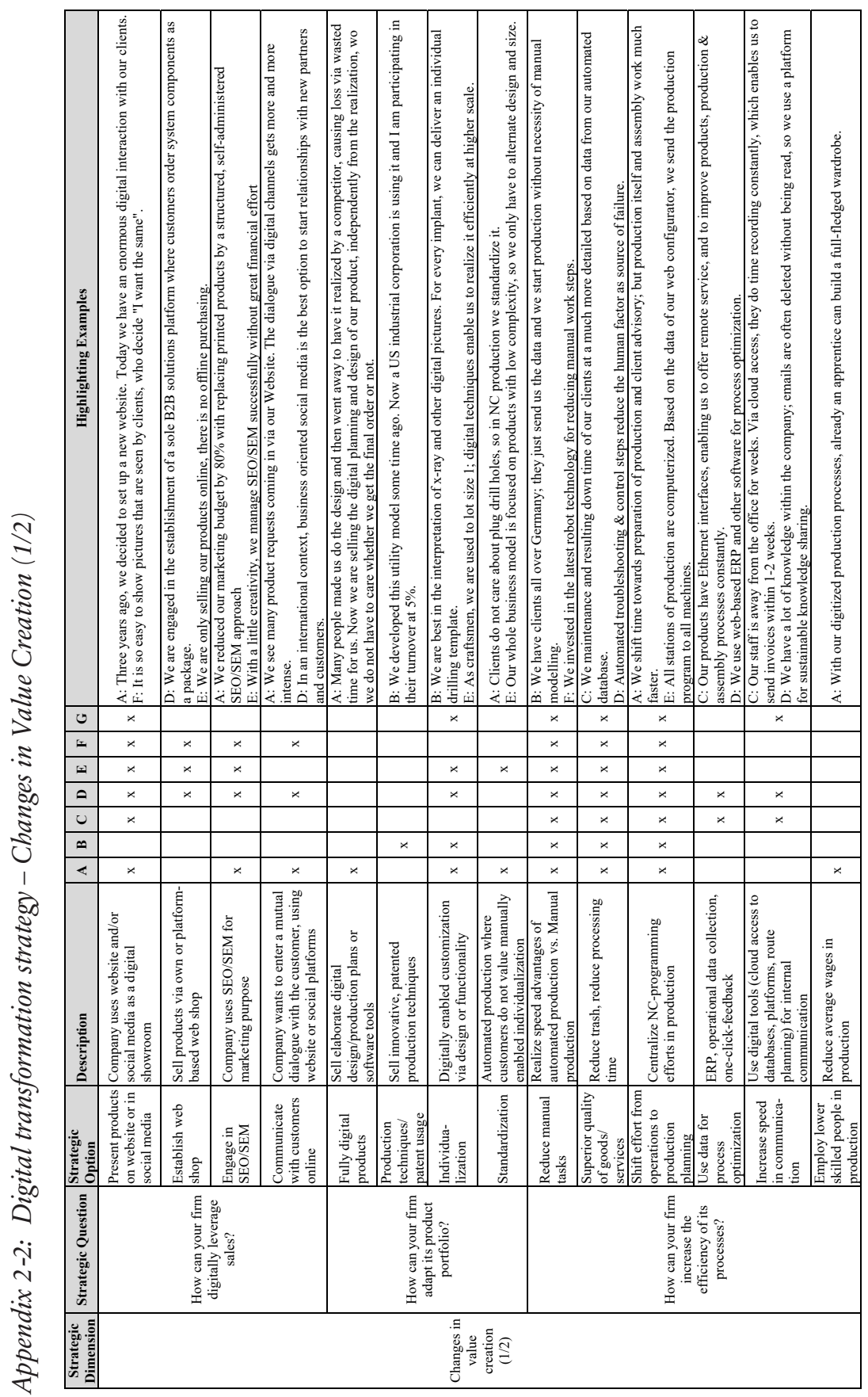




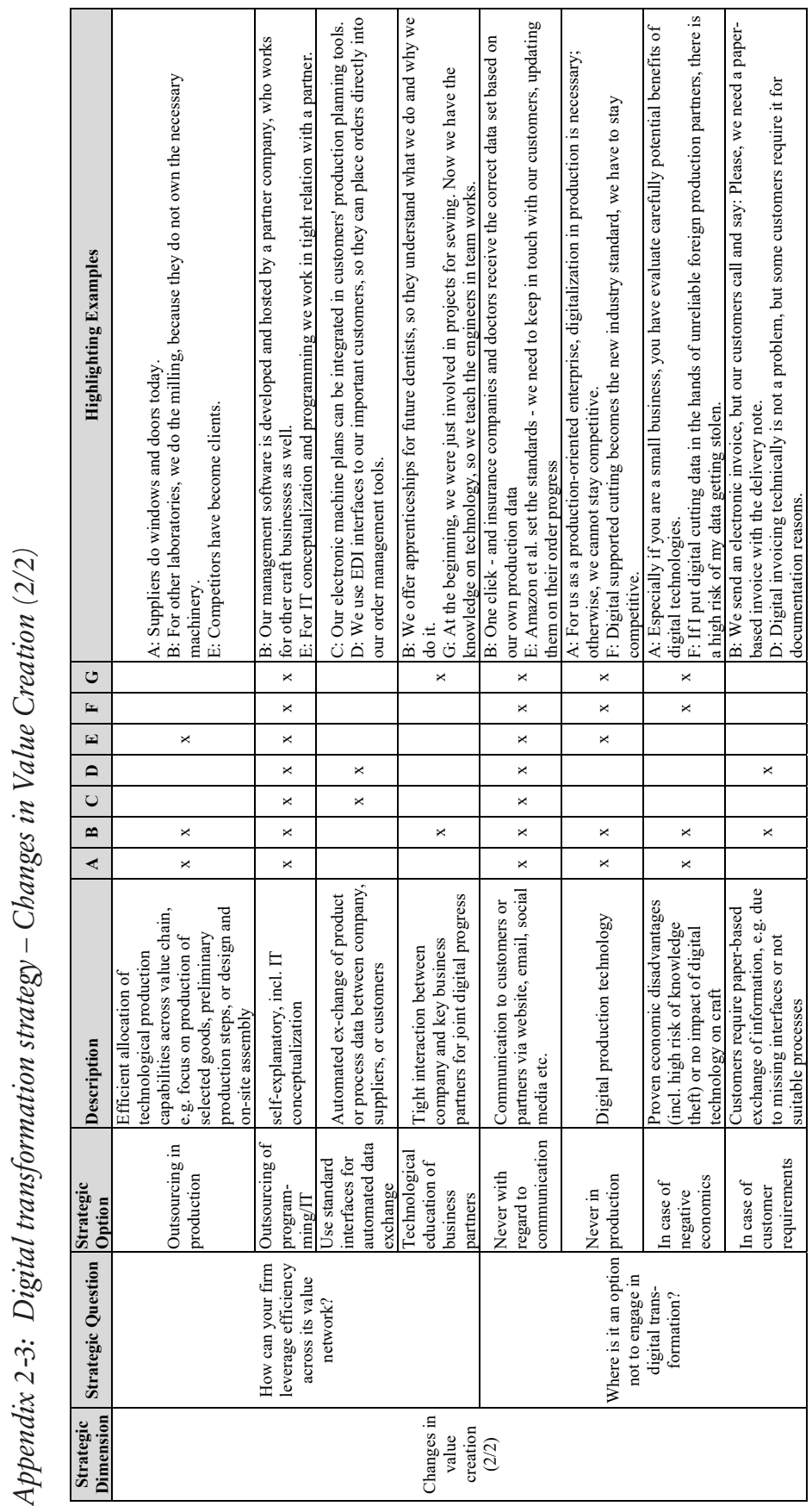




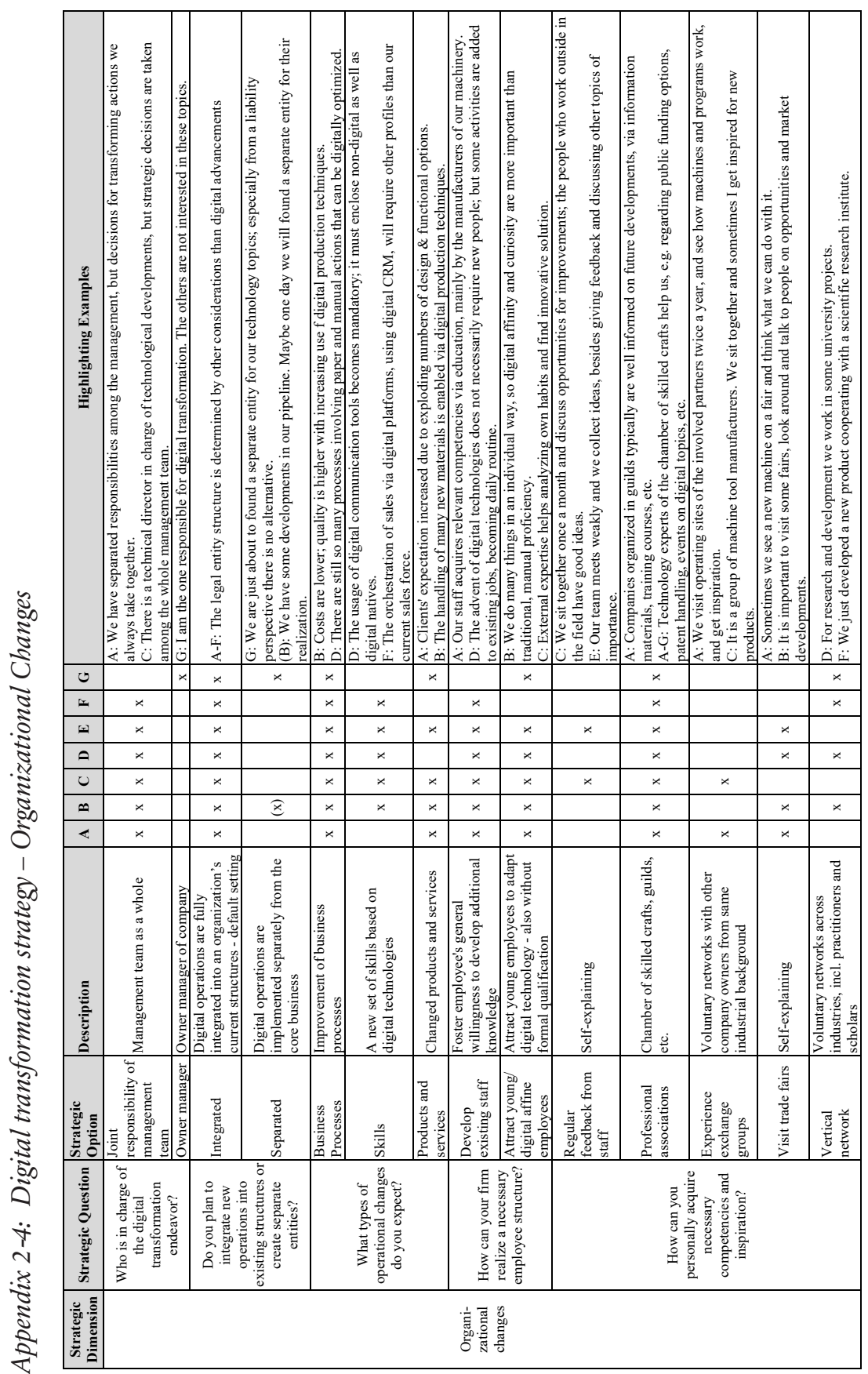


2 Essay I: Survival in the digital age

\begin{tabular}{|c|c|c|c|c|c|c|c|}
\hline 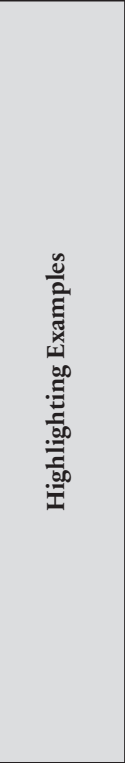 & 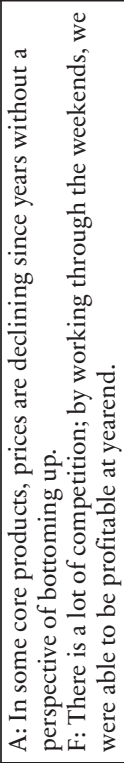 & 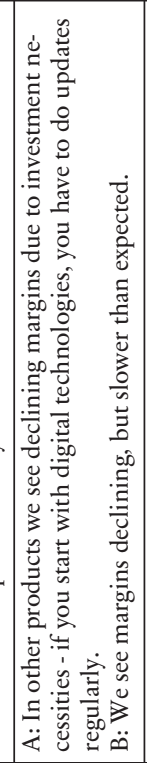 & & 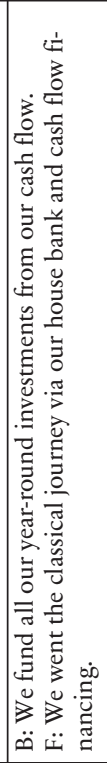 & 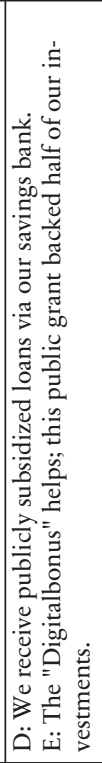 & 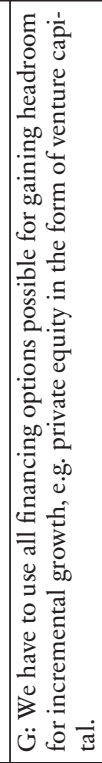 & 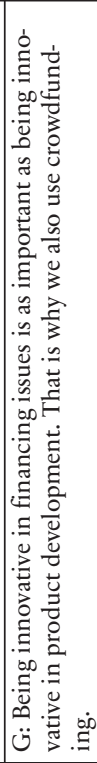 \\
\hline 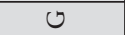 & & & & & $x$ & $x$ & $x$ \\
\hline 山 & $\star$ & & & $\star x$ & $\star x$ & & \\
\hline ㄸ & & & & $\star x$ & $\star x$ & & \\
\hline 0 & & & & $\star x$ & $\star x$ & & \\
\hline$u$ & & & & $\star$ & $\star x$ & & \\
\hline$\infty$ & & $\star$ & & $\star$ & & & \\
\hline$<$ & $\star$ & $\star$ & & $\star$ & $x$ & & \\
\hline 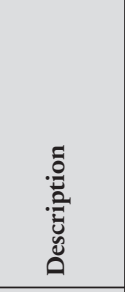 & 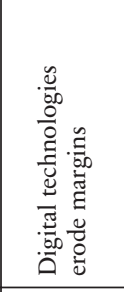 & 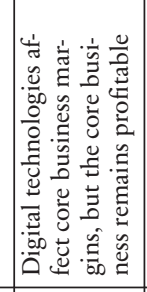 & 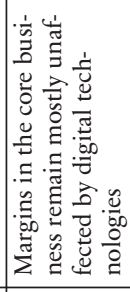 & 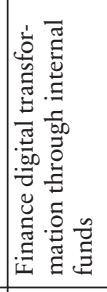 & 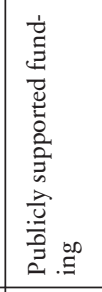 & 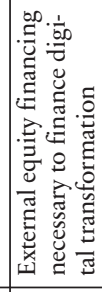 & 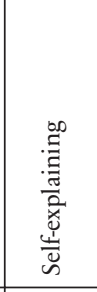 \\
\hline 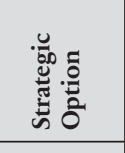 & $\begin{array}{l}\frac{5}{50} \\
.0 \\
\end{array}$ & 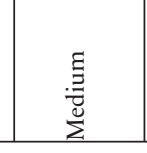 & .3. & 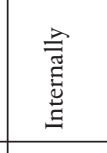 & 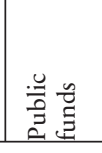 & 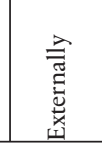 & 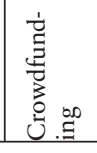 \\
\hline 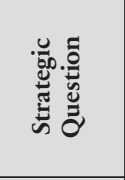 & & 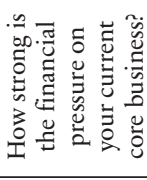 & & & 焉 & 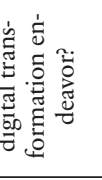 & \\
\hline 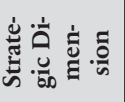 & \multicolumn{7}{|c|}{ 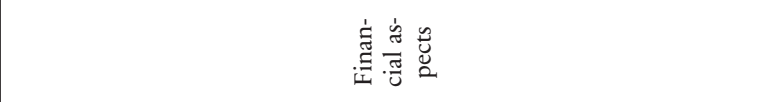 } \\
\hline
\end{tabular}




\title{
3 Essay II: Options for designing a digital transformation control system
}

\author{
Johannes Trenkle \\ Technical University of Munich \\ TUM School of Management \\ j.trenkle@tum.de
}

\begin{abstract}
II
This paper explores the use of management control measures in the course of digital transformation journeys in small and medium sized enterprises (SMEs) in order to sketch a digital transformation control system. It also examines the role of the publicly promoted concept of "trial-and-error". I describe SMEs that are leaders in terms of digital transformation and analyze the variety of control measures they use in order to follow a structured approach throughout their digital transformation endeavor. I elaborate the role that trial-and-error plays as part of management control procedures. The resulting package of management control measures from cultural, planning, administrative, and key performance indicator-oriented categories rests on the management control systems as a package framework by Malmi \& Brown, 2008. It shows the variety of management control measures useful in supporting successful digital transformation in SMEs, pigeonholes the relationship between management control and the phenomenon of "trial-and-error", and thereby gives clues for further academic research to analyze the relationship between sustainable success in digital transformation and management control systems, as well as providing practical advice for SME owners and managers on how to control a digital transformation endeavor.
\end{abstract}

Keywords: digital transformation, management control, management control systems, MCS, small and medium sized enterprise, SME

Status: Working paper

\subsection{Introduction}

Digital transformation is one of the most important management tasks in the current era of digitalization. All companies must position themselves toward technology exploitation and exploration. Most SMEs will have to adapt their business and their operating models to stay competitive. Thereby, SMEs can realize a range of benefits from the use of management con- 
trol measures, including increased financial and organizational performance, facilitated decision making, optimization in resource allocation, and faster adaptation to the surrounding environment. Assuming that the use of management control measures can have a positive impact on SMEs' digital transformation efforts, I answer the research question: How should a digital transformation control system be designed?

Digitization, digitalization, and digital transformation as collective terms describing the growing use of technology in company routines are undoubtedly drivers of economic development nowadays. Digital transformation, in particular, describes the managed adaptation of digital technologies, emphasizing the change aspect in ways of working, roles, and business offering caused by the adoption of digital technologies in an organization, or in the operational environment of an organization in order to ensure sustainable value creation (Gimpel \& Röglinger, 2015). The special feature that makes digital transformation new and special is the dynamic interaction of digital solutions and the resulting new business models as well as necessary adjustments of procedures and processes (Wiesböck \& Hess, 2019; Yoo et al., 2012). Digital transformation is therefore a multifaceted, high priority management task, involving high complexity regarding a company's use of technology, value creation, structure, and financial aspects (Hess et al., 2016; Matt et al., 2015). SMEs are not excluded as they face the same challenges as large firms.

Research in the field of SMEs has identified a wide range of potential benefits from the use of management control systems (MCS). The use of MCS in SMEs facilitates decision making (Chand \& Dahiya, 2010; Duréndez et al., 2011; Villarmois \& Levant, 2011), improves the quality of strategic analysis (Chand \& Dahiya, 2010; Garengo \& Bernardi, 2007; Peel $\&$ Bridge, 1998; Tapinos et al., 2005), improves controlling functions (Amat et al., 1994; Chand \& Dahiya, 2010; Hakola, 2010), allows for better integration of the business plan and key performance indicators (Manville, 2007), allows resources to be optimized (Laurinkevičiūtė \& Stasiškienè, 2011; Villarmois \& Levant, 2011), improves overall quality (Chand \& Dahiya, 2010), and finally leads to faster adaptation to the surrounding environment (Amat et al., 1994; Laurinkevičiūtė \& Stasiškienè, 2011).

The potential value added of MCS in the context of digital transformation, especially in SMEs, has not been addressed in previous literature. Yet, there is some empirical evidence from which I suggest that the use of MCS supports successful digital transformation. On the one hand, companies that invest in advanced information technology (IT) are more likely to adopt MCS (Sharma \& Bhagwat, 2007). Further factors that contribute to 
extended MCS usage include strong business competition (Amat et al., 1994; Marc, Peljhan, Ponikvar, Sobota, \& Tekavcic, 2010), perceived environmental uncertainty (Alattar, Kouhy, \& Innes, 2009; Amat et al., 1994; Gul, 1991; Laurinkevičiūte \& Stasiškienè, 2011), and the management's wish for higher financial performance (Gul, 1991). On the other hand, the failure of SMEs to make appropriate use of MCS contributes to enterprise collapses, especially in environments where distortions occur, as is the case with current technology development (De Loo \& Davis, 2003; El-Ebaishi, Karbhari, \& Naser, 2003; Halabi, Dyt, \& Barrett, 2010; Md. Mostaque, Laitinen, \& Gunasekaran, 1998). Formal and informal controls (H. C. Dekker, 2004; Ouchi, 1979) support reorganizing challenges and ensure long-term financial performance if companies are already in financially stressed situations (Laitinen, 2011). Adequately designed MCS also support decision making in organizations that show increasing complexity (Giovannoni et al., 2011). Taking all these facts into account, I expect a positive influence of MCS also throughout digital transformation endeavors.

As MCS are not stable, but evolve in the course of changing institutional environments (Burns \& Scapens, 2000; Johnson \& Kaplan, 1987), and digital transformation is a rather new challenge for companies to face, I expect that existing MCS may not be sufficient to depict the information and control challenges as well as resulting decision spectrums of SME owners and managers arising from this phenomenon. As a reaction, scholars call, for example, for an integration of agile measures into MCS by mobilizing a "trial-and-error-culture" to make management control leaner, more integrated, and faster (Schäffer \& Weber, 2016). Therefore, I use a qualitative research design to search for a digital transformation control system that fits the mindset of SME representatives, whose companies can be considered leaders in digital transformation. A combination of purposeful sampling approaches leads me to include 11 cases of SMEs in my study, ranging from 5 to around 300 employees.

I find the emerging categories to fit well with Malmi and Brown's 2008 MCS as a package conceptualization. Cultural controls, planning, administrative controls, and performance indicator-based controls cover all control measures that the cases under analysis mobilize throughout their digital transformation endeavors. More detailed measures are identified within all these categories to depict the great variety of transformation-fostering areas of control. The findings therefore provide value added to scholars in the field of MCS to expand existing concepts toward coverage of developments in the current age of digitalization, but they also support practitioners in 
underpinning their digital transformation efforts with structured control mechanisms.

\subsection{Theoretical background}

\subsubsection{Approaching management control from the SME perspective}

This research aims at broadening the literature stream targeting management control practices in the setting of SMEs. Yet the problem remains that there is little empirical management accounting research targeting the investigation of technological innovation and development. Research in this field has long been concentrated on large enterprises (Anderson, 1995; Robert S. Kaplan, 1994; Monden \& Hamada, 1991) because of a lack of supply of practical expertise from SMEs as well as a great amount of heterogeneity with regard to the definition of management control in the SME context (Mitchell \& Reid, 2000). Management control in SME settings has simply not been "fashionable" (see: Mitchell \& Reid, 2000, p. 386). Recent years have seen a growing interest in management accounting scholars focusing on family firms. To give two examples, Giovannoni, Maraghini, \& Riccaboni, 2011, describe the useful influence that management accounting practices can have on knowledge transfer, thereby facilitating professionalization as well as succession processes. Songini \& Gnan, 2015 , focus on the existence of control measures to solve distinctive, agency-related conflicts in family businesses and related performance outcomes. Around 20 papers focus on the specifics of management accounting and management control in family businesses (literature overviews are provided by, e.g., Helsen, Lybaert, Steijvers, Orens, \& Dekker, 2017; Prencipe, Bar-Yosef, Dekker, \& Dekker, 2014; Quinn, Hiebl, Moores, \& Craig, 2018; Senftlechner \& Hiebl, 2015). The overarching notion remains that there is great variance across family firms concerning the individual implementation and use of management accounting and control systems (Quinn et al., 2018). Still, the importance of management accounting and control in general is not affected or limited. Holding true for larger family businesses, but also in micro- and small business contexts, "mutual trust, family-specific goals and the centralization of power emerge as important antecedents of management accounting and control, but they are also affected by the use of management accounting and control instruments." (Senftlechner \& Hiebl, 2015, p. 573). 
The definition of management control in general, but especially in the SME context, still remains vague, which makes it difficult to precisely narrow down an object or unit of analysis and to provide theoretical background. Malmi \& Brown, 2008, define MCS as "systems, rules, practices, values and other activities management puts in place in order to direct employee behavior" (Malmi \& Brown, 2008, p. 290). In the study of MCS, this carries the danger of excluding informal, implicitly applied measures (Kingston \& Caballero, 2009). To make the theoretical background of my study as compelling as possible in order not to miss any aspect of management control, I search for connectivity with well-established frameworks of management control, e.g., by Malmi \& Brown, 2008, Merchant \& Van der Stede, 2012, and Simons, 1987.

Furthermore, I search for evidence regarding management accounting techniques in a broad sense including budgeting, performance evaluation, costing, decision making, communication, and strategic analysis (e.g., Chand and Dahiya, 2010; Ahmad and Zabri, 2016). My resulting, holistic view on management control references the term "controlling" used especially in German speaking literature, which is ascribed a coordination function within a company's leadership system, thereby aligning planning, control, management information, organization, and human resources management (e.g., Küpper et al., 2013). This perspective, combining elements of management accounting and management control under the denomination MCS, references Becker, Ulrich, \& Staffel, 2011, and Laitinen, 2011, and subsumes management accounting as well as performance measurement as formal, particular analytical tools that managers should use for planning, controlling, and improving the efficiency of a company.

A rather new aspect in the theoretical debate on MCS is trial-and-error, which is seen as a culturally anchored measure so that employees are given the freedom to take decisions independently of a previously defined goal within the boundaries of predefined budget limits (see, e.g., Schäffer \& Weber, 2016). The concept is related to agile working methods especially in the context of digital transformation, where the development of digital products, services, and processes in an uncertain, dynamically changing environment requires iterative test-and-learn cycles (see, e.g., Gimpel \& Röglinger, 2015; Malmi \& Brown, 2008; Sebastian et al., 2017). I elaborate the role that trial-and-error plays as part of management control procedures from an empirical perspective. 


\subsubsection{Management control systems as a lever of success in digital transformation?}

To my knowledge, no previous research has tackled the aspect of specific MCS that support successful digital transformation in SMEs, in either large company or SME settings. Heading in a similar, yet less comprehensive direction, Sharma \& Bhagwat, 2007, found, on the basis of four case studies of SMEs, that investments in advanced information systems increase the likelihood of adopting MCS, based on the ability to manage larger amounts of information more effectively.

However, as increasing digitalization is contributing to intense competition as well as perceived uncertainty, thereby forcing companies as well as management to take transformative actions, I draw on evidence from environmental situations that make SME owners intensify the use of MCS. At an individual level, Ritchie \& Richardson, 2000, investigated how an owner-manager who feels highly responsible for his or her business tends to increase the use of management accounting systems. A potential explanation is that they become more involved in improving performance and therefore need sophisticated information.

Amat et al. (1994) and Marc, Peljhan, Ponikvar, Sobota, \& Tekavcic (2010) highlight the importance of strong business competition as a key external factor that increases the usage as well as the design of MCS in SMEs. They argue that market pressure from competitors entails greater need for information on a company's own costs and operations. By using more MCS, SMEs adapt more quickly to their surrounding environment, as they benefit under perceived uncertainty from the implementation of rigorous internal controls that provide tools to react to and neutralize external threats (Alattar et al., 2009; Amat et al., 1994; Gul, 1991; Laurinkevičiūtė \& Stasiškienè, 2011). In addition, Gul, 1991, also found that insufficient use of MCS impedes SME performance in environments with high uncertainty. This may lead as far as inadequate and inappropriate use of MCS, as well as lack of knowledge around them, can leverage firms' difficulties, and thereby contribute to business failure (De Loo \& Davis, 2003; El-Ebaishi et al., 2003; Halabi et al., 2010; Md. Mostaque et al., 1998). The rejection of application of management accounting in an adequate manner may result in, e.g., less accurate cost calculations, causing negative effects on price calculation, investment decisions, overhead cost calculation and, above all, overall business performance (e.g., De Loo \& Davis, 2003; Laitinen, 2011). A case study by De Loo \& Davis, 2003, shows the case of a small record manufacturer at the beginning of the 1920s that faced heavy 
competition from radio broadcasting stations and, based on inadequate management decisions, headed for bankruptcy. The case reveals how technology evolution-caused market change demands management to react properly, relying, e.g., on the correct level of detail in the planning and control of investments in fixed assets, organization, and structures and causal accounting figures, and resulting performance ratios. The absence of such measures did not cause the firm's demise but exacerbated its critical situation.

A resulting support function of MCS in the case of reorganizing challenges is described by Laitinen (2011), searching for factors promoting the reorganization of micro companies in financially distressed situations. Among other factors, his study takes into account organizational change measures such as motivating change, creating vision, developing political support, managing the transition, and sustaining momentum as well as the implementation of MCS (Cummings \& Worley, 2015). The last item covers both formal and informal controls, whereas formal controls enclose contractual obligations and formal organizational mechanisms, including outcome and behavior control mechanisms (H. C. Dekker, 2004; Ouchi, 1979), and informal controls (i.e., social control and relational governance) relate to cultures and systems influencing members and are essentially based on mechanisms inducing self-regulation (H. C. Dekker, 2004; Ouchi, 1979). The results show a positive influence of organizational change measures and MCS on the long-term financial performance of micro companies undergoing a process of reorganization. Assuming that company adaptation to dynamic changes in competition, as is the case in digital transformation, demands at least a certain amount of reorganization, e.g., with regard to the metrics of value creation, company structures, and finances (Hess et al., 2016; Matt et al., 2015), I conclude that MCS have the potential to prove useful throughout a digital transformation journey. This conjecture is backed up by Johnson and Kaplan, 1987, as well as Burns and Scapens, 2000, who point out that management control procedures are interconnected and evolve over time. They are therefore not fixed, but develop further with a changing institutional environment, showing the ability to adapt to necessary institutional transformations. This perspective, on the one hand, supports a general usefulness of management control procedures to companies when entering a digital transformation journey and, on the other hand, it highlights how a potential digital transformation control system must reflect the specifics of a company or individual transformation journey. 
Finally, as Giovannoni et al., 2011, show, management control techniques can actively support decision making and thereby align organizations in situations where a business becomes more complex. As long as a formalized management control framework is tailored to a SME's individual leadership style and vision, it supports employees to become "more conscious of the company's changing priorities" (see: Giovannoni et al., 2011, p. 139; see also: Langfield-Smith, 1997). There is no doubt that the evolution of technologies-alongside the inherent, necessary digital transformation of businesses-are factors that critically challenge SMEs in general (De Lema \& Duréndez, 2007), thereby widening an owner-manager's decision spectrum.

\subsection{Research design, research methods, and sample characteristics}

\subsubsection{Research design}

Given the innovative essence of the research object, I apply explanatory and exploratory methods. Investigating a "contemporary phenomenon in depth and within its real-life context" (Yin, 2014, p. 16) without clear boundaries between phenomenon and context, I assessed a case-based research design in line with Yin, 2014, to be most appropriate. The necessity of "description, interpretation and explanation" (Lee et al. 1999, p. 164) follows from the as yet unknown terrain of the research field, again encouraging a qualitative approach. Executing the research under an interpretive paradigm allows me to take into account personal as well as participants' perceptions, understandings, experiences, and interpretations to identify concepts within the gathered data (J. W. Creswell \& Creswell, 2018). These concepts represent management control practices in SMEs, which are the central unit of analysis. When generating these concepts, I will make no difference whether they are explicitly appreciated or appear to be implicitly in use. The study takes up a call by Malmi and Brown, 2008 , stating that "building a cumulative body of knowledge about the design and use of MCS becomes difficult without well-articulated definitions and purposes of MCS" (Malmi \& Brown, 2008, p. 289). Regarding the design of management control in the digital transformation of SMEs, this study seeks to be a starting point toward a holistic and compelling discussion of what currently happens in the field.

Qualitative designs already play a considerable role in MCS research (López \& Hiebl, 2015). Nonetheless, I see no possibility of generalizing or 
transferring existing results toward the given research question. Therefore, entering a path of discovery, I chose to apply different strategies for theorizing.

I describe the cases under investigation based on the data gathered from the interviews as well as further data from publicly available sources, i.e., websites, newspaper articles, magazine articles, social media content, or published books, depending on availability. This narrative section delivers thick description necessary to interpret the results in the given context (Pratt, 2009). Context, stories, and meaning intend to promote the audience's understanding of the applicability of the obtained results (Langley 1999, p. 696-697). Next to major company events, I describe digitally transformative management actions, the accompanying rationales, and measures installed in order to control the initiated actions.

The main theory development is executed using an abductive methodological approach (Timmermans \& Tavory, 2012). No prior, pre-determined hypotheses guided the research project, yet the existing literature on management control practices cannot be neglected. Still, the evolving concepts are inductively developed from the reality of data. Considering the broad area of study, the research process included iterations of the collection of large volumes of non-standardized data, data coding, the generation of meaning from the data, and finally the elaboration of existing theory from the data (Fisher \& Aguinis, 2017). A multiple case design was chosen because, first, of the absence of prior research and resulting difficulty in formulating a priori hypotheses (Ferreira \& Merchant, 1992), and, second, multiple cases add confidence and robustness to the findings (Miles et al., 2014; Yin, 2014). The multiple case design provides the opportunity to show greater variance by comparing and contrasting found models of MCS. The study leads to a package of MCS that have been proved valuable by SMEs that successfully embarked on a journey of digital transformation.

\subsubsection{Sampling approach}

Empirical units of analysis are selected SMEs that successfully mastered digital transformation. In order to ensure fit to a real-life context and ongoing discussion with practitioners as well as in academia, the scope of digital transformation aspects under investigation is not limited upfront. According to the work of Matt et al., 2015, digital transformation in the cases under investigation can therefore be related to changes in the use of tech- 
nologies, changes in value creation, structural changes, and financial aspects. As an instance of verification of the degree of digital transformation in their respective fields, I applied a set of criteria by Dehning et al. (2003, p. 654). The sample firms used IT to either fundamentally alter traditional ways of doing business by redefining business capabilities and/or business processes and relationships, and/or to dramatically change how tasks are carried out. The latter aspect leads to IT being recognized as important in enabling the firm to operate in different markets, serve different customers, and help gain considerable competitive advantage by doing things differently. This categorization served as a preselection criterion to ensure the companies have successfully initiated or completed steps of digital transformation (Eisenhardt, 1989; Miles et al., 2014).

A purposeful, multi-level sampling approach was applied (Fletcher $\&$ Plakoyiannaki, 2009), making two rounds of sampling necessary. I identified an initial set of seven SMEs that successfully mastered steps of digital transformation. In order to find basic concepts, I therefore used a critical case sampling approach. The cases were chosen as being "rich in information because they are unusual, special or make a point quite dramatically. The logic of this sampling strategy lies in lessons learned about unusual conditions or extreme outcomes manifested in the case." (see: Fletcher \& Plakoyiannaki, 2009, p. 179). The cases were identified in cooperation with technological experts and consultants from the chamber of skilled crafts for Munich and Upper Bavaria, as they have the deepest insights into the business and operating models of the eligible firms. The SMEs under consideration had fully or partially transformed core elements of their business model (Osterwalder \& Pigneur, 2010). Interviews and the sampling of additional data around these initial cases took place in July and August 2017 , originally targeting the topic of digital transformation strategies (Trenkle, 2019). Therefore, core topics of the initial set of interviews were general questions about the digital transformation of the companies, covering aspects of management control only as a side aspect. Table 3-1 gives an overview of the seven initial cases including their core business, number of employees, the organizational scope of digital transformation, and major areas of success from digital transformation. 


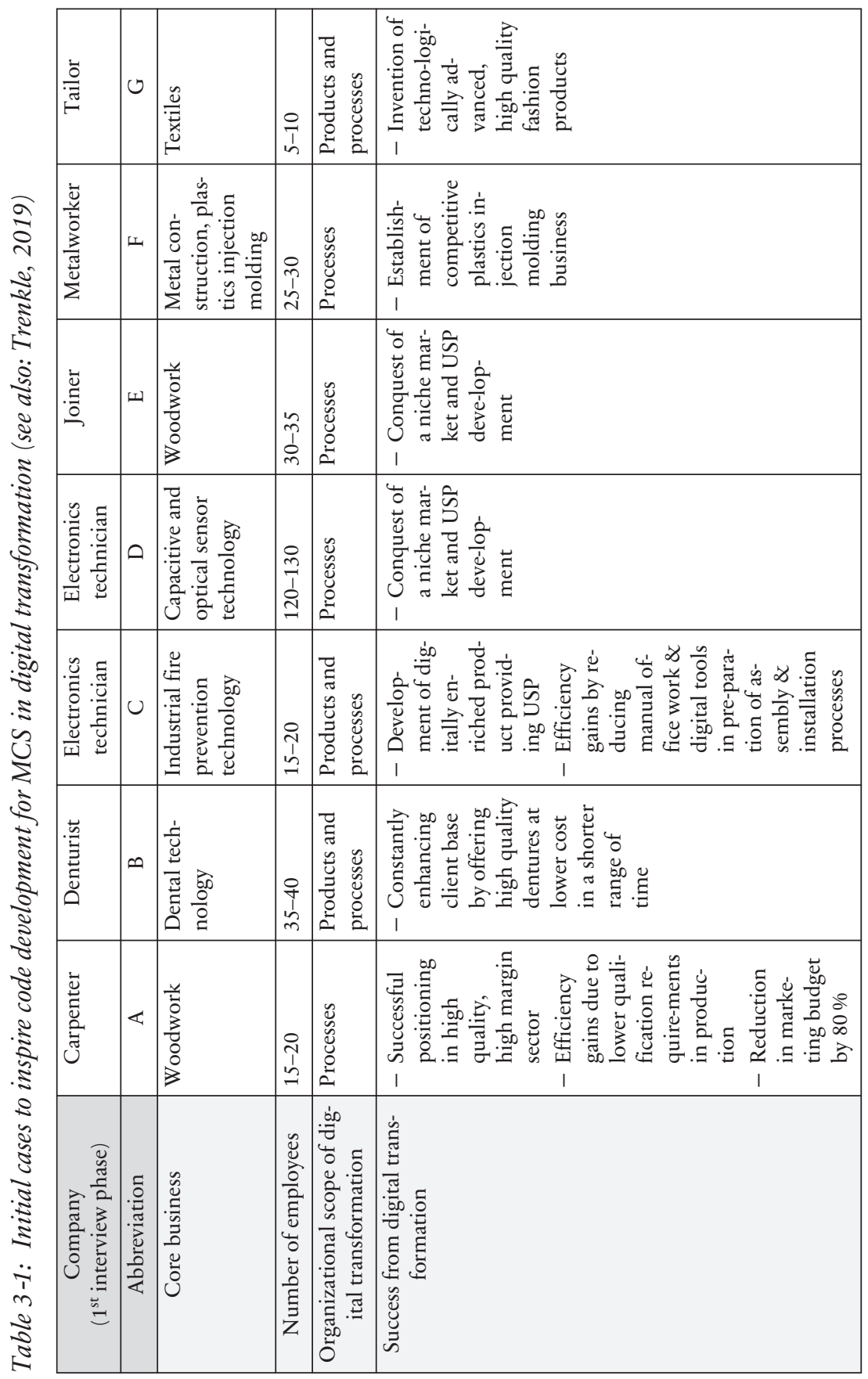


After data collection and initial analysis of the first set of cases were executed, I went back to the field to collect data from four additional cases to double-check and expand patterns emerging from the data (Timmermans $\&$ Tavory, 2012). I thereby changed the sampling strategy from critical case to theoretical sampling, where the cases under investigation are supposed to fit to the "emerging concepts in order to explore the dimensional range or conditions along which the properties of concepts vary. The rationale of theoretical sampling is to select cases that are likely to replicate or extend the emergent theory, or to fill theoretical categories." (see: Fletcher \& Plakoyiannaki, 2009, p. 179). Again partnering with technology experts and consultants from the chamber of skilled crafts for Munich and Upper Bavaria, I put the focus on SMEs that not only are known to be leaders in digital transformation aspects, but were also considered to be innovative in business model categories such as structured in their approach to execute business, being able to drive the discussion in interview situations more toward management control aspects. As is recommended for case studybased research to increase the likeliness of replication, I tried to choose "extreme situations and polar types in which the process of interest is 'transparently observable.." (see: Eisenhardt, 1989, p. 537, Pettigrew, 1990, p. 275). The resulting four additional cases formed the basis of my analysis, setting the focus of my study on SMEs ranging from around 20 up to 400 employees. Data collection in the second phase took place from September to November 2017. The interviewees in this round-one from each of the case companies-are listed below in Table 3-2, including additional company information. 


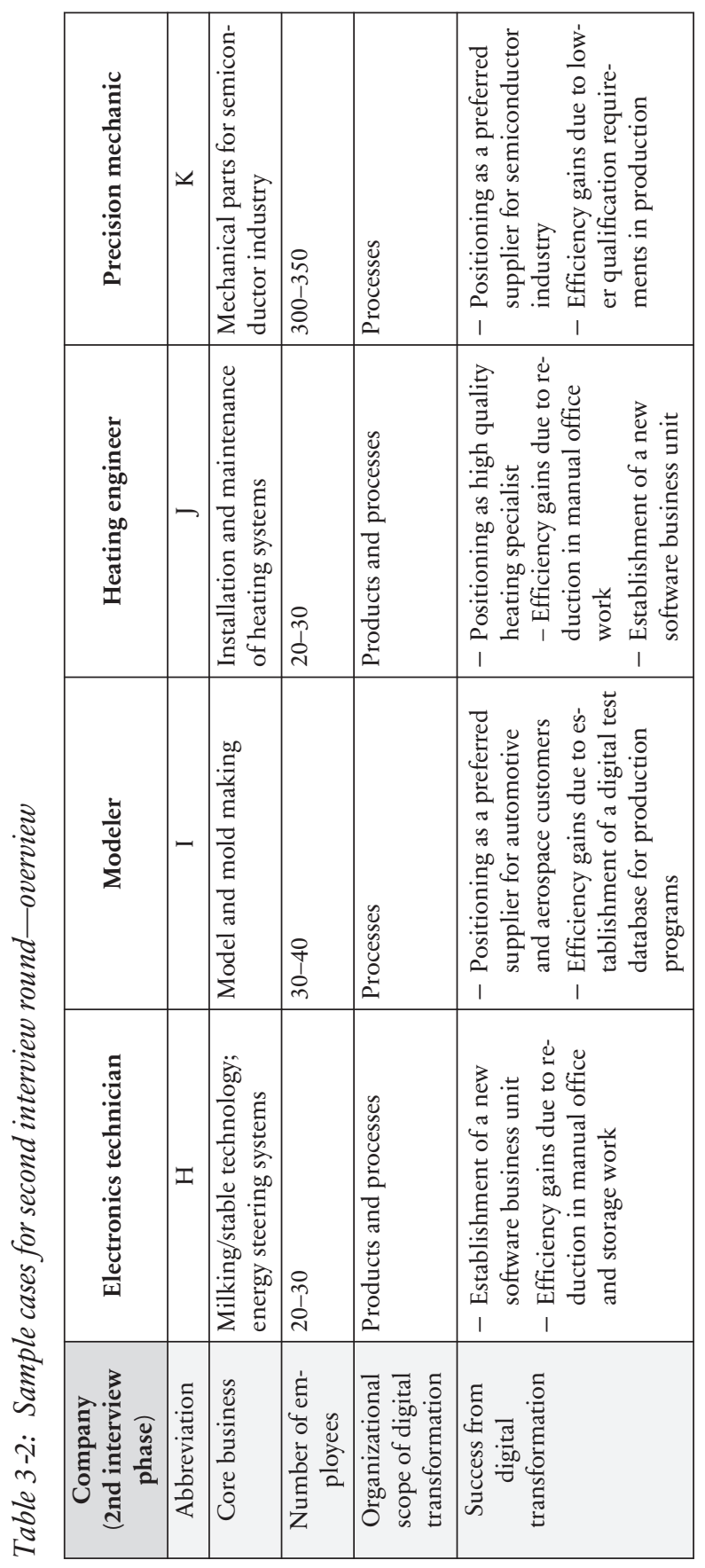


The final analysis and list of constructs are therefore based on 11 cases, which is slightly above the range of 4-10 cases recommended by Eisenhardt (1989) and Yin (2014) to ensure the quality and certainty of a qualitative study. Being located in a 100-kilometer radius around a major German city, all the SMEs share a common cultural background and cover urban as well as rural areas. As I claim generalizability across similar SME situations as provided by the cases under investigation, I applied an industry-spanning approach. All firms assessed the extensive use of digital technologies as generally beneficial across their value chains, regardless of whether the main source of value added stems from automation in production, digitally leveraged products, software products supplementing a hardware-oriented product portfolio, or the implementation of a web shop as the main sales channel. Therefore, I consider them leaders in digital transformation, being far ahead in terms of digital transformation of the current standards in their respective sectors.

By partnering with experts from the chamber of skilled crafts for $\mathrm{Mu}-$ nich and Upper Bavaria, all cases under analysis are attributable to the German skilled craft sector, a German phenomenon, most members of which can be characterized as SMEs. The German "Trade and Crafts Code" lists 98 professions that belong to the skilled craft sector. Although shielded by law, the classification of a skilled craft business is not clearly delimited, as companies characterized in this manner can provide both services and manufacturing goods (Glasl et al., 2008). As soon as a company fulfills the legal requirements to be a skilled craft business, its membership of the chambers of skilled crafts is mandatory. Almost all skilled craft firms can be considered family firms, where management and ownership lie in the same hands (Glasl, 2007). Around 1 million companies in Germany belong to the skilled craft sector, of which $55 \%$ have below five, $24 \%$ have $5-9,13 \%$ have between 10 and 19, and the remaining $8 \%$ have 20 employees or above (Statistisches Bundesamt, 2017).

I continued sampling until the new insights emerging from additional case analysis was minimal. At this point, I was not able to identify additional dimensions regarding particular aspects of MCS from an interview, the dimensions, constructs, and themes seemed well developed in terms of their properties and demonstrated variation (Fauchart \& Gruber, 2011). 


\subsubsection{Data sources}

I used my network within the chamber of skilled crafts for Munich and Upper Bavaria to identify both the seven case companies for the primary round of analysis as well as the four additional cases. Technology experts and consultants are in regular contact with a broad range of SMEs from the skilled craft sector, some attending 200 appointments with company representatives annually. Using their experience, I asked them to provide me with contact details of representatives from companies that fulfill the already mentioned criteria. I was given the opportunity to benefit from their well-developed personal relationships, as they first contacted the owner-managers via telephone or email and asked them whether they were willing to participate in the study. This approach proved to be highly successful in terms of willingness to participate as well as openness in the upcoming interview situations. There were no refusals to participate, although time management became critical because of time constraints regarding the availability of company representatives. After my introduction by experts and their consent to participate, I sent the potential interview partners an email that explained the purpose and scope of the study, asking for an interview at the company site. The resulting semi-structured, open interviews with the owners and managers of SMEs from different sectors in skilled craft businesses were the main source of valuable data. The chosen procedure involves risk prevention with regard to three potential challenges in interview situations: "lack of trust", "lack of time", and "level of entry" (Myers \& Newman, 2007).

In order to facilitate upcoming data analysis, I let a junior researcher join the interview situations whenever possible. Only two exceptions were caused by time constraints, when interviews were arranged at short notice. All interviewees were owner-managers. The primary approach to interviewing the owner-manager to gain knowledge around the digital transformation journey of a SME and its driving rationales was derived from the "focus of many family firm owners to keep control of the firm by also conducting the firm's management." (Dekker et al., 2013, p. 81-82). Nevertheless, interview situations were not closed. Whenever the owner-managers within the interview situation suggested inviting additional staff, I let, e.g., children working in the company or co-managers join. Overall, I conducted 11 interviews within the primary seven cases and one interview each in the additional four cases.

The interviews were recorded, and no participant imposed any restriction with regard to recording. At the start of each interview, I explained 
the context and targets of the project, not focusing on the given phenomenon of MCS in digital transformation, but instead asking the interviewees to elaborate on their firms' digital transformation journey, core areas of digital transformation, and their personal attitude toward technology, all in the form of an informal discussion. Whenever they explained a development step in their company, I asked them to go into the details of guiding rationales, thoughts, evaluations, convictions, opportunities, drawbacks, etc. Potential general questions were: How has your company developed throughout digital transformation? What changes occurred? Who was involved in decision making? How do you evaluate success in terms of digital transformation? Have you adapted the structures of your company? Given the broad field of investigation, these questions helped to give a necessary amount of guidance to the evolving conversation, while still allowing flexibility to explore in depth any issue raised by the interviewees.

All interviews were taped and transcribed. This led to more than 400 pages of written interview data. I triangulated the interview data obtained, according to availability, by additional information (e.g., Flick 2014; Easterby-Smith et al. 2008; Guba et al. 1981). Taking into consideration the systematic approach to triangulation of Denzin (1978), who distinguishes four different types of triangulation (data sources, investigators, theories, and methods), I applied two differential strategies: different data sources and different investigators. Potential sources of information were the firms' websites, social media entries, newspaper articles, books, gild information material, event invitations and summaries, and financial information. A conceptually comprehensive approach was hampered by the scarcity of structured information around the SMEs under investigation. Therefore, I had to confine myself to comparing interview data with publicly observable actions, which still yielded interesting insights, especially when elaborating the thick description.

\subsubsection{Methods of data analysis}

Data analysis included multiple iterations of coding. The written interview transcripts were imported into the data analysis software MAXQDA. Within a first cycle of coding, segments of data were conceptually labeled searching for evidence of control measures throughout the companies' digital transformation journeys (Saldaña, 2016). By making use of constant comparisons, I searched for appropriate classifications. This process resulted in the first version of a code book, which was a list of descriptive codes 
at the level of first order concepts (Gioia et al., 2013), including their properties. To give an example, in a data block where the interviewee explicitly or implicitly describes a company's controlling limitations to the use of technology, e.g., based on ethical concerns, this block was coded as implemented "boundaries of technology use". Cross-case analysis among the initially collected seven cases was applied to "improve the likelihood of accurate and reliable theory, that is, a theory with a close fit with the data" (Eisenhardt, 1989, p. 541).

In the second round, the concepts were then grouped into categories, a set of higher level concepts under which I grouped the lower level concepts that subsequently became subcategories. These second order categories will be referred to as themes in line with Gioia et al. (2013). To stay with the given example, I found interviewees explicitly or implicitly describing the company's core aspiration levels considering digital opportunities in business and operating models, defining "uniqueness". Together with the concept of "boundaries of technology use", I introduced the category, i.e., theme, "digital values". This was the point in the data analysis process at which I went back to the field to collect the additional four cases. A majority of patterns found in the original cases were replicable by the newly generated data, whereas new concepts also emerged from the additional cases (for a description of this replication strategy, see, e.g., Yin 2014; Miles et al. 2014, p. 103) by this systematic seeking of the full range of variation of the research object.

Using data structure figures proposed by Gioia et al. (2013), in a third round of coding, the categories found were further aggregated into core categories, i.e., aggregate dimensions. This last step led to a final set of four dimensions that seek to describe a comprehensive system of management controls, able to foster successful digital transformation in a SME context.

In order to give the context necessary to ensure a satisfying degree of transferability, junior scientists, after joining the interviews at the company sites, were asked to deliver summarizing case reports. These reports were used in two ways: The in-team discussion clarified understanding of digital transformation and supporting management control measures. Furthermore, summaries of the reports are presented as thick description in this paper, intended to support readers' understanding (Guba et al., 1981). The work of junior researchers included the coding of the data. Ambiguities and misunderstandings were eliminated using a negotiated agreement approach (Campbell et al., 2013). 


\subsection{Case descriptions}

The next paragraphs report major digital transformation developments in the four theoretically sampled cases under investigation from the second round of interviews. Special emphasis is thereby given to embedded management control measures. Taking an ex post perspective allows the treatment of explicit as well as implicit control measures and actions as equal. I label all observations toward management control, aside from the original formal or intuitive intention of the company owners.

\subsubsection{Electronics technician $(\mathrm{H})$}

The company under investigation is a founder-owned firm, about 80 kilometers outside Munich and specializing in sales, assembly, and servicing of automated machinery in dairy farming. Founded in 1992 as a single-man business, it had grown to about 30 employees at the time of this investigation. With the agriculture sector already depending heavily on digital tools, the firm specializes in sales and installation of highly digital enriched milking robots, additional electronic stable equipment, as well as automated steering software for single-farm energy consumption and production systems. The company has two branches, providing an emergency service in the case of machine failure at client sites within a few hours every day of the year. Since 1997, when milking robots became industry standard, the company has been able to deliver yearly double-digit growth in sales.

In the past 20 years, when the company first introduced computer technology for automated data processing, the owner has seen digital technologies as a normal source of efficiency increase. Various initiatives have already been implemented or tested. Inventory management and barcodebased warehouse logistics enable optimized traceability of consumption and the whereabouts of components. Current projects are dedicated to the introduction of cloud solutions, online document management, and smartphone app-based documentation of working hours. Furthermore, maintenance appointment planning is another procedural example that is already supported by automated database technology. On the product side, the company always headed for differentiation by focusing explicitly on sales, installation, and maintenance of high-tech milking robots, automated feed systems, and analytical hard- and software supply chain supervision tools. To enable fault-free operation of the installed machinery, the compa- 
ny is offering a digitally enabled remote maintenance service. Furthermore, the owner, together with technologically skilled employees, developed an energy management system for agricultural operations. It is used to manage locally produced electricity from farmers' own plants such as photovoltaic, wind, or biomass, which many farms have at their disposal. The intelligent control of electricity and its storage in batteries, ice reservoirs for milk cooling, the use for heating water to disinfect milk tanks, or for charging electric vehicles and equipment can provide considerable savings for farmers. As a result of the increasing automation on the client side, the firm was also able to constantly expand its expertise to the same extent and benefit from this development.

When considering additional technology investments, the basic motivation was mostly to scale activities with the current staff, e.g., current initiatives are targeted to speed up internal information exchange and billing, and reduce multiple manual data recording and checking of hours. Further motives for IT investments are an assurance of increased functionality and flexibility as well as higher security standards, thus preventing the internal IT infrastructure from becoming outdated. In this way, before entering a project as well as when evaluating a project's success, the owner assesses its potential benefits. Depending on the subject, financial figures are not generally calculated, but on a case-to-case basis. Decisions for investments are made exclusively by the owner, but input from employees is always actively encouraged within team meetings. The owner sees no advantage in a dedicated financial investment budget in technology, as a clear distinction between technology and non-technology investments is not possible. Projects are financed exclusively via traditional financing channels such as internal financing or bank loans. Public funds are considered unnecessary. For the issue of financial and operational risk mitigation, a spin-off including external equity financing of current software development activities is taken into consideration.

The in-house digitization projects are planned and carried out in cooperation with an IT service provider. Only the creation and maintenance of the homepage was carried out by the company itself.

As employee acceptance has appeared to be the most critical factor when striving for digitally enabled process improvements, several initiatives try to ensure staff support. Monthly employee interviews have proven their worth in clarifying problems. In addition, the provision of smartphones and laptops per employee leads to greater acceptance of the technologies and simplified cooperation workflows. Before entering a technology optimization project, feedback from employees plays a strong role in the per- 
sonal assessment of the company owner. Initiatives with a fundamental impact on work processes are tested and evaluated by internal lead users before going live, based on expected benefits such as time savings or process simplification. Even after the introduction of a new system, if it lacks acceptance by the employees in regular operation, it may well be discontinued. Taking digital warehouse optimization as an example, the initial initiative had to be abandoned after a couple of months. After 3 years, an optimized system was put back into operation including hiring a dedicated warehouse clerk, which increased employee acceptance. Another project served to digitize the assembly plans and thus to allocate the employees to the various orders for the current week. However, the system was not suitable for the high flexibility required as a result of plant failures as well as changing individual conditions on the individual construction sites. On the basis of these findings, the system was finally abolished again, showing evidence of a trial-and-error setting.

To overcome the biggest obstacle to expansion, the lack of skilled personnel, the owner offers employees the chance to get involved in programming or product development activities next to their job routine, thus leveraging their intrinsic technology skills.

\subsubsection{Modeler (I)}

The model construction company in the analysis was originally established in the 1960s. The current owner-manager took it over from his uncle at the beginning of the 1990s. At that time, all process steps were carried out by hand with only minimal mechanical support. Even during training with his uncle, today's owner recognized the potential benefits of automated manufacturing technology: for example, an efficient administration of the production programs, fast manufacturing with numerical control machines, and the manufacturing of complicated geometries. He had therefore already convinced his uncle of investments in digital technology during the handover phase.

In a first step, numerical control machines, a programming system, and digital measurement equipment were purchased and digitally networked, striving for efficiency gains from the abolition of floppy disk handling. The resulting flexibility and production speeds were well received by customers from the automotive and domestic appliances industries. From five employees at the beginning, the company has since grown to just under 50 employees today. The company still manufactures design and functional 
models, especially for the automotive and aviation industries. A special focus is on the processing of carbon fiber. As the company is regionally well recognized as an innovative leader, the owner is a member of political consultation committees at the highest level. He is a regular speaker on technology at dedicated professional meetings, which he uses on purpose for both networking as well as profiling and positioning his company.

Through its work for very attractive customers and the modern design of workspaces and production halls, including the latest technology, the company succeeds in recruiting highly qualified employees as required. Attractive technical facilities for private and business use are a matter of course.

The entire technical infrastructure, including the company's work stations, software program configuration, network systems and servers, are managed by an external provider. If employees have a technical problem, they approach the service provider independently. Here, the boss places full trust in the abilities of his employees, striving for a non-hierarchical organization where employees can approach the management without any hurdles. This implies open communication from top-down as well as bottom-up. In daily work routines, the use of digital tools such as desk sharing or advanced video-conferencing is mandatory. External partners are also integrated into the production process via technical communication interfaces.

Design and production are organized highly consistently. Employees write production programs and simultaneously book production times on the milling machines. This guarantees high quality production and optimum utilization of the technical potential of the machines regarding forward speed and dimensional scope. Digital test programs are used for production preparations to guarantee optimum feed speeds in the respective machine-material combinations. A continuous improvement process along speed and quality criteria, production and assembly times is the focus of the owner-manager's controlling. The goal is to reduce manual interventions along the production process as far as possible. Key financial figures such as sales or profit earning capacity play a minor role in planning the yearly degree of utilization, because of a planning lead time of just a few months. Nevertheless, as the owner-manager considers financials to be a result of well-structured operations, he ascribes the linkage between operations-oriented control measures and long-term business development high importance. 


\subsubsection{Heating engineer $(\mathrm{J})$}

The company was founded by the current owner and has been constantly expanded since 2004. Today, the company employs almost 30 people. In its core business, the company concentrates on the high quality installation of heating systems. The offer is supplemented by remote maintenance for both private and business customers. In order to ensure as high an efficiency as possible throughout the enterprise, the owner focused on the application of digital techniques from the start. With a background in measuring and sensor technology, the owner-manager himself considers digital opportunities to be a major future driver for his business. Based on a structured process model of his firm, the owner-manager exploits and explores new technologies by prioritizing areas according to the expected benefits, especially scalability based on existing resources and steady growth. On this path, he has already acquired two competitors in order to gain additional workforce. The focus in digital transformation is on the order processing workflow that is as technologically integrated as possible. Manual intervention at all levels, be it order creation, customer service provision, warehouse management, backoffice support and invoicing, is to be reduced. The main goals include increasing profitability, maximizing customer satisfaction, and minimal management influence in the service provision processes. Hierarchies are flat, yet there is a clear distinction between management and field staff. The owner-manager ideally does not want to get involved in the daily business, seeing himself more in a strategic leadership role. Digital transformation actions are targeted to support this role, yet he admits that his firm has not reached the estimated level.

Owing to limited financial and personnel resources, where management is solely in the hands of the owner and his wife, new digital transformation initiatives and targets are defined every year on a rolling basis. Digital transformation started with digital order management in the merchandise management system. The goal was to increase accuracy in the invoicing of service provisioning and installation, e.g., to bill consumed and assembled goods and working hours correctly. Bearing in mind those economic metrics and usability by mechanics in the field, the company developed a digital management cockpit together with other owners in similar situations. This system combines a customer relationship management system with a real-time order tracking functionality. After several development steps, involving regular research and development circles including subsidized research funding, this system has emerged to a full-scale field management software. The owner has real-time overview of pending orders and can op- 
timally allocate his employees. Financial key performance indicators such as sales and projected profits are available on a running basis, including a comparison year-on-year. Operation- and quality-focused performance indicators can also be extracted from the system, allowing the setting of standards and enabling steady company growth. The field staff have tablet computers at hand, supporting a predefined workflow and allowing automated data exchange with the office staff via web applications, email, and photos. External partners are partially integrated, and selected suppliers are bound by customized interfaces. Final, full-scale integration with the warehouse management for automatic invoicing is already planned, making the paperless company a vision, which is about to become reality within a few years. As a side effect, the field management system is nowadays distributed to other companies via a separate legal unit.

The owner-manager sees the impact that digital transformation has among the staff as a selection process. Employees who acknowledge the support of their work by digital tools are motivated, attracted, and bound to the company; employees who dislike the enclosed full transparency of their daily schedule leave the firm willingly. This offers every single employee the chance to steer his schedule according to what he considers to be the most economical use of his resources, leveraging overall perceived working quality and results.

External IT service providers are engaged in various positions. Data are hosted on cloud servers to allow plug-and-play integration in the case of hardware outages. Freelancers supported the development and implementation of the field management software. Customers can contact the company and place inquiries via a user-friendly website, with the design being optimized based on user experience. In addition, the company is present on a manufacturer-owned online transaction platform.

The company finances its digital transformation activities based on cash flows, bank loans, and selected government subsidy funding. Still, financial controlling objects such as sales, costs and savings, and profit are subordinate to operational measures, targeting process and structural improvements.

Trial and error as a control measure is not mobilized systematically. When evaluating the usability of the field management system, the ownermanager tested some alternative configurations. When implementing the system throughout his own firm, a limited transition period allowed the employees to get used to the system and to customize features. Still, trial and error as a distinct measure is limited to product development. 


\subsubsection{Precision mechanic $(\mathrm{K})$}

The company was founded by the current owner family about 40 years ago. Started as a two-person business, it employs more than 300 people today. The two sons of the founding couple are members of management. The company specializes in high-precision parts for the semiconductor industry. Most recently, it launched a self-developed, highly specialized 3D printer to cover an additional business segment.

Owing to early cooperation with large industrial companies and the resulting competition, the firm was encouraged to stay at the edge of production technology from the start. From punch cards to initial machine networking to central data storage to complete networking of production preparation and production, the company has gone along with every technological step. Recently, the company has been testing the use of robots that, in cooperation with employees, can further increase the speed of the production process. The main challenge along this digital transformation path has been to keep all interfaces in line; some projects were delayed by years because of lack of interface permeability, data consistency, and data quality. Most interfaces must be customized, combining data on products to manufacturing technologies. The production process is monitored digitally in real time. This means that data on incoming orders, order status, machine operating status, and customer inquiries is recorded, monitored, and optimized by the company management at any time.

Automated interfaces connect the company to its main customers, who send orders directly to the order management system. Data are then exchanged reciprocally, and actual data from produced workpieces are returned for further usage to the customers. Similarly, the company itself is interconnected to its core partners, e.g., tool suppliers. If any problem occurs, digital communication tools such as desk sharing are mobilized.

The company has a high demand for qualified manpower. In order to win the war for talent, the company opens up production facilities for society and conducts targeted public relations, e.g., in the local press or at schools, in order to recruit employees. The digital transformation journey has further increased the attraction, as young talented people as well as experienced skilled workers or lateral entrants are on recent recruitment lists. All employees are asked to share ideas on technological improvements openly, with either their supervisors or the management team.

As the largest company in the analysis, the company is structured hierarchically on account of its size. The current structure has been established in recent years to ensure manageability. Overall responsibility for digital 
topics lies with top management, but the department manager level also has objectives for digitization. Employees can make suggestions to their managers at any time, which are then passed on to the company management in aggregated form. Specially designated employees are responsible for the technical performance of selected machines ("machine godfathers"), and they also perform other operational functions throughout the production process. In order to be able to produce continuously, the machines are equipped with an automated emergency call system that sends an error message to employees during shift breaks when the machine is at a standstill. Employees can communicate interest if they wish to fill key digital positions.

When evaluating digital transformation activities, the management focuses on quantitative and qualitative operational objects first, e.g., throughput times, production speed, energy savings, and product quality. Expected sales, costs, and cash investments at a project level are brought in in relationship to these figures in the case of major process-influencing investments to measure the estimated impact. If only single production steps are involved, the company experiments with new technologies without any further consideration in order to increase efficiency by evaluating their impact on workers and their interplay with machines. Trial and error does not play a structured role in the company's management control efforts.

\subsection{Results: Components of a digital transformation control system}

The companies under investigation show great variance in management control measure use throughout digital transformation. The following section reveals four control dimensions, their essential specifications, and characteristic expressions that mark a digital transformation control system. Figure 3-1 provides an overview of the four dimensions: cultural controls, planning, administrative controls, and performance-indicator-based control objects. Selected examples from the case companies highlight the findings that are based on explicitly implemented control measures as well as implicitly or subjectively used controls that owner-managers in the companies consider. All measures are summarized in overview presentations in the appendix of essay II, i.e. appendix 3-1-3-4. 


\begin{tabular}{|c|c|c|c|c|c|c|}
\hline \multicolumn{7}{|c|}{ Cultural Controls } \\
\hline \multicolumn{2}{|c|}{ Digital Values } & \multicolumn{3}{|c|}{ Digital Symbols } & \multicolumn{2}{|c|}{ Digital Personnel } \\
\hline Planning & \multicolumn{6}{|c|}{ Administrative controls } \\
\hline $\begin{array}{l}\text { Digital risk } \\
\text { management }\end{array}$ & \multicolumn{2}{|c|}{$\begin{array}{l}\text { Digital controlling } \\
\text { procedures }\end{array}$} & $\begin{array}{c}\text { Communication } \\
\text { policy }\end{array}$ & \multicolumn{2}{|c|}{$\begin{array}{l}\text { Organization } \\
\text { structure }\end{array}$} & $\begin{array}{l}\text { Governance } \\
\text { structure }\end{array}$ \\
\hline \multicolumn{7}{|c|}{ Performance-indicator-based control objects } \\
\hline \multicolumn{2}{|c|}{ Financial objects of control } & \multicolumn{3}{|c|}{ Operational objects of control } & \multicolumn{2}{|c|}{ Web-based objects of control } \\
\hline
\end{tabular}

Figure 3-1: MCS package similar to Malmi \& Brown, 2008, adapted for digital transformation.

The general control categories evolving from the data are summarized, adapting the MCS as a package framework of Malmi \& Brown, 2008. The findings are subject to one general curtailment: aspects of strategic planning were excluded from the analysis. For dimensions and planning options when developing a digital transformation strategy, see, e.g., Hess et al., 2016.

\subsubsection{Cultural controls}

All cases under analysis are driven by a culture encouraging innovation and technological curiosity. Without this, a digital transformation-leading position in the sector is not attainable. This culture is manifested in three observable patterns: digital values, digital symbols, and digital personnel.

Digital values: Company owners are aware of strategic as well as operational opportunities provided by technology exploitation and exploration. In order to benefit, they need to allocate scarce financial and personal resources to their adoption. Digital values are thus basic principles that guide digital transformation-explicitly by core values that are formulated and internally or externally revealed, or implicitly formed by guiding thoughts that owner-managers apply when evaluating digital potentials. They take two basic forms: The value (1) "uniqueness" describes owners', i.e., companies', core aspiration levels when considering digital opportunities regarding value-creating activities such as client services, service levels, products, or processes. As one interviewee stated, "We are highworkers - we are not engaged in crafts, we are engaged in highcrafts." This mission is spread around employees as well as customers. In contrast, the value (2) "boundaries of technology usage" sets limitations on the use of technology, e.g., 
based on ethical concerns. "When machines start to interact with humans, boundaries have to be clear. That is not a funny issue." is an example statement from the data that describe this aspect.

Digital symbols: Besides being explicitly mentioned by the company owners, the values are transported by digital symbols. I was able to identify three potential areas played by company owners to signal the high emphasis they place on technology usage. One is a ubiquitous (1) "public presence" of technology related topics, where the company is present on websites, in newspaper articles, or social media channels, always fostering high technological standards. This can also mean offering inside views of the company production facilities, e.g., by "open doors days". Interviewees stated, "An attractive and convenient website, showing our abilities, is elementary today." or "We are open to the public, give interested people insights to our plants, and use social media for attracting talent." Another form of symbol is (2) "signaling hard- and software", where the high standards of technological equipment within the company and among the workforce are purposefully used to impress employees, customers, or the interested public. "We need to show our clients the highest technological standards, so they take us seriously." And "all work stations are equipped with high-level, design computers, signaling progress." are examples that mark this category. Another form of digital symbol is (3) "elementary publications", i.e., published technology-specific books and brochures, where, e.g., the company owner reveals his deep knowledge of technology topics from his field to the public. This category remains less often used among the companies under analysis. I found one interviewee stating, "I have written down my findings in a book, triggering debates with practitioners and academic staff." Another one: "Printing elaborate brochures on highvalue paper is a considerable investment, but it is worth it."

Digital personnel: A last category of digital controls I find in the data is the availability of sufficient digital personnel, which can be observed in two ways. On the one hand, this means the (1) "attraction of talent", where the companies prove their ability to attract digital talent at the individually necessary scale. The use of this aspect as a control measure is indicated by the following statement "Employees today want to work in a digitally enriched environment, it means a lot to them." Digital talent thus refers not only to the technical skill level, but also a value aspect: "Today we attract talent that values transparency provided by the usage of digital tools." Besides, I also consider a (2) "technologically knowledgeable leader" as a control measure itself. It is common among the case companies that all ownermanagers show a high personal level of ambition around technological ad- 
vancements. Being aware of their central role in leadership, they consider this fact necessary to create a successful digital transformation journey. All of them give statements such as: "Most things I could do myself, I have acquired the necessary knowledge." or "I read a lot, about business and technology. I have the personal ambition to understand everything."

\subsubsection{Planning}

Within planning as an ex ante form of control, a company sets goals to direct employee behavior and provides standards to be achieved (Flamholtz, Das, \& Tsui, 1985; Malmi \& Brown, 2008). As I have mentioned before, strategic planning issues were excluded from the analysis in order to reduce complexity in this research project, and as the issue is subject to other scholarly examination. Therefore, my analysis finds one central category that is subject to extensive planning efforts in the cases under analysis, the management of risks arising from technology adoption.

Digital risk management: Despite overweighing potential benefits that company owners ascribe to extensive technology usage, they are aware of incorporated risks. Two areas of concern are targeted by control measures among the cases under analysis, the first one being (1) "data theft prevention". Owner-managers, being aware of their leading and exposed positions, fear losing knowledge of products and processes to competitors or value chain partners. This not only incorporates proprietorial intellectual property, but also knowledge of customers, who place their trust in the reliability of the case companies. Therefore, they take extensive efforts to minimize threats from data theft. Example statements: "We carefully consider which data we give to partners outside the company." and "We have to be in line with highest security standards - that is an essential prerequisite by our clients." A second area of concern is (2) "digital disaster recovery planning", where companies introduce measures to ensure persistence in the case of major hardware, software, or network outages. This can be triggered by customer requirements, e.g., when "Clients expect to know what happens when a fallout occurs? This is an evolving task that needs to be updated regularly.", but can also be critical based on company-intrinsic considerations, when data and the availability of networks are critical to ensure sustainable functioning of processes. "Cloud data in general is safer than data on company owned servers. Therefore, we can be sure that critical data can't get lost." 


\subsubsection{Administrative controls}

The case companies use a range of measures that are explicitly focused on controlling the process of value creation. Administrative control measures summarize procedures, policies, and structural interventions occurring in the course of a digital transformation endeavor to ensure manageability, i.e., creation and distribution of information and knowledge, responsibilities, and accountabilities.

Digital controlling procedures: I find five dedicated procedural methods in use in digital transformation that are mobilized to extract key performance indicators (see next chapter), thereby allowing managers to gain explicit knowledge on the expected benefits and drawbacks of decisions and actions. This knowledge includes quantitative monetary information (sales, investments, costs, profit earning capacity, etc.), other quantifiable information (e.g., timelines), and more qualitative information (complexity, acceptance, etc.). (1) "Life cycle planning" targets to schedule machine and software investments and reinvestments along with technological improvement opportunities, enabling companies to streamline opportunities arising from technological improvements with imperatives along with the assurance of technological reliability throughout machinery and software landscapes. Company owners state: "We always evaluate future reliability when evaluating technology investments." and "All replacement investments are driven by technological improvements." Another measure in use is (2) "classical budget/actual comparison" of business-related figures, although the difference occurs when management cockpit tool and instrument usage allows real-time calculations. One participant in the study made clear: "I use our management cockpit twice or three times a day to see our current situation and headroom for optimization." Further procedures include (3) "scenario analysis in make-or-buy situations" to compare the value from internal vs. external provision of knowledge and resources toward technology, and (4) "target costing", i.e., to evaluate product prices according to customers' willingness to pay. While the first is used commonly among the cases ("With regard to products and services, we always evaluate whether it might be advantageous to rely on external providers."), the latter is only applied by two cases under analysis.

Guiding the overall interest of the study, cases under analysis make regular use of (5) "trial-and-error" circles. This means that they enable experimental settings, incorporating external (customer) and/or internal (employee) user experience. Potential foci target the product offering, e.g., innovative combinations of material and $3 \mathrm{D}$ printing technology to develop 
a new product offering in company $\mathrm{B}$, as well as the enrichment of workflows with digital tools, e.g., an optimized allocation of employee resources to assignments in company $\mathrm{H}$ or the introduction of robots to selected production lines in company K. Interviewees state: "In case of really new products, that never existed, experiments are absolutely necessary." "Robots were really new for us. We are carefully analyzing the benefits, trying different process alternatives, before we rollout on a larger scale." Nonetheless, none of the cases under analysis relies on experimental methods as a sole alternative to more conservative procedures, already known in past decades when digital methods were not omnipresent. As one interviewee clarifies: "In a case where no relevant financial investment is necessary, we just introduce a service and see how customers react." Other cases agree on this view, not only regarding services, but also including tools and product development activities. For "trial-and-error" to become a valid extension of the management control spectrum, it needs situations with an ex ante capsulated scope, limited initial financial investments, some relevant capabilities among the existing staff or existing core partnerships, and vision by the owner-manager to guide efforts. It is not a sense-making tool, randomly applicable independently from an individual company's situation.

Communication policy: The way in which information streams are directed and supported is crucial and a target of extensive consideration among the case companies. I identify four political principles regarding communication. Most company owners agree on the importance of regular (1) "bottom-up communication", actively fostering upward feedback regarding acceptance, benefits, and potential areas of improvement relating to the use of technologies. This can lead to an overall absence of hierarchies, where all employees including the owner-manager communicate face to face, to a simple encouragement to share ideas openly: "It is important to ask the employees: 'How do you like it?' - They have the best knowledge." This bottom-up communication often happens in informal daily business situations, but is also the core driver of regular, formalized (2) "technology dedicated meetings". Their institutionalization is ascribed high importance to create official platforms for exchanging innovative ideas, including giving rationales that drive management decisions and explicating individual employees' value-adding ideas throughout the digital transformation journey. To give examples from the interviews: "For us, communication is extremely important. Meetings among the leadership team as well as involving every single employee take place every week.", "Technology issues are collected throughout the entire company and discussed at least once a month 
among the whole team." Further political considerations also include the (3) "usage of digital tools", "externally" to communicate with partners (suppliers, customers) and (4) internally, using platforms for communication and knowledge sharing. External tools include video conference calls or desk sharing, so that "co-working across the value chain becomes normality" and "connections via team viewer in discussions with suppliers make it possible to solve problems instantaneously." Internally, one case company uses an intra-organizational social media-like platform to share knowledge, documents, and client information. A more common internal digital communication lever is sophisticated, customized data pools, e.g., to simulate production processes across departments, or to document order fulfillments to offer a more accurate client service and at the same time speed up the billing process.

Organization structure: The organizational structure needs to enable necessary flexibility to allow for adoptions outside the established business processes to support successful transformation activities. This entails enabling the inclusion of necessary skill sets, accounting for additional employees in IT-related positions, and enabling the management of critical interfaces along the value chain. I find four organizational measures supporting management control in digital transformation. Within (1) "digital lead user groups", some case companies ring-fence limited numbers of employees from the rest of the organization, giving them the objective to get used to and prove the benefits of new technologies. After a few weeks or months, these employees get back to their normal organizational environments, become promoters of the technology, and thereby enable it to spread around the rest of the employees, infecting the whole company. One interviewee stated: "When introducing a new tool, I pick a group of employees, let them try it, and ask for feedback before a company-wide rollout, incorporating investments on a larger scale." Whereas these groups can potentially be found in all parts of the organization, there is a focus on (2) "digital sales capacity" targets to ensure that especially sales resources understand digital channels and digitally enriched products. To speak in the words of interviewees: "Offering highly innovative products requires dedicated sales efforts - clients have to be convinced by a professional." and "If somebody orders a table online, she demands supreme online service as well. Availability on all channels is a must." Besides sales, (3) "headcount in IT positions" is affected in the course of a digital transformation journey, as soon as a company does not rely solely on outsourcing IT-related positions. To account for adaptations in IT-related headcount, three cases consider reassignments and new hires. "Investing in technology itself is 
not enough; often I need to hire staff that can handle the technology." Most cases see (4) "critical interface management" as a key organizational challenge. The optimal design of organizational interfaces along changed workflows, e.g., between production preparation, production, sales, is considered an imperative, regardless of whether the measure is used consciously to increase process efficiencies ("Throughout our workflow from design to production, people need to know technological requirements and limitations.") or unconsciously to achieve other business objectives such as excellent customer service ("As clients place their order directly in our ERP, our process design must take care of this.").

Governance structure: Whereas organizational aspects focus on process organization, governance measures are targeted to ensure that enterprise structures reflect the challenges of technology adoption. This includes managerial controlling activities that come along with the increasing influence of IT in general, external providers, and the growing number of employees who see technology not as "something new", but rather as something "natural". I find three governance measures that the cases under analysis introduced to account for technology adoption. Most evident is (1) "technological authorization management", where company management delegates executive activity and decision making regarding the use of technologies to knowledgeable specialists among the firm's staff. In general, the case companies consider action in this respect important to account for a rising degree of required special knowledge. Owner-managers admit that technology adoption and management increase the amount of top management decisions to be made at a technically detailed level, causing perceived overload. An example quote: "At some point, it becomes too much complexity for myself. I needed a professional who takes over responsibility." On the contrary, innovative workflow systems enable shifting routine activities from office and management to the field, yielding headroom for corporate development activities at top management level and perceived value added with non-managing employees. "We have given more responsibility to the employees in the field. Procurement, service documentation, etc. So there was a whole host of changes, which, I think, have led to a little bit of everyone coming back to a certain level." Another form of explicit governance control measure is (2) "technology contractor management". Company owner-managers assign the management of IT contractors fully or partially to operative employees without a formal management role. As most cases under analysis make use of outsourcing regarding vital IT functions, their connection to the management and accompanying responsibilities must be clarified. An interviewee sums it up: "An external profession- 
al is supervising our IT. He is almost part of the management." Besides the reduction in problems arising in principal-agent situations in general, the main rationale throughout digital transformation is to leverage dynamic reactions in the case of vital IT application outages that makes the partial delegation of power from owner management to employees useful, if not necessary. "It does not make any sense for me to control everything. I trust my people. If one has a technical problem, he himself calls the contractor." A last, yet only structurally used in two of the cases, measure, is (3) "preference-based job tasking". Owner-managers let employees enjoy a high degree of freedom toward individual exploration of technology. As the case companies experience how young employees naturally show a great interest in digital technologies and bring along capabilities in IT applications outside their normal job routines, they seek to benefit from windfall profits regarding the qualifications of their employees. These benefits can lead to an increase in motivation: "Every employee wants to be the first to work with the new machine. They wait for it, so I can assign the one who is most energized. This is highly motivating." Furthermore, it helps to deepen the roots employees have within their employing firm, diminishing the risk of individual boredom and resulting enticement: "Those young employees are really deep into IT. If I can offer them the necessary degree of freedom for personal development, the firm stays attractive for them."

\subsubsection{Performance indicator-based control objects}

The companies under analysis calculate a number of indicators in order to assess the potential advantages and disadvantages of digitization measures. I find evidence for three different areas that are illuminated by quantitative performance indicators in the course of digital transformation. Next to financial and operational objects of control, web-related aspects especially are explored numerically. The numbers obtained from the calculations form a central junction within the digital transformation control design. On the one hand, they are mobilized by some of the aforementioned types of control, e.g. procedures such as real-time budget/actual comparisons. On the other hand, they intend to operationalize, measure, and visualize most of the other types of control, enabling a cybernetic function of target setting, evaluation, and modification.

Financial objects of control: Financial considerations play a superior role in SMEs when it comes to planning digitization activities. All the cases under analysis mention the great importance of financial indicators, not only 
when evaluating technology investments, but throughout all investment decisions. Therefore, financial observation points in the control of digital transformation do not differ from general, basic financial indicators, yet the owner-managers mentioned eight measures explicitly in the interview situations. With regard to (1) "charge out rates", owner-managers focus on necessary adjustments caused by digital improvements, which may offer the opportunity to realize higher margins or to gain competitive advantages from lower prices. Case H: "Technology eases access to day, night, and holiday surcharges to calculate charge out rates more precisely." Changes arising in labor expenses due to adaptations regarding skill and job requirements emphasize the importance of (2) "labor costs" as a financial control object. Case G: "Technology professionals demand salaries way above what we are used to paying." New customer habits regarding communication and an arising shift in sales toward digital channels lead to the necessity of recalibrating (3) "marketing expenses", taking into account digital channels such as websites, social media, and platforms in contrast to and combination with traditional offline channels such as newspaper ads or mailings. Case A: "We were able to decrease our marketing expenses by $80 \%$ due to a shift from offline to online marketing." (4) "Total IT investments" and (5) "running IT costs" are both financial categories under direct influence over the course of adapting digital technology, making them self-evident objects of management control. Case I: "Of course we calculate the necessary investment. It's a vicious circle. Once you play along in the high-end sector, customer expectations trigger an investment spiral." By adding the expected influence of technological improvements in the business and operating model on (6) "sales", the firms' owner-managers evaluate the (7) "profit earning capacity", i.e., the overall financial benefits associated with technology investments. Case D: "Turnover is a very convincing figure to calculate the benefits of technology investments - not on a single-investment perspective, but strategically." Case J: "Profit earning capacity is an important aspect, not in the short run, but longterm." When it comes to funding digital transformation endeavors, the SMEs under analysis are actively screening the market for, e.g., scientific government subsidy programs granted for technology investments, making (8) "subsidy funding quota" another object of financial control. Case G: "Government and scientific subsidies are necessary, without them nothing would happen."

Operational objects of control: All owner-managers agree that, in considering and evaluating technological improvements, processes play a major role. Operational aspects relate to the process elements that are critical to 
the speed of value creation and the speed at which companies can realize the benefits from technology usage. I find four operational control objects. Technology improvements alongside necessary process alternations can require several months until they reveal their potential positive effects. Companies under analysis take into account transition periods for systems to work, and for organization and staff to get used to technology usage, controlling (1) "adaptation time". Considerations include an adaptation period of staff to technology usage, new workflows including data handling, and software selection times, whereby the evaluation of the future viability of software providers is crucial in the decision on a software provider. Focusing on their staff and the importance qualified personnel play at a strategic and operational level, selected cases ascribe (2) "employee motivation" a special importance, thereby emphasizing employees' positive associations with routine use of technology. Case D: "I see the expenses associated with a tool, and I can relate it to acceptance by the staff, they like it, and I see it is no longer dispensable." Case K: "There are always people who do not feel comfortable with change in workflows. They need to see the benefits to be in, e.g., increased production speed." All cases agree on the importance of (3) "processing time" and control essential influence factors in the value creation process. Examples include failure rates, interface complexity-measured by the frequency of manual entries of the same data alongside the value creation process-shipping times, production and assembly time per object/order, and the time span between the provision of a service or product provision and the related invoicing. Finally, cases take into account (4) "scalability of current activities", thereby judging the ability to increase scale in current activities based on technological improvements by calculating the degree of utilization of machines and employees before and after technology investments. This last control object is related in the examples to a bottleneck perspective in the value creation process. Actively considering flexibility in personnel deployment reveals headroom where existing human capacity can be allocated more efficiently based on technology-oriented job infusion. Case $\mathrm{H}$ reveals: "Our website and social media integration were developed by an employee, who is a tech fanatic." Cases E and G, on the contrary, focused on their machinery to scale their operations, as they evaluated the potential benefits from including robots in production lines, taking into account that production machines did not operate at capacity limits.

Web-based objects of control: The online channel as an addition to traditional offline sales channels incorporates an imperative such as a website, accompanied by additional tools such as social media platforms, and web 
shops. Along come opportunities to evaluate the success factors of each channel, to communicate with customers, and to build or even lose reputation. Some cases under analysis make extensive use of web-based controlling. I distinguish four different objects of control. The most common is (1) "search engine positioning", where cases watch and steer their placement in relevant search engines. They admit: Case A: "Of course we look on web ranking and play around with search engine optimization and marketing." Case H: "It is important that we are found by clients. We are very active in this direction." Furthermore, cases constantly control their (2) "web recessions and valuations" by screening and interacting on online commentaries, judgments, ratings, or reviews. Case D: "If a potential customer nowadays is interested in a company, he/she reads recessions." Case I: "Also business clients look online for valuations and experiences from peers. The search engine ranking in that case is not too important." When the website is considered a central element in the sales process, cases control (3) "website convenience", where they scrutinize customers' and partners' experiences when entering the company website and relate improvements to user experience. Case A: "We regularly get feedback from customers that their attention was caught by our website; they appreciate structure and information density." Case I: "Especially for new clients, the website is extremely important. They not only appreciate the final product, but also our technical equipment." The interplay between website and social media is targeted by selected cases via (4) "web journeys". They measure discoverability and click journeys by defined target groups via digital channels to customize the overarching online experience, apart from the website, to user preferences. Case H: "On Facebook, it is very easy to see which information was considered valuable, e.g., via likes." Case I: "Applicants, but also young engineers from existing and potential customers, appreciate the sort of information and pictures they get via social media channels."

\subsection{Discussion}

This paper identifies four categories of a digital transformation control system by revealing the variance of indicators that were applied by SMEs that successfully transformed either their business and/or their operating models based on technology adoption. The driving thoughts of SME proprietors and managers who are leaders in digital transformation are condensed into a package of controls, applying a case-based research design. 
By setting my results into the context of the existing literature on MCS as a package, I aim to elaborate on how the specific context of digital transformation can be operationalized in a comprehensive control framework. This study reveals categories and concepts of controls suitable for application in digital transformation. The categories evolving from the data show fit to the "MCS as a package" framework of Malmi \& Brown, 2008, where different types of management controls are systemized to a package for further empirical research. This indicates the encompassed exhaustiveness of different types of management control measures supporting successful digital transformation. Covering cultural, planning, administrative, and performance indicator-based controls fostering successful digital transformation, a broad theoretical understanding of management controls is provided by reference to Malmi \& Brown, 2008, which supports the high degree of generalizability of their MCS framework (see also: Strauß \& Zecher, 2013). Potential influence factors such as societal context and types of rationality are left out (Broadbent \& Laughlin, 2009).

Adopting the Malmi and Brown, 2008, "MCS as a package" view allows me to show the wide variety of measures and at the same time neutrally attribute the same level of impact to all categories in order to discuss the specifics of digital transformation control as opposed to general aspects of management control. In contrast to Merchant \& Van der Stede, 2012, I do not find evidence for a strict command and control process, where management control measures are only used to execute a predetermined strategy without an influence of MCS on the development process of strategic initiatives. I find both evidence that SME managers act deliberately and monitor a strategic initiative based on defined measures, and also evaluate indicators subjectively or consider measurements implicitly, thereby re-adjusting their strategy. This observation positions my results in line with Simons, 1995, who sees an influence of MCS on strategy as MCS "serve as 'levers' for implementing business strategy and achieving profit goals" (see: Strauß \& Zecher, 2013, p. 247). Compared with both Merchant and Van der Stede's 2012 results, actions and personnel/culture as objects of control, as well as Simons', 1995, belief, boundary, diagnostic control, and interactive control systems, my findings serve to detail applicable measures in the context of digital transformation, e.g., by including trial-and-error as a controlling procedure or by introducing web-based key performance indicators. Yet, in contrast, both concepts enclose informal control mechanisms such as values and beliefs only if they are written down and thereby become formalized. This narrow point of view would exclude observations from my data based on interpretation, which gives my results higher ex- 
planatory power in the context of SMEs, where MCS appear to be less formalized and sophisticated (Quinn, 2011).

Cultural controls are revealed in three forms. Digital values seek to motivate uniqueness by use of technologies and incorporate boundaries of technology use, e.g., based on ethical concerns. Digital symbols are dedicated signs that signal to the general public, especially the interested public, and internally the priority that management assigns to technology. Both value categories operationalize well-established accounting concepts. Simons, 1995, describes values as belief systems to direct organizations, as is the case in the companies under analysis. Symbols, on the other hand, are visible expressions of innovativeness and modernity, and thereby influence employees' behavior (Schein, 2016). As a third cultural control category, I identified digital personnel to be a control measure highly valued by SME owner-managers. My study corroborates that of Malmi \& Brown, 2008, by including Merchant \& Van der Stede's 2012 selection of talent capable of technology usage as a cultural control measure. This categorization is based on some company owners' assessment that digital transformation at least partially involves a paradigm shift in corporate culture toward more transparency and agility. Furthermore, regarding personnel, SME ownermanagers act with a high degree of self-reflection on their personal level of knowledge of technologies, being aware of themselves as a key resource driving digital transformation. This control perspective so far has not been tackled by existing management control frameworks, making the assessment of technological knowledge of management candidates an interesting field for further examination.

As stated before, planning controls were excluded from the research scope, as they are discussed in prior research on digital transformation strategies in great depth (see, e.g., Hess et al. (2016); Matt et al. (2015)). Still, I find at least some evidence among the cases under analysis in this study that the application of control measures always incorporates a portion of planning, both on 12-month action planning as well as at a longterm strategic level (Malmi \& Brown, 2008). Planning toward digitalization thereby occurs on a rather informal, subjective, and estimative level than in an extensive goal setting and standard development sense (Flamholtz et al., 1985), which drives me to the conclusion that a dedicated planning process does not take place as part of the digital transformation itself, but is integrated into the regular corporate planning process. Exceptions to this are considerations relating to the management of risks arising from the ongoing digitalization process. Here, some cases show a structured and detailed framework with clear, action-oriented standards to- 
ward data theft and digital disaster recovery planning. Furthermore, I do not find any evidence that reward and compensation measures (see, e.g., Bonner \& Sprinkle, 2002) are adopted by SMEs in digital transformation, either emphasizing individual use of digital technologies or regarding digital transformation of the overall organization.

I generally find the three groups of administrative controls of Malmi \& Brown, 2008. Digital controlling procedures cover institutionalized processes and standard behaviors used to direct SMEs' digital transformation efforts. Yet my findings are limited to the use of standardized management procedures for decision making (Malmi \& Brown, 2008; Simons, 1987). The characterization as procedures thereby is primarily based on the classification of my findings based on formalized, well-established financial accounting procedures. Not surprisingly, considering the size and structure of the cases under analysis, I do not find measures to be regarded as policies in the context of digital transformation. I regard trial-and-error circles as a digital controlling procedure, referencing what Merchant $\&$ Van der Stede 2012 call action controls. Focused trial-and-error circles represent a behavioral constraint, incorporating pre-action reviews and action accountability. As the cases under analysis reveal, they are one measure among a set of other formal procedures, primarily used in new product and new service development, or when reworking processes significantly, i.e., not just replacing process steps, but redesigning workflows, and when financial risk is limited and not affecting a company's existence. Once these conditions are met, business owners address the usefulness of experimental settings, but do not attribute them the power of a fundamental paradigm shift in management. No business owner will see anything fundamentally new in this.

The organization structure is adapted significantly throughout the SME digital transformation endeavors under analysis. In particular, digital lead user groups, digital distribution capacities, and critical interface management are organizational innovations that have been introduced to promote business transformation. This finding supports Malmi \& Brown, 2008, in ascribing the organization structure a control function instead of a contextual variable. Similarly, focusing the formal lines of authority and accountability (Abernethy \& Chua, 1996), the governance structure is impacted by digital transformation. Management team responsibility was excluded from analysis in this project, yet we focused on operational control activities explicitly targeting digital transformation activities. Preference-based job tasking, technological authorization management, and technology contractor management appear to be new concepts in MCS designs. 
I introduce "communication policy" as a new administrative control dimension, based on the importance that SME owner-managers ascribe to this aspect of digital transformation. Prior management control research mentioning rules, procedures, policies, operating manuals, next to job descriptions and other operational prescriptions used to be rather unspecific regarding the specific context and area of application (Macintosh \& Daft, 1987; Simons, 1987). The setup of information flow and information infrastructure is considered elementary for success in dealing with technology by the cases under analysis in this study. Bottom-up communication, digital tool usage when communicating internally as well as with partners or customers, and technology dedicated meetings therefore represent control measures able to deliver a high degree of value added in digital transformation.

As a last group of controls, I identify performance indicator-based control objects. This dimension of MCS is related to cybernetic controls (Malmi \& Brown, 2008). Green and Welsh, 1988, characterize cybernetic controls by five criteria. They enable quantification of an underlying phenomenon, activity or system, set standards of performance or targets to be met, comprise a feedback process that enables comparison of an outcome with the target, include an analysis of the variance arising from the feedback, and last allow modifications of the system's behavior or underlying activities. To enable this role, quantitative performance indicators are in use. As I am executing this research under the paradigm of interpretation, which allows me to include implicit actions undertaken by the empirical units of analysis, it occurs that not all performance indicators arising from this analysis are motivated in a purely cybernetic way. Sometimes, they lack, e.g., consistent standard or target setting and yet are only used as a source of information rather than as a formal control object. Similarly, other controls do not comprise a structured feedback process as well as variance analysis, but are only evaluated irregularly and on purpose. This leads me to denote them as performance indicator-based instead of cybernetic. Among performance indicator-based controls, a set of financial objects of control play the most prominent role that leads to calculating the impact of technology investments at the business and operating model level on profit earning capacity, thereby showing no great variance from classical financial measurement systems. A novel finding of my study is the consideration of a subsidy funding quota around digitalization in four of the eleven cases under analysis. This aspect so far is only covered by management control literature on farming (Ndemewah, Menges, \& Hiebl, 2019), leaving headroom for further investigation in future research. Non-financial measurement 
systems can be differentiated in a more general category around operational objects of control, and more specific web-based objects of control. Operational objects of control cover the influence of technology adoption on internal business processes, e.g., time to select and adapt hard- and software and to get staff onboard, to realize benefits from increased employee motivation as well as from time-oriented process optimization. These controlling objects are related to the internal business, i.e., process dimension within balanced scorecard models (Ittner \& Larcker, 1998; R.S. Kaplan \& Norton, 1992). I therefore do not consider them as being novel concepts, but an operationalization and update of a well-established classical instrument of control.

As a new group of controls, I introduce web-related objects of control into MCS design, i.e., search engine positioning, the evaluation and management of web recessions, website convenience, and web journeys of customers. This special accentuation is based on the relative importance assigned by the cases under analysis to a sophisticated management of their web footprint for their success in winning new customers, triggering interest by business partners, and overall increasing sales. The integration of web traffic-related performance measures, e.g., focusing on website usability or customer traffic flows, is already discussed in academia (e.g., Karagozoglu \& Lindell, 2004; Sterne, 2002). The high degree of diligence that owner-managers of SMEs put into this category of controls justifies great attention in the design of a digital transformation control system.

\subsection{Contribution, Limitations, and Conclusion}

This paper outlines options for designing a MCS capable of promoting successful digital transformation in SMEs. Case studies of successful companies in terms of digital transformation provide the necessary context to place the results in operational reality. In this way, I contribute to the detailing of the existing literature on MCS. The theoretical contribution is an empirically founded basis on which the components of MCS and their interrelations can be analyzed further. Also, from this starting point, the value added nature of MCS with regard to success categories in SMEs, not only in digital transformation, but also in a general business context, can be investigated in greater detail. As a practical contribution, this work provides companies and their management with a structured framework of control measures so that success in digital transformation is not a happenstance, but the effect of a deliberate approach. 
One could argue that this paper is just giving a list of arbitrary options instead of introducing a comprehensive, logically derived, and connected framework. My research strives for applicability in all companies entering digital transformation endeavors, independent of their current level of professionalization. Therefore, I do not develop a comprehensive digitally balanced scorecard approach (see, e.g., in a family business context: J. Craig \& Moores, 2005) in order not to wag the dog with the tail. My aim is to offer a framework of potential control mechanisms suitable for digital transformation efforts, independent of the original state of MCS. A link to the balanced scorecard concept would limit the results to cases that have already reached at least a minimum level of management control practice. Nevertheless, the incorporation of digital perspectives into the balanced scorecard concept would be an interesting path for further research.

As is common in qualitative research, the results obtained do not lay claim to be generalizable at an empirical level. Instead, the evidence presented from outstanding examples of digital transformation in SMEs was used to develop a range of arguments as to how MCS can be designed in order to foster successful implementation of digital technologies as well as execute digital transformation strategies. The focus on a clearly defined segment of the German economy and the incorporated collaboration with technology experts from the chamber of skilled crafts provided excellent access to the field and enabled a purposeful sampling approach at all stages of the project. Based on this analysis of successful examples of SMEs passing a digital transformation endeavor, I claim transferability and usefulness to the situation of most SMEs striving for a structured approach to tackle the challenge to stay competitive in the current digitalization environment. Still, this study is essentially based on the statements made by the owner-managers of the SMEs surveyed, who highlight the subject of control in the form of both explicit measures and implicit actions. Triangulation to confirm interview statements, e.g., with reference to cultural control objects, was possible, but as the internal decision-making area of the company was affected, many statements could not be assessed from a neutral or external point of view. Future scientific projects could, for example, take up the topic in the form of action research over longer periods of time in order to ascertain a connection between control measures and digitization success. Furthermore, the results of this study can also serve as a basis for large-scale descriptive studies in order to learn more about the dissemination and application of control measures in the course of digital transformations. As the progress of digital technologies across sectors may vary, as will the resulting necessity for companies to transform business 
and operating models, the usefulness of certain measures of control to support digital transformation is most likely to vary as well. Industry specifics are therefore another promising field of study.

Whether a company needs to introduce a dedicated digital transformation control system, or whether it needs to adapt already existing formal and informal control measures to incorporate viewpoints with essential importance in digital transformation cannot be decided from this study, which might be another interesting angle for further research. Yet, the cases under analysis in this study highlight the importance of structure and control in companies striving to benefit from digital technologies. Trialand-error is thus nothing companies with an established and approved level of formality in their control systems have to be afraid of. It is an essential measure when developing new product and service offerings and establishing digitally enriched processes, but does not represent a complete paradigm shift in management control. 


\subsection{Appendix essay II}

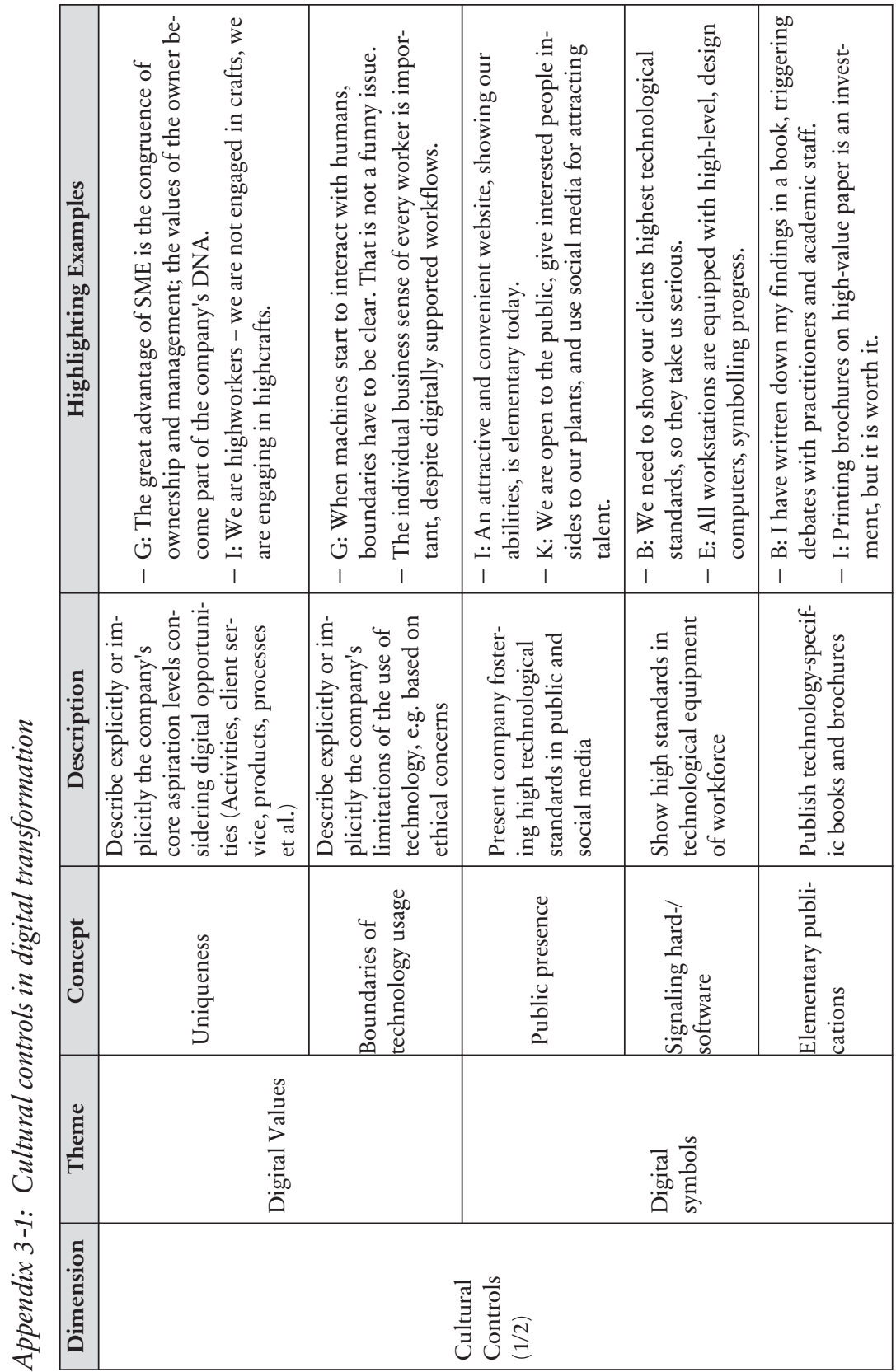




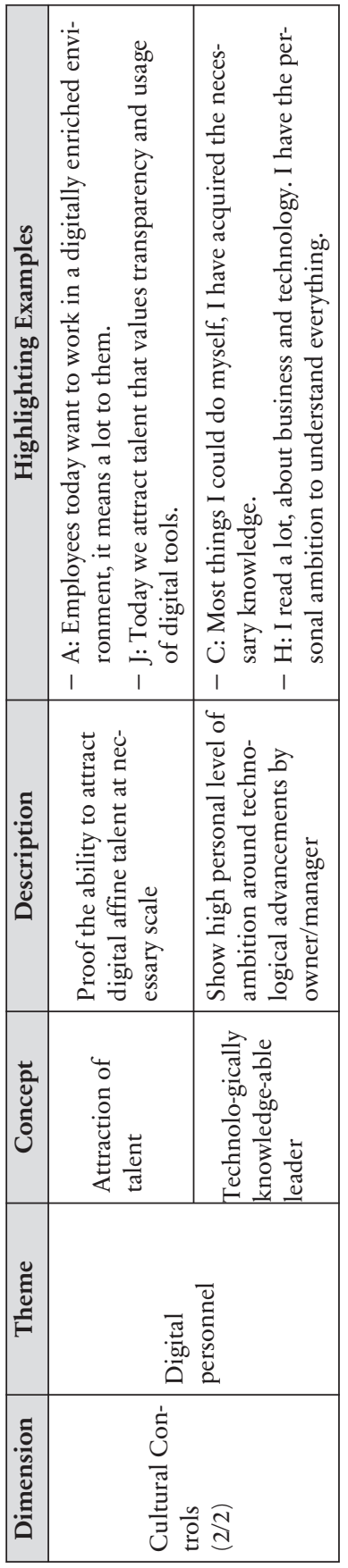




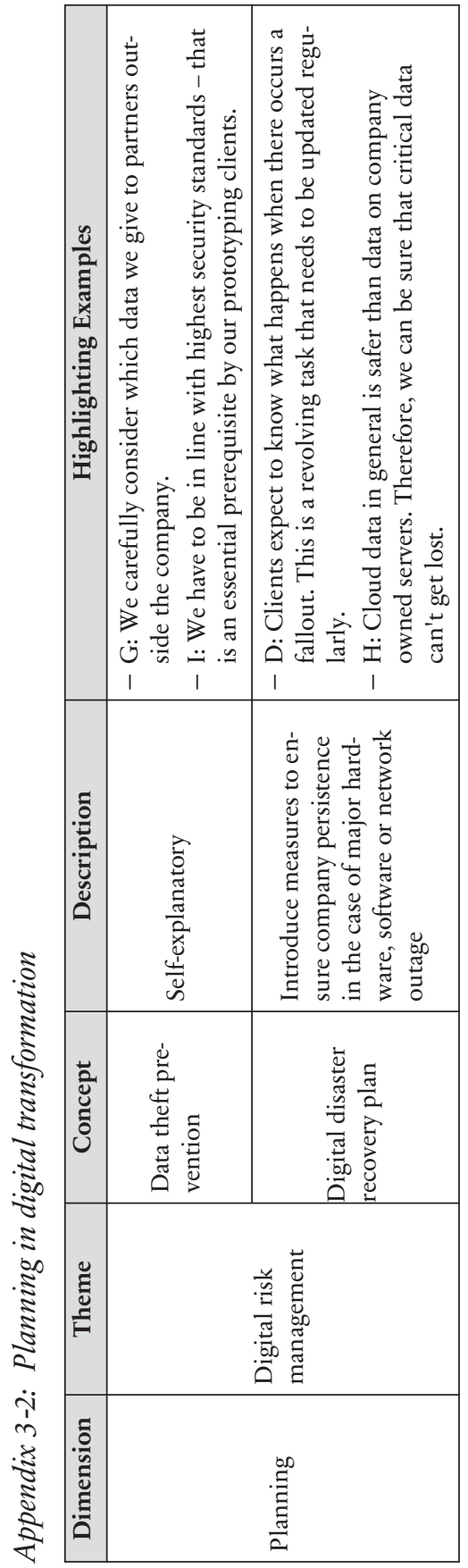




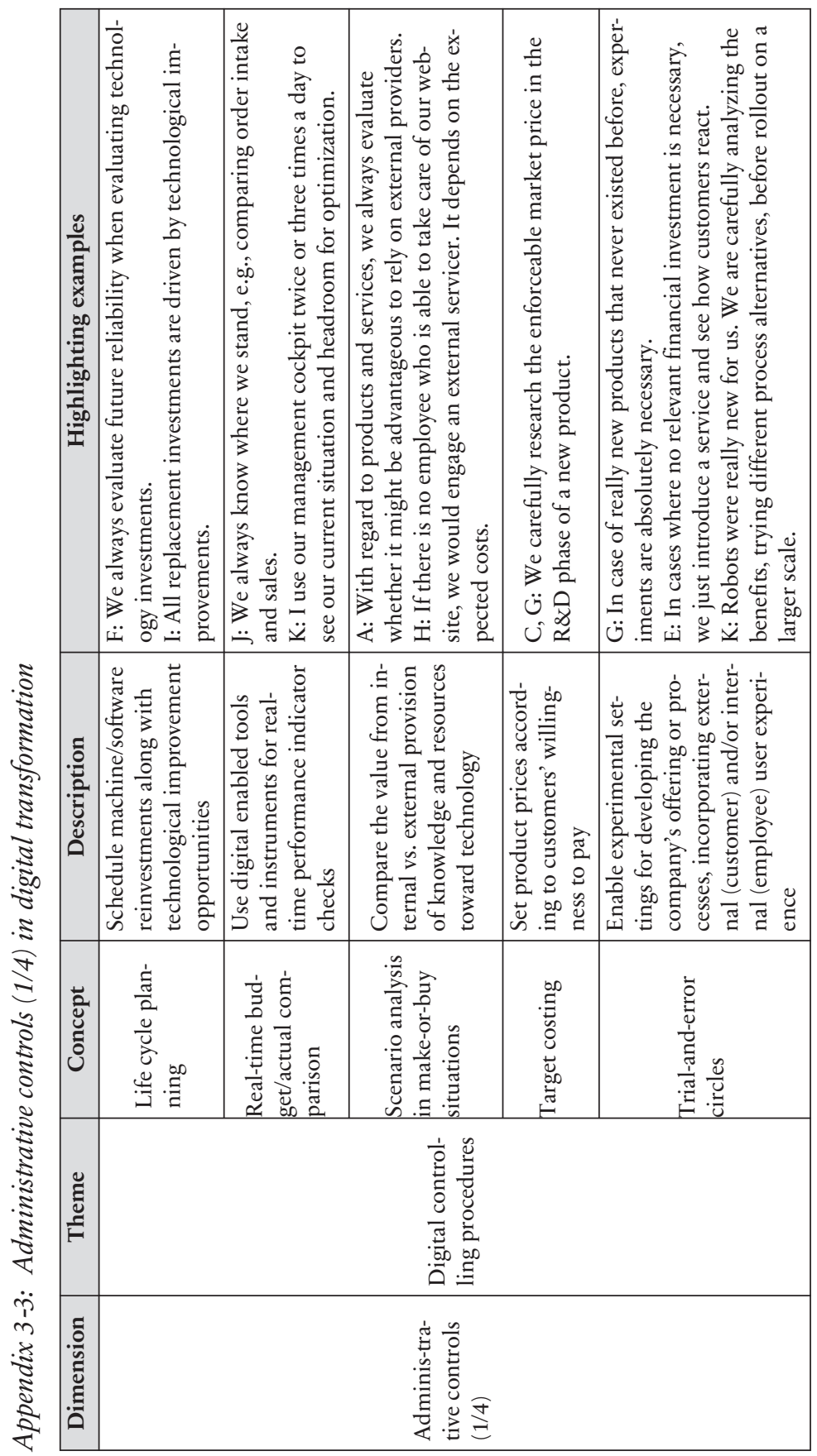




\begin{tabular}{|c|c|c|c|c|}
\hline 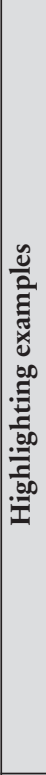 & 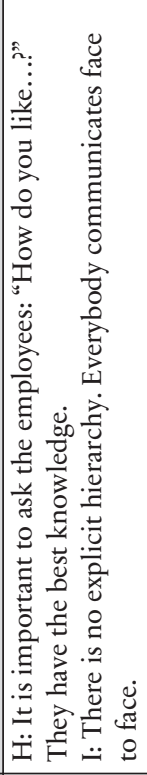 & 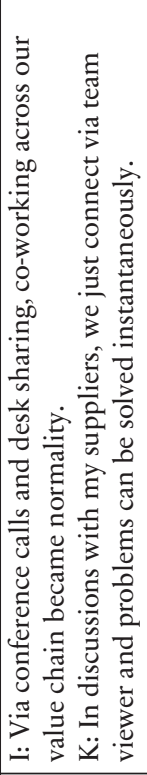 & 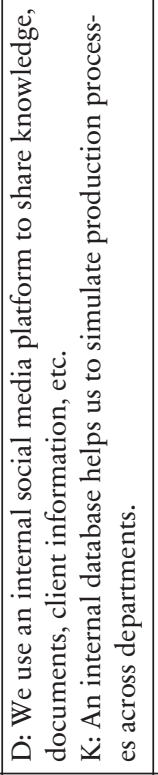 & 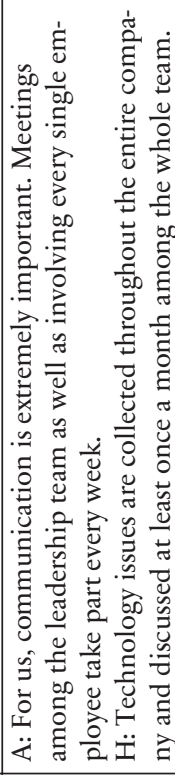 \\
\hline . & 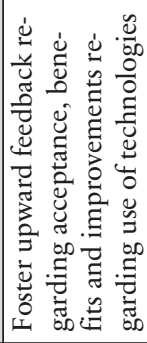 & 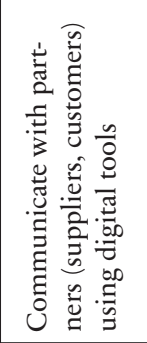 & 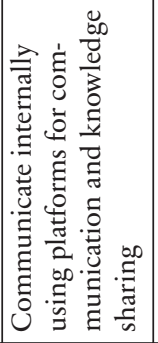 & 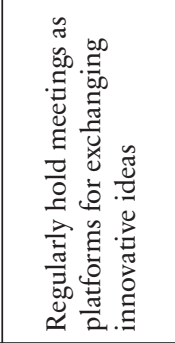 \\
\hline 节 & 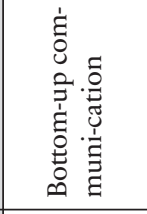 & 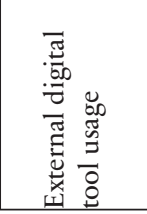 & 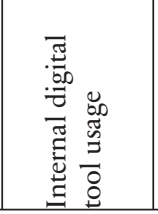 & 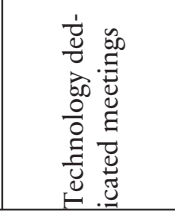 \\
\hline 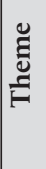 & \multicolumn{4}{|c|}{ 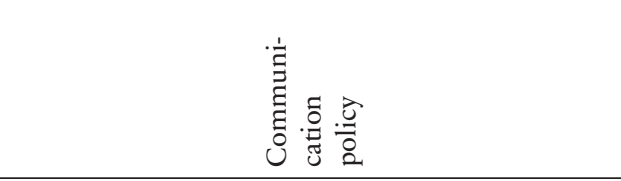 } \\
\hline 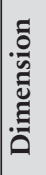 & \multicolumn{4}{|c|}{ 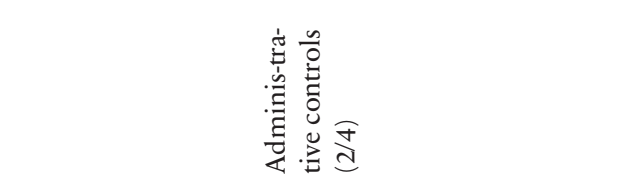 } \\
\hline
\end{tabular}




\begin{tabular}{|c|c|c|c|c|}
\hline 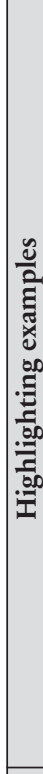 & 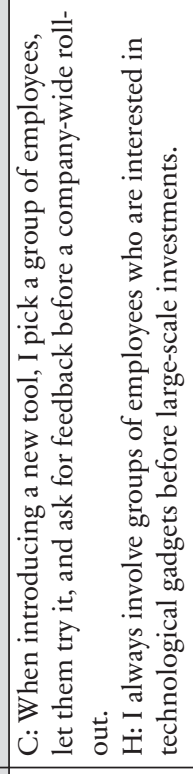 & 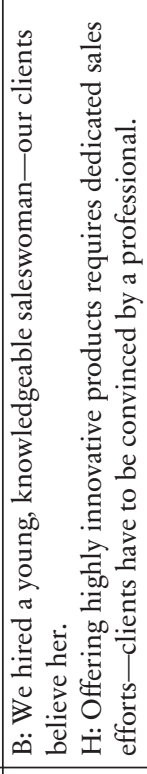 & 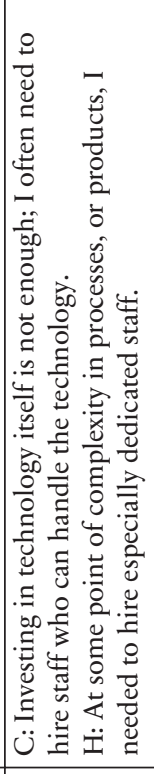 & 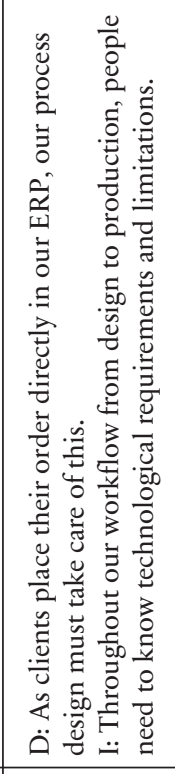 \\
\hline ڤ్ & 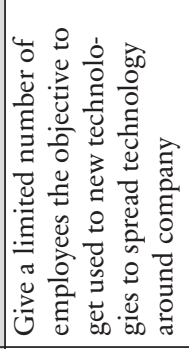 & 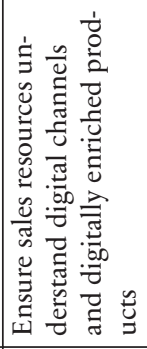 & 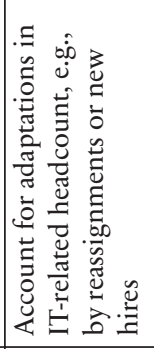 & 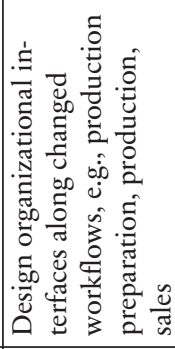 \\
\hline נֶ & 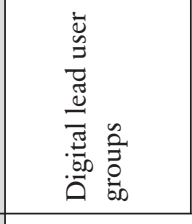 & 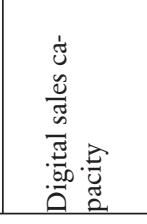 & 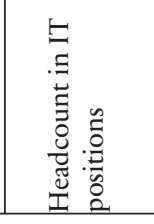 & 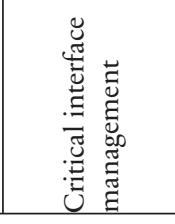 \\
\hline 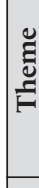 & \multicolumn{4}{|c|}{ 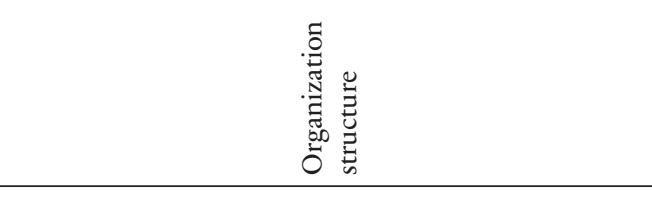 } \\
\hline & \multicolumn{4}{|c|}{ 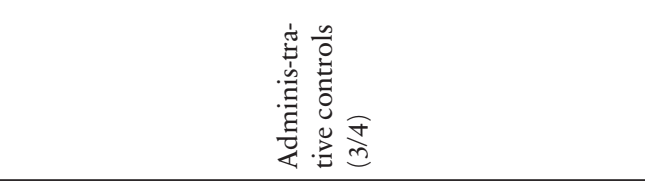 } \\
\hline
\end{tabular}




\begin{tabular}{|c|c|c|c|}
\hline 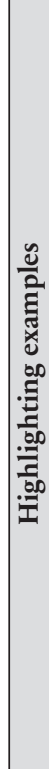 & 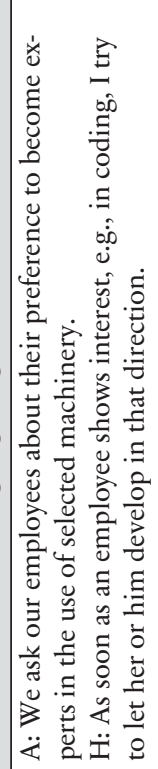 & 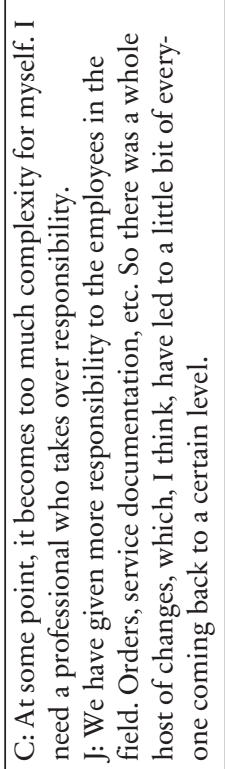 & 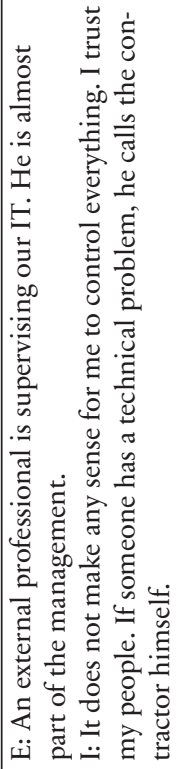 \\
\hline مَّ & 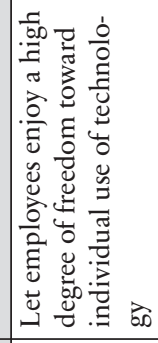 & 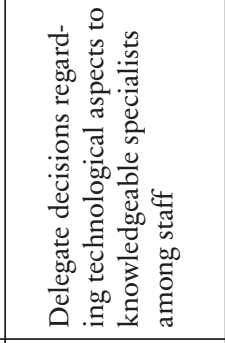 & 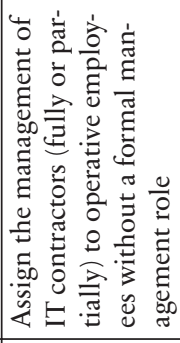 \\
\hline $\begin{array}{l}\text { चे } \\
\tilde{\Xi} \\
0\end{array}$ & 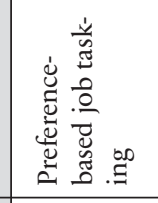 & 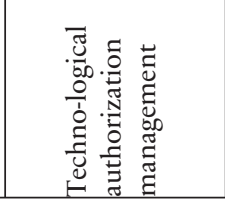 & 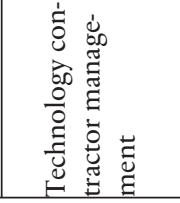 \\
\hline $\begin{array}{l}\stackrel{\Xi}{\Xi} \\
\text { Е }\end{array}$ & & 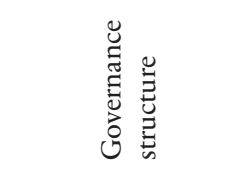 & \\
\hline 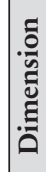 & & 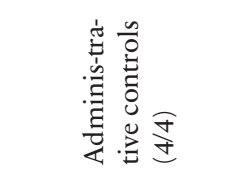 & \\
\hline
\end{tabular}




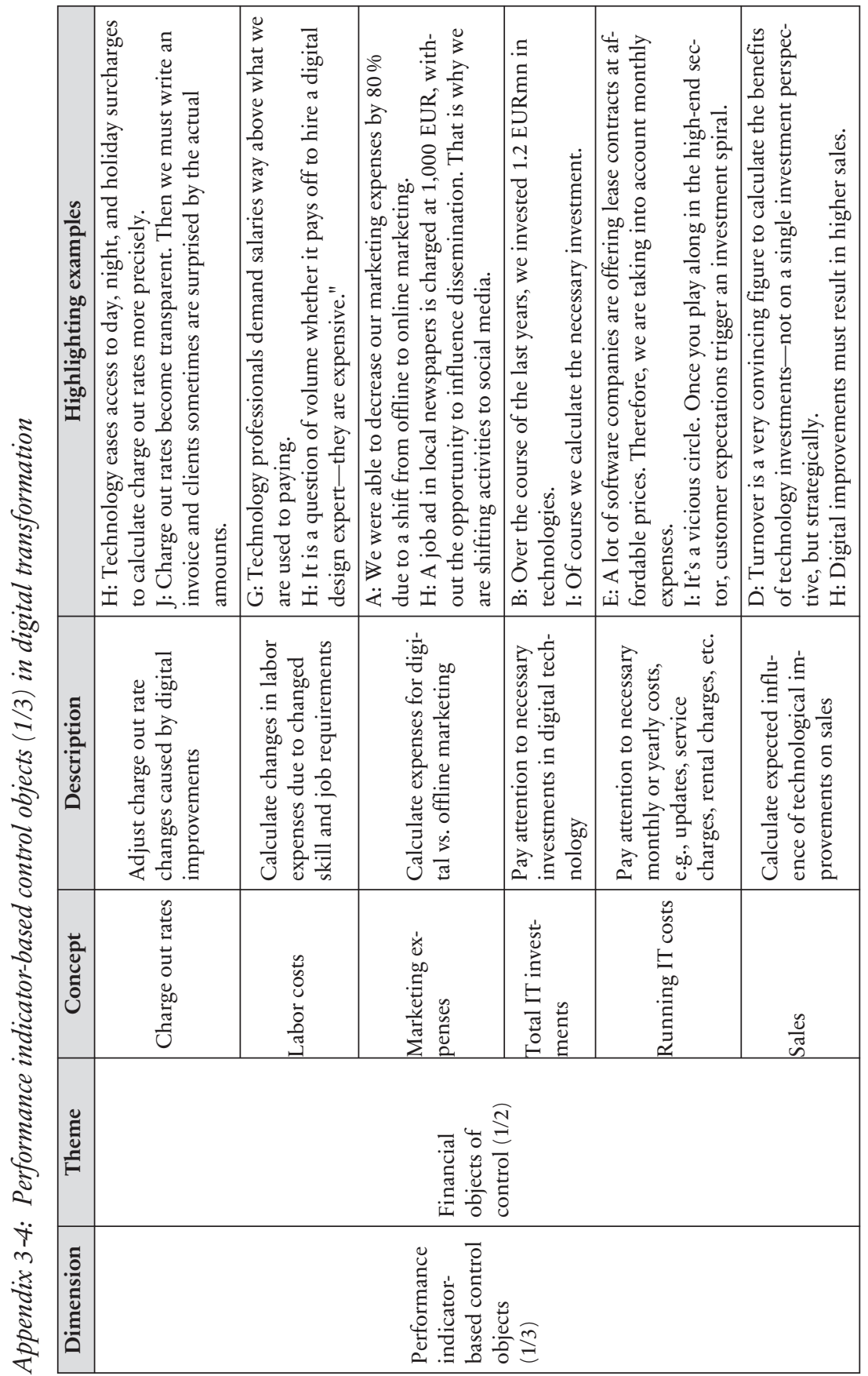




\begin{tabular}{|c|c|c|c|c|c|}
\hline$\hat{\vartheta}$ & 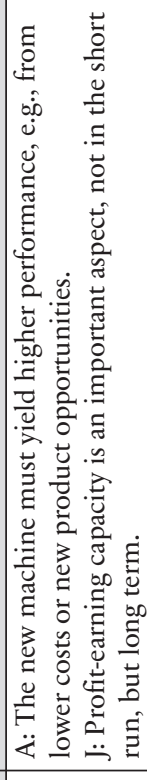 & 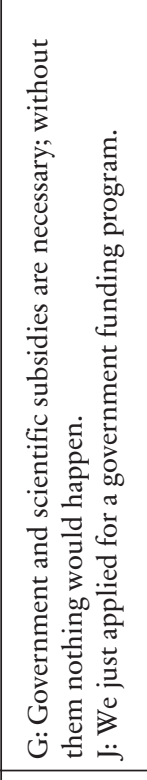 & 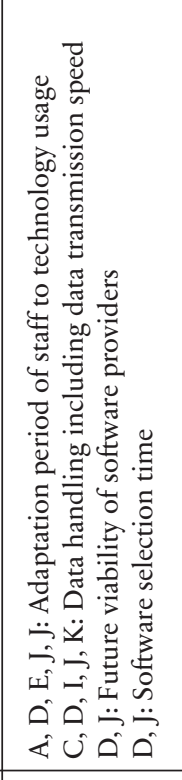 & 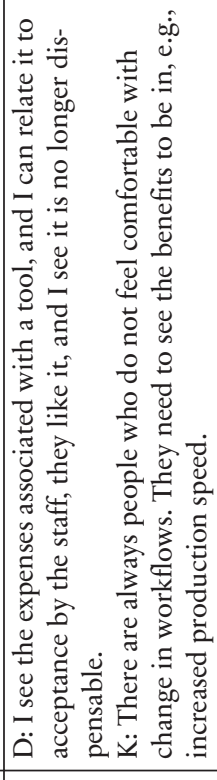 & 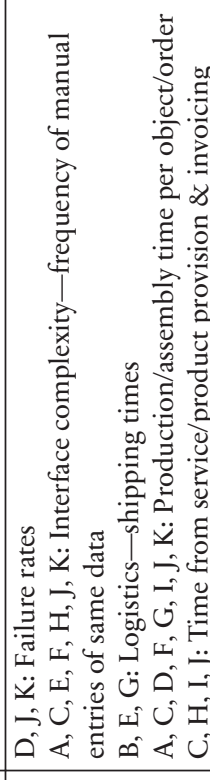 \\
\hline مَ & 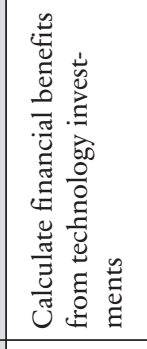 & 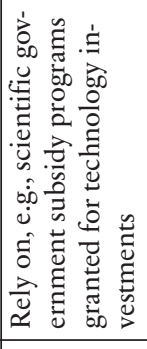 & 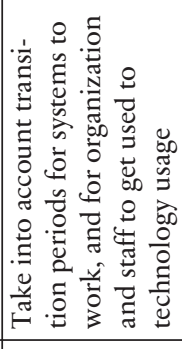 & 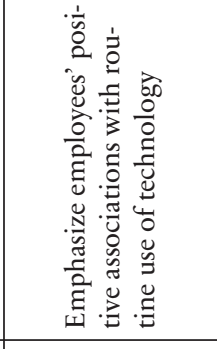 & 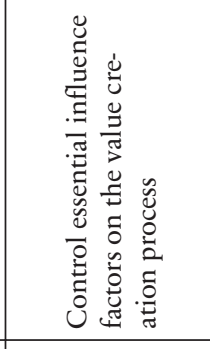 \\
\hline נֶ & 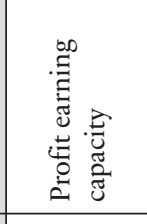 & 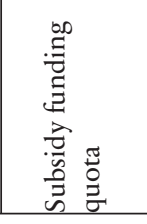 & 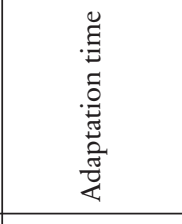 & 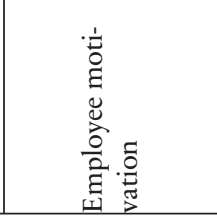 & 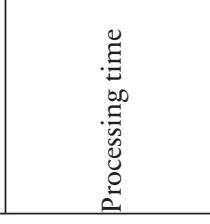 \\
\hline Ё & \multicolumn{2}{|c|}{ 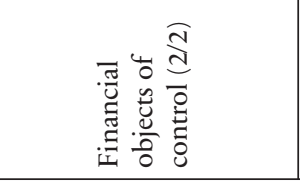 } & \multicolumn{3}{|c|}{ 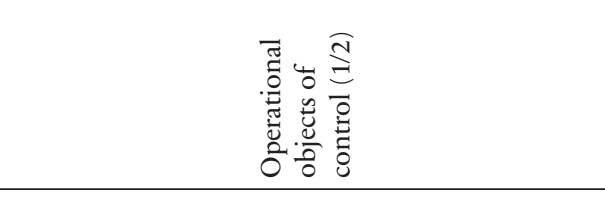 } \\
\hline & \multicolumn{5}{|c|}{ 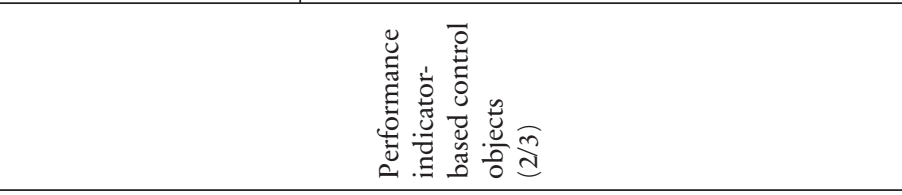 } \\
\hline
\end{tabular}




\begin{tabular}{|c|c|c|c|c|c|}
\hline 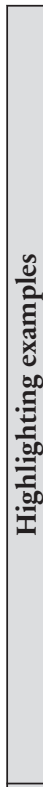 & 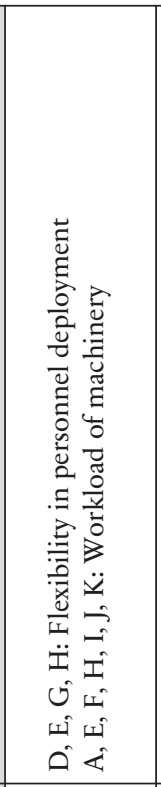 & 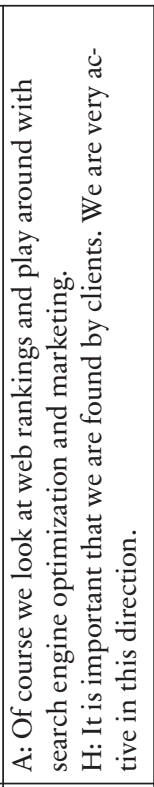 & 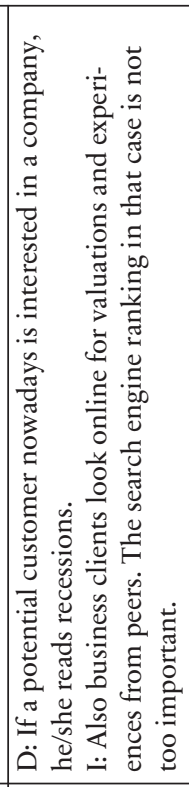 & 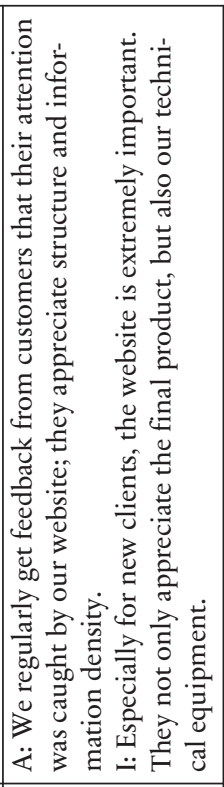 & 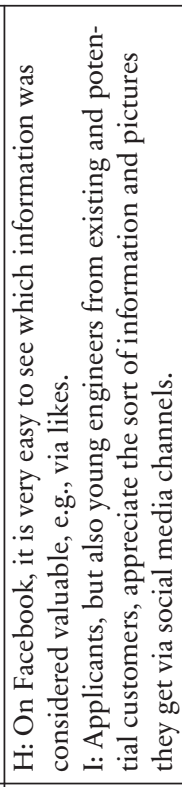 \\
\hline مَّ & 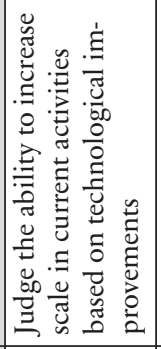 & 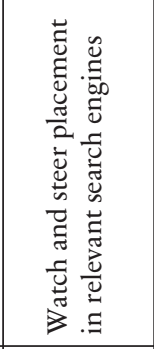 & 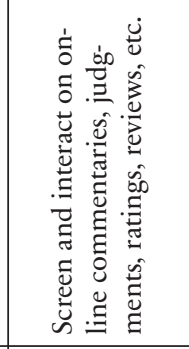 & 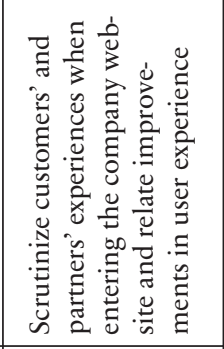 & 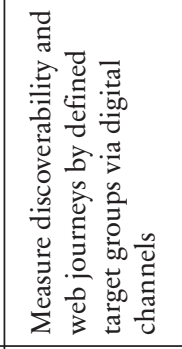 \\
\hline 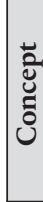 & 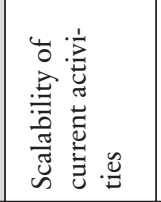 & 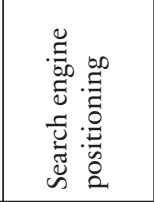 & 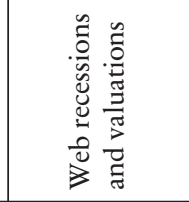 & 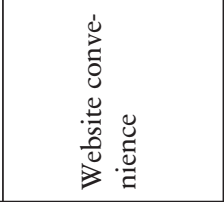 & 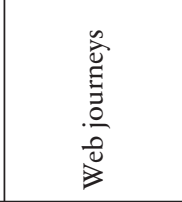 \\
\hline Еँ & 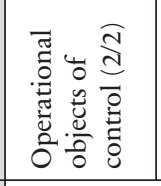 & \multicolumn{4}{|c|}{ 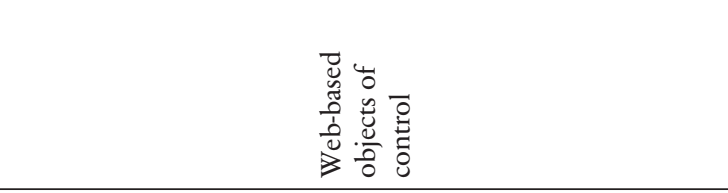 } \\
\hline & & & 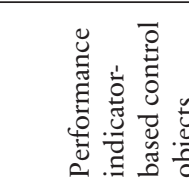 & & \\
\hline
\end{tabular}




\title{
4 Essay III: Guidance in the network jungle-a typology of inter-company innovation networks
}

\author{
Johannes Trenkle \\ Technical University of Munich \\ TUM School of Management \\ j.trenkle@tum.de \\ Carl-Philipp Beichert \\ Technical University of Munich \\ TUM School of Management \\ c.beichert@tum.de
}

\begin{abstract}
III
Inter-organizational networks are recognized as a collaborative means of enabling small and medium-sized enterprises to compete and innovate in a dynamic environment. Previous studies have analyzed network types and their characteristics, yet there is no empirically grounded network typology combining and integrating these lone-standing attributes from either an academic or a practitioner-oriented point of view. By applying an explorative, sequential, mixed methodology approach, we ${ }^{11}$ provide the first typology of innovation networks based on both previous theories and newly generated empirical data. We conduct a directed content analysis to compile a comprehensive data set and apply a hierarchical, agglomerative clustering approach using the Ward linking method. We contribute to existing academic network research by providing the first compelling, generic typology of inter-organizational innovation networks and thereby offer guidance to practitioners and policy makers in the jungle of word creations around innovation networks. We identify and describe 11 types of formal inter-organizational innovation networks: Avid Persuaders, Value Chain Drivers, Collective Facilitators, Niche Specialists, Lateral Thinkers, Transnational Opportunity Seekers, Financially Resilient Connectors, Local Trend Sponsors, Regional Activists, Associated Industry Supporters, and Dynamic Research Groups.

Keywords: inter-organizational networks; innovation networks; SME; cluster analysis

Status: Working paper
\end{abstract}

11 Essay III is based on a joint research project by Carl-Philipp Beichert and myself. I refer to both of us when using 'we' in the context of essay III. A description of the contributions of each author is given in Appendix 4-2. 


\subsection{Introduction}

Digitalization and fast-paced company environments are increasing the competitive pressure on companies (BMWi, 2018). In order to succeed, companies aim to include collaborative activities in their innovation strategies, thereby executing a change in paradigms as companies and organizations transform their innovation processes from privately conducted research to collaborative behavior, from closed to open innovation (Chesbrough, 2003). Within this change, engagement in innovation networks increases, which plays a crucial role in innovation strategies for almost all kinds of companies. The firms seek collaboration through networks to overcome limited resources as well as to share risks incorporated in research and development (R\&D) activities (Sydow, 2001).

Networks are of particular relevance to small and medium-sized enterprises (SMEs). SMEs are bound by limited financial as well as human resources in seeking innovation (Mieke, 2008). Other than large enterprises, SMEs do not have a regular exchange with partners from science or engage in common R\&D partnerships (Rammer et al., 2016). Therefore, networks and collaborative activities are recognized as playing a crucial role in enabling SMEs to compete and innovate in a dynamic environment (Valkokari \& Helander, 2007). Nevertheless, the participation of SMEs in innovation networks is still significantly lower than for large companies (BMWi, 2018; Buhl et al., 2019; Mieke, 2008; Rammer et al., 2016). In order to support SMEs in their collaboration efforts, policy makers aim to further promote the engagement of SMEs in innovation networks. Therefore, it is of interest which innovation networks are available for SMEs to promote these networks in a directed manner and to offer companies guidance when defining an innovation strategy.

Previous literature has identified a variety of network types based on different, non-consistent sets of characteristics, including direction of collaboration (Hagenhoff, 2008; Killich, 2011; Morschett, 2003; Payer, 2008; Schmidt \& Kiefer, 2003), geographical orientation (Eckert, 2009; Hess, 2002; Killich, 2011; Morschett, 2003; Payer, 2008; Schmidt \& Kiefer, 2003), the intensity of collaboration (Killich, 2011; Schmidt \& Kiefer, 2003), the commitment of the involved parties (Hagenhoff, 2008; Killich, 2011; Schmidt \& Kiefer, 2003), duration (Eckert, 2009; Hagenhoff, 2008; Killich, 2011; Morschett, 2003; Schmidt \& Kiefer, 2003), goal identity among actors (Eckert, 2009; Killich, 2011), and departments or functions involved (Eckert, 2009; Hagenhoff, 2008; Killich, 2011). Thus, existing studies are either bound to common limitations of qualitative studies, especially the 
lack of generalizability, or suffer from a limited range of network characteristics they take into account. This has led to the emergence of various network typologies (see, e.g., Provan \& Kenis (2008), Achrol \& Kotler (1999), Inkpen \& Tsang (2005), Cooke, Gomez Uranga, \& Etxebarria (1997), Bau et al. (2014)), which are especially lacking in their underlying empirical database. To address this gap in the literature, $\mathrm{we}^{12}$ combine previously identified, lone-standing characteristics and attributes of networks to create a comprehensive typology for formal inter-organizational innovation networks. We ask: What are the predominant types of formal inter-organizational innovation networks and how can they be characterized?

To address this question, we apply an exploratory, sequential, mixed method approach. We conduct a directed content analysis using a framework of network characteristics and attributes derived from previous research to compile a comprehensive data set of innovation networks. Subsequently, we apply hierarchical agglomerative clustering (HAC), building on similarities and differences across the identified network attributes. As a result, we observe 11 general types of networks with distinctive characteristics that constitute our typology of formal inter-organizational innovation networks. We compare our typology with previously existing literature and identify potential research directions for further analysis.

The remainder of this study is structured as follows. In section 2, we give an overview of the research background, deriving the study's relevance from potential benefits that SMEs can realize from collaboration within network integration, and give an overview on formal networks and related typologies. Section 3 shows our sample and data construction and introduces our sequential use of qualitative content analysis and quantitative clustering. Section 4 introduces and describes our 11 network types, which we discuss in section 5. Section 6 concludes the study, explicates implications as well as limitations, and sheds light on avenues for further research.

\subsection{Theoretical background}

The theoretical background sheds light on the broad area of networks and educates the reader on previous research. We outline the need for collaboration for SMEs and their motivation to join network solutions. We pro-

12 Essay III is based on a joint research project by Carl-Philipp Beichert and myself. I refer to both of us when using 'we' in the context of essay III. A description of the contributions of each author is given in Appendix 4-2. 
vide an overview of the variety of existing studies targeting network typologies and characteristics and identify the need for an empirically grounded network model. We further define our research focus by giving a definition of formal inter-organizational innovation networks and formulate our research question.

\subsubsection{SMEs' benefits from collaboration and network integration}

SMEs show great innovation capabilities and quality, as they strive to gain competitive advantages through innovative products, manufacturing technologies, and services. The development of such innovations ties up considerable resources and requires special know-how, both being limited factors especially in SMEs (Mieke, 2008). Furthermore, SMEs have significant limitations in terms of their ability to internationalize, innovate, and cope with competitive and environmental pressures (Agostini \& Nosella, 2019). At the same time, the competitive pressure on SMEs is increasing nowadays, boosted by the development of digital technologies. As an example, the share of implemented digital processes is comparatively lower for SMEs than for large companies (BMWi, 2018). The era of digitization forces companies more than ever to develop and implement new processes and products or to adapt their business models to changing market environments.

In order to meet future challenges, a high degree of innovation orientation of SMEs in Germany is reflected in their business strategies. A large proportion of German SMEs, however, carry out technological innovation activities without internal R\&D activities, particularly because of barriers that have recently arisen in terms of high economic risks, innovation costs, and lack of financial resources (Rammer et al., 2016). This can be regarded as an indicator of a great need to access external know-how (Mieke, 2008). Barriers can be overcome by collaborative activities and networks, as they can reduce the need for capital as well as the strategic risk (Sydow, 2001). Collaborative activities and networks are suitable for SMEs to compete and innovate in dynamic business environments (Valkokari \& Helander, 2007). Policy makers are already taking the need for collaboration into account by offering public funding and various support programs to promote engagement in networks (Rammer et al., 2016). The promotions target the technology transfer at the interface of industry and research with a special focus on the integration of SMEs into initiative programs $(\mathrm{BMWi}$, 2020). Technology-open promotions and support programs are intended 
to strengthen and expand competitiveness, networking, innovative strength, and employment among SMEs (Buhl, Sedlmayr, \& Meier, 2019).

\subsubsection{Formal inter-organizational innovation networks}

In contrast to simple forms of dyadic collaboration, a network is generally characterized by complex relationships between several entities involved. Owing to the broad, cross-disciplinary use of terms referring to networks, such as collaboration, network, and cluster, various definitions exist for networks. Within the heterogeneous spectrum of definitions, many terms are used differently depending on the individual definition of the author (Friese, 1998). Therefore, it is crucial to first define the scope of networks under analysis in this study.

Participation in a network reflects a strategic decision by organizations seeking to exchange resources and gain a competitive advantage that they could not obtain alone (Child et al., 2005; Sydow, 2001; Wissema \& Euser, 1991). Previous research discusses different approaches and theories dealing with the motivation, emergence, and processes of networks, resulting in two commonly accepted approaches (Casals, 2011). The Transaction Cost approach explains collaboration with the aim of minimizing costs, whereas the Resource Based View explains collaboration as the bundling of resources (Loasby et al., 1979; Williamson, 1981). As internal resources are limited, the Resource Based View approach suggests that, in order to exploit all existing resources and to develop a long-term competitive advantage, firms need to access external knowledge (Barney, 1991; Williamson, 1981). To reduce the uncertainty of resource availability, organizations can either acquire them or access them through collaboration (Sydow, 1992). Access through collaborative activities and networks offers the opportunity to increase strategic flexibility and, furthermore, to reduce capital requirements. In contrast, the resulting risks include a loss of strategic autonomy and a potential increase in coordination costs (Sydow, 2001).

Different types of collaboration and networks are hybrid forms of coordinating economic activities between the two established paradigms of market and hierarchy. Networks combine market and hierarchical, competitive and collaborative elements (Sydow, 1992). In contrast, Powell (1990) claimed that networks have to be seen as an independent form of coordination besides the forms of market and hierarchy. As this assumption would imply that only one general form of networks exists, other 
studies disprove this view and suggest network typologies to differentiate forms of collaboration accounted for as networks (Provan, Fish, \& Sydow, 2007; Provan \& Kenis, 2008). As all forms of collaboration and networks share different market- and hierarchical-oriented characteristics, we consider that different types of networks can be positioned within the spectrum of market and hierarchy, influencing, e.g., network governance (Friese, 1998; Sydow, 1992). This, furthermore, implies that networks can "produce positive outcomes that would not be possible in a market or a hierarchy" (Provan \& Kenis, 2008, p. 5), fostering beneficial expectations for network engagement among SMEs.

Networks are an organizational form of economic activity aimed at realizing competitive advantages that are characterized by complex reciprocal, collaborative rather than competitive and relatively stable relationships, whereas involved entities are legally independent, but economically mostly dependent enterprises and organizations (Sydow, 1992). Reciprocal behavior suggests that social exchange always leads to an immediate or later counter-exchange; however, the motivation is based on a social norm rather than on a contract (Gouldner, 1960). As collaboration can exist between two entities, networks consist of multiple organizations linked through multilateral ties that result in a group of three or more organizations. The connections are created in order to facilitate the achievement of a common goal (Provan et al., 2007) that can vary, e.g., from access to new or complementary knowledge, marketing, the increase in economies of scale, and risk sharing (Mariti \& Smiley, 1983). Members of a network usually aim for a combination of different objectives (Morschett, 2003). Provan, Fish, \& Sydow, 2007, distinguish inter-organizational and intra-organizational networks. For this study, we only consider inter-organizational networks of at least three organizations interacting across their organizational boundaries (Provan et al., 2007; Rank, 2015). Networks can emerge between organizations resulting from business transactions without being created by any kind of authority. These networks are described as informal networks, but lack visibility and publicly available data (Cross et al., 2002). On the other hand, networks can be created and managed by either a hierarchical or a heterarchical structure (Sydow, 2001). Networks are established by collaborative actions and fixed by an explicit collaboration agreement (Van Aken \& Weggeman, 2000). In order to ensure consistent data availability, we limit our study to formalized networks.

Especially in R\&D, which is assumed to play a crucial role in the value creation process and can determine the competitiveness of companies, collaborations can lever product innovation and market success of new prod- 
ucts (Hottenrott \& Lopes-Bento, 2016). Collaboration is therefore usually determined by a combination of the different skills and knowledge bases of the partners involved. Collaborative networks are the most significant source of innovation that leverage resources and capabilities across multiple organizations (Schilling, 2013). Networks offer vast opportunities, e.g., to enhance the use of tacit specialist knowledge, overall competence exchange, and dynamic technological innovation (Powell, 1990). Innovation networks are characterized by organizations that are engaged in product, process, or service innovation (Van Aken \& Weggeman, 2000). For this study, we include networks in which organizations or departments of companies are involved that focus on R\&D projects. We do not limit our focus to inter-firm R\&D partnerships (Hagedoorn, 2002), but rather regard networks consisting of different organizations that share research or development activities toward their common objectives.

In order to narrow our research focus, we determine a working definition of formal inter-organizational innovation networks based on the previously presented literature and research: Formal inter-organizational innovation networks are multiple legally independent organizations linked through multilateral ties in order to achieve common process, product, or service innovation. The linkages and activities between the organizations are aligned and coordinated by a management, organization, or authority.

Particularly occurring in high-technology sectors, collaboration is often facilitated by geographical proximity, which can lead to regional technology clusters (Schilling, 2013). The interaction between firms tends to be more intense when they share some type of similarity, such as geographical or technological proximity (Schilling \& Phelps, 2007). Regional knowledge networks of related organizations are often referred to as "clusters" (Vieregge, 2011). This term was coined by Porter (1998, p.78), who defined clusters as "(...) geographic concentrations of interconnected companies and institutions in a particular field." Clusters can consist of competitors, suppliers, customers, and other entities such as governmental organizations, research institutes, universities, and trade associations (Porter, 1998). In contrast to clusters as local agglomerations, formal networks are not necessarily linked to specific locations and are actively controlled by an authority or management. However, for the purpose of this study, our definition includes clusters that also share the characteristics of formal inter-organizational networks with strong regional ties. 


\subsubsection{Typologies of networks}

Even though some preliminary literature on inter-organizational networks exists, yet no consistent typology of networks grounded in empirical data is established. Existing analyses based on qualitative methodologies such as case studies and semi-structured interviews from company perspectives are limited in their ability for generalization (see, e.g., Bau, Bentivegna, \& Forster, 2014). Still, academic predecessors provide a number of network typologies and give a broad selection of distinctive network characteristics, able to distinguish between networks (Payer, 2008). As definitions of network types are often based on their characteristics, previously identified network types can differ significantly and lack comparability. Some are defined based on one specific key characteristic, and others refer to a set of selected characteristics. A proposed morphological box of collaboration characteristics by Killich (2011) summarizes common characteristics in Figure 4-1, independent of the type of collaborative activities. Within the morphological box, a variety of different features of the respective characteristics are suggested.

\begin{tabular}{|c|c|c|c|c|c|c|c|}
\hline Characteristic & \multicolumn{7}{|c|}{ Features } \\
\hline Direction & \multicolumn{2}{|c|}{ Horizontal } & \multicolumn{2}{|c|}{ Vertical } & \multicolumn{3}{|c|}{ Lateral } \\
\hline $\begin{array}{l}\text { Geographical } \\
\text { extension }\end{array}$ & Local & & Regional & Natio & & \multicolumn{2}{|c|}{ Global } \\
\hline Intensity & \multicolumn{2}{|c|}{ Low } & \multicolumn{2}{|c|}{ Moderate } & \multicolumn{3}{|c|}{ High } \\
\hline Commitment & \multicolumn{2}{|c|}{ Agreement } & \multicolumn{2}{|c|}{ Contract } & \multicolumn{3}{|c|}{$\begin{array}{c}\text { Capital } \\
\text { commitment }\end{array}$} \\
\hline Duration & \multicolumn{3}{|c|}{ Temporary } & \multicolumn{4}{|c|}{ Unlimited } \\
\hline Goal identity & \multicolumn{3}{|c|}{ Redistributive } & \multicolumn{4}{|c|}{ Reciprocal } \\
\hline $\begin{array}{l}\text { Collaborative } \\
\text { departments }\end{array}$ & $\mathrm{R} \& \mathrm{D}$ & Sale & $\begin{array}{c}\text { Procure } \\
\text { ment }\end{array}$ & $\begin{array}{l}\text { Market- } \\
\text { ing }\end{array}$ & & $\begin{array}{l}\text { duc- } \\
\text { on }\end{array}$ & Other \\
\hline
\end{tabular}

Figure 4-1: Morphological box of collaboration characteristics, based on Killich (2011, p. 18).

The direction indicates the value creation stage at which collaboration partners operate. Horizontal collaboration is conducted between partners at the same stage, whereas vertical collaboration includes partners from different stages in the value chain. Lateral collaboration can include partners from different value chains as well (Hagenhoff, 2008; Killich, 2011; Morschett, 2003; Payer, 2008; Schmidt \& Kiefer, 2003). Geographical activ- 
ities of collaboration can be distinguished between very locally concentrated up to global spanning collaboration (Eckert, 2009; Hess, 2002; Killich, 2011; Morschett, 2003; Payer, 2008; Schmidt \& Kiefer, 2003). The intensity of collaboration describes the degree to which activities need to be coordinated with partners (Killich, 2011; Schmidt \& Kiefer, 2003). Another key characteristic is the commitment, which can extend from loose agreements up to signed contracts or monetary investments (Hagenhoff, 2008; Killich, 2011; Schmidt \& Kiefer, 2003). Therefore, the duration is also often regarded, but is only distinguished between temporary and unlimited time horizons (Eckert, 2009; Hagenhoff, 2008; Killich, 2011; Morschett, 2003; Schmidt \& Kiefer, 2003). A crucial characteristic for collaboration is the goal identity, which describes the benefit the actors aim to achieve. A distinction is made between the pooling of resources with the same intention, a redistributive goal identity, and an exchange of services to achieve individual but complementary goals, namely reciprocal goal identity (Eckert, 2009; Killich, 2011). Additionally, collaboration can be characterized by the departments or functions actively involved (Eckert, 2009; Hagenhoff, 2008; Hess, 2002; Killich, 2011).

Academically identified characteristics are complemented by additional network characteristics and typologies. Although typologies should ideally be free of overlaps, previous research indicates that transitions between network types are often fluent and not precisely determinable (Schuh et al., 2011). Sydow (2001) has already described the opportunities for creating typologies of inter-organizational networks as infinite and provides a list of 26 different possibilities to distinguish network types based on their characteristics. A review of empirical research about inter-organizational networks by Provan, Fish, \& Sydow (2007) has already identified a general focus on network governance and network structure. Following on from this, Provan \& Kenis (2008) differentiate networks according to their form of governance, resulting in three types of networks: Participant-Governed Networks, Lead Organization-Governed Networks, and Network Administrative Organization. Network types are further determined based on their structure, as some are dominated by a focal organization and others have polycentric structures (Child et al., 2005; Glückler et al., 2012; Schuh et al., 2011; Sydow, 2001). Sydow (2001) suggests a typology of networks based on the type of control (hierarchical-heterarchical) and the stability of relationships (stable-dynamic) and derives four types: Strategic Networks, Regional Networks, Project Networks, and Virtual Undertakings. Networks are also observed regarding the positioning of the actors in the value chain. A commonly identified network type is the collaboration of partners with a 
vertical relationship in the value chain, referred to as vertical integration or vertical partnerships (Achrol \& Kotler, 1999; Bau et al., 2014; Dussauge \& Garrette, 1999; Gereffi et al., 2005; Hess, 2002; Sydow, 2001). As local agglomerations are associated with networks, previous studies also described networks by their local and regional focus (Inkpen \& Tsang, 2005; Payer, 2008; Porter, 1998; Schuh et al., 2011; Sydow, 2001, 2010). Cooke, Gomez Uranga, \& Etxebarria (1997) established the theory of Regional Innovation Systems. Regarding innovation, networks have been observed in terms of their purpose and the common objectives of their actors. A series of previous studies identified several different network types that aim to foster innovation among their actors (Bau et al., 2014; Lyytinen et al., 2016; Priestley \& Samaddar, 2007; Wissema \& Euser, 1991; Yoo et al., 2008). To mention one example that is directing our analysis, Bau, Bentivegna, \& Forster (2014) conducted a quantitative analysis of network characteristics to identify types of informal innovation networks. However, as they collected secondary data from semi-structured interviews with company representatives, their typology solely reflects the company perspective. Based on a consecutive cluster analysis, a typology of five innovation network types with their corresponding characteristics is suggested: Knowledge and Learning, Financial Procurement, Vertical Integration, International Scope, and Isolate Islands.

To summarize, the existing literature provides a large selection of network characteristics to describe and differentiate possible network types. This results in a wide variety of independent network typologies. Provan et al. (2007) have already proposed the combination of previously gained insights with an analysis at a network level. They formulated the need to study inter-organizational networks using a qualitative and quantitative approach. Yet a considerable number of qualitative studies contribute to the area of network types and characteristics, whereas only a few conducted a mixed method approach to structure previous insights and provide a framework. In an attempt to build a comprehensive framework based on a mixed method approach, e.g., Bau et al. (2014) used secondary data from a multiple case study and conducted a quantitative cluster analysis in order to generate their typology. Comparably, existing typologies are based on the derivation of individually conceptualized matrices that consist only of selected network features from theory. Thus, existing typologies are difficult to compare and are not comprehensively grounded in empirical data. As reflected by Provan et al., (2007), this represents only individual perspectives on networks, yet the existing literature does not provide a comprehensive generalizable classification. 
Therefore, we recognize a need to combine previously identified, lonestanding network types and attributes into a comprehensive typology with a solid empirical foundation. Taking into account network characteristics and attributes from existing literature, we aim to identify and analyze types of formal inter-organizational innovation networks in order to derive a comprehensible, generally applicable typology, thereby answering the question: What are the predominant types of formal inter-organizational innovation networks and how can they be characterized?

\subsection{Sample characteristics and methods}

We conduct a qualitative content analysis followed by a quantitative cluster analysis, inspired by previous research about innovation networks by Bau et al. (2014), the applied clustering approach of Delgado, Porter, \& Stern (2016), and the applied mixed method approach of Täuscher \& Laudien (2018). Our methodology represents an exploratory sequential mixed method approach (J. C. Creswell, 2014). We first use directed content analysis to compile a comprehensive data set (Hsieh \& Shannon, 2005). Subsequently, we apply a hierarchical clustering approach using Ward's linkage method to cluster the results from our content analysis (Ward, 1963). In the following section, we describe our sampling procedure and applied methods.

\subsubsection{Sample}

In order to identify networks in a structured manner, we use a large online listing of networks provided by "Clusterplattform Deutschland" (BMWi, 2020). This guarantees a structured sampling procedure as well as networks of sufficient quality. The term cluster can be misleading, as the focus of the platform is not limited to clusters in a narrow sense. The listed networks on the platform, so-called cluster initiatives, are supported by funding programs to foster the development of cluster and network structures. The networks are subject to the assumption that the actors involved are key players in the innovation process and thus make a decisive contribution to innovation and value creation (Buhl et al., 2019).

As we generate our sample data, all entries from the online listing of "Clusterplattform Deutschland" are retrieved, resulting in a list of 463 networks. Within a first screening process, the entries are tested in terms of 
consistency with our previously formulated definition of formal inter-organizational innovation networks. Following this, some identified networks do not match our definition and are excluded from the sample. Furthermore, several entries are removed, as they either do not provide sufficient information to fulfill the purpose of a content analysis or represent duplicates. After this process, our sample consists of 300 formal inter-organizational innovation networks.

The resulting sample of networks shows the following characteristics. As we retrieve the networks from a German online listing, the sample is geographically limited. Besides, no further limitations are made regarding the networks' locations across Germany as well as the age or size of the networks. A distribution across the 16 federal states of Germany can be observed, as presented in Figure 4-2. A few states, namely Baden-Wuerttemberg and Lower Saxony ("Niedersachsen") are represented with more networks in our sample, but we did not include aspects of representativeness in our analysis. This issue is not solely present in our final sample, but also reflects the initial distribution of networks on "Clusterplattform Deutschland" (BMWi, 2020) before our exclusions.

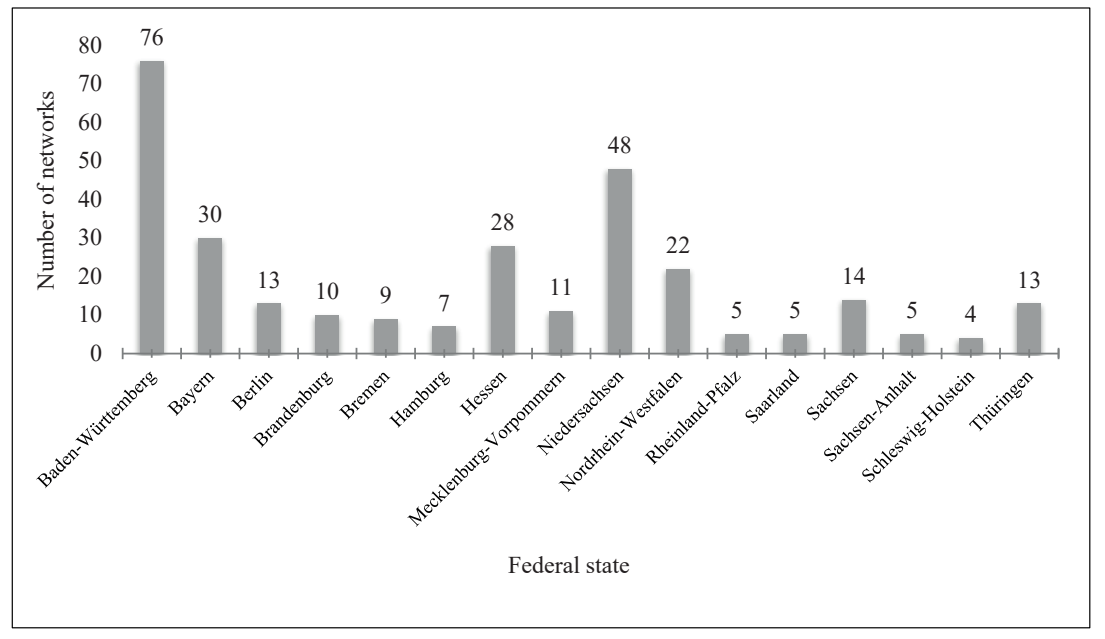

Figure 4-2: Distribution of analyzed networks by federal state.

We use the number of actors involved in a network to describe the size of the networks. No information or an exact number of actors could be found for 26 networks, marked as N/A in Figure 4-3. As illustrated, most 
of the networks range between 10 and 100 actors. Only very few networks consist of less than 10 or more than 500 actors.

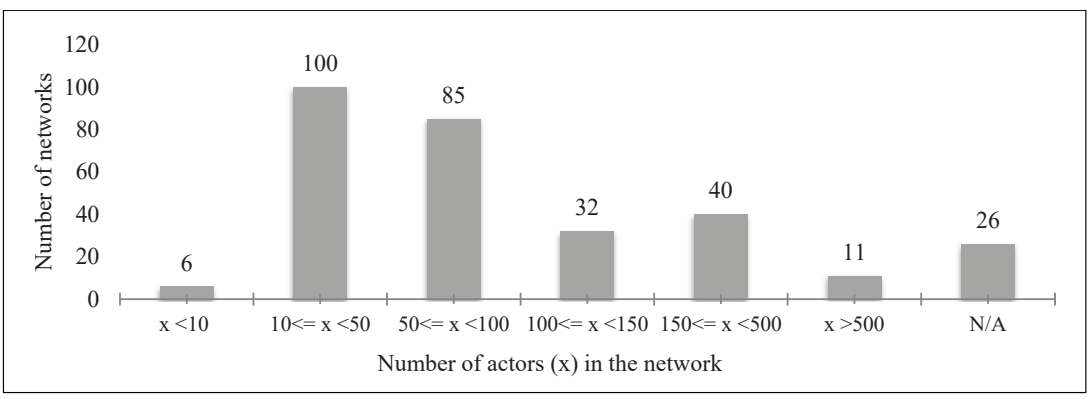

Figure 4-3: Distribution of analyzed networks by size (number of actors).

\subsubsection{Qualitative content analysis}

In order to generate a comprehensive data set, we conduct a qualitative content analysis using a directed approach. The purpose of this content analysis is to translate qualitative information into numerical data, which can be analyzed consecutively using a quantitative method (Potter \& Levine-Donnerstein, 1999).

For a directed content analysis, codes are first derived from theory and relevant research findings and are adapted during the analysis $(\mathrm{Hsieh} \&$ Shannon, 2005). We first consider a selection of network and collaboration characteristics based on previous literature as initial coding categories (Potter \& Levine-Donnerstein, 1999). The coding process is conducted based on publicly available information on the websites of the identified networks, complemented by information provided by "Clusterplattform Deutschland" (BMWi, 2020). The set of characteristics and features is continuously adapted during this process (Hsieh \& Shannon, 2005). An overview of our initial set of characteristics is given in Appendix 4-1. Characteristics that appear to be less appropriate, difficult to interpret, or that can only be determined based on highly subjective assessments are removed from the data set. Furthermore, characteristics must be removed if sufficient information cannot be retrieved from publicly available sources.

The final set of characteristics we take into account for the quantitative cluster analysis covers a wide range of potential factors, able to explain differentiated types of networks. Origin explains whether the network is created top-down by one or more entities or emerged through the relationships 
of several organizations. Control captures the expected weighting of management influence among the partners in the network, i.e., whether a network is managed via a focal company or controlled by several entities. Governance, in contrast, describes the stringency of administration throughout the network and in relation to the partners involved. Network identity evaluates the objectives of the network and its members. Geographical extent covers the geographical range of the network. The positioning of actors in the value chain describes the relationship of the network partners with regard to their process of value creation. Commitment depicts the binding nature by which network partners enter to become network members, i.e., an agreement, a contract, or even an equity contribution. Initiators of the network include a range of organizations that kick-off and thereby initiate networks. Actors in the network, on the other hand, can be companies, scientific institutions, and others at an appropriate level of explanation depth. Further single features target special foci such as a special industry, startups, physical premises, lobbying, and technology. The final characteristics and features of the sample are presented in Table 4-1 together with the corresponding description.

Table 4-1: Definition of network characteristics for survey during the directed content analysis.

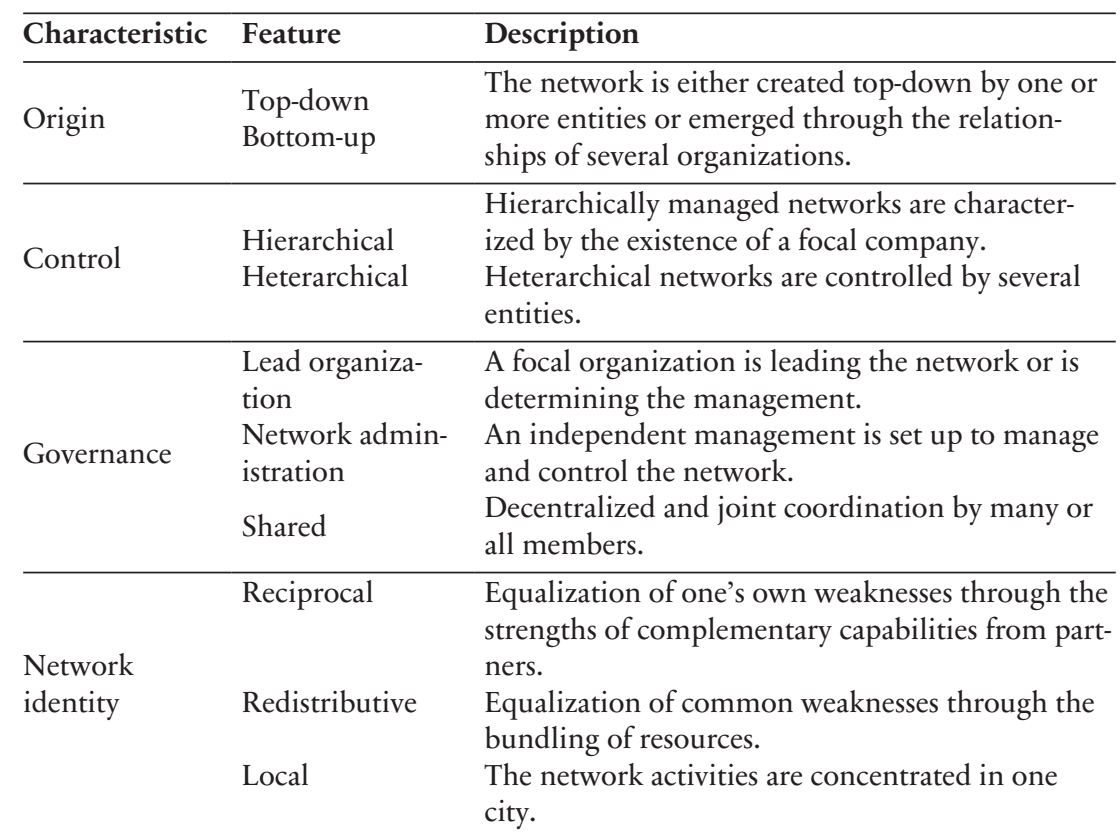




\begin{tabular}{|c|c|c|}
\hline Characteristic & Feature & Description \\
\hline \multirow[b]{3}{*}{$\begin{array}{l}\text { Geographical } \\
\text { extent }\end{array}$} & Regional & The network focus is set on one region. \\
\hline & State & The network activities concentrate within a federal \\
\hline & $\begin{array}{l}\text { National } \\
\text { International }\end{array}$ & $\begin{array}{l}\text { state. } \\
\text { The network activities are nationwide. } \\
\text { The network activities are across national borders. }\end{array}$ \\
\hline \multirow{2}{*}{$\begin{array}{l}\text { Positioning of } \\
\text { actors in the }\end{array}$} & Horizontal & $\begin{array}{l}\text { The actors are positioned at the same stage within } \\
\text { the same value chain. }\end{array}$ \\
\hline & Vertical & $\begin{array}{l}\text { The network includes actors in upstream and } \\
\text { downstream stages of the value chain. }\end{array}$ \\
\hline value & Lateral & $\begin{array}{l}\text { Actors from different value chains and stages are } \\
\text { involved. }\end{array}$ \\
\hline \multirow{5}{*}{ Commitment } & Arrangement & Loose collaboration based on verbal agreements. \\
\hline & Contract & $\begin{array}{l}\text { The membership of a network requires the signing } \\
\text { of a contract. }\end{array}$ \\
\hline & Equity & $\begin{array}{l}\text { The membership of a network requires a monetary } \\
\text { investment. }\end{array}$ \\
\hline & $\begin{array}{l}\text { University/R\&D } \\
\text { institutes }\end{array}$ & $\begin{array}{l}\text { Research institutes or universities are among the } \\
\text { initiators. }\end{array}$ \\
\hline & Association & Associations are among the initiators. \\
\hline \multirow{5}{*}{$\begin{array}{l}\text { Initiators of } \\
\text { the network }\end{array}$} & Company & Companies are among the initiators. \\
\hline & Chamber & Chambers are among the initiators. \\
\hline & Network & $\begin{array}{l}\text { Another (established) network is among the initia- } \\
\text { tors. }\end{array}$ \\
\hline & $\begin{array}{l}\text { Local develop- } \\
\text { ment organiza- } \\
\text { tion }\end{array}$ & $\begin{array}{l}\text { A local development organization is among the } \\
\text { initiators. }\end{array}$ \\
\hline & Public institution & A public institution is among the initiators. \\
\hline \multirow{3}{*}{$\begin{array}{l}\text { Actors } \\
\text { in the } \\
\text { network }\end{array}$} & Compante & Compants are active min tne network. \\
\hline & $\begin{array}{l}\text { Universities/R\& } \\
\text { D institutes }\end{array}$ & $\begin{array}{l}\text { Universities or research institutes are active in the } \\
\text { network. }\end{array}$ \\
\hline & Other & $\begin{array}{l}\text { Other organizations, not further specified, are ac- } \\
\text { tive in the network. }\end{array}$ \\
\hline \multirow{5}{*}{$\begin{array}{l}\text { Single } \\
\text { features }\end{array}$} & Industry focus & $\begin{array}{l}\text { The common objectives of the network target an } \\
\text { industry. }\end{array}$ \\
\hline & Start-up support & The network interacts with start-ups. \\
\hline & $\begin{array}{l}\text { Common premis- } \\
\text { es }\end{array}$ & $\begin{array}{l}\text { The network offers common premises, such as co- } \\
\text { working spaces or think labs. }\end{array}$ \\
\hline & Lobbying & $\begin{array}{l}\text { The network actively engages in lobbying activities } \\
\text { for its actors. }\end{array}$ \\
\hline & Technology focus & $\begin{array}{l}\text { The network focuses on the development of a spe- } \\
\text { cific technology. }\end{array}$ \\
\hline
\end{tabular}

The preselected characteristics are transferred into binary variables to assess whether a network fulfills a feature or not. During the coding process, a "1" is as- 
signed for each existing feature and a " 0 " for every feature that is not fulfilled by an observed network. In order to reduce elements of subjective interpretations during the coding process, the coding of qualitative information is partially counter-tested vice versa by the authors.

\subsubsection{Quantitative cluster analysis}

We apply a quantitative cluster analysis to identify groups of networks with similar features in the previously generated binary data set (Backhaus et al., 2018). Before conducting a cluster analysis, crucial decisions regarding the measure of proximity, clustering method, and number of clusters are made. Before all this, the sample variables must be prepared to guarantee interpretable results (Everitt et al., 2011).

First, each feature is assigned to a cluster variable for the cluster analysis. As the cluster variables represent the network characteristics and features, we ensure that the variables are of sufficient quality. We conduct a frequency analysis to identify characteristics that occur rarely. They are considered less appropriate for the cluster analysis and are removed. Not all variables within the same characteristic sum up to $100 \%$ as multiple feature selection is considered for certain characteristics. Moreover, variables indicating a doubled characteristic are omitted. Variables representing a feature of a hybrid characteristic are merged. Thus, for a hybrid characteristic, a " 1 " can represent the first feature and a "0" represents the second. The merged variables are listed in Table 4-2. This modification reduces the number of variables from 35 to 32 .

Table 4-2: Merged cluster variables

\begin{tabular}{|c|c|c|c|c|}
\hline Characteristic & Original variable & $\begin{array}{l}\text { Original } \\
\text { feature }\end{array}$ & $\begin{array}{l}\text { Merged } \\
\text { variable }\end{array}$ & Merged feature \\
\hline Origin & $\begin{array}{l}\text { C_orig_topdown } \\
\text { C_orig_bottomup }\end{array}$ & $\begin{array}{l}\text { Top-down } \\
\text { Bottom-up }\end{array}$ & C_origin & $\begin{array}{l}1=\text { Top-down } \\
0=\text { Bottom-up }\end{array}$ \\
\hline Control & $\begin{array}{l}\text { C_control_hier } \\
\text { C_control_heter }\end{array}$ & $\begin{array}{l}\text { Hierarchical } \\
\text { Heterarchical }\end{array}$ & C_control & $\begin{array}{l}1=\text { Hierarchical } \\
0=\text { Heterarchical }\end{array}$ \\
\hline $\begin{array}{l}\text { Network } \\
\text { identity }\end{array}$ & $\begin{array}{l}\text { C_ident_reciproc } \\
\text { C_ident_redistr }\end{array}$ & $\begin{array}{l}\text { Reciprocal } \\
\text { Redistributive }\end{array}$ & C_identity & $\begin{array}{l}1=\text { Reciprocal } \\
0=\text { Redistributive }\end{array}$ \\
\hline
\end{tabular}

Highly correlated cluster variables lead to an overrepresentation of the underlying aspects as they provide redundant information. In order to guarantee a high quality of cluster variables, we conduct a correlation analysis 
of the 32 remaining variables, where we classify a correlation coefficient above 0.9 as critical. No critical correlation was observed between the sample variables; therefore, our final set of characteristics for analysis consists of 32 variables, which are shown in Table 4-3.

We apply hierarchical agglomerative clustering (HAC) methods, as they appear to be most suitable for our research purpose (Bau et al., 2014; Delgado et al., 2016; Täuscher \& Laudien, 2018). HAC offers the advantage that it provides cluster solutions, but can also be used to determine the optimal number of clusters (Kassambara, 2017). In order to conduct a structured cluster analysis, we follow the approach suggested by Backhaus et al. (2016), which contains three steps. At first, a proximity measure is chosen, which is required for the selection of the cluster method that represents the clustering algorithm. Finally, the optimal number of clusters is determined to conduct the cluster analysis.

Therefore, we first select a distance measure and linkage method that determines how the algorithm combines the objects in our data set into clusters. The selection of a suitable method is of the utmost importance as the results can vary on the same data (Everitt et al., 2011). For the comparison of absolute data, it is suggested to use a distance measure instead of similarity measures as a proximity measure (Backhaus et al., 2018). We apply Ward.D2 as a linkage method in combination with the Euclidean distance as both aim to maximize the homogeneity within the clusters and generate clusters that are as different as possible from one another (Backhaus et al., 2018; Ward, 1963). This is a crucial characteristic of the underlying algorithm, as we aim to achieve more easily interpretable results. Network types are generally assumed to have fluent transitions and are therefore difficult to distinguish (Schuh et al., 2011). The third step in the cluster analysis represents the determination of the optimal number of clusters, referred to as $k$. As the determination of $k$ has a great impact on the final cluster solution, we apply various methods to indicate an optimal $k$; as yet there is no optimal method suggested in the literature. We apply an indicator method by Han, Kamber, \& Pei (2012), and compare this number with the Elbow Method, Silhouette Method, and Gap Statistic Method (Everitt et al., 2011; Kassambara, 2017; see also: Kaufman \& Rousseeuw, 2005; Tibshirani, Walther, \& Hastie, 2001). Based on the results of the conducted methods, we consider $k=11$ as an optimal number of clusters for the following analysis. After determining the optimal number of clusters, we conduct a hierarchical agglomerative clustering analysis. The cluster analysis is performed using the Ward.D2 method as the algorithm to combine objects into clusters based on the generated Euclidean distance matrix 
(Ward, 1963). We use the programming language $\mathrm{R}$ to perform the cluster analysis. Following the cluster analysis, we review each group of networks in terms of their characteristics and features in order to identify distinctive characteristics for each cluster. Therefore, the frequencies of the cluster variables are calculated within each cluster. Through an iterative process, followed by a profound discussion between the authors, we define network types by choosing concise and appropriate names to reflect the networks in the respective clusters.

Table 4-3: Final set of cluster variables

\begin{tabular}{|c|c|c|}
\hline Characteristic & Variable & Feature \\
\hline Origin & C_origin & $\begin{array}{l}1=\text { Top-down } \\
0=\text { Bottom-up }\end{array}$ \\
\hline Control & C_control & $\begin{array}{l}1=\text { Hierarchical } \\
0=\text { Heterarchical }\end{array}$ \\
\hline Governance & $\begin{array}{l}\text { C_gov_lead } \\
\text { C_gov_admin } \\
\text { C_gov_shared }\end{array}$ & $\begin{array}{l}\text { Lead organization } \\
\text { Network administration } \\
\text { Shared }\end{array}$ \\
\hline Network identity & C_identity & $\begin{array}{l}1=\text { Reciprocal } \\
0=\text { Redistributive }\end{array}$ \\
\hline Geographical extent & $\begin{array}{l}\text { C_geo_local } \\
\text { C_geo_regio } \\
\text { C_geo_state } \\
\text { C_geo_natio } \\
\text { C_geo_intern }\end{array}$ & $\begin{array}{l}\text { Local } \\
\text { Regional } \\
\text { State } \\
\text { National } \\
\text { International }\end{array}$ \\
\hline $\begin{array}{l}\text { Positioning of actors in the } \\
\text { value chain }\end{array}$ & $\begin{array}{l}\text { C_vchain_horiz } \\
\text { C_vchain_vertic } \\
\text { C_vchain_lat }\end{array}$ & $\begin{array}{l}\text { Horizontal } \\
\text { Vertical } \\
\text { Lateral }\end{array}$ \\
\hline Commitment & $\begin{array}{l}\text { C_commit_arrange } \\
\text { C_commit_contract } \\
\text { C_commit_equity }\end{array}$ & $\begin{array}{l}\text { Arrangement } \\
\text { Contract } \\
\text { Equity }\end{array}$ \\
\hline Initiators of the network & $\begin{array}{l}\text { C_init_uni } \\
\text { C_init_assoc } \\
\text { C_init_comp } \\
\text { C_init_chamber } \\
\text { C_init_netw } \\
\text { C_init_devorga } \\
\text { C_init_pub }\end{array}$ & $\begin{array}{l}\text { University/research institutes } \\
\text { Association } \\
\text { Company } \\
\text { Chamber } \\
\text { Network } \\
\text { Local development organiza- } \\
\text { tion } \\
\text { Public institution }\end{array}$ \\
\hline Actors in the network & $\begin{array}{l}\text { C_act_comp } \\
\text { C_act_uni } \\
\text { C_act_other }\end{array}$ & $\begin{array}{l}\text { Companies } \\
\text { Universities/R\&D institutes } \\
\text { Other }\end{array}$ \\
\hline
\end{tabular}




\begin{tabular}{lll}
\hline Characteristic & Variable & Feature \\
\hline Industry focus & C_industryspecific & $\begin{array}{l}1=\text { existent } \\
0=\text { non-existent }\end{array}$ \\
\hline Start-up support & C_founders & $\begin{array}{l}1=\text { existent } \\
0=\text { non-existent }\end{array}$ \\
\hline Common premises & C_premises & $\begin{array}{l}1=\text { existent } \\
0=\text { non-existent }\end{array}$ \\
\hline Lobbying & C_lobbying & $1=$ existent \\
& & $0=$ non-existent \\
\hline \multirow{2}{*}{ Technology focus } & C_technologyfocus & $1=$ existent \\
& & $0=$ non-existent \\
\hline
\end{tabular}

\subsection{Results: Types of networks}

In the following section, we present the results of our HAC analysis. We describe common results and characteristics of the clusters and identify distinctive characteristics that we define as key characteristics for each group of networks. In order to create a comprehensive typology, we name every group of networks after their specific characteristics and provide a concise description.

As the optimal number of clusters is determined within our method, we observe 11 groups of networks. The number of networks defines the cluster size and is illustrated in Figure 4-4. The average cluster size is 27.27 networks per cluster, whereas the median is 17 . Only three clusters are above the average size, of which cluster \#3 represents the largest with 86 networks. The other eight clusters range from seven to 26 networks. The smallest cluster is represented by cluster $\# 8$ with seven networks. 


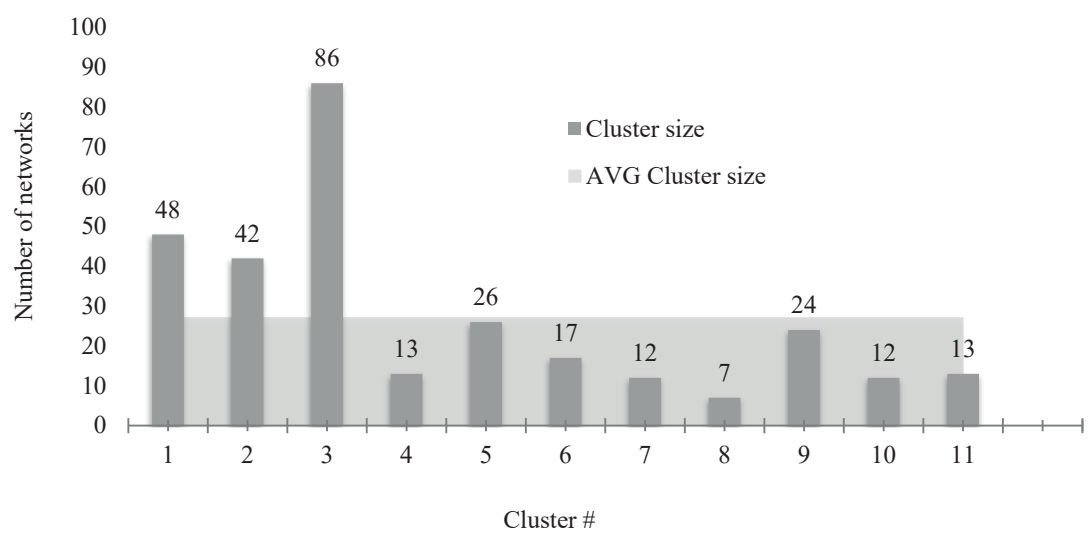

Figure 4-4: Cluster size: distribution of networks by cluster size (number of member networks).

\subsubsection{Avid Persuaders}

The first cluster represents 48 networks. The networks in the cluster show a diverse set of actors that are committed via either arrangements (54.17\%) or contracts $(43.75 \%)$. The networks are mostly controlled via hierarchical structures $(95.83 \%)$. Complementarily, the governance of the network is determined by a leading organization $(85.42 \%)$. Distinctive from other clusters, the networks in cluster \#1 are partially initiated by chambers of commerce $(27.08 \%)$. This is complemented by a comparably high frequency of engagement in lobbying activities $(43.75 \%)$. However, the networks are not solely positioned in one value chain but are rather distributed across different stages in several value chains $(70.83 \%)$ with a strong focus on a certain technology $(91.67 \%)$.

Based on the previously described characteristics and features, we identify the following key characteristics for the networks in cluster \#1:

- Engagement in lobbying activities

- Managed by a lead organization

- Hierarchical control structures

According to their key characteristics, we call the networks in cluster \#1 the Avid Persuaders. The networks are focally initiated and managed and engage in start-up support and lobbying activities. The network is generally initiated by large focal organizations that seek to identify or develop new technologies. The objective of the network is clearly determined and 
tailored to the individual needs of the focal organization. The interactions and activities of the network are geared toward access to external resources that represent complementary capabilities not only for the leading organization, but also for the other network actors. However, other actors are not necessarily fully committed to the network via contracts.

Illustrative example: Cluster Nutzfahrzeuge Schwaben (CNS) www.cns-ulm.com

The cluster was focally initiated and is managed by the chambers of commerce of Ulm and of Swabia to connect and lobby the interests of regional commercial and special vehicle industry, as well as suppliers, service providers and the scientific community. It targets to make selected technologies, methods and processes jointly available to the member companies in order to gain efficiency potentials and to minimize expenses and risks for the individual, to facilitate access to academia in the region and thus to new technologies and methods, and to establish a network for partnership, benchmarking and exchange of experience. Membership is granted based on application.

\subsubsection{Value Chain Drivers}

The second cluster comprises 42 networks. The networks in cluster $\# 2$ are determined by shared governance forms $(73.81 \%)$, which enable members to engage on equal participation rights within the network. This is also reflected by the high commitment of the members in the networks by contracts $(92.86 \%)$. With a feature frequency of $73.81 \%$, most of the network activities are concentrated within a single federal state. The actors in the networks are solely active across different stages within the same value chain $(83.33 \%)$. Different from other clusters, the networks in cluster \#2 also have redistributive $(42.86 \%)$ goal identities as they aim for resource bundling to overcome common weaknesses. The networks are initiated either top-down (45.24\%) or bottom-up (54.76\%). Mostly, companies $(64.29 \%)$ are involved in the initiation process; other actors are universities and public institutions (38.10\%) as well as R\&D institutes (26.19\%).

Following the above-mentioned characteristics and features, we define the following key characteristics for the networks in cluster \#2:

- Vertical positioning of actors within the same value chain

- Shared governance forms

- Geographical concentration in federal states 
We call this group of networks the Value Chain Drivers that are characterized by joint decision makers who foster the development of value chains, concentrated within federal states. The organizations in a network are positioned within the same value chain. The networks follow objectives that target structural challenges and key technological changes for the value chain in order to stay competitive.

Illustrative example: Aviaspace Bremen - www.aviaspace-bremen.de

The association serves as a mouthpiece for companies from the international aerospace industry located in the federal state and networks them with other industries. Its purpose is to increase cooperation and the development of innovative projects by mediating between companies, science and authorities. The focus is on network formation, technology transfer and economic growth including the support of young entrepreneurs and start-ups. This involves the technological and organizational linkage of producers, suppliers, service providers, and scientific institutions. The governance of the network is shared among association members, especially corporate representatives.

\subsubsection{Collective Facilitators}

With 86 networks, the third cluster represents the largest identified group of networks. Most of the networks in cluster \#3 are emergent networks that are formed bottom-up by several organizations (79.09\%). Complementary distinct characteristics of the networks are heterarchical $(81.40 \%)$ structures and shared governance forms $(94.19 \%)$. In most initiations of the networks, companies are engaged $(77.91 \%)$ that are also present in every network $(100 \%)$. A comparable high share of universities and R\&D institutes $(41.86 \%)$ is engaged in the initiation process as well. They also represent actors in the network in $93.02 \%$ of the networks. The actors in the network are positioned across different value chains as well as value chain stages $(95.35 \%)$. All actors in the networks are committed by a binding contract $(100 \%)$. The strong reciprocal network identity $(90.70 \%)$ as well as the technology focus $(74.42 \%)$ is consistent with the common characteristics of all clusters. Additionally, networks within this cluster partially engage in lobbying (37.21\%) and start-up support activities (38.37\%). The activities of the networks are often focused on a specific industry (59.30\%).

With the above-described characteristics and features, we recognize the following key characteristics for the networks in cluster \#3: 
- Emergent formation (bottom-up)

- Heterarchical control structure

- Shared governance

- Lateral positioning of actors in the value chains

We call this group of networks the Collective Facilitators that are characterized by emergent formations with equal participation rights to increase the scope of action beyond value chain boundaries. The networks on the one hand aim to actively support companies, R\&D facilities, and other institutions in order to facilitate connections and partnerships. Innovations, projects, and solutions are jointly developed and implemented. On the other hand, they promote general trends and technology developments. For example, the establishment of standards for new technologies

Illustrative example: Landesnetzwerk Mechatronik BW www.mechatronik-bw.del

The network is a cooperation network of partners from industry, service, research and education in the selected field of mechatronics. The network is a research source and communication platform. Companies for hardware and software, construction and project planning are integrated, as are powerful partners from the service, research and teaching sectors as well as regional associations. The partners within the network come from different sectors and levels of value creation. Tasks are implemented by the member companies, enriched by competences from the network.

\subsubsection{Niche Specialists}

The fourth cluster represents 13 networks from our sample. Most networks in this cluster are top-down (92.31\%) initiated by already established networks $(100 \%)$. Complementary to the origin of the networks, the control structure is hierarchically organized $(84.62 \%)$. However, a governance structure that is determined by a leading organization occurs in only $53.85 \%$ of the networks in this cluster. We further observe a geographical concentration of network activities within federal states (84.62\%). The objectives of the networks are mainly reciprocal $(84.62 \%)$. The actors in the networks are mostly committed with contracts $(84.62 \%)$ and are rather positioned across different value chains and value chain stages $(69.23 \%)$. The networks share a common technology focus $(76.92 \%)$ and a comparably weak industry focus $(30.77 \%)$. 
Based on the previously described characteristics and features, the following key characteristics for the represented networks in cluster \#4 are defined:

- Top-down initiated by established networks

- Tight technology focus

- Geographical concentration on federal states

We call this group of networks Niche Specialists that are described as network-initiated formations to foster specialized technologies within federal states. The integration of leading technology experts into the management of the networks ensures the achievement of long-term objectives. Targetoriented structures are established to achieve generally valid regulations and standardizations that are required for new technologies. The networks aim to develop and establish new key technologies.

Illustrative example: Wasserstoff- und Brennstoffzelleninitiative Hessen www.h2bz-hessen.de

Representatives of Hessian companies, universities and institutions founded the initiative, initiated and organizationally supported by political decision-makers. The dissemination of hydrogen and fuel cells is to be supported holistically in order to drive the long-term market breakthrough. This includes the establishment of necessary regulations and standardization, which will be applied beyond technology and industry boundaries. Targeted structures with political support are considered indispensable.

\subsubsection{Lateral Thinkers}

The fifth cluster consists of 26 networks from our sample. In every network in cluster $\# 5$, companies $(100 \%)$ as well as universities and research institutes are involved (100\%). Both companies $(73.08 \%)$ and universities and $\mathrm{R} \& \mathrm{D}$ institutes $(34.62 \%)$ are engaged in the initiation process, complemented by public institutions $(30.77 \%)$. The actors are positioned across different stages and value chains $(92.31 \%)$ and share a reciprocal goal identity $(92.31 \%)$. The networks are mostly managed very independently and are characterized by a network administration (80.77\%). The initiation was conducted either top-down $(46.15 \%)$ or bottom-up $(53.85 \%)$. Control structures are slightly more hierarchical $(65.38 \%)$. The cluster represents the highest specific technology focus (96.15\%) as well as industry focus $(92.31 \%)$ of all clusters. The networks in the cluster can be 
distinguished further as they provide support for their members to connect with start-ups or support start-ups directly $(80.77 \%)$.

Regarding the previously described characteristics and features, we distinguish the following key characteristics for the networks in cluster \#5:

- Network administration

- Positioning of actors across value chains and value chain stages (lateral)

- Strong industry and technology focus

- Interaction with start-ups

We call this group of networks the Lateral Thinkers that are characterized by independent industry centers seeking to identify innovative solutions through interaction with start-ups. Publicly funded non-profit associations foster the exchange of experience, knowledge, contacts, and ideas within a regional scope. The networks build an interface for entrepreneurs, scientists, technology seekers, as well as business angels to promote new technologies, which are of great relevance for the specialized companies that were already engaged in the establishment of the network. High-tech companies and start-ups in fast-growing industries represent the members. Companies are supported across all maturity phases of company development.

\section{Illustrative example: IT-Forum Rhein-Neckar - ifforum.de}

The network serves as a competence platform for companies in the media and IT sector, municipal institutions and educational institutions in the RhineNeckar metropolitan region. To this end, the network bundles know-how and experience, networks experts and promotes new ideas, technologies, concrete projects and cooperation. Knowledge transfer includes all companies, from start-ups to global players. Members live active exchange at eye level, expand their know-how and pass on knowledge. The network originates from a private initiative of entrepreneurs, the network is accordingly focused on entrepreneurial networking.

\subsubsection{Transnational Opportunity Seekers}

The sixth cluster comprises 17 networks. The networks in this cluster are rather initiated bottom-up (64.71\%) and described by heterarchical structures $(76.47 \%)$. Shared governance $(52.94 \%)$ represents the preferred form of control by the networks and their actors. The networks within the cluster share common characteristics with other clusters such as a reciprocal network identity (94.12\%) and actors committed by contracts (88.34\%). 
The actors within the networks are rather positioned across stages on different value chains $(64.71 \%)$ and are represented by companies $(100 \%)$ as well as universities and R\&D institutes (94.12\%). Companies (82.35\%), universities and R\&D institutes (41.18\%), as well as public institutions $(47.06 \%)$ are engaged in the initiation process of the networks. A significant feature is observed within this cluster as all networks are engaged in international activities $(100 \%)$ or relate to international partners. The networks are further characterized by a high technology (88.24\%) and industry focus $(58.82 \%)$.

Based on the previously described characteristics and features, the following key characteristics for the networks in cluster \#6 are recognized:

- International scope

- Initiated by companies

- Strong reciprocal network identity

We call this group of networks the Transnational Opportunity Seekers that are jointly initiated by companies to achieve complementary capabilities across national borders. Registered non-profit associations aim to foster technology and market-oriented collaboration in science, research, and economics within an international scope. The actors intensify joint R\&D activities with the possibility of opening new business fields. The network further represents its actors to the public and supports them in identifying experts as well as acquiring funds from the European Union.

Illustrative example: Innovationszentrum Bahntechnik Europa - izbe-cont.eu

The company network is committed to lobbying in transport policy decisionmaking processes, organizes events for mutual information and marketing, orchestrates exchanges of experience, acquires and advises on subsidies, and provides technical and organizational support for specific topics and project work. Members contribute technical know-how and innovative ideas, acquire new contacts and use the association as a platform to implement ideas and realize know-how and monetary benefits - first and foremost with a transnational focus.

\subsubsection{Financially Resilient Connectors}

The seventh cluster contains 12 networks, which are described by hierarchical structures $(83.33 \%)$ and top-down $(66.67 \%)$ initiation. All members are committed to the networks by monetary equity investments (100\%). This enables the network to enhance innovation partnerships driven by 
connections with start-ups $(50 \%)$. The cluster shares the characteristics of a strong technology focus $(91.67 \%)$ and a reciprocal network identity $(83.33 \%)$. Furthermore, companies (66.67\%), public institutions (50\%), as well as universities and R\&D institutes $(33.33 \%)$ are involved in the initiation of the networks. The positioning of the actors is a rather lateral $(66.67 \%)$ distribution of the actors across value chains. The networks are primarily concentrated in regions $(41.67 \%)$ or within a single federal state $(33.33 \%)$. We also observe that especially small networks are represented within cluster \#7.

Based on the above-described characteristics and features, we identify the following key characteristics for the networks represented in cluster \#7:

- Actors are committed through equity

- Interaction with start-ups

- Strong technology focus

We call this group of networks Financially Resilient Connectors that we describe as purpose-driven enablers of financially sustainable innovation partnerships. The networks are initiated as limited liability companies and funded by public institutions and the European Union, together with partners from industry and science. They serve as a regional competence center to strengthen the region and entire industry. The networks reveal regional $\mathrm{R} \& \mathrm{D}$ capacities to promote and strengthen innovations and start-ups on behalf of the public sector. The partners from industry, research, and universities develop supra-regionally oriented forums, workshops, and working groups on current development trends in various fields of technology.

Illustrative example: Kompetenz-Netzwerk Mechatronik in Ostbayern mc-netz.de

The network is administered by representatives of companies, chamber of commerce, politics and research institutions. A particularly close cooperation between the partners involved is aimed at the exchange of experience, trust and exchange of sensitive data. Companies are involved in the network-wide training of their skilled workers, seeking synergy effects and thus cost savings. Likewise, cooperation and networking strengthen the companies and enhance their competitiveness. Particularly in the research-intensive and highly specialized sector, contact with potential cooperation partners, customers, suppliers, but also with students and qualified skilled workers plays an important role. The project focuses on cooperation in qualification, research \& development and marketing/services - with mechatronics being the main focus in each case. As the network develops over time, various forms of cooperation were created. 


\subsubsection{Local Trend Sponsors}

With seven networks, the eighth cluster represents the smallest identified group of networks. Most networks within this cluster are initiated topdown $(85.71 \%)$ by public institutions $(71.43 \%)$. The networks are locally $(100 \%)$ concentrated as many of them offer common premises $(42.86 \%)$ for their members and partners. The clusters share common cluster characteristics of reciprocal goal identities $(71.43 \%)$ as well as commitments based on contracts $(71.43 \%)$. The actors within the networks are mainly based within the same value chain at different stages $(71.43 \%)$, but also share common connections to start-ups $(57.14 \%)$. The networks seem generic as they have a comparably low technology focus (28.57) and are not specialized on specific industries (14.29\%).

Based on their characteristics and features, we identify the following distinctive key characteristics for the networks in cluster \#8:

- Local concentration

- Common premises

- Initiated by public institutions

- Vertical positioning of actors within the same value chain

We call this group of networks Local Trend Sponsors that are described as concentrated, publicly initiated, local interfaces for companies of all sizes. Public institutions that aim to shape and promote local industry districts or science parks determine the networks. The networks offer a meaningful point of contact for companies from different industries and sizes and act as a mediator with municipal partners. The networks draw attention to strategic trends and current developments at an early stage in order to involve actors in the development. A close network is offered by providing common premises and interaction with start-ups. 
Illustrative example: Cluster Green City Freiburg - www.greencity-cluster.del

The politically initiated network supports the growing market for environmental and solar economy in the economic region of Freiburg. In particular, the areas of research and development, knowledge transfer and environmental education are the driving force behind the development of the industry portfolio in the areas of solar technologies, renewable energies, sustainability, energy efficiency, planning and construction and environmental technology. The diverse activities of small and medium-sized companies from commerce, production and services are a further pillar of the region's activities. With the network, the region's strengths in this field are expanded and marketed. Within the framework of a green industrial park, possibilities are demonstrated for a future-oriented, sustainable, energy- and resource-efficient transformation of a large industrial area.

\subsubsection{Regional Activists}

The ninth cluster represents 30 networks. The networks within this cluster are top-down $(95.83 \%)$ initiated by local development organizations $(95.83 \%)$. Consistently, they have a hierarchical structure $(91.67 \%)$ and are led by an organization $(62.50 \%)$. They focus on several industries $(41.67 \%)$ across different value chains $(75 \%)$. Furthermore, the networks within this cluster share a reciprocal network identity $(87.50 \%)$. Companies (100\%) and universities and R\&D institutes (87.50\%) are among the actors in the networks. The networks also represent the interests of their actors as they engage in lobbying activities $(50 \%)$. The technology focus of the networks is rather low $(45.83 \%)$ compared with other clusters.

Regarding the above-mentioned characteristics and features, the following distinctive key characteristics for the networks in cluster $\# 9$ are determined:

- Top-down initiated by local development organizations

- Lobbying activities

- Strong local concentration

We call this group of networks Regional Activists that we describe as regional platforms to promote and foster selected business sectors holistically. The networks are based on initiatives from the federal states founded as collaborations to strengthen economic sectors within a region. They support actors in networking and development as well as in innovation and settlement projects. The networks bundle and coordinate resources between the actors for the purpose of knowledge transfer, exchange of experi- 
ence, and initiation of joint projects. Therefore, they act as a mediator between politics, administration, and practitioners from industry, trade, and the service sector.

Illustrative example: Forst und Holz Allgäu-Oberschwaben www.forst-und-holz-allgaeu-oberschwaben.de

The Forestry and Timber Network Allgäu-Oberschwaben sees itself as a voluntary association of companies along the timber chain that cooperate with other institutions such as associations, clubs, universities, municipalities, politics and funding programs. It is initiated and administered by a support association of the district. The main objectives include securing raw materials, efficient handing of materials, efficient structuring of value creation along the wood chain, as well as knowledge transfer in the use of wood. Exchange of experience and information between the network partners as well as public representation of interests are promoted.

\subsubsection{Associated Industry Supporters}

The tenth cluster comprises 12 networks. Even though all the networks are at least partly initiated by associations $(100 \%)$, they are not necessarily created top-down $(58.33 \%)$. They also rather have a shared governance form $(58.33 \%)$. Consistently with the large share of initiations by associations, many networks are engaged in lobbying activities (83.33\%). Within the cluster, a high share of networks has an industry focus (91.67\%). The scope of network activities is rather concentrated within federal states $(66.67 \%)$. The actors consist of companies $(100 \%)$ as well as universities and R\&D institutes $(91.67 \%)$. The positioning of the actors within a value chain is not specified as they are either at different stages of the same value chain $(50 \%)$ or across different value chains $(50 \%)$. As in the other clusters, the networks share common characteristics of a reciprocal goal identity $(91.67 \%)$ as well as contract-based commitments $(91.67 \%)$. The networks interact with start-ups (41.67\%).

Based on the previously described characteristics and features, we identify the following distinctive key characteristics for the networks in cluster $\# 10$ :

- Initiated by associations

- Lobbying activities

- Industry focus within federal states 
We call this group of networks the Associated Industry Supporters. We describe this network type as sector-specific associations, based on company engagement to promote relevant topics, strengthen networks, and foster companies. With contacts from business, science, and politics, the associations represent an industry and form the interface between industry and politics. Additionally, projects are developed and implemented together with companies, research institutes, and local authorities to increase regional value added and competitiveness.

\section{Illustrative example: media:net berlinbrandenburg - www.forst-und-holz-allgaeu-oberschwaben.de \\ media:net berlinbrandenburg is, according to its own statement, one of the largest and most successful regional networks of the media and digital economy in Germany. It connects businesses and politics in Berlin-Brandenburg. The network represents its member companies, including established and globally active companies as well as start-ups and young companies, across all sectors and states. Together with public and private institutions, associations and opin- ion leaders from business, research and politics, media:net participates in shap- ing the economic environment of the region and addresses current topics and needs of its members with studies and surveys. The aim of the independent asso- ciation is to network the members and lobby their interests.}

\subsubsection{Dynamic Research Groups}

The 11th cluster consists of 13 networks. The networks within this cluster are mainly initiated top-down $(69.23 \%)$ by universities and research institutes $(69.23 \%)$ as well as public institutions $(30.77 \%)$. The formations have either a lead $(46.15 \%)$ or shared $(46.15 \%)$ governance form. Contrary to the common characteristics of other clusters, the actors in the networks within this cluster are mostly represented by universities and R\&D institutes $(92.31 \%)$, but only a few companies are involved (7.69\%). Consistently, many actors are positioned at the same stage within the same value chain $(53.85 \%)$. Additionally, a high degree of industry specialization $(61.54 \%)$ as well as technology focus $(84.62 \%)$ is observed. The commitment, however, is rather loose, as it is mostly based on arrangements $(69.23 \%)$. The networks are primarily concentrated within federal states (76.92\%).

Following the above-mentioned characteristics and features, we distinguish the following key characteristics for the networks in cluster \#11: 
- Commitment of actors via arrangements

- Initiated by universities and R\&D institutes

- Actors are represented by universities and R\&D institutes

We call this group of networks the Dynamic Research Groups that are characterized by university-driven, topic-specific centers to engage in multi-disciplinary research primarily in academic fields, including companies as sparring partners. The networks provide a collaboration platform for joint basic as well as applied research at the interface between science and industry. Interdisciplinary research activities are bundled for future-oriented complex topics. Institutes of universities as well as other research institutes in the region combine resources as well as know-how.

Illustrative example: Bremen Research Cluster for Dynamics in Logistics logdynamics.de

The network stands for interdisciplinary research in logistical subject areas, including an international doctoral program at the University of Bremen, thereby contributing to the University's profile in research, transfer and doctoral training. The cluster provides new impulses and driving forces for Bremen as a business location. The basic idea is to use the synergy effects that arise from the coordination of the specific problem-solving competencies of the partners involved in working on logistical tasks. Such interdisciplinary research should lead to valuable progress in the search for logistics solutions. The aim of the research association is to strengthen the logistics department of Bremen's university and research institutions. This includes basic research, the application of scientific logistics and scientific education. Research projects therefore often have a connection to industrial practice. This creates willingness and opportunities for cooperation between science and industry. SMEs gain access to scientific partners.

\subsection{Discussion}

We identify 11 differential types of formal, inter-organizational innovation networks along a selection of distinctive characteristics. By ascribing each type a unique name, we propose a comprehensive typology of formal interorganizational innovation networks. Our proposed typology is presented in Table 4-4, which lists each network type with its key characteristics and a concise description. Furthermore, examples of networks are provided from our sample. The following section serves as a comparison of our defined network types with typologies and networks from previous studies. Thus, we fill existing gaps from previous research and identify possible dis- 
crepancies for further research. We might exclude networks from previous research that are not relevant in our typology, as we limit our observations to formalized innovation networks that focus on inter-organizational interaction.

\section{Table 4-4: Typology of formal inter-organizational innovation networks}

\begin{tabular}{|c|c|c|c|}
\hline $\begin{array}{l}\text { Network } \\
\text { name }\end{array}$ & Key characteristics & Description & Example networks \\
\hline $\begin{array}{l}\text { id Per- } \\
\text { aders }\end{array}$ & $\begin{array}{l}\text { - Engagement in lobbying } \\
\text { activities } \\
\text { - Managed by a lead orga- } \\
\text { nization } \\
\text { - Hierarchical control } \\
\text { structures }\end{array}$ & $\begin{array}{l}\text { Focally initiated and man- } \\
\text { aged, engaged in start-up } \\
\text { support and lobbying ac- } \\
\text { tivities. }\end{array}$ & $\begin{array}{l}\text { - Nutzfahrzeuge } \\
\text { Schwaben } \\
\text { - AQUANET Berlin Bran- } \\
\text { denburg } \\
\text { - BIO.NRW }\end{array}$ \\
\hline $\begin{array}{l}\text { Value } \\
\text { Chain } \\
\text { Drivers }\end{array}$ & $\begin{array}{l}\text { - Positioning of actors } \\
\text { across value chain stages } \\
\text { - Shared governance form } \\
\text { - Geographical concentra- } \\
\text { tion on federal states }\end{array}$ & $\begin{array}{l}\text { Joint decision makers who } \\
\text { foster the development of } \\
\text { value chains, concentrated } \\
\text { within federal states. }\end{array}$ & $\begin{array}{l}\text { - AVIASPACE BREMEN } \\
\text { - Netzwerk Logistik Mit- } \\
\text { teldeutschland } \\
\text { - SolarInput }\end{array}$ \\
\hline $\begin{array}{l}\text { Collective } \\
\text { Facilitators }\end{array}$ & $\begin{array}{l}\text { - Emergent formation } \\
\text { (bottom-up) } \\
\text { - Heterarchical control } \\
\text { structure } \\
\text { - Shared governance } \\
\text { - Lateral positioning of } \\
\text { the actors in value chains }\end{array}$ & $\begin{array}{l}\text { Emergent formations with } \\
\text { equal participation rights } \\
\text { to increase the scope of ac- } \\
\text { tion beyond value chain } \\
\text { boundaries. }\end{array}$ & $\begin{array}{l}\text { - Landesnetzwerk Mecha- } \\
\text { tronik BW } \\
\text { - Energieagentur Region } \\
\text { Göttingen } \\
\text { - PolymerMat }\end{array}$ \\
\hline $\begin{array}{l}\text { Niche Spe- } \\
\text { cialist }\end{array}$ & $\begin{array}{l}\text { - Top-down initiated by } \\
\text { established networks } \\
\text { - Tight technology focus } \\
\text { - Geographical concentra- } \\
\text { tion on federal states }\end{array}$ & $\begin{array}{l}\text { Network-initiated forma- } \\
\text { tions to foster specialized } \\
\text { technologies within fed- } \\
\text { eral states. }\end{array}$ & $\begin{array}{l}\text { - Wasserstoff- und } \\
\text { Brennstoffzellen-Initia- } \\
\text { tive Hessen } \\
\text { - ikt.saarland } \\
\text { - Competence Center } \\
\text { Aerospace Kassel-Calden }\end{array}$ \\
\hline $\begin{array}{l}\text { Lateral } \\
\text { Thinkers }\end{array}$ & $\begin{array}{l}\text { - Network administration } \\
\text { - Lateral positioning of } \\
\text { the actors in value chains } \\
\text { - Strong industry and } \\
\text { technology focus } \\
\text { - Interaction with start-ups }\end{array}$ & $\begin{array}{l}\text { Independent industry cen- } \\
\text { ters seeking to identify in- } \\
\text { novative solutions } \\
\text { through interaction with } \\
\text { start-ups. }\end{array}$ & $\begin{array}{l}\text { - IT-Forum Rhein-Neckar } \\
\text { - Virtual Reality Berlin- } \\
\text { Brandenburg } \\
\text { - CyberForum }\end{array}$ \\
\hline $\begin{array}{l}\text { Transna- } \\
\text { tional Op- } \\
\text { portunity } \\
\text { Seekers }\end{array}$ & $\begin{array}{l}\text { - International scope } \\
\text { - Initiated by companies } \\
\text { - Strong reciprocal net- } \\
\text { work identity }\end{array}$ & $\begin{array}{l}\text { Jointly initiated by com- } \\
\text { panies to achieve comple- } \\
\text { mentary synergies across } \\
\text { national borders. }\end{array}$ & $\begin{aligned} & \text { - } \text { Innovationszentrum } \\
& \text { Bahntechnik Europa } \\
& \text { - BalticNet - PlasmaTec } \\
& \text { - BioLAGO }\end{aligned}$ \\
\hline
\end{tabular}




\begin{tabular}{|c|c|c|c|}
\hline $\begin{array}{l}\text { Network } \\
\text { name }\end{array}$ & Key characteristics & Description & Example networks \\
\hline $\begin{array}{l}\text { Financially } \\
\text { Resilient } \\
\text { Connectors }\end{array}$ & $\begin{array}{l}\text { - Committed by equity } \\
\text { - Interaction with start-ups } \\
\text { - Strong technology focus }\end{array}$ & $\begin{array}{l}\text { Purpose-driven enablers of } \\
\text { financially sustainable in- } \\
\text { novation partnerships. }\end{array}$ & $\begin{array}{l}\text { - Kompetenz-Netzwerk } \\
\text { Mechatronik in Ostbay- } \\
\text { ern } \\
\text { - } \text { BIOPRO Baden-Würt- } \\
\text { temberg } \\
\text { - BioRegio STERN Man- } \\
\text { agement }\end{array}$ \\
\hline $\begin{array}{l}\text { Local Trend } \\
\text { Sponsors }\end{array}$ & $\begin{array}{l}\text { - Local concentration } \\
\text { - Common premises } \\
\text { - Initiated by public insti- } \\
\text { tutions } \\
\text { - Vertical positioning of } \\
\text { actors within the same } \\
\text { value chain }\end{array}$ & $\begin{array}{l}\text { Concentrated, publicly } \\
\text { initiated, local interface } \\
\text { for companies of all sizes. }\end{array}$ & $\begin{array}{l}\text { - Cluster Green City } \\
\text { Freiburg } \\
\text { - Cluster Medizintech- } \\
\text { nologie } \\
\text { - Hamburg Kreativ } \\
\text { Gesellschaft }\end{array}$ \\
\hline $\begin{array}{l}\text { Regional } \\
\text { Activists }\end{array}$ & $\begin{array}{l}\text { - Top-down initiated by } \\
\text { local development orga- } \\
\text { nizations } \\
\text { - Lobbying activities } \\
\text { - Strong local concentra- } \\
\text { tion }\end{array}$ & $\begin{array}{l}\text { Regional platforms to pro- } \\
\text { mote and foster selected } \\
\text { business sectors holistical- } \\
\text { ly. }\end{array}$ & $\begin{array}{l}\text { - Forst und Holz Allgäu- } \\
\text { Oberschwaben } \\
\text { - Digitale Wirtschaft } \\
\text { Schleswig-Holstein } \\
\text { - Cluster Gesund- } \\
\text { heitswirtschaft Berlin- } \\
\text { Brandenburg }\end{array}$ \\
\hline $\begin{array}{l}\text { Associated } \\
\text { Industry } \\
\text { Supporters }\end{array}$ & $\begin{array}{l}\text { - Initiated by associations } \\
\text { - Lobbying activities } \\
\text { - Industry focus within } \\
\text { federal states }\end{array}$ & $\begin{array}{l}\text { Sector-specific asso- } \\
\text { ciations, based on compa- } \\
\text { ny engagement to pro- } \\
\text { mote relevant topics, } \\
\text { strengthen networks, and } \\
\text { foster companies. }\end{array}$ & $\begin{array}{l}\text { - media:net berlinbran- } \\
\text { denburg } \\
\text { - deENet Kompetenznet- } \\
\text { zwerk dezentrale Energi- } \\
\text { etechnologien } \\
\text { - BTS - Rail Saxony }\end{array}$ \\
\hline $\begin{array}{l}\text { Dynamic } \\
\text { Research } \\
\text { Groups }\end{array}$ & $\begin{array}{l}\text { - Commitment via ar- } \\
\text { rangements } \\
\text { - Initiated by universities } \\
\text { and R\&D institutes } \\
\text { - Actors represented by } \\
\text { universities and R\&D in- } \\
\text { stitutes }\end{array}$ & $\begin{array}{l}\text { University-driven, topic- } \\
\text { specific centers to engage } \\
\text { in multi-disciplinary re- } \\
\text { search primarily in aca- } \\
\text { demic fields, including } \\
\text { companies as sparring } \\
\text { partners. }\end{array}$ & $\begin{array}{l}\text { - Bremen Research Clus- } \\
\text { ter for Dynamics in Lo- } \\
\text { gistics } \\
\text { - COALA Kompetenzzen- } \\
\text { trum } \\
\text { - Niedersächsisches } \\
\text { Forschungszentrum } \\
\text { Fahrzeugtechnik }\end{array}$ \\
\hline
\end{tabular}

As we focus on the identification of different types of innovation networks, it is not surprising that most networks within the sample indicate a strong technology focus. Consistently with the definition of networks by Sydow (1992), we observe a high frequency of reciprocal network identities among our networks. As all observed networks have a diverse actor structure, the prerequisite for inter-organizational interaction is well met. Table 4-5 summarizes network types from previous literature for which we assume overlapping characteristics with our identified networks. 
Table 4-5: Assignment of the identified networks to previous literature

\begin{tabular}{|c|c|c|}
\hline $\begin{array}{l}\text { Networks identified } \\
\text { within this study }\end{array}$ & $\begin{array}{l}\text { Networks with similar characteristics } \\
\text { from previous literature }\end{array}$ & Reference \\
\hline & Dominated Networks & (Child et al., 2005) \\
\hline \multirow[t]{3}{*}{ Avid Persuaders } & Lead Organization-Governed Networks & (Provan \& Kenis, 2008) \\
\hline & Federated Innovation Networks & (Lyytinen et al., 2016) \\
\hline & Vertical Partnerships & (Dussauge \& Garrette, 1999) \\
\hline \multirow[t]{4}{*}{ Value Chain Drivers } & Clan Innovation Networks & (Bau et al., 2014) \\
\hline & Vertical Integrations & (Lyytinen et al., 2016) \\
\hline & Cross-Industry Agreements & (Dussauge \& Garrette, 1999) \\
\hline & Equal Partner Networks & (Child et al., 2005) \\
\hline \multirow[t]{3}{*}{ Collective Facilitators } & Participant-Governed Networks & (Provan \& Kenis, 2008) \\
\hline & Knowledge and Learning & (Bau et al., 2014) \\
\hline & Anarchic Innovation Network & (Lyytinen et al., 2016) \\
\hline \multirow[t]{2}{*}{ Niche Specialist } & N/A & N/A \\
\hline & Structure-based Innovation Networks & (Wissema \& Euser, 1991) \\
\hline \multirow[t]{2}{*}{ Lateral Thinkers } & Clan Innovation Networks & (Dussauge \& Garrette, 1999) \\
\hline & Strategic Alliances & (Child et al., 2005) \\
\hline $\begin{array}{l}\text { Transnational Opportuni- } \\
\text { ty Seekers }\end{array}$ & International Scope & (Bau et al., 2014) \\
\hline Financially Resilient & Joint Venture & (Dussauge \& Garrette, 1999) \\
\hline Connectors & Financial Procurement & (Bau et al., 2014) \\
\hline Local Trend & Regional Innovation Systems & (Cooke et al., 1997) \\
\hline \multirow[t]{2}{*}{ Sponsors } & Clusters & (Porter, 1998) \\
\hline & Industrial Districts & (Inkpen \& Tsang, 2005) \\
\hline Regional & Regional Innovation Systems & (Cooke et al., 1997) \\
\hline Activists & Regional Networks & (Sydow, 2001) \\
\hline \multirow{2}{*}{$\begin{array}{l}\text { Associated Industry } \\
\text { Supporters }\end{array}$} & Associations as Innovation Platforms & (Mieke, 2008) \\
\hline & Dynamic Networks & $\begin{array}{l}\text { (Snow, Miles, \& Coleman, } \\
\text { 1992) }\end{array}$ \\
\hline Dynamic Research & R\&D Partnership & (Hagedoorn, 2002) \\
\hline Groups & R\&D Network & $\begin{array}{l}\text { (Priestley \& Samaddar, } \\
\text { 2007) }\end{array}$ \\
\hline
\end{tabular}

\section{Avid Persuaders}

We identify the Avid Persuaders as equivalent to the Dominated Network described by Child et al. (2005) as well as the Lead-Organization-Governed Net- 
work defined by Provan \& Kenis (2008). The network is initiated, managed, and controlled by a focal organization. Additionally, we identify significant engagement in lobbying activities and interactions with start-ups. The focal organization is suspected to have high bargaining power; however, the other organizations are not necessarily committed by contracts. Thus, they are rather loose collaboration partners based on agreements. Lyytinen et al. (2016) describe this organizational form as the Federated Innovation Network, which consists of a heterogeneous set of actors, integrated into a hierarchical control structure.

\section{Value Chain Drivers}

Value Chain Drivers are characterized by collaboration of actors within the same value chain, which are concentrated in a single federal state. The focus within these networks is on innovation among the value chain and does not necessarily include usual business relations between actors in the value chain. Dussauge \& Garrette (1999) describe Vertical Partnerships between non-competing firms as a form of strategic alliances. However, we do not generally exclude competitors from Value Chain Drivers. A crucial aspect is mentioned as vertical partnerships might create conflicts as a result of different bargaining powers of the partners (Dussauge \& Garrette, 1999). This issue is possibly targeted within the Value Chain Drivers, as we observe a high frequency of shared governance forms. As Bau, Bentivegna, \& Forster (2014) identify the informal innovation network of Vertical Integration, we observe a strong consistency with the Value Chain Drivers, as both act along the value chain and are geographically limited to national borders or federal states. We assume that the Value Chain Drivers represent a formalized pendant to Vertical Integration. Additionally, Lyytinen et al. (2016) define the Clan Innovation Network, which shares common characteristics with the Value Chain Drivers, such as a homogeneous set of actors that are driven by common interests while no hierarchical control structure is established.

\section{Collective Facilitators}

We regard the Collective Facilitators as the most common type of formal innovation networks occurring in Germany, as they represent the largest group in our sample. The network is an emergent formation with equal participation rights that enables its actors to increase their scope of action beyond their value chain boundaries. This network type indicates similarities to the Equal-Partner Network described by Child, Faulkner, \& Tallman (2005) as well as the Participant-Governed Network defined by Provan \& Ke- 
nis (2008). The network is set up and controlled by multiple actors. The power is shared among different actors, which does not necessarily imply that all network members have equal power (Child et al., 2005). The actors within Collective Facilitators aim to leverage their complementary capabilities. Thus, actors from different industries build lateral connections, which corresponds to Cross-Industry Agreements from Dussauge \& Garrette (1999). We further observe overlapping features with the informal innovation network Knowledge and Learning described by Bau, Bentivegna, \& Forster (2014). Both are characterized by a very diverse and large set of actors who aim to access external knowledge and bridge internal knowledge gaps. We further indicate overlapping characteristics with the Anarchic Innovation Network described by Lyytinen et al. (2016). A high level of knowledge heterogeneity and the absence of hierarchical control structures characterize this network.

\section{Niche Specialists}

The Niche Specialists represent a group of networks that are initiated by established networks in order to occupy a niche for a specialized technology. A generalist network initiates a special purpose-focused network benefiting from its existing network structures. Company-wide initiatives and networks also initiate subordinated networks that are targeted at certain regions or technologies (BMWi, 2020).

\section{Lateral Thinkers}

The Lateral Thinkers are independent industry centers seeking to identify innovative solutions primarily through interaction with start-ups. The governance form of this network is comparable with the network administrative organization of Provan \& Kenis (2008). The strong industry and technology focus represents similarities to Strategic Alliances that aim to access and establish new technologies (Child et al., 2005; Dussauge \& Garrette, 1999). The Lateral Thinkers inhibit characteristics of Cross-Industry Agreements described as collaboration "(...) formed by companies from totally different industries which seek to diversify their activities by leveraging their complementary capabilities" (Dussauge \& Garrette, 1999, p. 55). Different from this definition, the actors within our Lateral Thinkers have their origin within the same industry. This is also reflected by StructureBased Innovation Networks defined by Wissema \& Euser (1991), in which companies from a sector interact to achieve common innovation. 


\section{Transnational Opportunity Seekers}

We identify the Transnational Opportunity Seekers as networks that are jointly initiated by companies in order to achieve complementary synergies across national borders. Similar to the informal innovation network type International Scope described by Bau et al. (2014), Transnational Opportunity Seekers can be represented by large projects that are promoted by the European Union. This is also assumed to be a motivational factor to participate in such networks to get access to public funding.

\section{Financially Resilient Connectors}

We identify networks that consist solely of equity-committed actors. We call these networks Financially Resilient Connectors that represent a purpose-driven enabler of financially sustainable innovation partnerships. Even though these networks represent Joint Ventures of different organizations, they do not necessarily share the common characteristics of described forms of Joint Ventures in previous research (Dussauge \& Garrette, 1999; Killich, 2011; Schuh et al., 2011). We observe similarities to the informal innovation network, called Financial Procurement, described by Bau et al. (2014). As the networks rather consist of a small number of actors, they share a strong common objective. This is represented by the strong technology focus of the Financially Resilient Connectors. To access and achieve new innovations, the networks seek connections with other innovators and start-ups. As access to financial resources for innovation projects is limited, the network management can access the equity committed by its actors to initiate projects.

\section{Local Trend Sponsors}

The Local Trend Sponsors are highly concentrated networks that are initiated by public institutions to offer a local interface for companies of all sizes. The networks can include local hubs or innovation and technology centers that also offer common premises for their members. The innovation centers are politically supported and therefore initiated by public institutions, but also involve local universities and R\&D institutes. The benefits of local concentration of companies are widely accepted and seen as a driver for the direction and pace of innovation (Porter, 1998). We find Local Trend Sponsors related to Industrial Districts, described by Inkpen \& Tsang (2005). Their Industrial Districts consist of independent firms that operate in the same or related market segments and benefit from agglomeration effects. Cooke et al. (1997) describe such local concentrations as Regional Innova- 
tion Systems that are also regarded as inter-organizational networks for SMEs (Kofler \& Marcher, 2018).

\section{Regional Activists}

We identify a group of networks that we call the Regional Activists. These networks are focused regional platforms to promote and foster selected business sectors holistically. Contrary to Regional Networks defined by Sydow (2001), the Regional Activists are described by hierarchical control structures. We assume that this results from the engagement of local development organizations during the initiation process of the networks. We see these organizations as the determining actors within the network. They can also be highly influenced by political initiatives and programs. The $R e$ gional Activists correspond to Regional Innovation Systems (Cooke et al., 1997). Owing to the strong local focus, we assume a high relevance for SMEs (Kofler \& Marcher, 2018).

\section{Associated Industry Supporters}

We identify Associated Industry Supporters as sector-specific networks that promote relevant topics, strengthen networks, and foster interaction between companies. They also represent the common interests of the actors within the network. Mieke (2008) has already described industry associations as a platform for innovations, especially for SMEs. They form a forum for discussion and joint processing of innovation-oriented technological areas. According to Mieke (2008), industry associations can bring together companies with complementary information channels and assessment skills that are willing to provide early information and thus contribute to a more active involvement in future technological issues. Based on the insights given by Mieke (2008), we assume that the Associated Industry Supporters benefit from the involved skill set and connections of the engaged industry associations. We suppose that the Associated Industry Supporters can play a crucial role within the innovation process of SMEs.

\section{Dynamic Research Groups}

We describe rather loose forms of research collaborations between actors from the research and university environment as Dynamic Research Groups. Previous research has already identified several different collaboration forms for R\&D. Priestley \& Samaddar (2007) describe R\&D Networks as having a decentralized governance structure and a low intensity of competition. Dynamic Research Groups consist mainly of relations between universities and research institutes that maintain only a few relations with single, 
selected industry partners. Therefore, we have to make a differentiation from common $R \& D$ Partnerships that consist of inter-firm relations (Hagedoorn, 2002). The rather loose form of collaboration of Dynamic Research Groups is mainly based on agreements. Such loose formations are also described as Dynamic Networks, which inhibit the possibility of continuous network adaptations (Snow et al., 1992).

Based on the number of members, our typology includes three major network types, Collective Facilitators, Avid Persuaders, and the Value Chain Drivers. Each type follows a different approach to enhance the exchange of knowledge among its actors and to enable access to external resources. We find that most of these network types are open to include SMEs, which does not necessarily mean that they are also the most suitable approaches for SMEs. Large networks with a broad focus could offer opportunities to internationalize or to enter new markets. As the business activities of SMEs are often geographically concentrated, we assume that especially networks with a regional and local focus, such as Regional Activists, Associated Industry Supporters, and Local Trend Sponsors, could enhance interaction with partners from science and industry to foster innovation. The Financially Resilient Connectors require a monetary investment that could indicate a barrier for SMEs to enter these networks. Capital provided by state initiative programs could reduce this barrier. Thus, this network could also reflect a very interesting approach to foster innovation among SMEs.

\subsection{Conclusion, implications, and limitations}

Our study serves as guidance for researchers, practitioners, and policy makers in the jungle of innovation networks. We address the lack of a comprehensive typology of innovation networks that combines the lone-standing attributes of previous studies into a holistic network typology. To our knowledge, we offer the first comprehensive typology of formal inter-organizational innovation networks that is grounded in theory as well as empirical data. As we find a clear answer to our formulated research question on the identification of different types of innovation networks, we can give several theoretical and practical implications. We believe that the mixed method approach including a cluster analysis suits the purpose of this paper very well. However, there are various limitations resulting from our applied methods and sampling procedure. 


\section{Theoretical implications}

We contribute to the literature by introducing the first comprehensive, empirically grounded network typology. Thereby, we confirm previously identified typologies and networks and reveal differences by comparing our findings with existing literature. Furthermore, we a find new network type-Niche Specialist-and refine and clarify existing types. Methodically, we contribute to the field of network research by applying a mixed method approach. We recommend this method as a very suitable approach to identify and verify network types based on their empirically identifiable characteristics. Previous studies analyze network types and their characteristics using qualitative data, yet there is no empirically grounded network model combining and integrating these lone-standing attributes from either an academic or a practitioner-oriented point of view. By applying an exploratory sequential mixed method approach, we provide a typology of innovation networks that takes into account previous theory as well as purposefully generated empirical data. Our typology of innovation networks is therefore well suited to serve as a basis for further research. It enables scholars to analyze networks and related topics like network performance or network benefits based on a precise model including clearly defined and delineated network types. So far existing typologies are not able to deliver a common basis for analysis and discussion, as they are not comprehensively depicting the empirical reality of networks.

\section{Practical implications}

The typology provides guidance for all actors already involved in innovation networks or striving to engage in networks in line with their innovation strategy. As every organization possesses a different set of resources, the need to access external resources is widely diverse across companies and sectors. Our typology can enable organizations to identify suitable networks regarding their individual needs, based on, e.g., geographical considerations, the ability and willingness to take individual influence or responsibility, or the aspired business support focus. Companies can choose network involvement targeting research and development and scientific partnerships, marketing, or a combination of motives. They can purposefully enter in networks that foster political contacting or that focus on business partnerships in privately administered associations. The typology can thereby be applied across industries as well as actor perspectives. The framework also serves as an orientation guide for the initiation of new networks or in formalizing existing informal innovation networks. 
As many networks are supported and funded by public institutions, federal administrations, or the German and European governments, this typology provides guidance for policy makers. The typology can be applied to better implement political and economic instruments to promote selected network types. We propose reducing barriers for SMEs to enter innovation networks by offering financial and organizational support.

\section{Limitations}

Our study incorporates certain limitations resulting from the applied sampling procedure and methods. As all considered networks are identified from the online listing provided by "Clusterplattform Deutschland", we are aware of possible exclusions of network types that might not meet the benchmark of the platform. The listing enables a structured sampling procedure to identify formalized networks at a comparable level of data and information quality. Still, we cannot ensure our typology to be complete. Nevertheless, we assume it is unlikely that other forms play a crucial role in undermining our results, if they occur rarely. Furthermore, we cannot exclude the possibility that our sampled networks are more actively influenced by political interventions than networks not listed on the platform. Additionally, our data set is geographically limited to Germany. We do not include observations regarding location, founding year, and size in our analysis. Therefore, we do not control for correlations between these characteristics and the network types. Public funding programs as well as technological, economic, and environmental developments might influence the time of foundation. Furthermore, promotions of federal states could influence the location, size, and emergence of specific network types. Nevertheless, we do not regard these aspects as important in influencing our typology.

The selection of network characteristics and features as well as the coding process within the qualitative content analysis underlie critical subjective elements of interpretation. To reduce this, the coding process is partially counter-tested among the authors. Nevertheless, certain elements of subjective interpretation could remain.

We excluded networks during the coding process, as insufficient data were accessible through publicly available resources at the time of the analysis. By excluding these networks, we possibly limit the outcome of the cluster analysis as well as the resulting typology. By only considering publicly available sources, we may lack information that would provide additional insights into the observed networks. 
Recommended avenues for further research

As networks play a crucial role in innovation strategies as well as economic developments, we suggest the analysis of the performance and effectiveness of different network types. The influence of specific characteristics on the performance of a network is of particular interest, as it could lead to contributions to steer the outcome of networks. Thus, it could support practitioners and policy makers during the initiation and promotion of certain network types.

By enriching the existing data set of identified formal, inter-organizational innovation networks, we expect to gain possible insights into the actor structure, the degree of involvement, geographical connections, as well as the temporal development of different network types. Additionally, private information from the networks could validate our findings and generate additional insights into the observed networks. We propose to analyze the identified networks in terms of their relevance and benefits for SMEs from both the network as well as the company perspectives.

As our data set is geographically limited, we suggest enriching the data set by additional data from Germany as well as from other European countries. This could yield more insights regarding national or regional differences in network types. 


\subsection{Appendix essay III}

Appendix 4-1: Initial network characteristics considered in the qualitative content analysis.

\begin{tabular}{|c|c|}
\hline Characteristic & Features \\
\hline Origin & $\begin{array}{l}\text { Top-down } \\
\text { Bottom-up }\end{array}$ \\
\hline Network positioning & $\begin{array}{l}\text { Superior network } \\
\text { Sub-network } \\
\text { Independent }\end{array}$ \\
\hline Network cooperations & $\begin{array}{l}1=\text { existent } \\
0=\text { non-existent }\end{array}$ \\
\hline Legal structure & $\begin{array}{l}\text { Registered association (e.v.) } \\
\text { GmbH } \\
\text { GmbH \& Co. KG } \\
\text { GbR } \\
\text { Foundation } \\
\text { "Körperschaft des öffentlichen Rechts" } \\
\text { Project or initiative by an organization }\end{array}$ \\
\hline $\begin{array}{l}\text { Legal representation (im- } \\
\text { print) }\end{array}$ & $\begin{array}{l}\text { Special purpose vehicle SPE by another organization/ } \\
\text { company } \\
\text { Organization for local development } \\
\text { Natural person from board } \\
\text { Research facility or university } \\
\text { Company } \\
\text { Corporation under public law } \\
\text { Chamber of commerce }\end{array}$ \\
\hline Power distribution & $\begin{array}{l}\text { Focal } \\
\text { Polycentric }\end{array}$ \\
\hline Control & $\begin{array}{l}\text { Hierarchical } \\
\text { Heterarchical }\end{array}$ \\
\hline Governance & $\begin{array}{l}\text { Lead organization } \\
\text { Network administration } \\
\text { Shared }\end{array}$ \\
\hline Network management & $\begin{array}{l}\text { Independent management } \\
\text { University/research organization } \\
\text { Local development organization } \\
\text { Company representatives } \\
\text { Chamber representatives } \\
\text { Association representatives } \\
\text { Public institution }\end{array}$ \\
\hline
\end{tabular}


4 Essay III: Guidance in the network jungle

\begin{tabular}{|c|c|}
\hline Characteristic & Features \\
\hline Network identity & $\begin{array}{l}\text { Reciprocal } \\
\text { Redistributive }\end{array}$ \\
\hline Structure & $\begin{array}{l}\text { Simple } \\
\text { Complex }\end{array}$ \\
\hline Geographical extent & $\begin{array}{l}\text { Local } \\
\text { Regional } \\
\text { State } \\
\text { National } \\
\text { International }\end{array}$ \\
\hline Duration & $\begin{array}{l}\text { Temporary } \\
\text { No limit }\end{array}$ \\
\hline Functional purpose & $\begin{array}{l}\text { Procurement } \\
\text { Production } \\
\text { Marketing } \\
\text { Customer } \\
\text { R\&D }\end{array}$ \\
\hline Direction & $\begin{array}{l}\text { Horizontal } \\
\text { Vertical } \\
\text { Lateral }\end{array}$ \\
\hline Membership & $\begin{array}{l}\text { Open } \\
\text { Closed } \\
\text { Partly open }\end{array}$ \\
\hline $\begin{array}{l}\text { Requirements for member- } \\
\text { ship }\end{array}$ & $\begin{array}{l}\text { Industry specific } \\
\text { Branch location } \\
\text { No requirements }\end{array}$ \\
\hline Bond intensity & $\begin{array}{l}\text { Low } \\
\text { Medium } \\
\text { High }\end{array}$ \\
\hline Commitment & $\begin{array}{l}\text { Arrangement } \\
\text { Contract } \\
\text { Equity }\end{array}$ \\
\hline Initiators of the network & $\begin{array}{l}\text { University/research institute } \\
\text { Association } \\
\text { Company } \\
\text { Chamber } \\
\text { Cluster/network } \\
\text { Local development organization } \\
\text { Public institution }\end{array}$ \\
\hline Actors in network & $\begin{array}{l}\text { Companies } \\
\text { Universities/R\&D institutes } \\
\text { Other }\end{array}$ \\
\hline
\end{tabular}




\begin{tabular}{ll}
\hline Characteristic & Features \\
\hline Supporting the search for & $1=$ existent \\
skilled workers & $0=$ non-existent \\
\hline Industry specific & $\begin{array}{l}1=\text { existent } \\
0=\text { non-existent }\end{array}$ \\
\hline Start-up support & $1=$ existent \\
& $0=$ non-existent \\
\hline \multirow{2}{*}{ Common premises } & $1=$ existent \\
\hline \multirow{2}{*}{ Lobbying } & $1=$ non-existent \\
\hline \multirow{2}{*}{ Technology focus } & $0=$ non-existent \\
\hline
\end{tabular}




\section{Appendix 4-2: Declaration of co-authorship for essay III}

Co-author declaration and confirmation concerning essay III

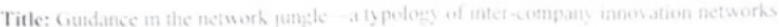

Candidate: Johannes I renkle

Authers: Johannes Irenhle, (art-Phalipp Betchert

Description of the independent research contributions of the candidate and the co-author

The contribution of the candidate:

1. Conception and desten wh the studs

2) 1) evign and intial esecuton of literature teview

3) Develonment of the model. is characteristics and attributes for analysis

4.) Acquisition of data

6) Corcoding of data on networb

6.) Data analysis - development of R-code for cluater analysi

7.) Interpretation of results - development of elester tuames hased on results of cluster amalysi and development of typology

8.) Draft of paper

9.) Flaboration of example cases

10.)Finish of paper

Candidate: Johannes Trenkle

Co-author's contribution:

1.) Support of literature review tow ards methods, refinement at liferat ure fevers tow ards network characteristics

2.) Co-coding of data on networks

3.) Data analysis - implementation of R-code according to model suggested by candidate

4.) Support of interpretation of results - participation in oral and written discussions on cluster denomination

5.) Critical revision of paper

Name: Carl-Philipp Beichert

We find the descriptions of our contribution in accordance with our view of the cooperation

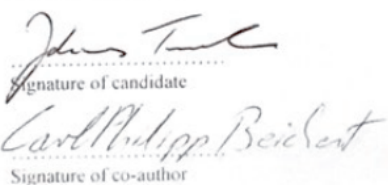

Signature of co-author 


\section{Conclusion}

\subsection{Summary of research findings and limitations}

"The dynamic advances in IT are not only central to the technological changes surrounding us, but also driver and mediator of societal and economic changes. Businesses need to react to these changes in concerted and organized ways,..."

(see: Teubner, 2013, p. 254)

The three essays in this dissertation support a structured approach to digital transformation in the context of SMEs on several levels. A digital transformation strategy along the four categories "use of technologies", "changes in value creation", "organizational aspects", and "financial aspects" should be the starting point for any firm-individual digital transformation endeavor. In order to realize benefits from technology absorption and to adapt to the increasingly digital business environment, components of a digital transformation control system covering cultural, planning, administrative, and performance indicator-based controls are derived as a promising measure. And last, a typology of 11 precisely characterized, empirically grounded innovation networks offer SMEs to expand own resources by external know-how, depending on individual targets, preferences and restrictions. The following paragraphs summarize the core implications of the three essays that form this dissertation and mention the incorporated limitations.

Essay I analyzes the view of SME owners on their journey of success through their individual digital transformation endeavors. I develop a digital transformation strategy framework that incorporates variations of the thoughts and actions that best practice SMEs ran through on their individual pathways of digital transformation. Scholars and practitioners get a comprehensive and systematic view on examples of successful digital transformation in seven cases of SMEs. The experiences of the people responsible for these developments are summarized in strategic questions in the four categories "use of technologies", "changes in value creation", "organizational aspects", and "financial aspects". My findings allow researchers to analyze, compare, discuss, and understand digital transformations across company sizes and sectors. The results thereby complement existing literature on digital business strategies (Bharadwaj et al., 2013) and expand exist- 
ing knowledge on digital transformation from single-industry, large-company backgrounds (Hess et al., 2016; Matt et al., 2015; Wiesböck et al., 2017) toward the specific features of SMEs. Based on the results, SME representatives can manage digital transformation more systematically and address inherent business challenges along the four presented categories more effectively. In the format of a structured questionnaire, I lead SME managers along elementary elements of their business and raise questions they should consider while structuring their digital transformation efforts comprehensively, thereby increasing the likelihood of success.

All cases under analysis are SMEs from the skilled craft sector, situated within a 100-kilometer radius around Munich. Although the cases cover urban and rural areas and I am therefore confident that infrastructure aspects do not make a difference regarding the strategic management considerations, the sample is biased regarding its geographic setting. Furthermore, the focus on companies from the skilled craft sector, despite covering various professions, incorporates a sectorial bias. Applying a qualitative approach incorporates an array of limitations. Seven cases are not representative and limit the validity of the results to the presented contexts. SMEs are confronted with only limited disclosure requirements, which makes information availability for triangulation a critical issue. I matched facts from the interview data as far as possible with publicly available sources, i.e., SMEs' websites, social media channels, books written by the owners, company brochures, and media articles. Nevertheless, a reconfirmation of all statements was not possible. Furthermore, I am unable to determine directions of causality as well as the level of intention of the interviewees, and I focus on critical, successful cases only.

Essay II develops a digital transformation control system from the actions, experiences, and opinions of the proprietors and managers of digitally leading SMEs. Routed in the "management control systems as a package" conceptualization by Malmi \& Brown, 2008, I find a selection of various measures among the categories of cultural controls, planning, administrative controls, and performance indicator-based controls that may support SMEs to control their digital transformation efforts. Trial-and-error as a representative, agile, controlling measure is incorporated in the concept. All identified measures are consciously or unconsciously applied by the decision makers in the case studies under analysis. I thereby elaborate the existing literature on MCS by incorporating controls with a special focus on digital transformation (Malmi \& Brown, 2008; Merchant \& Van der Stede, 2012; Simons, 1995), and combine it with recent claims for more agility (Schäffer \& Weber, 2016). For SME managers, the digital transformation 
control system yields a starting point for connecting existing MCS to the era of digitization or for establishing a MCS in response to the increasing business complexity resulting from digital transformation. Based on the obtained results, I want to encourage and guide decision makers in SMEs to control and track digital transformation initiatives based on cultural, planning, administrative, and performance indicator-based controls to realize benefits like increased performance or faster adaption to the digital environment that scholars ascribe to MCS usage in SMEs (e.g.: Amat et al., 1994; Laurinkevičiūtė \& Stasiškienė, 2011).

The limitations of essay II are comparable to those of essay I. All SMEs under analysis stem from the skilled craft sector and are covered by a 100kilometer radius around Munich. Also, the applied methodologies are comparable, incorporating a similar set of limitations, although the number of 11 cases is slightly higher. The lack of information availability was even more tangible as I had to rely completely on data and observations provided by the owner-managers of the firms. Many observations are subject to interpretation by me, as control measures are in use unintentionally or informally. To eliminate some degree of subjective interpretation, I invited junior researchers to join the interview situations and onsite visits with the companies as often as possible. Their observations were mobilized twofold. They helped to prepare company reports as a basis for the case descriptions, and they were engaged as second coders. Again, directions of causality are not deducible and essay II as well relies on successful cases of digital transformation only.

Essay III introduces a typology of formal, inter-organizational innovation networks. We find 11 distinct, generic, clearly defined and delineated network types by applying an exploratory sequential mixed method approach (Täuscher \& Laudien, 2018). Therefore, our typology of innovation networks is based just as much in previous theory as in specifically collected, empirical data. We conduct a directed content analysis to compile a comprehensive data set and use HAC, involving the Ward D2 linkage method. Existing literature regarding network characteristics and features (e.g., Killich, 2011; Sydow, 1992) serves as input for our content analysis, where we manually collect and code the attributes of initially more than 400 networks. The resulting, numerical results of 300 networks in the final dataset are then processed within hierarchical agglomerative clustering to derive the first comprehensive generalizable network typology. We identify Avid Persuaders, Value Chain Drivers, Collective Facilitators, Niche Specialists, Lateral Thinkers, Transnational Opportunity Seekers, Financially Resilient Connectors, Local Trend Sponsors, Regional Activists, Associated Industry Sup- 
porters, and Dynamic Research Groups as 11 generic types of networks and we discuss them extensively based on existing literature. This makes us the first to develop a universally valid typology that is based purely on empirical observations and is independent of specific objects of observation. Therefore, we see our model to be the ideal basis for further research, e.g. comparing network performance or benefits. It also gives guidance to practitioners from corporate or political backgrounds. Corporate decision makers can search for involvement in network types that fit his preferences, while political institutions can foster networks that support their respective agenda.

Our approach still yields some limitations. We identify all networks for our analysis from the online listing provided by "Clusterplattform Deutschland" (BMWi, 2020), which may incorporate possible exclusions of network types. This also implies a geographic limitation. The selection of network characteristics and features as well as the coding process within the qualitative content analysis underlie subjective elements. To reduce subjectivity in coding, critical codes were counter-tested by the co-authors. Furthermore, we excluded networks during the coding process, as not enough data were accessible through publicly available sources. By only considering publicly available sources, we may lack information that would provide additional insights. And last, cluster analysis is subject to several critical limitations. If the data, the selection process, the number of clusters, or the underlying algorithm were changed, it could affect the outcome as well as the final typology. We follow a structured process to select the cluster variables, the clustering method, and the optimal number of clusters to ensure high-quality results (Backhaus et al., 2018; Everitt et al., 2011).

\subsection{Avenues for further research}

Though digital transformation on an individual company level should be a temporary phenomenon, the dynamics of digitalization and necessary transformational activities will probably become part of everyday life for companies to counter the incorporated opportunities and risks. Therefore, it might be a promising path of research to analyze digital transformation from a longitudinal, process-oriented standpoint. Furthermore, the results of my study can be modeled as input variables to investigate variance in the mid- to long-term financial and nonfinancial benefits from digital transformation, at a single company or even societal level. Addressing the 
incorporated limitations of my study, a similar study with an extended geographic as well as sectorial coverage might yield interesting results to confirm and discuss my findings. Even a variation in environmental and infrastructure issues might be useful to deepen our understanding of strategy development in digital transformation. So far, most studies on digital transformation journeys are single or multiple case studies, including my study. The thereby generated qualified hypothesis can promote quantitative studies of the phenomenon of digital transformation to strive for generalization across the boundaries of sectors and industries, or even countries. A key issue in the context of SMEs will be data availability, so surveys and/or large-scale interview panels might be options to generate valuable data sets. In discussions of my work at conferences, a key issue raised was whether my results empower SME representatives to handle digital transformation and develop a digital transformation strategy from the provided framework? Reviewers doubted the capabilities of average SME representatives to answer the presented questions in a fruitful, value-creating way. As I develop the framework inductively from the data I gathered, I can say that there are SME managers who can develop a digital transformation strategy successfully. To put it bluntly, I only wrote down what my interview partners had done and achieved. But as I am only relying on data from successful examples, it would be interesting to contrast my results with examples of failure, as well as to test my results regarding their user friendliness for average SMEs.

In my study of potential management control measures useful throughout digital transformation, I try to be as "neutral" as possible regarding connectivity to related academic concepts, i.e., management control conceptualizations as well as explicit constructs such as the balanced scorecard (e.g., Craig \& Moores, 2005). Yet the combination of dedicated instruments of management control with fields of action in digital transformation, especially in the context of SMEs, still offers an almost unlimited exploration ground for further research. In line with existing research on potential benefits from management control measure usage, studies of the advantageousness of digital transformation control implementation regarding digital transformation performance would greatly advance academic knowledge as well as support practitioners in the decision on whether or not to allocate SMEs' scarce financial and personal resources to digital transformation control efforts. In this context, a contrast with less successful companies in terms of digital transformation would also yield interesting insights, in terms of both digital transformation control system design as well as expected benefits. Comparable to essay I, the limited geographic 
and sectorial coverage of my study offers opportunities for repetition across countries, industries, regions, etc., in order to challenge and refine my results and strengthen the foundations of digital transformation control systems. The inclusion of less digitally successful case studies would contribute to a better understanding of actions and measures of digital transformation control. Large-scale descriptive studies promise knowledge on dissemination and application of control measures during digital transformation journeys. Another viewpoint for further studies is the existence and roles of further agile methods. My study creates a first empirical connection between agile control in the form of trial-and-error and MCS. Further agile working methods are spreading in the course of digitalization. I consider their relationship to MCS concepts as a highly promising field of research.

Regarding networks and their estimated, crucial role in innovation and digital transformation strategies as well as their influence on economic ecosystems, we suggest focusing on an analysis of performance and effectiveness among different types of networks. Furthermore, the influence of specific characteristics and attributes on network performance is of interest, as this might contribute to steer network outcomes in targeted directions. To give an example, we propose an analysis of the identified network types in terms of their relevance and benefits for SMEs. Especially for company and policy representatives, findings in this field would be of great value when initiating and promoting certain network types. In our analysis, we only rely on publicly available data. Private information from networks could validate our findings and provide valuable insights for refinement of our typology. Another interesting area of research emerges from our geographic limitation to Germany. Data on networks from European or worldwide countries might yield a conformation of our findings, geographic foci of selected network types, or even additional network types emerging from the current, dynamic era of digitalization. 


\section{References}

Abernethy, M. A., \& Chua, W. F. (1996). A Field Study of Control System "Redesign": The Impact of Institutional Processes on Strategic Choice. Contemporary Accounting Research, 13(2), 569-606.

Achrol, R. S., \& Kotler, P. (1999). Marketing in the network economy. Journal of Marketing, 63(SUPPL.), 146. https://doi.org/10.2307/1252108

Adler, R., Everett, A. M., \& Waldron, M. (2000). Advanced management accounting techniques in manufacturing: utilization, benefits, and barriers to implementation. Accounting Forum, 24(2), 131-150. https://doi.org/10.1111/1467-6303. 00032

Agostini, L., \& Nosella, A. (2019). Inter-organizational relationships involving SMEs: A bibliographic investigation into the state of the art. Long Range Planning, 52(1), 1-31. https://doi.org/10.1016/j.lrp.2017.12.003

Ahmad, K., \& Zabri, S. M. (2016). Management accounting practices among small and medium enterprises. Proceedings of the 28th International Business Information Management Association Conference - Vision 2020: Innovation Management, Development Sustainability, and Competitive Economic Growth, (November 2016), $3627-3637$.

Alattar, J. M., Kouhy, R., \& Innes, J. (2009). Management accounting information in micro enterprises in Gaza. Journal of Accounting \& Organizational Change, 5(1), 81-107. https://doi.org/10.1108/18325910910932223

Amat, J., Carmona, S., \& Roberts, H. (1994). Context and change in management accounting systems: a Spanish case study. Management Accounting Research, 5(2), $107-122$.

Anderson, S. (1995). A framework for assessing cost management system changes: the case of activity-based costing implementation at General Motors, 1986-1993. Journal of Management Accounting Research, 7, 1-51. https://doi.org/10.5267/j.msl. 2015.1.017

Astor, M., Rammer, C., Klaus, C., Klose, G., \& Böllhoff, C. (2016). Innovativer Mittelstand 2025 - Herausforderungen, Trends und Handlungsempfehlungen für Wirtschaft und Politik. ZEW-Gutachten Und Forschungsberichte., 191. Retrieved from http://ftp.zew.de/pub/zew-docs/gutachten/InnovativerMittelstand2 025.pdf

Atkinson, R. D., \& Kay, A. S. M. C. (2018). Digital Prosperity: Understanding the Economic Benefits of the Information Technology Revolution. Washington. Retrieved from http://ssrn.com/abstract=1004516

Backhaus, K., Erichson, B., Plinke, W., \& Weiber, R. (2018). Multivariate Analysemethoden. Multivariate Analysemethoden (14th ed.). Berlin, Heidelberg: Springer Berlin Heidelberg. https://doi.org/10.1007/978-3-662-56655-8 
Barney, J. (1991). Firm resources and sustained competitive advantage. Journal of Management, 17(1), 99-120. https://doi.org/10.1177/014920639101700108

Bau, F., Bentivegna, T., \& Forster, M. (2014). Ad-hoc innovation networks of european SMEs - a typology of networks based on a multiple case study. Retrieved from https:/ /www.researchgate.net/profile/Frank_Bau/publication/268895381_Ad-hoc_Inno vation_Networks_of_European_SMEs_A_typology_of_networks_based_on_a multiple_case_study/links/547ad3400cf́2a961e487b6e7/Ad-hoc-Innovation-Netw orks-of-European-SMEs-A-typology-of

Becker, W., Ulrich, P., \& Staffel, M. (2011). Management accounting and controlling in German SMEs - do company size and family influence matter? International Journal of Entrepreneurial Venturing, 3(3), 281-300.

Bharadwaj, A., El Sawy, O. A., Pavlou, P. A., \& Venkatraman, N. (2013). Digital Business Strategy: Toward a next generation of insights. MIS Quarterly, 37(2), 471-482.

BMWi. (2018). Monitoring-Report Wirtschaft Digital 2018. Berlin.

BMWi. (2020). Clusterplattform Deutschland.

Bonner, S. E., \& Sprinkle, G. B. (2002). The effects of monetary incentives on effort and task performance: Theories, evidence, and a framework for research. Accounting, Organizations and Society, 27(4-5), 303-345. https://doi.org/10.1016/S03 61-3682(01)00052-6

Bowersox, D. J., Closs, D. J., \& Drayer, R. W. (2005). The Digital Transformation: Technology and Beyond. Supply Chain Management Review, 9(1), 22-29.

Broadbent, J., \& Laughlin, R. (2009). Performance management systems: A conceptual model. Management Accounting Research, 20(4), 283-295. https://doi.org/ 10.1016/j.mar.2009.07.004

Brynjolfsson, E., \& McAfee, A. (2014). The second machine age (1st ed.). New York, NY; London: W.W. Norton \& Company.

Buhl, C. M., Sedlmayr, B., \& Meier, G. (2019). Trendatlas: Entwicklungsdynamiken von Clusterinitiativen in Deutschland im Zeitverlauf. Berlin: Institut für Innovation und Technik.

Burns, J., \& Scapens, R. W. (2000). Conceptualizing management accounting change: An institutional framework. Management Accounting Research, 11(1), 325. https://doi.org/10.1006/mare.1999.0119

Campbell, J. L., Quincy, C., Osserman, J., \& Pedersen, O. K. (2013). Coding Indepth Semistructured Interviews: Problems of Unitization and Intercoder Reliability and Agreement. Sociological Methods and Research, 42(3), 294-320. https://d oi.org/10.1177/0049124113500475

Carney, M. (2005). Corporate governance and competitive advantage in familycontrolled firms. Entrepreneurship Theory \& Practice, 29(3), 249-265. https://doi.o rg/10.1111/etap. 12080

Casals, F. E. (2011). The SME co-operation framework: A multi-method secondary research approach to SME collaboration. In 2010 International Conference on Ebusiness, Management and Economics (IPEDR) (Vol. 3, pp. 118-124). Hong Kong. 
Chand, M., \& Dahiya, A. (2010). Application of management accounting techniques in Indian small and medium hospitality enterprises: An empirical study. International Journal of Entrepreneurship \& Small Business, 11(1), 25-41. https://do i.org/10.1504/IJESB.2010.034430

Chenhall, R. H. (2003). Management control systems design within its organizational context: findings from contingency-based research and directions for the future. Accounting, Organizations and Society, 28(2-3), 127-168. https://doi.org/10 $.1016 /$ S0361-3682(01)00027-7

Chesbrough, H. W. (2003). Open innovation: The new imperative for creating and profiting from technology. Boston: Harvard Business School Press.

Child, J., Faulkner, D., \& Tallman, S. (2005). Cooperative strategy: managing alliances, networks and joint ventures (2nd ed.). New York: Oxford University Press.

Cooke, P., Gomez Uranga, M., \& Etxebarria, G. (1997). Regional innovation systems: Institutional and organisational dimensions. Research Policy, 26(4-5), 475491. https://doi.org/10.1016/S0048-7333(97)00025-5

Craig, J., \& Moores, K. (2005). Balanced Scorecards to drive the Strategic Planning of Family Firms. Family Business Review, 18(2), 105-122.

Creswell, J. C. (2014). Research design: Qualitative, quantitative and mixed methods approaches (4th ed.). SAGE Publications, Inc. https://doi.org/0.1177/2050312117 740990

Creswell, J. W., \& Creswell, J. D. (2018). Research Design: Qualitative, Quantitative, and Mixed Methods Approaches (5th ed.). Thousand Oaks, CA: SAGE Publications.

Cross, R., Nohria, N., \& Parker, A. (2002). Six miths about informal organizationand how to overcome them. MIT Sloan Management Review, 43(3), 67-75. https:/ /doi.org/10.1371/journal.pone.0015090

Cummings, T. G., \& Worley, C. G. (2015). Organization Development and Change (10th ed.). Stamford, CT: Cengage Learning.

Davila, T. (2000). An empirical study on the drivers of management control systems' design in new product development. Accounting, Organizations and Society, 25(4-5), 383-409. Retrieved from http://www.scopus.com/inward/record.url?eid =2-s2.0-0034179289\&partnerID=40\&md5=68d099f9d135523119e19c922731ed43

De Lema, D. G. P., \& Duréndez, A. (2007). Managerial behaviour of small and medium-sized family businesses: An empirical study. International Journal of Entrepreneurial Behaviour and Research, 13(3), 151-172. https://doi.org/10.1108/1355 2550710751030

De Loo, I., \& Davis, D. (2003). Black Swan records, 1921 to 1924: from a swanky swan to a dead duck. Accounting History, 8(2), 35-60.

Degryse, C. (2016). Digitalisation of the economy and its impact on labour markets. European Trade Union Institute. Retrieved from http://www.ssrn.com/abstract=27 30550

Dehning, B., Richardson, V. J., \& Zmund, R. W. (2003). The value relevance of announcements of transformational information technology investments. MIS Quarterly, 27(4), 637-656. 
Dekker, H. C. (2004). Control of inter-organizational relationships: Evidence on appropriation concerns and coordination requirements. Accounting, Organizations and Society, 29(1), 27-49. https://doi.org/10.1016/S0361-3682(02)00056-9

Dekker, J. C., Lybaert, N., Steijvers, T., Depaire, B., \& Mercken, R. (2013). Family Firm Types Based on the Professionalization Construct: Exploratory Research. Family Business Review, 26(1), 81-99. https://doi.org/10.1177/0894486512445614

Dekker, J., Lybaert, N., Steijvers, T., \& Depaire, B. (2015). The Effect of Family Business Professionalization as a Multidimensional Construct on Firm Performance. Journal of Small Business Management, 53(2), 516-538. https://doi.org/10. 1111/jsbm.12082

Delgado, M., Porter, M. E., \& Stern, S. (2016). Defining clusters of related industries. Journal of Economic Geography, 16(1), 1-38. https://doi.org/10.1093/jeg/lbv0 17

Denzin, N. K. (1978). The research act in sociology: a theoretical introduction to sociological methods (2nd ed.). New York: McGraw-Hill.

Dörner, K., \& Edelman, D. (2015). What ' digital' really means. McKinsey Quarterly, (July), 1-3. Retrieved from http:/www.mckinsey.com/industries/high-tech/o ur-insights/what-digital-really-means

Downes, L., \& Nunes, P. F. (2013). Big-bang disruption. Harvard Busines Review, 91(3), 44-56.

Drnevich, P. L., \& Croson, D. C. (2013). Information technology and business-level strategy: toward an integrated theoretical perspective. MIS Quarterly, 37(2), 483-509. https://doi.org/10.1016/j.sbspro.2013.06.099

Duréndez, A., Madrid-Guijarro, A., \& García-Pérez-de-Lema, D. (2011). Innovative culture, management control systems and performance in small and mediumsized spanish family firms. Innovar, 21(40), 137-154.

Duréndez Gómez-Guillamón, A., Ruíz-Palomo, D., García-Pérez-de-Lema, D., \& Diéguez-Soto, J. (2016). Management control systems and performance in small and medium family firms. European Journal Of Family Business, 6(1), 10-20. https://doi.org/10.24310/ejfbejfb.v6i1.5043

Dussauge, P., \& Garrette, B. (1999). Cooperative strategy: Competing successfully through strategic alliances. Chichester: John Wiley \& Sons, Ltd.

Earley, S. (2014). The Digital Transformation: Staying Competitive. IT Professional, 16(2), 58-60.

Easterby-Smith, M., Golden-biddle, K., \& Locke, K. (2008). Working With Pluralism. Organizational Research Methods, 11(3), 419-429. https://doi.org/10.1177

Eckert, S.-M. (2009). Strategieorientiertes Kostenmanagement in Unternehmensnetzwerken (1st ed.). Wiesbaden: Gabler. https://doi.org/10.1007/978-3-8349-8367-1

Eisenhardt, M. K. (1989). Building Theories from Case Study Research. The Academy of Management Review, 14(4), 532-550.

El-Ebaishi, M., Karbhari, Y., \& Naser, K. (2003). Empirical evidence on the use of management accounting techniques in a sample of Saudi manufacturing companies. International Journal of Commerce and Management, 13(2), 74-101. 
El Masri, T., Tekathen, M., Magnan, M., \& Boulianne, E. (2017). Calibrating management control technologies and the dual identity of family firms. Qualitative Research in Accounting and Management, 14(2), 157-188. https://doi.org/10.1108/ QRAM-05-2016-0038

El Sawy, O. A., Amsinck, H., Kræmmergaard, P., \& Vinther, A. L. (2016). How Lego Built the Foundations and Enterprise Capabilities for Digital Leadership. MIS Quarterly Executive, 15(2), 1-17.

European Commision. (2015). User guide to the SME Definition. User Guide to the SME Definition. https://doi.org/10.2873/782201

European Commission. (2019). Annual Report on European SMEs 2018/2019. SME Performance Review 2018/2019, accessed 04/30/2020. Retrieved from https://ec.eur opa.eu/docsroom/documents/38366/attachments/2/translations/en/renditions/na tive

Eurostat. (2020). Yearly statistics - SME overview in non-financial business economy. Retrieved from https://ec.europa.eu/eurostat/de/web/products-datasets/prod uct? code=tin00145

Everitt, B., Landau, S., Leese, M., \& Stahl, D. (2011). Cluster analysis. (D. Balding, N. Cressie, G. Fritzmaurice, H. Goldstein, G. Molenberghs, D. Scott, ... S. Weisberg, Eds.) (5th ed.). London: John Wiley \& Sons, Ltd.

Fauchart, E., \& Gruber, M. (2011). Darwinians, Communitarians, and Missionaries: the Role of Founder Identity in Entrepreneurship. The Academy of Management Journal, 54(5), 935-957. https://doi.org/10.2307/41413600

Fernández, Z., \& Nieto, M. J. (2005). Internationalization Strategy of Small and Medium-Sized Family Businesses: Some Influential Factors. Family Business Review, 18(1), 77-89. https://doi.org/10.1111/j.1741-6248.2005.00031.x

Ferreira, L. D., \& Merchant, K. A. (1992). Field Research in Management Accounting and Control: A review and evaluation. Accounting, Auditing \& Accountability Journal, 5(4), 3-34.

Fisher, G., \& Aguinis, H. (2017). Using Theory Elaboration to Make Theoretical Advancements. Organizational Research Methods, 20(3), 438-464. https://doi.org/ $10.1177 / 1094428116689707$

Fitzgerald, M., Kruschwitz, N., Bonnet, D., \& Welch, M. (2013). Embracing Digital Technology: A New Strategic Imperative. MITSloan Management Review. https://doi. org/10.1057/palgrave.ejis.3000650

Flamholtz, E. G., Das, T. K., \& Tsui, A. S. (1985). Toward an integrative framework of organizational control. Accounting, Organizations and Society, 10(1), 35-50. https://doi.org/10.1016/0361-3682(85)90030-3

Fletcher, M., \& Plakoyiannaki, E. (2009). Case selection in international business : key issues and common misconceptions, (Hyde 2000), 171-191.

Flick, U. (2014). An Introduction To Qualitative Edition 5. SAGE Publications. https://doi.org/10.3390/toxins 8020037 
Friese, M. (1998). Kooperation als Wettbewerbsstrategie für Dienstleistungsunternehmen. (M. Kleinaltenkamp, H. Engelhardt, A. Meyer, H. Mühlbacher, \& B. Stauss, Eds.). Wiesbaden: Deutscher Universitätsverlag. https://doi.org/10.1007/9 78-3-663-01487-4

Galenson, D. W. (2010). Understanding creativity. Journal of Applied Economics, XIII(2), 1-32. https://doi.org/10.1111/j.1469-185X.2008.00065.x

Garengo, P., \& Bernardi, G. (2007). Organizational capability in SMEs: Performance measurement as a key system in supporting company development. International Journal of Productivity and Performance Management, 56(5-6), 518-532. https://doi.org/10.1108/17410400710757178

Gereffi, G., Humphrey, J., \& Sturgeon, T. (2005). The governance of global value chains. Review of International Political Economy, 12(1), 78-104. https://doi.org/10 $.1080 / 09692290500049805$

Gimpel, H., \& Röglinger, M. (2015). Digital Transformation: Changes and Chances Insights based on an Empirical Study. Project Group Business and Information Systems Engineering (BISE) of the Fraunhofer Institute for Applied Information Technology FIT. Augsburg/Bayreuth.

Gioia, D. A., Corley, K. G., \& Hamilton, A. L. (2013). Seeking Qualitative Rigor in Inductive Research: Notes on the Gioia Methodology. Organizational Research Methods, 16(1), 15-31. https://doi.org/10.1177/1094428112452151

Giovannoni, E., Maraghini, M. P., \& Riccaboni, A. (2011). Transmitting knowledge across generations: The role of management accounting practices. Family Business Review, 24(2), 126-150. https://doi.org/10.1177/0894486511406722

Glasl, M. (2007). Handwerksbetriebe. In R. Köhler, H. U. Küpper, \& A. Pfingsten (Eds.), Handwörterbuch der Betriebswirtschaft (6th ed., pp. 664-674). Stuttgart: Schäffer-Poeschel.

Glasl, M., Maiwald, B., \& Wolf, M. (2008). Handwerk - Bedeutung, Definition, Abgrenzung. Munich.

Glückler, J., Dehning, W., Janneck, M., \& Armbrüster, T. (2012). Unternehmensnetzwerke. (J. Glückler, W. Dehning, M. Janneck, \& T. Armbrüster, Eds.). Berlin, Heidelberg: Springer Berlin Heidelberg. https://doi.org/10.1007/978-3-642-29531 $-7$

Gouldner, A. W. (1960). The Norm of Reciprocity: A Preliminary Statement. American Sociological Review, 25(2), 161. https://doi.org/10.2307/2092623

Green, S. G., \& Welsh, M. A. (1988). Cybernetics and Dependence: Reframing the Control Concept. Academy of Management Review, 13(2), 287-301. https://doi.or g/10.5465/amr.1988.4306891

Greengard, S. (2016). Cybersecurity gets smart. Communications of the ACM, 59(5), 29-31. https://doi.org/10.1145/2898969

Grover, V., \& Kohli, R. (2013). Revealing Your Hand: Caveats in Implementing Digital Business Strategy. MIS Quarterly, 37(2), 655-663. https://doi.org/https://d 1.acm.org/citation.cfm?id=2535679 
Guba, E. G., Re-, S., Clark, D., Havlicek, L., Mclaughlin, J., \& Miskel, C. (1981). ERIC / ECTJ Annual Review Paper Criteria for Assessing the Trustworthiness of Naturalistic Inquiries. Educational Communication and Technology Journal, 29(2), 75-91.

Gul, F. A. (1991). The Effects of Management Accounting Systems and Environmental Uncertainty on Small Business Managers' Performance. Accounting and Business Research, 22(85), 57-61. https://doi.org/10.1080/00014788.1991.9729418

Gunawan, G., Ellis-Chadwick, F., \& King, M. (2008). An empirical study of the uptake of performance measurement by Internet retailers. Internet Research, 18(4), 361-381. https://doi.org/10.1108/10662240810897781

Haberich, R. (2018). Digital transformation: seven mistakes to be avoided by CEOs. Retrieved March 18, 2020, from https://www.industry-of-things.de/digitale-trans formation-diese-7-fehler-sollten-ceos-vermeiden-a-698009/

Hagedoorn, J. (2002). Inter-firm R\&D partnerships: an overview of major trends and patterns since 1960. Research Policy, 31(4), 477-492. https://doi.org/10.1016/ S0048-7333(01)00120-2

Hagenhoff, S. (2008). Innovationsmanagement für Kooperationen: Eine instrumentenorientierte Betrachtung. Göttingen: Universitätsverlag Göttingen.

Hakola, M. (2010). Balanced scorecard as a tool for small business reorganisation. International Journal of Management and Enterprise Development. https://doi.org/1 0.1504/ijmed.2010.037564

Halabi, A. K., Dyt, R., \& Barrett, R. (2010). Understanding financial information used to assess small firm performance: An Australian qualitative study. Qualitative Research in Accounting \& Management, 7(2), 163-179. https://doi.org/10.1108 /11766091011050840

Han, J., Kamber, M., \& Pei, J. (2012). Data mining. Concepts and techniques (3rd ed.). Waltham: Morgan Kaufmann.

Hansen, R., \& Sia, S. K. (2015). Hummel's Digital Transformation Toward Omnichannel Retailing: Key Lessons Learned. MIS Quarterly Executive, 14(2), 51-66.

Helsen, Z., Lybaert, N., Steijvers, T., Orens, R., \& Dekker, J. (2017). Management Control Systems in Family Firms: a Review of the Literature and Directions for the Future. Journal of Economic Surveys, 31(2), 410-435. https://doi.org/10.1111/j oes. 12154

Henderson, J. C., \& Venkatraman, N. (1993). Strategic alignment: Leveraging information technology for transforming organizations. IBM Systems Journal, 38(1), 4-16.

Henriette, E., Feki, M., \& Boughzala, I. (2015). The Shape of Digital Transformation: A Systematic Literature Review. In Mediterranean Conference on Information Systems (MCIS) Proceedings (pp. 1-13). Samos, Greece.

Hess, T. (2002). Netzwerkcontrolling (1st ed.). Wiesbaden: Deutscher Universitätsverlag. https://doi.org/10.1007/978-3-322-81987-1

Hess, T., Benlian, A., Matt, C., \& Wiesböck, F. (2016). Options for Formulating a Digital Transformation Strategy. MIS Quarterly Executive, 15(2), 123-139. https:// doi.org/10.1108/10878571211209314 
Hiebl, M. R. W., \& Mayrleitner, B. (2017). Professionalization of management accounting in family firms: the impact of family members. Review of Managerial Science, 1-32. https://doi.org/10.1007/s11846-017-0274-8

Hirschheim, R., \& Sabherwal, R. (2001). Detours in the Path toward Strategic Information Systems Alignment. California Management Review, 44(1), 87-108. https://doi.org/10.2307/41166112

Horlacher, A., \& Hess, T. (2016). What does a chief digital officer do? Managerial tasks and roles of a new C-level position in the context of digital transformation. Proceedings of the Annual Hawaii International Conference on System Sciences, March, 5126-5135. https://doi.org/10.1109/HICSS. 2016.634

Hottenrott, H., \& Lopes-Bento, C. (2016). R\&D partnerships and innovation performance: Can there be too much of a good thing? Journal of Product Innovation Management, 33(6), 773-794. https://doi.org/10.1111/jpim.12311

Howorth, C., \& Westhead, P. (2003). The focus of working capital management in UK small firms. Management Accounting Research, 14(2), 94-111. https://doi.org/ 10.1016/S1044-5005(03)00022-2

Hsieh, H.-F., \& Shannon, S. E. (2005). Three approaches to qualitative content analysis. Qualitative Health Research, 15(9), 1277-1288. https://doi.org/10.1177/1049 732305276687

Hussin, H., King, M., \& Cragg, P. (2002). IT alignment in small firms. European Journal of Information Systems, 11(2), 108-127. https://doi.org/10.1057/palgrave/ej is/3000422

HwO. Gesetz zur Ordnung des Handwerks (Handwerksordnung).

IfM. (2016). SME in Germany according to the definition of the European commission (original: KMU in Deutschland gemäß der KMU-Definition der EU-Kommission). Retrieved from https:/www.ifm-bonn.org/fileadmin/data/redaktion/st atistik/unternehmensbestand/dokumente/KMU-D_2012-2016_EU-Def.pdf

IfM. (2018). SME in Germany according to the definition of the European commission (engl. original: KMU in Deutschland gemäß der KMU-Definition der EUKommission). Retrieved April 27, 2020, from https:/www.ifm-bonn.org/filead $\mathrm{min} /$ data/redaktion/statistik/unternehmensbestand/dokumente/KMU-D_2014-2 018_EU-Def.pdf

Inkpen, A., \& Tsang, E. (2005). Social capital, networks, and knowledge transfer. The Academy of Management Review, 30(1), 146-165.

Ittner, C., \& Larcker, D. (1998). Innovations in Performance Measurement: Trends and Research Implications. Journal of Management Accounting Research, 10, $205-$ 238.

Johnson, H. T., \& Kaplan, R. S. (1987). Relevance Lost: The Rise and Fall of Management Accounting. Boston, MA: Harvard Business School.

Jorissen, A., Laveren, E., Martens, R., \& Reheul, A. M. (2005). Real versus samplebased differences in comparative family business research. Family Business Review, 18(3), 229-246. https://doi.org/10.1111/j.1741-6248.2005.00044.x 
Kallmuenzer, A., Strobl, A., \& Peters, M. (2018). Tweaking the entrepreneurial orientation-performance relationship in family firms: the effect of control mechanisms and family-related goals. Review of Managerial Science, 12(4), 855-883. https://doi.org/10.1007/s11846-017-0231-6

Kane, G. C., Palmer, D., Philips, A. N., Kiron, D., \& Buckley, N. (2015). Strategy, Not Technology, Drives Digital Transformation. MIT Sloan Management Review. https://doi.org/http:/www2.deloitte.com/content/dam/Deloitte/cn/Documents/t echnology-media-telecommunications/deloitte-cn-tmt-strategy-not-technology-d rive-digital-transformation-en-150930.pdf

Kaplan, R.S., \& Norton, D. P. (1992). The Balanced Scorecard: measures that drive performance. Harvard Business Review, 70(January and February), 71-79.

Kaplan, Robert S. (1994). Management accounting (1984-1994): development of new practice and theory. Management Accounting Research, 5(3-4), 247-260.

Karagozoglu, N., \& Lindell, M. (2004). Electronic commerce strategy, operations, and performance in small and medium-sized enterprises. Journal of Small Business and Enterprise Development, 11(3), 290-301. https://doi.org/10.1108/1462600 0410551555

Karimi, J., \& Walter, Z. (2015). The role of dynamic capabilities in responding to digital disruption: A factor-based study of the newspaper industry. Journal of Management Information Systems, 32(1), 39-81. https://doi.org/10.1080/07421222. 2015.1029380

Kassambara, A. (2017). Practical Guide to Cluster Analysis in R: Unsupervised Machine Learning. Multivariate Analysis I. STHDA.

Katz, R. L., \& Koutroumpis, P. (2013). Measuring digitization: A growth and welfare multiplier. Technovation, 33(10-11), 314-319. https://doi.org/10.1016/j.tech novation.2013.06.004

Kaufman, L., \& Rousseeuw, P. J. (2005). Finding Groups in Data: An Introduction to Cluster Analysis. Hoboken, New Jersey: John Wiley \& Sons, Inc.

Killich, S. (2011). Formen der Unternehmenskooperation. In T. Becker, I. Dammer, J. Howaldt, \& A. Loose (Eds.), Netzwerkmanagement (pp. 13-22). Berlin, Heidelberg: Springer Berlin Heidelberg. https://doi.org/10.1007/978-3-64 2-19333-0_2

Kingston, C., \& Caballero, G. (2009). Comparing theories of institutional change. Journal of Institutional Economics, 5(2), 151-180. https://doi.org/10.1017/s1744137 409001283

Kofler, I., \& Marcher, A. (2018). Inter-organizational networks of small and medium-sized enterprises (SME) in the field of innovation: A case study of South Tyrol. Journal of Small Business \& Entrepreneurship, 30(1), 9-25. https://doi.org/10.1 080/08276331.2017.1401202

Kohnke, O. (2017). It's Not Just About Technology: The People Side of Digitization. In G. Oswald \& M. Kleinemer (Eds.), Shaping the Digital Enterprise: Trends and Use Cases in Digital Innovation and Transformation (pp. 69-92). Switzerland: Springer. https://doi.org/10.1007/978-3-319-40967-2_13 
Kontinen, T., \& Ojala, A. (2010). The internationalization of family businesses: A review of extant research. Journal of Family Business Strategy. https://doi.org/10.10 16/j.jfbs.2010.04.001

Küpper, H.-U., Friedl, G., Hofmann, C., Hofmann, Y., \& Pedell, B. (2013). Controlling: Konzeption, Aufgaben, Instrumente. Stuttgart: Schäffer-Poeschel.

Laitinen, E. K. (2011). Effect of reorganization actions on the financial performance of small entrepreneurial distressed firms. Journal of Accounting and Organizational Change, 7(1), 57-95. https://doi.org/10.1108/18325911111125540

Langfield-Smith, K. (1997). Management control systems and strategy: A critical review. Accounting, Organizations and Society, 22(2), 207-232. https://doi.org/10.10 16/S0361-3682(95)00040-2

Langley, A. (1999). Strategies for theorizing from process data. The Academy of Management Review, 24(4), 691-710. https://doi.org/10.5465/AMR.1999.2553248

Lanzolla, G., \& Anderson, J. (2008). Digital transformation. Business Strategy Review, 19(2), 72-76.

Laurinkevičiūtè, A., \& Stasiškienè, Ž. (2011). SMS for decision making of SMEs. Clean Technologies and Environmental Policy, 13(6), 797-807. https://doi.org/10.10 07/s10098-011-0349-1

Lee, T., Mitchell, T., \& Sablynski, C. (1999). Qualitative Research in Organizational and Vocational Psychology, 1979-1999. Journal of Vocational Behavior, 55, 161-187. https://doi.org/10.1006/jvbe.1999.1707

Legner, C., Eymann, T., Hess, T., Matt, C., Böhmann, T., Drews, P., ... Ahlemann, F. (2017). Digitalization: Opportunity and Challenge for the Business and Information Systems Engineering Community. Business \& Information Systems Engineering, 59(4), 301-308. https://doi.org/10.1007/s12599-017-0484-2

Loasby, B. J., Pfeffer, J., \& Salancik, G. R. (1979). The external control of organizations. A resource dependence perspective. The Economic Journal, 89(356), 969970. https://doi.org/10.2307/2231527

Loonam, J., Eaves, S., Kumar, V., \& Parry, G. (2018). Towards digital transformation: Lessons learned from traditional organizations. Strategic Change, 27(2), 101-109. https://doi.org/10.1002/jsc.2185

López, O. L., \& Hiebl, M. R. W. (2015). Management Accounting in Small and Medium-Sized Enterprises: Current Knowledge and Avenues for Further Research. Journal of Management Accounting Research, 27(1), 81-119. https://doi.org/ 10.2308/jmar-50915

Lucas, H. C., Agarwal, R., Clemons, E. K., El Sawy, O. A., \& Weber, B. (2013). Impactful research on transformational information technology: an opportunity to inform new audiences. MIS Quarterly, 37(2), 371-382.

Lyytinen, K., Yoo, Y., \& Boland, R. J. (2016). Digital product innovation within four classes of innovation networks. Information Systems Journal, 26(1), 47-75. https://doi.org/10.1111/isj.12093

Macintosh, N. B., \& Daft, R. L. (1987). Management control systems and departmental interdependencies: An empirical study. Accounting, Organizations and Society, 12(1), 49-61. https://doi.org/10.1016/0361-3682(87)90015-8 
Main, A., Lamm, B., \& McCormack, D. (2018). What Boards Need to Know About Digital Transformation. Corporate Governance Advisor, 26(1), 18-22. Retrieved from http://search.ebscohost.com/login.aspx?direct=true\&db=bth\&AN=1271046 73\&site $=$ ehost-live\&scope $=$ site

Malmi, T., \& Brown, D. A. (2008). Management control systems as a package-opportunities, challenges and research directions. Management Accounting Research, 19(4), 287-300.

Manville, G. (2007). Implementing a balanced scorecard framework in a not for profit SME. International Journal of Productivity and Performance Management, 56(2), 162-169. https://doi.org/10.1108/17410400710722653

Marc, M., Peljhan, D., Ponikvar, N., Sobota, A., \& Tekavcic, M. (2010). Performance Measurement In Large Slovenian Companies: An Assessment Of Progress. International Journal of Management \& Information Systems (IJMIS), 14(5), 63-76. https://doi.org/10.19030/ijmis.v14i5.20

Mariti, P., \& Smiley, R. H. (1983). Co-Operative Agreements and the Organization of Industry. The Journal of Industrial Economics, 31(4), 437-451. https://doi.org/10 $.2307 / 2098340$

Matt, C., Hess, T., \& Benlian, A. (2015). Digital Transformation Strategies. Business \& Information Systems Engineering, 57(5), 339-343. https://doi.org/10.1007/s1259 9-015-0401-5

McDonald, M. P. (2012, November 19). Digital Strategy Does Not Equal IT Strategy. Retrieved August 1, 2018, from https://hbr.org/2012/11/digital-strategy-doesnot-equa

Md. Mostaque, H., Laitinen, E. K., \& Gunasekaran, A. (1998). Management accounting systems in Finnish service firms. Technovation, 18(1), 57-67.

Merchant, K. A., \& van der Stede, W. A. (2007). Management Control Systems. Operational Research Quarterly (1970-1977) (2nd ed.). Harlow, Essex, UK: Prentice Hall, Pearson Education Limited. https://doi.org/10.2307/3007872

Merchant, K. A., \& Van der Stede, W. A. (2012). Management control systems. Harlow: Financial Times/Prentice Hall.

Mieke, C. (2008). Branchenverbände als Innovationsplattform. In D. Specht (Ed.), Produkt- und Prozessinnovationen in Wertschöpfungsketten (1st ed., pp. 107-124). Wiesbaden: Gabler. https://doi.org/10.1007/978-3-8349-9765-4_6

Miles, M. B., Huberman, A. M., \& Saldaña, J. (2014). Qualitative Data Analysis - A Methods Sourcebook (3rd ed.). Los Angeles, London, New Dehli, Singapore, Washington DC: SAGE Publications.

Mitchell, F., \& Reid, G. C. (2000). Problems, challenges and opportunities: the small business as a setting for management accounting research. Management Accounting Research, 11(4), 385-390. https://doi.org/10.1006/mare.2000.0152

Monden, Y., \& Hamada, K. (1991). Target Costing and Kaizen Costing in the Japanese Automobile Industry. Journal of Management Accounting Research, 3, 16-34. https://doi.org/10.4324/9780203735350-2

Morgan, G., \& Smircich, L. (1980). The case for qualitative research. Academy of Management Review, 5[4](4), 491-500. https://doi.org/10.2307/257453 
Morschett, D. (2003). Kooperationen, Allianzen und Netzwerke. (J. Zentes, B. Swoboda, \& D. Morschett, Eds.), Kooperationen, Allianzen und Netzwerke. Wiesbaden: Gabler Verlag. https://doi.org/10.1007/978-3-322-99865-1

Myers, M. D., \& Newman, M. (2007). The qualitative interview in IS research: Examining the craft. Information and Organization, 17(1), 2-26. https://doi.org/10.1 016/j.infoandorg.2006.11.001

Nambisan, S., Lyytinen, K., Majchrzak, A., \& Song, M. (2017). Digital Innovation Management: Reinventing Innovation Management Research. MIS Quarterly, 41(1), 223-238. https://doi.org/10.25300/MISQ/2017/41

Ndemewah, S. R., Menges, K., \& Hiebl, M. R. W. (2019). Management accounting research on farms: what is known and what needs knowing? Journal of Accounting and Organizational Change, 15(1), 58-86. https://doi.org/10.1108/JAOC-05-20 18-0044

Negroponte, N. (1995). Being Digital. New York, NY: Vintage Books.

Oestreicher-Singer, G., \& Zalmanson, L. (2013). Content or Community? A Digital Business Strategy for content providers in the social age. MIS Quarterly, 37(2), 591-616.

Øiestad, S., \& Bugge, M. M. (2014). Digitisation of publishing: Exploration based on existing business models. Technological Forecasting and Social Change, 83(1), 54-65. https://doi.org/10.1016/j.techfore.2013.01.010

Oliver, J. J. (2018). Strategic transformations in a disruptive digital environment. Strategic Direction, 34(5), 5-8.

Osterwalder, A., \& Pigneur, Y. (2010). Business Model Generation: A handbook for visionaries, game changers and challengers. Hoboken, NJ: John Wiley and Sons, Inc.

Otley, D. (2016). The contingency theory of management accounting and control: 1980-2014. Management Accounting Research, 31, 45-62. https://doi.org/10.1016/j .mar.2016.02.001

Ouchi, W. G. (1979). A Conceptual Framework for the Design of Organizational Control Mechanisms. Management Science, 25(9), 833-848. https://doi.org/10.12 87/mnsc.25.9.833

Parviainen, P., Tihinen, M., Kääriäinen, J., \& Teppola, S. (2017). Tackling the digitalization challenge: how to benefit from digitalization in practice. International Journal of Information Systems and Project Management, 5(1), 63-77. https://doi.or g/10.12821/ijispm050104

Patel, P. C., \& Fiet, J. O. (2011). Knowledge combination and the potential advantages of family firms in searching for opportunities. Entrepreneurship: Theory and Practice, 35(6), 1179-1197. https://doi.org/10.1111/j.1540-6520.2011.00497.x

Patton, M. (1990). Qualitative Evaluation and Research Methods. Qualitative Evaluation and Research Methods, 169-186. https://doi.org/10.1002/nur.4770140111

Payer, H. (2008). Netzwerk, Kooperation, Organisation - Gemeinsamkeiten und Unterschiede. In S. Bauer-Wolf, H. Payer, \& G. Scheer (Eds.), Erfolgreich durch Netzwerkkompetenz (pp. 5-22). Vienna: Springer. https://doi.org/10.1007/978-3-2 11-73127-7 
Peel, M. J., \& Bridge, J. (1998). How Planning and Capital Budgeting Improve SME Performance. Long Range Planning, 31(6), 848-856. https://doi.org/10.1016/ s0024-6301(98)00102-2

Peirce, C. S. (1934). Collected papers of Charles Sanders Peirce, Vol. V. (C. Hartshorne $\&$ P. Weiss, Eds.). Cambridge, MA: Harvard University Press.

Pettigrew, A. M. (1990). Longitudinal Field Research on Change: Theory and Practice. Organization Science, 1(3), 267-292.

Pfohl, H.-C. (2006). Leadership. In H.-C. Pfohl (Ed.), Betriebswirtschaftslehre der Mittel- und Kleinbetriebe - größenspezifische Probleme und Möglichkeiten zu ibrer Lösung (4th ed., pp. 79-111). Berlin: Erich Schmidt Verlag.

Pfohl, H.-C. (2013). Distinction of Small- and Medium-sized from Large Enterprises (original: "Abgrenzung der Klein- und Miteelbetriebe von Großbetrieben"). In Betriebswirtschaftslehre der Mittel- und Kleinbetriebe - größenspezifische Probleme und Möglichkeiten zu ihrer Lösung (5th ed., pp. 1-26). Berlin: Pfohl, Hans-Christian.

Porter, M. E. (1998). Clusters and the new economics of competition. Harvard Business Review, 76(6), 77-90.

Potter, W. J., \& Levine-Donnerstein, D. (1999). Rethinking validity and reliability in content analysis. Journal of Applied Communication Research, 27(3), 258-284. https://doi.org/10.1080/00909889909365539

Powell, W. (1990). Neither market nor hierarchy: Network forms of organization. In Research in Organizational Behavior (Vol. 12, pp. 295-336). https://doi.org/10.1 590/s1415-65552003000200016

Pratt, M. (2009). From the editors: The lack of a boilerplate: Tips on writing up (and rewriting) qualitative research. Academy of Management Journal, 52(5), 856862. https://doi.org/10.5465/AMJ.2009.44632557

Prencipe, A., Bar-Yosef, S., Dekker, H. C., \& Dekker, H. C. (2014). Accounting research in family firms: Theoretical and empirical challenges. European Accounting Review, 23(3), 361-385. https://doi.org/10.1080/09638180.2014.895621

Priestley, J. L., \& Samaddar, S. (2007). Multi-organizational networks: Three antecedents of knowledge transfer. International Journal of Knowledge Management (IJKM), 3(1), 86-99. https://doi.org/10.4018/jkm.2007010106

Provan, K. G., Fish, A., \& Sydow, J. (2007). Interorganizational networks at the network level: A review of the empirical literature on whole networks. Journal of Management, 33(3), 479-516. https://doi.org/10.1177/0149206307302554

Provan, K. G., \& Kenis, P. (2008). Modes of network governance: Structure, management, and effectiveness. Journal of Public Administration Research and Theory, 18(2), 229-252. https://doi.org/10.1093/jopart/mum015

Quinn, M. (2011). Routines in management accounting research: Further exploration. Journal of Accounting and Organizational Change, 7(4), 337-357. https://doi. org/10.1108/18325911111182303 
Quinn, M., Hiebl, M. R. W., Moores, K., \& Craig, J. B. (2018). Future research on management accounting and control in family firms: suggestions linked to architecture, governance, entrepreneurship and stewardship. Journal of Management Control, 28(4), 529-546. https://doi.org/10.1007/s00187-018-0257-1

Rammer, C., Gottschalk, S., Peters, B., Bersch, J., \& Erdsiek, D. (2016). Die Rolle von KMU für Forschung und Innovation in Deutschland. Mannheim.

Rank, O. N. (2015). Unternehmensnetzwerke. Wiesbaden: Springer Fachmedien Wiesbaden. https://doi.org/10.1007/978-3-658-09316-7

Riasanow, T., Setzke, D. S., Hoberg, P., \& Krcmar, H. (2018). Clarifying the Notion of Digital Transformation in IS Literature: A Comparison of Organizational Change Philosophies. Retrieved from https://ssrn.com/abstract=3072318

Ritchie, J., \& Richardson, S. (2000). Smaller business governance: Exploring accountability and enterprise from the margins. Management Accounting Research, 11(4), 451-474. https://doi.org/10.1006/mare.2000.0144

Saldaña, J. (2016). The Coding Manual for Qualitative Researchers. Sage (2nd ed.). Los Angeles, London, New Dehli, Singapore, Washington DC: SAGE Publications.

Schäffer, U., \& Weber, J. (2016). Die Digitalisierung wird das Controlling radikal verändern. Controlling \& Management Review, 60(6), 6-17.

Schein, E. H. (2016). Organizational Culture and Leadership (5th ed.). Hoboken: Wiley.

Schilling, M. A. (2013). Strategic management of technological innovation (4th ed.). New York: McGraw-Hill.

Schilling, M. A., \& Phelps, C. C. (2007). Interfirm collaboration networks: The impact of large-scale network structure on firm innovation. Management Science, 53(7), 1113-1126. https://doi.org/10.1287/mnsc.1060.0624

Schmidt, A., \& Kiefer, C. (2003). Kooperationen zwischen Mittelständischen Unternehmen. In J. Zentes, B. Swoboda, \& D. Morschett (Eds.), Kooperationen, Allianzen und Netzwerke (pp. 1259-1282). Wiesbaden: Gabler Verlag.

Schuh, G., Kampker, A., \& Rittstieg, M. (2011). Vernetzte Wertschöpfung und Kooperationsmanagement. In G. Schuh \& A. Kampker (Eds.), Strategie und Management produziernder Unternehmen (pp. 463-536). Berlin, Heidelberg: Springer Berlin Heidelberg. https://doi.org/10.1007/978-3-642-14502-5

Schwab, K. (2015). The Fourth Industrial Revolution. Accessed July 31, 2018. Retrieved from https://www.foreignaffairs.com/articles/2015-12-12/fourth-industria 1-revolution

Sebastian, I. M., Mocker, M., Ross, J. W., Moloney, K. G., Beath, C., \& Fonstad, N. O. (2017). How Big Old Companies Navigate Digital Transformation. MIS Quarterly Executive, 16(3), 197-213.

Senftlechner, D., \& Hiebl, M. R. W. (2015). Management accounting and management control in family businesses. Journal of Accounting \& Organizational Change, 11(4), 573-606. https://doi.org/10.1108/jaoc-08-2013-0068

Sharma, M. K., \& Bhagwat, R. (2007). Performance measurement system: case studies from SMEs in India. International Journal of Productivity and Quality Management, 2(4), 475-509. 
Simons, R. (1987). Accounting control systems and business strategy: An empirical analysis. Accounting, Organizations and Society, 12(4), 357-374. https://doi.org/10. 1016/0361-3682(87)90024-9

Simons, R. (1995). Control in an age of empowerment. Harvard Business Review, 73(2), 80-88.

Singh, A., \& Hess, T. (2017). How Chief Digital Officers Promote the Digital Transformation of their Companies. MIS Quarterly Executive, 16(1), 141-166.

Snow, C. C., Miles, R. E., \& Coleman, H. J. (1992). Managing 21st century network organizations. Organizational Dynamics, 20(3), 5-21.

Songini, L., \& Gnan, L. (2015). Family Involvement and Agency Cost Control Mechanisms in Family Small and Medium-Sized Enterprises. Journal of Small Business Management, 53(3), 748-779. https://doi.org/10.1111/jsbm.12085

Statistisches Bundesamt. (2017). Handwerksunternehmen, Tätige Personen, Umsatz. Retrieved October 5, 2018, from https://www-genesis.destatis.de/genesis/on line;sid=C51E18B24B5DB5D42F27D790F218FE4D.GO_1_5?operation=previous \&levelindex=3\&levelid=1538746496124\&step=3

Sterne, J. (2002). Web Metrics: Proven Methods for Measuring Web Site Success. New York, NY.: Wiley.

Strauß, E., \& Zecher, C. (2013). Management control systems: A review. Journal of Management Control, 23(4), 233-268. https://doi.org/10.1007/s00187-012-0158-7

Sydow, J. (1992). Strategische Netzwerke: Evolution und Organisation. Wiesbaden: Gabler Verlag. https://doi.org/10.1007/978-3-322-86619-6

Sydow, J. (2001). Management von Netzwerkorganisationen - Zum Stand der Forschung. In Management von Netzwerkorganisationen (pp. 293-339). Wiesbaden: Gabler Verlag. https://doi.org/10.1007/978-3-322-91999-1_11

Sydow, J. (2010). Management von Netzwerkorganisationen. (J. Sydow, Ed.). Wiesbaden: Gabler Verlag.

Tapinos, E., Dyson, R. G., \& Meadows, M. (2005). The impact of performance measurement in strategic planning. International Journal of Productivity and Performance Management, 54(5-6), 370-384. https://doi.org/10.1108/1741040051060 4539

Täuscher, K., \& Laudien, S. M. (2018). Understanding platform business models: A mixed methods study of marketplaces. European Management Journal, 36(3), 319-329. https://doi.org/10.1016/j.emj.2017.06.005

Teubner, R. A. (2013). Information systems strategy: Theory, practice, and challenges for future research. Business and Information Systems Engineering, 5(4), 243-257. https://doi.org/10.1007/s12599-013-0279-z

theEconomist. (2012). The third industrial revolution [Online]. Accessed July 31, 2018. Retrieved from http://www.economist.com/node/21553017

Tibshirani, R., Walther, G., \& Hastie, T. (2001). Estimating the number of data clusters via the gap statistic. Journal of the Royal Statistical Society: Series B, 63(Part 2), 411-423. https://doi.org/63411 
Tilson, D., Lyytinen, K., \& Sørensen, C. (2010). Digital infrastructures: The missing IS research agenda. Information Systems Research, 21(4), 748-759. https://doi. org/10.1287/isre.1100.0318

Timmermans, S., \& Tavory, I. (2012). Theory construction in qualitative research: From grounded theory to abductive analysis. Sociological Theory, 30(3), 167-186. https://doi.org/10.1177/0735275112457914

Trenkle, J. (2019). Survival in the digital age - A framework for formulating a digital transformation strategy in SME. In Proceedings of The 19th International Conference on Electronic Business (pp. 428-442). Newcastle upon Tyne.

Tushman, M. L., \& Reilly, C. A. O. (1996). Ambidextrous Organizations: managing evolutionary and revolutionary change. California Management Review, $38(4), 8-30$.

Valkokari, K., \& Helander, N. (2007). Knowledge management in different types of strategic SME networks. Management Research News, 30(8), 597-608. https://d oi.org/10.1108/01409170710773724

Van Aken, J. E., \& Weggeman, M. P. (2000). Managing learning in informal innovation networks: overcoming the Daphne-dilemma. R\&D Management, 30(2), 139-150. https://doi.org/10.1111/1467-9310.00164

van de Ven, A. H. (2007). Variance and Process Models. In Engaged Scholarship: A Guide for Organizational and Social Research (pp. 143-160). New York: Oxford University Press Inc.

Vieregge, P. (2011). Cluster und Kompetenzstandorte: Wie identifiziert man Potenziale für regionale Kooperationen und Netzwerke. In Thomas Becker, I. Dammer, J. Howaldt, \& A. Loose (Eds.), Netzwerkmanagement (pp. 63-76). Berlin, Heidelberg: Springer Berlin Heidelberg. https://doi.org/10.1007/978-3-64 2-19333-0

Villarmois, O. D. La, \& Levant, Y. (2011). From adoption to use of a management control tool: Case study evidence of a costing method. Journal of Applied Accounting Research, 12(3), 234-259. https://doi.org/10.1108/09675421111187683

Ward, J. H. (1963). Hierarchical grouping to optimize an objective function. Journal of the American Statistical Association, 58(301), 236-244. https://doi.org/10.10 80/01621459.1963.10500845

Wiesböck, F., \& Hess, T. (2019). Digital innovations: Embedding in organizations. Electronic Markets. Electronic Markets. https://doi.org/10.1007/s12525-019-003649

Wiesböck, F., Li, L., Matt, C., Hess, T., Richter, A., \& Thomas Hess LMU Munich, P. (2017). How Management in the German Insurance Industry Can Handle Digital Transformation. Retrieved from www.wim.bwl.lmu.de

Williamson, O. E. (1981). The economics of organization: The transaction cost approach. American Journal of Sociology, 87(3), 548-577. https://doi.org/10.1086/227 496

Wissema, J. G., \& Euser, L. (1991). Successful innovation through inter-company networks. Long Range Planning, 24(6), 33-39. https://doi.org/10.1016/0024-6301( 91)90041-L 
Yin, R. K. (2014). Case Study Research: Design and Methods. Sage Publications (Vol. 26). https://doi.org/10.1097/FCH.0b013e31822dda9e

Yoo, Y., Boland, R. J., Lyytinen, K., \& Majchrzak, A. (2012). Organizing for Innovation in the Digitized World. Organization Science, 23(5), 1398-1408. https://do i.org/10.1287/orsc.1120.0771

Yoo, Y., Lyytinen, K., \& Boland, R. J. (2008). Distributed innovation in classes of networks. Proceedings of the Annual Hawaii International Conference on System Sciences, (May 2014). https://doi.org/10.1109/HICSS. 2008.125

ZEIT-Foundation. (2018). Charter of Digital Fundamental rights of the European Union. Retrieved from https://digitalcharta.eu/wp-content/uploads/Digital_Char ter_english_2018.pdf, accessed 08/16/2018 
